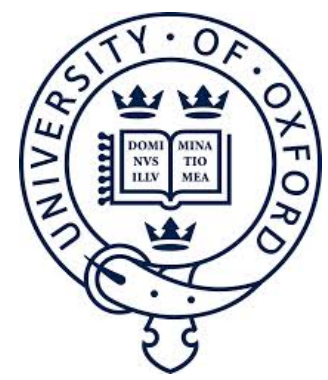

Models of Bilingual Education in Majority Language Contexts:

An Exploratory Study of Bilingual Programmes in Qatari Primary Schools

Fatma Al-Maadheed

Thesis submitted for the degree of Doctor of Philosophy at the

University of Oxford

Wolfson College

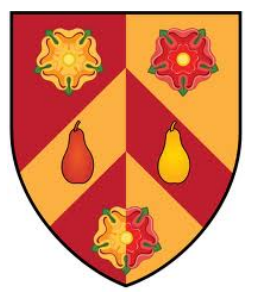

Michaelmas 2012 
Models of Bilingual Education in Majority Language Contexts: An Exploratory Study of Bilingual Programmes in Qatari Primary Schools

Wolfson College

Doctor of Philosophy Michaelmas, 2012

The purpose of this thesis was to explore and describe how bilingual programmes are organized and implemented within the unique linguistic and socio-economic case of Qatar. Specifically the thesis explored bilingual programs offered by two types of primary schools in Qatar: international schools and independent schools. Qatar launched a new initiative for educational development in 2001 but with hardly any research linked to these changes.

The study was positioned within a qualitative interpretive tradition drawing on elements of ethnography and grounded theory as tools of methodology. However, quantitative methods were also incorporated within the design. The research design is structured within two main phases: phase one included statistical analysis of secondary data investigating three variables: average teaching time in the first and the second language, students' and teachers' nationality. Phase two utilized a multi-case study design. One school from each type was examined in depth over a period of nine weeks. Data were collected by means of school documents, interviews, and non-participant observation of English and Arabic classes.

The first phase made an initial impression of the model of bilingual education followed by international and independent schools compared to bilingual typologies found in the literature. The analysis of the two cases examined revealed various differences across the two types. Findings reveal that the international school followed a partial immersion type of programme while the independent school followed a Content and Language Integrated Learning (CLIL) type of programme. The study reveals that the Qatari bilingual schools context was one of heteroglossia, with three codes in operation: Modern Standard Arabic, Colloquial Arabic dialects and English. Findings reveal that teachers and students in the international school adopt a strict separation policy between the two languages following a monoglossic belief. Language teachers and students in the independent school were found to apply a flexible language policy inside English and Arabic classes. The study revealed a gap between claimed programme features and implementation of these features. An absence of a clear language policy in the schools was also a main finding relating to the practice of these schools.

In light of these findings, adopting a clear and explicit language-in-education policy should be a priority for policy makers in Qatar. The study revealed how the diglossia situation in Qatari schools is unique and therefore schools must be aware of the languages at the disposal of students and teachers. Schools must also concentrate on developing academic language skills needed for success in L2 schooling. 
Table of Contents

\section{CHAPTER ONE:INTRODUCTION}

1.1 Introduction 1

1.1.1 Aim of the Thesis 2

1.1.2 Thesis Structure 3

$1.2 \quad$ Background and Rationale 4

1.2.1 Introduction to Qatar 4

1.2.2 Socio-historical Context of Education in Qatar 6

1.2.3 The Qatari Schooling System 8

1.2.4 The Education Initiative: Education for New Era 12

1.2.5 The Language Situation in Qatar 14

1.2.6 Diglossia in the Arabic language 15

$\begin{array}{lll}\text { 1.2.7 Diglossia in the Arab Classroom } & 19\end{array}$

$\begin{array}{lll}\text { 1.2.8 } & \text { English in Qatar } & 19\end{array}$

1.2.9 Bilingual Education in Qatar 21

1.3. Conclusion 22

\section{CHAPTER TWO:LITERATURE REVIEW}

$\begin{array}{lll}2.1 & \text { Introduction } & 24\end{array}$

$2.2 \quad$ Bilingual Education and Bilingualism 25

$\begin{array}{lll}\text { 2.2.1 Bilingualism Defined } & 25\end{array}$

$\begin{array}{lll}2.2 .2 & \text { Bilingual Education } 26\end{array}$

$\begin{array}{lll}2.3 & \text { Theoretical Framework } & 27\end{array}$

2.3.1 Models and Typologies of Bilingual Education 28

2.3.2 Bilingual Programmes 36

$\begin{array}{lll}\text { 2.3.2.1 Immersion Education } & 37\end{array}$

2.3.2.2 Enrichment Programmes 39

$2.4 \quad$ Bilingual Practices Within Programmes 40

2.4.1. Language Organization and Biliteracy Teaching Approaches 43 
2.4.1.1 Language Allocation 43

2.4.1.2 Written Language Provision 45

2.4.1.3 Language Separation 45

2.4.1.4 Classroom Interaction 48

$2.5 \quad$ Multilingual Education $\quad 49$

2.5.1 Majority-minority Distinction 50

2.5.1.1 Research in East Asia 51

2.5.1.2 Research in the Arabic Middle East 51

2.5.2 Gaps between School Policies and Classroom Policies 52

2.5.3 Gaps in the Research $\quad 54$

$\begin{array}{lll}2.6 & \text { Summary } & 55\end{array}$

$\begin{array}{lll}2.7 & \text { Conclusion } & 56\end{array}$

\section{CHAPTER THREE METHODOLOGY}

$\begin{array}{lll}3.1 & \text { Introduction } & 57\end{array}$

$\begin{array}{lll}3.2 & \text { Research Questions } & 57\end{array}$

3.3 Research Design 59

3.3.1 Phase I: Description of Bilingual Schools 60

3.3.2 Pilot Phase: Mini-Case Study at One School 61

3.3.3 Phase II: Case Studies at Two Schools 61

3.3.4 Reflections on the Pilot Phase 62

3.4 Research Strategy 64

$\begin{array}{lll}3.5 & \text { Sampling } & 68\end{array}$

3.5.1 Phase I Sampling $\quad 69$

3.5.2 Phase II Sampling 69

$\begin{array}{lll}3.6 & \text { Data Collection } & 71\end{array}$

3.6.1 Phase I Data Collection 71

$\begin{array}{lll}\text { 3.6.2 } & \text { Phase II Data Collection }\end{array}$

$\begin{array}{lll}\text { 3.6.3 Observation Procedures } & 74\end{array}$ 
$\begin{array}{lll}\text { 3.6.4 Interview Procedures } & 75\end{array}$

$\begin{array}{lll}\text { 3.6.5 Case Study Conclusion } & 75\end{array}$

$\begin{array}{lll}3.7 & \text { Analytical Strategy }\end{array}$

$\begin{array}{lll}\text { 3.7.1 Analytical Strategy for Phase I } & 76\end{array}$

3.7.2 Analytical Strategy for Phase II 76

$\begin{array}{lll}\text { 3.7.3 Descriptive Framework } & 77\end{array}$

3.7.4 Analysis of Interview Responses $\quad 79$

3.7.5 Analysis of Classroom Observations 80

3.8 Findings and Interpretations 85

3.8.1 Cross-Case Analysis 85

$\begin{array}{lll}3.9 & \text { Ethical Consideration }\end{array}$

3.10 Limitations 86

3.11 Original Contribution 88

\section{CHAPTER FOUR:DESCRIPTION OF THE SCHOOLS}

$\begin{array}{lll}4.1 & \text { Introduction } & 92\end{array}$

$\begin{array}{lll}4.2 & \text { Students } & 92\end{array}$

$\begin{array}{lll}4.3 & \text { Teachers } & 93\end{array}$

4.4 Teaching Hours 95

$\begin{array}{lll}4.5 & \text { Conclusion } & 97\end{array}$

\section{CHAPTER FIVE:CASE STUDY-1 SALAM SCHOOL}

$\begin{array}{lll}5.1 & \text { Introduction } & 99\end{array}$

5.1.1 Profile of Salam School 99

$\begin{array}{lll}\text { 5.1.2 } & \text { Profile of Participants } & 100\end{array}$

5.2 Organisation of the Bilingual Programmes 102

$\begin{array}{lll}\text { 5.2.1 Linguistic Goals } & 103\end{array}$

$\begin{array}{lll}\text { 5.2.2 School Identity } & 104\end{array}$

$\begin{array}{lll}\text { 5.2.3 Educational Goals } & 106\end{array}$ 
$\begin{array}{lll}\text { 5.2.4 Language of Communication } & 107\end{array}$

$\begin{array}{ll}\text { 5.2.5 Language Allocation } & 109\end{array}$

5.2.6 Interview Responses 113

5.2.7 Awareness of School Bilingual Policy 114

$\begin{array}{lll}\text { 5.2.8 Language Choice Behaviour } & 119\end{array}$

5.2.9 Role of Teachers in Bilingual Development Practices 120

5.2.10 Summary of Interview Responses 122

5.3 Summary of the Organization of Bilingual Programmes 122

$\begin{array}{lll}5.4 & \text { Implementation of the Bilingual Programmes } & 124\end{array}$

5.5 Observation in English Language Classes 124

$\begin{array}{lll}\text { 5.5.1 Language Choice } & 125\end{array}$

$\begin{array}{lll}\text { 5.5.2 Communication Mode } & 126\end{array}$

$\begin{array}{lll}\text { 5.5.4 Grouping } & 128\end{array}$

$\begin{array}{lll}\text { 5.5.5 } & \text { Instructional Practices } & 130\end{array}$

5.5.6 Summary of Observations in English Classroom 146

5.6 Observation of Arabic Language Classroom 147

$\begin{array}{lll}\text { 5.6.1 Language Choice } & 147\end{array}$

$\begin{array}{lll}\text { 5.6.2 Communication Mode } & 149\end{array}$

$\begin{array}{lll}\text { 5.6.3 Grouping } & 150\end{array}$

$\begin{array}{lll}\text { 5.6.4 Instructional Practices } & 150\end{array}$

5.6.6 Summary of Classroom Observations 156

$\begin{array}{lll}5.7 & \text { Course Material } & 158\end{array}$

$\begin{array}{lll}\text { 5.7.1 English Text Books } & 158\end{array}$

$\begin{array}{lll}\text { 5.7.2 } & \text { Arabic Text Books } & 159\end{array}$

$\begin{array}{lll}\text { 5.7.3 } & \text { Other Resources } & 159\end{array}$

$\begin{array}{ll}5.8 & \text { Language Outside the Classroom }\end{array}$

$\begin{array}{lll}\text { 5.8.1 Assemblies } & 161\end{array}$

$\begin{array}{lll}\text { 5.8.2 ESL Sessions } & 161\end{array}$

$\begin{array}{lll}\text { 5.8.3 Library Sessions } & 162\end{array}$ 
5.8.4 Extra-curricular Activities 162

$\begin{array}{lll}\text { 5.8.5 } & \text { Book Fair } 163\end{array}$

$\begin{array}{lll}\text { 5.8.6 Read-a-Thon } & 163\end{array}$

5.8.7 Summary of Language Outside the Classroom 164

$\begin{array}{lll}5.9 & \text { Case Summary } & 165\end{array}$

$\begin{array}{lll}\text { 5.9.1 School Portrait } & 165\end{array}$

$\begin{array}{lll}5.9 .2 & \text { Conclusion } & 168\end{array}$

\section{CHAPTER SIX:CASE STUDY-2 JAZEERA INDEPENDENT}

$\begin{array}{lll}6.1 & \text { Introduction } & 170\end{array}$

$\begin{array}{lll}\text { 6.1.1 Profile of Jazeera School } & 170\end{array}$

$\begin{array}{lll}\text { 6.1.2 Profile of Participants } & 171\end{array}$

6.2 Organisation of the Bilingual Programme 172

6.2.1 Linguistic Goals 173

$\begin{array}{lll}\text { 6.2.2 School Identity } & 175\end{array}$

$\begin{array}{ll}\text { 6.2.3 Educational Goals } & 177\end{array}$

$\begin{array}{ll}\text { 6.2.4 Language of Communication } & 178\end{array}$

$\begin{array}{ll}\text { 6.2.5 Language Allocation } & 179\end{array}$

$\begin{array}{lll}\text { 6.2.6 Interview Responses } & 183\end{array}$

6.2.7 Awareness of School Bilingual Policy 184

$\begin{array}{ll}\text { 6.2.8 Language Choice Behaviour } & 188\end{array}$

6.2.9 Role of Teachers in Bilingual Development Practices 189

6.2.10 Summary of Interview Responses 189

6.3 Summary of the Organization of the Bilingual Programme 190

6.4 Implementation of the Bilingual Programme 191

6.5 Observation in English Language Classes 192

6.5.1 Language Choice 192

$\begin{array}{lll}\text { 6.5.2 Communication Mode } & 194\end{array}$

$\begin{array}{lll}\text { 6.5.3 Grouping } & 195\end{array}$ 
$\begin{array}{lll}\text { 6.5.4 Instructional Practice } & 196\end{array}$

6.5.5 Summary of Observation in English Classroom 209

6.6 Observation of the Arabic Language Classroom 210

$\begin{array}{lll}\text { 6.6.1 Language Choice } & 210\end{array}$

$\begin{array}{lll}\text { 6.6.2 Communication Mode } & 211\end{array}$

$\begin{array}{lll}\text { 6.6.3 Grouping } & 212\end{array}$

$\begin{array}{lll}\text { 6.6.4 Instructional Practice } & 213\end{array}$

$\begin{array}{lll}\text { 6.6.5 Summary of Classroom Observations } & 221\end{array}$

6.7 Course Materials 222

6.8 Language Use Outside the Classroom 224

$\begin{array}{lll}\text { 6.8.1 } & \text { Assemblies } 225\end{array}$

6.8.2 Reading 226

6.8.3 Curriculum Integration Projects 227

$\begin{array}{lll}\text { 6.8.4 } & \text { Extra-Curricular Activities } & 228\end{array}$

6.8.5 Summary of Language Outside the Classroom 228

$\begin{array}{lll}6.9 & \text { Case Summary } & 229\end{array}$

$\begin{array}{lll}\text { 6.9.1 School Portrait } & 229\end{array}$

$\begin{array}{lll}6.10 & \text { Conclusion } & 232\end{array}$

CHAPTER SEVEN :CROSS -CASE SYNTHESIS

$\begin{array}{lll}7.1 & \text { Introduction } & 234\end{array}$

$\begin{array}{lll}7.2 & \text { Salam International School } & 234\end{array}$

7.3 Jazeera Independent School 235

$\begin{array}{lll}7.4 & \text { Cross-Case Synthesis } 236\end{array}$

$\begin{array}{lll}\text { 7.4.1 Language Provision } & 240\end{array}$

$\begin{array}{lll}\text { 7.4.2 Pedagogy } & 240\end{array}$

$\begin{array}{lll}\text { 7.4.3 Student Support } & 241\end{array}$

$\begin{array}{lll}\text { 7.4.4 School Culture } & 242\end{array}$

$\begin{array}{lll}7.5 & \text { Summary } & 242\end{array}$ 


\section{CHAPTER EIGHT: DISCUSSION}

$\begin{array}{lll}8.1 & \text { Introduction } & 245\end{array}$

8.2 Perceived and Practiced Policy 246

$\begin{array}{lll}\text { 8.3 Bilingual Pedagogy } & 251\end{array}$

8.4 Type of Bilingual Programme 255

$\begin{array}{lll}\text { 8.5 Bilingual Education in Qatar } & 257\end{array}$

8.6 Implications and Future Research 265

CHAPTER NINE: CONCLUSION

\section{References}

Appendix i

Case Study Protocol Outline

Appendix ii

Observation Checklist

Appendix iii

Consent forms

Appendix iv

Interview Protocol

Appendix v

Research Perspectives

Appendix vi

Bilingual Program Descriptive Inventory

Appendix vii

Code Book

Appendix viii

Interview Analysis Tables

\section{Glossary}




\section{List of Tables}

$\begin{array}{lll}\text { Table } 1.1 \quad \text { Languages Spoken by Students } & 11\end{array}$

Table 1.2 Languages in Student Homes 12

Table 2.1 Bilingual Ideologies, Goals, Programmes and Type of Children 36

Table 2.2 Language Separation Types 44

Table 2.3 Functional Taxonomies on Bilingual Classroom Interaction 48

$\begin{array}{lll}\text { Table } 3.1 & \text { Research Timeline } & 60\end{array}$

$\begin{array}{lll}\text { Table } 3.2 & \text { Observation Schedule } & 73\end{array}$

Table 3.3 Lesson Extract $\quad 82$

Table 3.4 Data Reduction Card 83

Table 3.5 Matrix of Instructional Practices 84

Table 4.1 Average Class Time per School Type 96

Table 5.1 Evidence Reflecting the School Identity 105

Table 5.2 Translated Arabic Lesson Plan 112

Table 5.3 Frequency of Use of Instructional Practices used in English Classes 130

Table 5.4 Frequency of Use of Instructional Practices in Arabic Classes 151

Table5.5 Comparison of Instructional Practices in English and Arabic Classes 157

$\begin{array}{lll}\text { Table5.6 Salam School portrait } & 166\end{array}$

Table6.1 Statements Reflecting the Islamic Identity of the School 176

Table 6.2 Statements Reflecting the National Identity of the School 177

Table 6.3 Frequency of Use of instructional Practices in English Classes 196

Table 6.4 Frequency of Use of Instructional Practice in Arabic Classes 213

Table 6.5 Comparison of Instructional Practices in English and Arabic Classes 221

$\begin{array}{lll}\text { Table } 6.6 & \text { Jazeera School Portrait } & 228\end{array}$

Table 7.1 Case-Ordered Descriptive Meta-Matrix (BPDI) 237

Table 7.2 Case-Ordered Conceptually Clustered Meta-Matrix 238 


\section{List of Figures}

$\begin{array}{lll}\text { Figure 3.1 Overview of Research Design } & 60\end{array}$

Figure 3.2 Research Analysis Strategy and Levels of Investigation 65

$\begin{array}{lll}\text { Figure } 3.3 & \text { Multiple Case Study Design } & 78\end{array}$

$\begin{array}{lll}\text { Figure } 4.1 & \text { Students by Nationality and School Type } & 92\end{array}$

Figure 4.2 Frequency Distributions of Students by Language and School Type 93

Figure 4.3 Distributions of Teachers by Gender and School Type 94

Figure 4.4 Frequency Distributions of Teachers by Nationality and School Type 95

Figure 4.5 Percentage of Language Allocation per School Type 96

Figure 5.1 Example of Bilingual (English and Arabic) Letter to Parents 108

Figure 5.2 Copy of the Weekly Timetable for Grade 4-3 110

$\begin{array}{lll}\text { Figure 5.3 Extract from English Weekly Plan } & 111\end{array}$

$\begin{array}{lll}\text { Figure 5.4 Communication Mode Used in English Classes } & 127\end{array}$

$\begin{array}{lll}\text { Figure 5.5 } & \text { Grouping of in English Classes } & 128\end{array}$

$\begin{array}{lll}\text { Figure 5.6 } & \text { Year Four-1 Classroom Diagram } & 129\end{array}$

$\begin{array}{lll}\text { Figure 5.7 } & \text { Year Four-2 Classroom Diagram } & 129\end{array}$

$\begin{array}{lll}\text { Figure 5.8 } & \text { Grammar Exercises } & 140\end{array}$

$\begin{array}{lll}\text { Figure } 5.9 & \text { Focus on Vocabulary } & 141\end{array}$

$\begin{array}{lll}\text { Figure } 5.10 & \text { Fluency Book } & 143\end{array}$

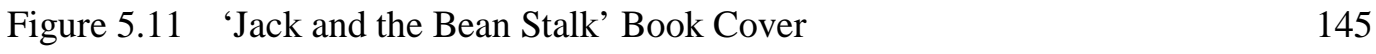

Figure 5.12 Communication Modes in Arabic Classes 149

Figure 5.13 Grouping of Students in Arabic Classes 150 
$\begin{array}{lll}\text { Figure } 5.15 & \text { Book Posters Made by Students } & 160\end{array}$

Figure 5.16 Reading Log for English and Arabic Stories 162

$\begin{array}{lll}\text { Figure 6.1 School Vision } & 176\end{array}$

Figure 6.2 Copy of the Weekly Timetable for Grade 4-4 180

$\begin{array}{lll}\text { Figure } 6.3 & \text { Arabic Weekly Plan } & 181\end{array}$

$\begin{array}{lll}\text { Figure } 6.4 & \text { English Daily Lesson Plan } & 182\end{array}$

$\begin{array}{lll}\text { Figure 6.5 Communication Mode in English Classes } & 194\end{array}$

$\begin{array}{lll}\text { Figure 6.6 Grouping of Students in English Classes } & 195\end{array}$

$\begin{array}{lll}\text { Figure } 6.7 & \text { Instructional Activities in English Classes } & 197\end{array}$

$\begin{array}{lll}\text { Figure 6.8 Vocabulary Quiz } & 200\end{array}$

Figure 6.9 Grammar Practice Worksheets 201

Figure 6.10 Communication Models in Arabic Classes 211

Figure 6.11 Grouping of Student in Arabic Classes 212

Figure 6.12 Homework about Volcanoes in Arabic 216

Figure 6.13 Display of Grammatical Structures in Arabic 218

Figure 6.14 Display of Synonyms in an Arabic Classroom 219

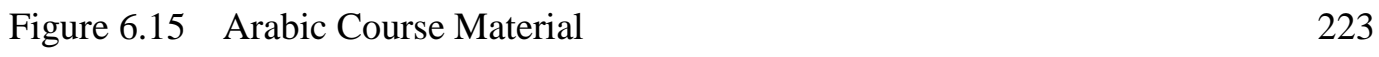

Figure 6.16 Contents Page from Arabic Text Book and Translation 223

$\begin{array}{lll}\text { Figure } 6.17 & \text { English Course Material } & 224\end{array}$

Figure 6.18 Who is the Poet Competition (Wall Display) 226

Figure 6.19 English, Science and Social Studies Integration Posters 226 






\section{CHAPTER ONE: INTRODUCTION}

\subsection{Introduction}

In today's interdependent world, multilingualism is increasingly reflected in schools. Sometimes it is reflected in the many languages the children bring into the school, with these languages at times developed in the school, and at times ignored. Other times, it is reflected in the languages the school teaches in order to develop the child's bilingualism and biliteracy. Schools in the twenty-first century not only have to make language-ineducation policy decisions, but also have to carefully address the multilingualism of the students and of the world.

Studies of bilingual education suggest that different types of programmes within differing contexts can promote different levels of bilingualism. Within the field of bilingual education, a distinction must be made between studies conducted with minority language leaners and the ones that explore bilingual programmes aimed at majority language learners (e.g. Genesee, 2006; Garcia, 2009). This distinction is a critical concept to bear in mind, considering the vast body of research covering bilingual education. Within heteroglossic contexts (i.e. multilingual and multi-dialect, Garcia, 2009) catering for majority language learners, various studies have been conducted on bilingual education covering a multitude of themes. The academic discourse arising from East Asian contexts

points to several conclusions. A few studies indicate the need for alternative versions of the established models of bilingual education, ones that suit the heteroglossic reality of non-western communities. This migration from using western oriented, ready-made bilingual programmes is apparent in studies and reviews done by $\mathrm{Hu}$ (2008), Lin (2006), and Feng (2007), to name a few. Other studies highlight the gap between the policies set by schools or authorities and actual school practices (for example, Fryer, 2010, Johnson, 1997 
and Bostwick, 2000). Virtually no studies examining bilingual education have been conducted in the context of the Middle East. Moreover, Hunt et al (2009) suggested that awareness of the sociolinguistic context of bilingual education appears to be lacking in the research.

\subsubsection{Aim of the Thesis}

Qatar is one of a number of countries that has recently made a decision to include two languages (Arabic and English) as curriculum standards in all their schools. As such, it can be said that Qatar values Arabic-English bilingualism as a goal of the state's education system. The majority of Qatari and Arabic-speaking children attend these new bilingual schools or 'Independent schools'. In addition, a vast number of students in Qatar opt for private international schools that offer their own bilingual programmes. Empirical research covering this country and the immediate Middle East region is scarce, with only a handful of studies focusing on adult social bilingualism (Mallah, 2006) or linguistic features between the first and second language (al-Khattib, 2003). Some research has also been conducted on the role of diglossia within bilingual education (e.g. Abu-Rabia, 2000, Saiegh-Haddad, 2003), notwithstanding the work done by Maamouri (1998). Nevertheless, none of these studies cover bilingual programs' overall structures and processes.

Therefore, exploring bilingual education in the Qatari context provides a unique opportunity to examine bilingual education in a majority language learners' context with two languages that are typologically different, ascertaining the extent to which some of the findings from other parts of the world also apply within an important but as yet underinvestigated linguistic and educational context. The aim of the proposed study will be to investigate two bilingual school types and explore their bilingual practices in regard to literacy in the two languages on offer. As categorized by Garcia (2009), the project will 
undertake investigation into language distribution policies (i.e. the percentage of the two languages in the programme and the subjects assigned to each language, etc.) and language separation (i.e. whether a school permits code-switching between the two languages, etc.). In addition, the contrast between policy and actual school and classroom practice will be highlighted by identifying teachers' and students’ language of interaction in and outside the classroom, the broad functions of any mixing of the two languages and what these practices tell us about the school's biliteracy approach within a model of biliteracy practice as described in the literature. Using ethnography, the researcher will collect data from one international and one independent school. Audio-recording, field notes and semi-structured interviews will be utilized.

The overall aim of the research is to try and identify the place of the Qatari bilingual programmes compared to known typologies in the literature of bilingual education policies and programmes. The study as a whole will lay the groundwork for future research and international comparsions, as the work will be a valuable resource for such comparison aimed at developing the theortical positions offered in the area of bilingual education in general. Within the rapid changes that the Area of the Middle East and Arabian Gulf countries are witnessing, Qatar is showing rapid changes in all sectors especially eductaion. It will be intresting to examine bilingual education in this context of change.

\subsubsection{Thesis Structure}

The structure of the thesis is as follows. Chapter One presents a socio-political and linguistic description of the state of Qatar, which serves to contextualize the research questions. This chapter also presents a somewhat extended description of the schooling system, paying particular attention to Arabic and English, the two languages present in the Qatari educational system. Chapter Two, the literature review, defines the terms used in 
this approach, followed by the theortical frameworks as set by Garcia (2009) and their ensuing programme classifications. The second part of this literature review presents empirical studies done in multilingual contexts, predominantly those that focused on issues connected to the organization of bilingual programmes and student and teacher interactions within these programmes. Chapter Three outlines the methodology used to carry out the project, describing the research questions, instruments, research procedures and ethical dimensions. The findings are presented in chapters 4, 5, and 6. Chapter Four presents the findings of the first phase which explored secondary data. Chapter Five presents the findings related to the first case study- Salam International School. Chapter Six presents findings related to the second case study- Jazeera Independent School. Chapter Seven presents the cross-case synthesis of the two cases explored using Case-Ordered Matrices to display and interpret the various themes found across the two cases. Chapter Eight depicts the discussion of the findings to answer the research questions producing a comprehensive overview of the results. Chapter Nine concludes the thesis and includes practical implications and recommendations

\subsection{Background and rationale}

This section describes the context of the current study in the State of Qatar, the development of its educational system, and the uniqueness of the Qatari educational and linguistic situation as it stands today.

\subsubsection{Introduction to Qatar}

Qatar is a small country of 11,427 sq. $\mathrm{km}$. (approximately 4,412 sq. miles) on the western coast of the Persian (Arabian) Gulf. After World War I, Qatar became a British protectorate, following four centuries of Turkish (Ottoman) control (Lesko, 2002). It became an independent nation on 3 September, 1971. 
The main cities in Qatar are the capital city of Doha, the industrial city of Misaiaeed, and the smaller cities of Al Khor, Al Wakrah, Dukhan, Al Shamal, Al Zubarah, and Ras Laffan. The population of Qatar in 2004 was about 800,000 people, although, of this number, only an estimated 120,000-150,000 were national Qataris, with non-Qataris comprising $80 \%$ of the population (Qatar Planning Council, 2005). This mass consisted of foreign workers, mainly from Iran and Pakistan, as well as India and other Asian countries in addition to various European and western professionals. These are workers brought in to meet the labour needs of the oil industry. The country has a large public sector (including education) that serves as the dominant employer in the country, importing expatriate labour (skilled and unskilled) to fill the shortage in the local labour pool (Gonzalez, Karoly, Constant, Salem, and Goldman, 2008).

Despite the large numbers of expatriates, Qatar is still a homogeneous tribal society ${ }^{1}$ where most Qataris have ancestors from central Arabia and embrace Wahhabi Islamic ‘jurisprudence' (Saif, 2008). This nature of Qatar as a 'community state' - with its small population enhanced by colossal riches but still strongly rooted in past values and traditions despite the infusion of wealth - results in a population with a tendency towards disconnection with the community of the world. The Qatari community, despite its gleaming, modern, urban face, is still profoundly drawn to long-standing Qatari and Islamic values, with a certain type of 'conservatism' that might not be negative but is certainly characteristic of Qatar and the immediate region. Devlin and Jewson (1995) note that this deep religious commitment governs, in ways often difficult for outsiders to fathom, decisions taken in many contexts. Therefore, the impressive social and economic achievements of the twentieth century were not accompanied by similar changes in

\footnotetext{
${ }^{1}$ The tribe is composed of a close union of several extended families linked by blood relations and kinship (Al Ghanim, 2002)
} 
domestic culture and values, as the mentality and attitudes of gulf citizens remain largely unchanged (Bahgat, 1999).

Qataris speak Arabic, which is the official language of the state. Other Arabs and nonArabs speak other languages such as English, Urdu, Hindi, Tagalog and Farsi (Lesko, 2002). In Qatar, oil and gas account for more than 60 per cent of the gross domestic product (GDP), roughly 85 per cent of export earnings, and 70 per cent of government revenues (Qatar Planning Council, 2006). Therefore the majority of its nationals enjoy high standards of living with major services such as education and health provided by the government free of charge. Subsequently, Qatar has the highest per capita expenditure on education in the world (ibid).

\subsubsection{Socio-historical context of education in Qatar}

The modern history of Qatar and most Arab Gulf states began with the settlement of Bedouin tribes who migrated from central Arabia and established their sheikhdoms on the eastern coast of the Arabian Peninsula by the late eighteenth century. These tribes practiced their Quranic and Sharia laws besides their small trade, hunting, poetry and other traditional customs. They led simple lives and remained uninfluenced by the vast Islamic Empire created by their own Arab ancestors over the centuries (Al-Misnad, 1985). They never showed any desire or need for formal education and the imparting of knowledge was limited to the male children attending the elders' salons (Majlis) and listening to their discussions and stories. Sheikhs did not believe in formal education for their own sons, nor for their subjects, apart from Islamic teachings for the few (ibid). Likewise, the subsistence economy of their society did not provide for activities such as education. While the Sheikh or the ruler enjoyed political authority, their financial position was no better than that of their subjects. They depended heavily on meager taxes collected from local 
merchants. The extreme poverty of most of the population did not help in this respect. Pearl-fishing was the main economic activity of the region and this absorbed all ablebodied males in the community for at least six months a year. Even with its many dangers, it never raised the economic standards of the community above the poverty line. These economic conditions worsened as a result of World War I, the economic recession of the 1930s and the introduction of cultured pearls by the Japanese (Al Ghanim, 2002). Therefore, the question of formal education or provision in that era did not arise in Qatar and the immediate region.

Before the start of modern education in Qatar in the 1950s, the only form of education was the traditional provision provided by one teacher (Mutawa) to a group of girls or boys (al Kuttab).This was mainly religious in content, based on memorizing verses of the Quran and religious scripts, as well as basic Arabic orthography and simple arithmetic. In 1952, Qatar had one elementary school for boys with 240 pupils and six teachers. By 1980, however, Qatar had 71 schools for boys with 20,588 pupils and 70 schools for girls with 19,356 students. It established its academic system with six years of primary education, three of preparatory education, and three of secondary education. The compulsory age for starting school is six (Al-Ammari, 2004; Al-Nuaimi, 2003).

From having only a few Quranic schools for boys in the early 1900s, Qatar's system of education evolved into the comprehensive educational infrastructure that exists today. Both private and government schools offer preschool and primary education. The Qatari K-12 education system serves about 100,000 students, with two thirds of them attending schools that are government financed and operated. According to the latest Schools and Schooling Report (2009), at the primary level, there are around 200 schools in operation of different types, following the Qatari educational curricula or, in the case of private schools, 
following curricula that will meet the needs of the various expatriate communities in the country. British, French, Norwegian, American, Filipino, Japanese, Indian, Bangladeshi and other communities have schools that serve the needs of their respective members. The majority of these private schools coordinate closely with educational authorities in the home countries of their constituents, and the standard of education in these private schools is generally high.

\subsubsection{The Qatari schooling system}

According to the report prepared by RAND, a US-based non-profit advisory institute which the Qatari Government invited to oversee educational changes (Brewer, Augustine, Zellman and Ryan, 2007), under the new reforms there are five types of schools available to Qatari pupils and parents. Independent schools, MOE (Ministry of Education) schools, and Private schools, which include International schools, Community schools, and Private Arabic schools, as follows:

Independent schools are publically funded, privately run schools similar to charter schools in the United States. The charter schools' system claim to tailor programs to the particular needs of the students. Most are controlled locally and enjoy a high level of administrative and financial autonomy. The focus of the school evaluation is on outcomes not on processes (ECSSR, 1999). The independent schools in Qatar were established through the educational reform that started in 2003 in partnership with and under the guidance of RAND. These schools' main corner stone is their independence from state intervention. However, centrality is creeping back. Although all schools should comply with the National Curriculum standards and undergo an annual review, other aspects are also now being organized by the Supreme Education Council (SEC) in much the same way that the old Ministry of Education acted as a bureaucratic central institute. Approval from the 
council is sought on many issues, from uniform sales to teacher appointment. As a general regulation, any Qatari pupil can attend these schools according to proximity of housing. In addition, any employee of the government (even if non-Qatari) is entitled to free education and eligible to enroll in an independent school. Other non-Qataris and children of nongovernment employees can enroll for a small fee. In total, there are 137 Independent schools distributed around all of Qatar (including villages), 44 of which are primary schools. In general the medium of instruction in these schools should be in English especially in Mathematics and science.

Boys and girls have different schools. All teachers at the primary stage are females, with very few exceptions when children in grades 5 and 6 are taught by male teachers in separate premises. On the one hand, the female teachers are mainly Qatari with a number of Arabic and Middle Eastern expats. The male teachers, on the other hand, are mainly Arab and non-Arab expats who view themselves on a temporary contract with little 'loyalty' to the achievement of the educational outcomes set by the educational initiatives of the higher leadership. This presents a sharp distinction between the teaching staff of boys and girls. The SEC Report of 2008-2009 distinctively indicates this imbalance in the teaching force, at it shows that Qataris constitute just 35\% of the teaching staff whereas non-Qataris account for $65 \%$.

MOE (Ministry of Education) schools are publically funded and run by the Ministry of Education under highly centralized governance. In very recent documents, these are referred to as semi-independent schools. There is no data available to the researcher on the number of these schools, but there are definitely fewer than the independent schools and many more turn into independent schools each year. The medium of instruction in these schools is totally in Arabic except for the 5 hours of English instruction per week. 
Private schools comprise three different types: International Schools (locally known as English private schools), community schools, and Arabic private schools, as follows:

The majority of international schools are managed and run for English-speaking expatriates, although many Qatari and Arabic-speaking families choose to send their children to these schools. They follow the curriculum of a foreign country or a general international curriculum and often enroll children of both Qataris and expatriates living in Qatar. The curriculum is mainly taught with English as the medium of instruction and these schools are not under embassy sponsorship. Most of these schools are co-educational up until grade 6. In general, standards at private international schools are high, with small class sizes and modern facilities. There are about 25 International schools in the city of Doha. Garcia (2009) describes one Qatari international school (Doha Academy) as an example of a successful immersion school. In this school, Qatari children are immersed in English, while also receiving a strong Islamic religious education and Arabic language classes. It follows the British National Curriculum, as well as the Qatar Curriculum Guidelines.

Community schools offer a curriculum from another country, generally for children of a specific expatriate group living in Qatar (e.g. Indian, Pakistani, American, French, German and Japanese). These schools are sponsored by the embassy of the relevant country and mostly they are small schools catering only for their nationals. There are about 20 community schools centered in the city of Doha as well. Their medium of instruction varies according to each school nationality. 
Private Arabic schools are, consistent with their label, are Arabic-based schools that mainly follow the curriculum of the Ministry of Education. These are also small schools catering for parents with no interest in encouraging extra proficiency in English (most are Islamic schools). There are about 12 Arabic private schools. Tuition usually costs less than the international schools as well ${ }^{2}$. The Medium of instruction in these schools is Arabic with English taught as a second language.

The tables below give a general idea about language use in students' homes and the languages they are reported to be proficient in according to each school type. It should be noted that the report and its tabulations provide separate information based on the three stages of schooling (primary, preparatory and secondary) and on four school types (referred to as Ministry of Education, Private Arabic, Independent and International) ${ }^{3}$. It is important to stress that the data are "presented essentially as provided by the various respondents. They represent what the respondents think, feel and report and have not been filtered and/or verified” (P. iii Report, 2009). Therefore, no judgment has been made about the veracity or indeed the actual quality or fitness-for-purpose of the feature.

Table 1.1 : Languages spoken by students

$\begin{aligned} & \text { Main languages which students report } \\
& \text { they can speak in general }\end{aligned}$
\begin{tabular}{|l|c|l|l|}
\hline Percentage & $\begin{array}{l}\text { Percentage } \\
\text { English }\end{array}$ & $\begin{array}{l}\text { Percentage } \\
\text { Other }\end{array}$ \\
\hline Ministry of Education & $\%$ & $\%$ & $\%$ \\
\hline \multirow{2}{\Sigma}{ Private Arabic } & $\%$ & $\%$ & $\%$ \\
\hline
\end{tabular}

\footnotetext{
${ }^{2}$ It should be noted that neither the Qatar Statistics Authority nor the SEC site provides this information. The SEC site doesn't present any data about schools, number of schools, number of students and nature of demographics. The previous information was accumulated from various websites about Qatar, school sites, and the researcher's own background information.

${ }^{3}$ The Report doesn't include information on Community schools.
} 


\begin{tabular}{|c|c|c|c|c|}
\hline & International & $\%$ & $\%$ & $\%$ \\
\hline & Primary & $\%$ & $\%$ & $\%$ \\
\hline & Preparatory & $\%$ & $\%$ & $\%$ \\
\hline 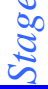 & Secondary & $\%$ & $\%$ & $\%$ \\
\hline & chools & $\%$ & $\%$ & $\%$ \\
\hline
\end{tabular}

Table 1.2: Languages spoken in students’ homes

\begin{tabular}{|c|c|c|c|c|}
\hline \multicolumn{2}{|c|}{$\begin{array}{l}\text { Main languages reported by students } \\
\text { as being spoken at their home }\end{array}$} & $\begin{array}{l}\text { Percentage } \\
\text { Arabic }\end{array}$ & $\begin{array}{l}\text { Percentage } \\
\text { English }\end{array}$ & $\begin{array}{l}\text { Percentage } \\
\text { Other }\end{array}$ \\
\hline \multirow{4}{*}{$\overbrace{i}^{\infty}$} & Ministry of Education & $\%$ & $\%$ & $\%$ \\
\hline & Private Arabic & $\%$ & $\%$ & $\%$ \\
\hline & Independent & $\%$ & $\%$ & $\%$ \\
\hline & International & $\%$ & $\%$ & $\%$ \\
\hline \multirow[b]{3}{*}{ 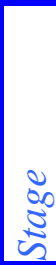 } & Primary & $\%$ & $\%$ & $\%$ \\
\hline & Preparatory & $\%$ & $\%$ & $\%$ \\
\hline & Secondary & $\%$ & $\%$ & $\%$ \\
\hline \multicolumn{2}{|c|}{ All Schools } & $\%$ & $\%$ & $\%$ \\
\hline
\end{tabular}

\subsubsection{The education initiative: Education for a New Era}

In Qatar, education reform had long been on the agenda of the leader of Qatar and, in 2001, a team of experts arrived from RAND's California headquarter to review the entire primary and secondary school system and recommend substantial changes (Glasser, 2003). The team described the older educational system as 'rigid and bureaucratic', with little emphasis on Science, English and the Internet, and too much stress on memorization and teacher control. They recommended an entirely new system, based on parent choice, intended to eliminate the centralized model prevalent in Qatar and most Arab countries and 
bypass the tradition-bound Ministry of Education. Following the RAND review, the SEC was appointed (headed by the crown prince of Qatar) to oversee the reform. Two new independent agencies, the Education Institute and the Evaluation Institute, were created to carry it out (Brewer et al, 2007).

The government of Qatar launched a comprehensive initiative to reform the educational system under the title 'Education for a New Era', with the aim of matching developments in this field at the international level. Saif (2008) notes that the initiative, which started in May 2001, is considered the cornerstone of efforts towards reform in Qatar, considering education to be crucial if progress is to be made. Qatar has also fostered partnerships with its western counterparts through the establishment of the Qatar Foundation in 1995. This is comprised of a group of the best Western Universities and institutions which support the development of the quality of human resources through centres of excellence in education, research and technology.

The two key elements of this reform initiative are building the new government-funded Independent schools and establishing annual student assessment and surveys to help monitor student learning and performance. Every independent school must establish curriculum standards in Arabic, English, Mathematics and Science, while complying with periodic financial requirements (SEC, 2010). According to the SEC's official website, there are four critical principles in the new school system:

1. Autonomy: for schools and teachers in choosing their staff, teaching methods, and approaches in dealing with the needs of individual students and parents, all within a framework of international curriculum standards. 
2. Accountability: through a transparent assessment system holding all school leaders, teachers and parents responsible for the success of students.

3. Variety: in schooling alternatives, encouraging schools to engage in different types of instructional programmes.

4. Choice: for parents in selecting the schools that they think best suit their children.

Qatar has also requested assistance from international sources of expertise such as the RAND-Qatar Policy Institute, as well as Australian and British institutions. It has also signed an agreement with a New Zealand-based education service provider to help mentor Qatari schools through a process of modernization and decentralization.

\subsubsection{The language situation in Qatar}

According to the EFA Global Monitoring Report (2006) titled 'Literacy for Life', in the Arab states section, the Arabic Language is spoken by over 200 million people in the Middle East and in countries with a significant Muslim population. There are three types of Arabic: Classical Arabic (found in the Quran and old religious texts and poetry), Modern Standard (MSA) (used by many countries as the national and official language) and then there are over thirty forms of colloquial or spoken Arabic vernaculars. Speakers of these dialects will understand each other in reference to their geographical proximity. MSA is described as a mainly written, literary and formal language that displays a high degree of uniformity, and functions as the official standard language in all Arab countries. It is the language of Islam (the second largest religion in the world), of pan-Arab nationalism, and marks the overarching Arab identity (Haeri, 2000).

The EFA report indicates that there is a paradox in that literacy in all Arab-speaking countries is taught through MSA, which sometimes for young learners will be quite distinct 
from the spoken form they are used to. Thus learners will have to perform two tasks in their literacy education: they have to learn the standard form of Arabic, and then learn how to encode the oral standard form (which they might not have used prior to their school experience) into script and decode the script back into oral language.

\subsubsection{Diglossia and the Arabic language}

In this light, it can be seen that Arabic-speaking children are born into a unique linguistic context called ‘diglossia’ (see Ferguson’s seminal article of 1959 and Garcia, 2008, p.75). Diglossia as a term was developed as a conceptual model for the analysis of societal differentiation of the use of varieties of language. The linguistic situation includes the following two features: (a) differentiation between the written and oral modes; and (b) socio-functional differentiation based on the functions performed by the two linguistic codes. Here, a (H)igh variety of one language is used for certain prestigious functions (such as formal schooling and as content for literature, poetry and prose, civics, lectures, in tertiary education, religious sermons, formal political speeches, newspaper articles, news broadcasts, and official communication in the government offices) and the (L)ow variety of the same language is used in ordinary functions (such as in conversation with friends and family, the home language, at the marketplace and almost everywhere outside the school environment, as well as in folk literature, radio and TV soap-operas, plays and advertisements) (see Fishman, 1991; Garcia, 2009). This is clearly the case in the Qatari context, with MSA as the $\mathrm{H}$ variety and the Qatari Arabic as the $\mathrm{L}$ variety. Within instructional contexts, it should be noted that there exists a degree of code-switching according to the teacher's own proficiency in the H variety.

Overall, as noted by Haeri (2000) in her review of Arabic socio-linguistics and literature on Education, there is a lack of empirical study of the Arabic diglossic situation, bilingual 
education, and literacy in the two languages. In particular, the study of the bilingual programs and their implication on literacy of the two languages in a diglossic situation for Arabic speaking children in Qatar is sparse. The research body provides inconsistent results as to the positive or negative effects of diglossia on Arabic children. Some studies have focused on the effects of early exposure to literary Arabic texts on reading comprehension abilities in Arab pre-school children (Abu-Rabia, 2000; Saiegh-Haddad, 2003; Feitelson, Goldstein, Iraqi and Share, 1993). Specifically, Abu Rabia (2000) investigated the hypothesis that reading difficulties in Arabic in primary schools result from the diglossic situation, whereby MSA, the language of books and school instruction, is in opposition to the spoken dialect of the home. Saiegh-Haddad (2003) examined the role of oral language in the acquisition of basic MSA reading processes, exploring the interface between exposure to MSA and the development of top-level reading comprehension skills. The study showed that diglossia and the phonological distance between the two varieties of Arabic were indeed related to the negative decoding ability of young Arab children. This conclusion supports Maamouri (1998) in his claim that MSA is difficult to learn and use because it is nobody's native language. He argued that MSA and dialectal Arabic code-switching constitute a major cause of serious pedagogical problems in Arabic classrooms.

The body of research on diglossia and Arabic literacy also focuses on the development of meta-linguistic awareness in either normally developing children or children with reading or learning disabilities (e.g. Abu-Rabia, Share and Mansour, 2003; Eviatar and Ibrahim, 2000). Given that bilingual children reveal heightened metalinguistic abilities as a result of acquiring two linguistic systems (Bialystock, 2001), Evitar and Ibrahim, explored how newly literate Arab children might acquire metalinguistic abilities similar to the ones found 
in bilingual children as a result of their exposure to a high and low dialects of Arabic (i.e. their own local Arabic dialect and MSA. This was done in order to determine whether this effect is evoked before they have been exposed to any other language. Three samples of children were tested: Hebrew monolinguals, Russian-Hebrew bilinguals who came from Russian-speaking immigrant homes and attended Hebrew school and Arabic speakers whose first language was spoken Arabic but who also had exposure to MSA via children's books, television, and formal instruction in kindergarten and first grade. The results of the Arabic speakers revealed similar performance levels in metalinguistic tests to the RussianHebrew bilinguals and higher performance in comparison to monolinguals. The researchers concluded that exposure to MSA in early childhood affects their metalinguistic skills in the same manner as that reported for children who are exposed to two different languages. Their results were consistent with subsequent studies (Ibrahim, 2009).

We can see then that there is a clear consensus in the literature that the differences between MSA and the spoken colloquial Arabic manifest themselves in all language domains, but there is disagreement about whether this linguistic situation is seen as a positive or negative attribute. Some researchers go so far as to view MSA as a second language (e.g. Eviatar and Ibrahim, 2000). Others propose that this sociolinguistic situation delays literacy acquisition due to a lack of a transparent relation between speech and literacy (Abu-Rabia, 2000; Saiegh-Haddad, 2003; and Maamouri, 1998), attributing the widespread functional illiteracy in the Arab world to diglossia, which is argued to have a negative impact on Arab children's ability to acquire reading and writing skills, and consequently on their academic attainment in general. 
On the other hand, Wagner (1993) remarks that, in spite of the difference between MSA and Moroccan Arabic, Moroccan Arabic speakers can be thought of as learning literacy in their mother tongue in the same sense that nonstandard dialectical English speakers (e.g. African-Americans in the US or Scottish English-speakers in the UK) learn to read Standard English. Wagner's longitudinal study of literacy acquisition in Moroccan children investigated whether preschool experience with a spoken Moroccan Arabic dialect facilitated literacy acquisition differently from preschool experience with Berber, a member of the Hamitic family of languages that has no semantic or syntactic similarity to Arabic. This study compared the performance of monolingual and bilingual Arabic- and Berber-speaking children in learning to read MSA and French. The results showed an advantage for the Arabic-speaking children over the Berber-speaking children in learning to read MSA, whereas the preschool experience of the two language groups had little effect on learning to read French. The researchers concluded that the superiority of the Arabicspeaking children in the early stages of MSA literacy acquisition was due primarily to the substantial similarity and transfer from spoken Moroccan Arabic to MSA, an advantage which did not apply to French. To this end, Parkinson (1991) argues that MSA has a concrete reality in the communicative lives of all Arabs, commenting that, although MSA may not have 'native speakers' in the fullest sense of the term, it certainly does have native users, which is the case in any $\mathrm{H} / \mathrm{L}$ diglossic situation.

Although several researchers claim that Arab children are not exposed to MSA until they enter school (Holes, 1995; Suleiman, 1986), children do have some MSA exposure before entering full-time education through television programmes and literacy events, such as contact with stories, letters, and street signs. However, as this exposure might be relatively limited depending on the child's environment, it is; in general, fair to say that children are 
primarily exposed to MSA at school. There has been no research, however, to accurately measure the extent of children's exposure to MSA prior to their schooling experience in Qatar. Consequently, the extent of exposure to MSA before starting school is not clear.

However, it should be noted once more that the literature (especially in the case of Qatar) does not have enough data to fully show the extent of children's exposure to MSA prior to their schooling experience. Young parents are keener these days on reading to their children, Islamic conservatives teach the Quran to children from a very early age, and there are free children's TV series presented in MSA too. Therefore, the extent of exposure to MSA before starting school is not entirely clear.

\subsubsection{Diglossia in the Arab classroom}

According to Maamouri (1998), a clash seems to exist in Arab classrooms, presenting the education system with various pedagogical implications. The clash occurs between two conflicting practices: on the one hand, teachers try to discourage and undermine students' speech habits; on the other hand, the same teachers find themselves often obliged to use the colloquial form to communicate with their learners. Most teachers of subjects other than Arabic use the colloquial form to communicate difficult content. In addition, most Arab educators seem to keep a reserved and silent attitude regarding which MSA rules teachers should accept in the classroom. Maamouri (ibid) notes that most Arab teachers agree to accept a relatively low level of tolerance to use of MSA in literacy and other subjects, despite strict regulations from school leadership.

\subsubsection{English in Qatar}

English is used widely in the state of Qatar. According to Kachru (2008), Qatar falls within the expanding circle of the use of world Englishes. Kachru's model divides the world use 
of the English language in terms of three concentric circles: the inner circle, the outer circle and the expanding circle. The inner circle represents the traditional historical and sociolinguistic bases of the English language in the regions where it is used as a primary language (i.e. the UK, the USA, Canada, Australia and New Zealand). The outer circle represents regions of the world which were former colonies of the UK or France In these regions, English has been adopted as a formal language of law administration and education (e.g. India, Hong Kong, Nigeria and the Philippines). The expanding circle includes areas of the world were English is increasingly used as a medium of international communication in the areas of commerce, banking and technology (e.g. China, Japan and the Middle East) (Kachru, 2008, p.4). Qatar, after its independence in 1973, has maintained some use of English as a communication language with the international community, especially after becoming a major exporter of oil and natural gas. For example, street signs and shop hoardings are often written in both Arabic and English. With growing Eastern-Asian communities (Indian, Filipino and Pakistani), English is also becoming a lingua-franca for many daily activities. Banking and commerce also use English widely as a language of written communication.

In the educational system, English has been taught from either grade 4 or 5 since the 1970s until the recent reforms in the educational system where English became a second language taught from grade 1, as well as a language of instruction in core subject such as Mathematics, Science, and sometimes Arts and PE in many schools across Qatar. Unlike most countries in similar situations (e.g. Israel, India, the Philippines), the term 'bilingual Education' is rarely mentioned or addressed as an issue in educational contexts. When the SEC website is examined as well as published school policies, it is noteworthy that bilingualism is not a professed policy in the country, and English is not considered a second language in the community. The term 'bilingual' is not a part of any school policy, 
despite the fact that bilingual education is actually taking place in almost all state schools and the majority of private schools. The lack of this type of documentation and formal conversation about bilingualism makes it difficult to map out the bilingual situation without further study. According to Garcia, the situation in Qatar might be that of monoglossic bilingualism, with bilingual education seen as an additive attribute without the aim of bi-cultural diversity. In general, it seems that Qatar is interested in raising the level of proficiency in the English language and thus 'experimenting' with bilingual forms of Education with English is thought of as an elite language of science and technology and as an important tool in the industrial and economic race of the world (Garcia, 2009). This unprofessed 'bilingualisation' process, which has been taking place for more than a decade, presents the research body with an alternative perspective that tells a different story of bilingual education.

\subsubsection{Bilingual education in Qatar}

Based on the previous description of the use of the Qatari Arabic, MSA and English in the community and schools it can be concluded that the bilingual education scene in Qatar is unique. Unlike Hong Kong, India and many other eastern countries in which the bilingual education system was created as a consequence of colonization by English-speaking countries, Qatar started a bilingualisation process in 2001 following the massive reforms in the education sector in the 'Education for a New Era'. There have been many concerns surrounding this bilingualisation process, such as the level of students' performance, the availability of bilingual teachers and parent satisfaction (Gulf Times, 2009). However the local authorities and Arabic research doesn’t provide much information about the bilingual policies or realities in Qatar. Some newspaper articles (ibid) refer to unpublished reports on 
student achievement in key subjects, which is very low and unsatisfactory considering the huge amounts of effort and money injected in the new reforms of 2001. This can also be deducted from the low results of students in Qatar in the international tests PISA ${ }^{4}$ in 2009 where more than $50 \%$ of the students who participated were described as lowest performers in the data (level 1). Students who do not attain the baseline proficiency in the PISA (set at level 2) are described to 'lack the essential skills needed to participate effectively and productively in society' (PISA, 2009). Furthermore there is an increasing shortage of bilingual teachers, with parents left to take on extended tutoring for their children after school, especially in English and Mathematics.

\subsubsection{Conclusion}

This section described briefly the demographic and historical features of education in Qatar. The schooling system was described briefly based on school types on offer. These two types are also the most popular among Qatari and other Arabic speaking families. However there is a lot to be explored in regard to language use, choice and pedagogical features of the L1 and L2 classes in these schools. Regarding the linguistic situation in Qatar; it was reported that Qatari children grow up speaking Qatari dialect of Arabic, begin their literacy in MSA and English at the age 5-6 years. English is also the medium of instruction of many subjects as well as MSA with varying degrees according to school type. English is also used widely in the community as a lingua-franca between Arab and non-Arab nationals, residents and expats.

These features are mainly characteristic to Qatar. Although the study is not intended as a study in policy of education or educational politics and bilingual policies, it was crucial to

\footnotetext{
${ }^{4}$ Qatar participated in the 2003, 2006 and 2009 cycles of the assessment of reading, mathematics and science of PISA ( programme for International Student Assessment) which organized by the OECD( Organization for Economic Co-Operation \& Development)
} 
sketch out the political features of the State of Qatar and Qatari education to grasp a better understanding of the bilingual situation within Qatari schools and the impact of these conditions on students learning within these schools. This description also helps to illustrate the reason that Qatar presents a special context to examine bilingual education. 


\section{CHAPTER TWO: LITERATURE REVIEW}

\subsection{Introduction}

It has been underlined in the previous chapter that there is clear shortage of empirical studies on bilingual education, multi-literacy provision and bilingual programmes in the multi-dialect situation of the Arab Middle East, and specifically in the case of Qatar. To understand the scope of the questions asked by this research project, various themes and topics in the literature will be clarified. The structure and purpose of the literature review is to (a) define what is meant by bilingualism and bilingual education; (b) outline the theoretical framework upon which this study is grounded, with reference to established models and typologies of bilingual education and bilingual programmes; (c) discuss pedagogic practices, language organization, and biliteracy teaching approaches within existing school bilingual programmes; (d) describe the specifics of curriculum and pedagogical practices in bilingual education, with special reference to the majorityminority language context distinction that is vital for understanding how the Qatari context is different to other socio-linguistic contexts; (e) provide evidence for a gap between observed language teaching practices with the bilingual policies professed by the schools in East Asia and the Middle East, leading to dissatisfaction with the policies and practices of bilingual education; and ( $\mathrm{f}$ ) emphasize that there is a gap in the research concerning bilingual education in Qatar and the Middle East, providing a rationale and direction for this study.

When considering bilingualism and bilingual education in a particular country it is important to take into account the experiences in countries that have the most common socio-linguistic context. As there are a handful of studies which were concerned with some aspect of bilingualism in the Arab region, these will be included to demonstrate that 
there is indeed a scarcity of empirical studies about the linguistic and academic outcomes of children who participate in bilingual programmes in this region, and to flesh out how the current study is presenting an original contribution to the field. Consequently, research conducted in other regions of the world that bear some similarities with the Qatari context (e.g., countries in East Asia and the Middle East, where two or more typologically different languages are taught) is reviewed in preference to that in other socio-linguistic contexts

\subsection{Bilingual Education and Bilingualism}

This section will briefly define bilingualism and bilingual education before discussing the theoretical framework and other theoretical perspectives relevant to the study of bilingual programmes in Qatar.

\subsubsection{Bilingualism Defined}

The study of bilingualism is not exempt from the scholarly trend of creating dichotomies. These include coordinate vs. compound bilingualism, early vs. late bilingualism, simultaneous vs. successive bilingualism, elite vs. folk bilingualism and additive vs. subtractive bilingualism (Hakuta, 1990). While such distinctions serve to highlight different attributes of the individual or social group within which bilingualism is found and depend to an extent on the point of view adopted by a researcher, these 'polar opposites' do not provide a clear definition of bilingualism as an individual attribute, for bilingualism cannot be examined in isolation from the political and social environment in which it is utilized. No one single definition is broad enough to account for all the contexts in real-life communities; it is therefore perhaps more useful to consider definitions of bilingualism as resting on a continuum ranging from 'native-like control of two or more languages' to 'possessing minimal communicative skills in a second language' (ibid). The former

definition has been rejected by many researchers in the linguistic community simply 
because few people will ever gain this 'native-like' competence and therefore it is not relevant to the considerable majority (Cook, 2001). On the other hand, most experts consider the latter definition as a starting point for bilinguals and emergent bilinguals (beginners), from which a variety of bilingual skills can develop (Hornberger, 1989). Some researchers have attempted to define the term by developing models encapsulating all of the conditions and variables surrounding bilingualism. Hornberger (ibid) has introduced a continua model of four parts: the context of bilingualism, the development of bilingualism, the media of bilingualism and the content of bilingualism. Each of these has different subsets, a discussion of which is beyond the scope of this review. However, the main idea behind Hornberger's model is to illustrate that it is only according to the specifics of these sets and conditions that one can define an umbrella term such as bilingualism.

\subsubsection{Bilingual Education}

Bilingualism can be achieved in many ways, one of which is through educational experience in more than one language or "Bilingual Education”. It was shown above that there are difficulties apparent in defining bilingualism, given its complex and multifaceted variables and often highly individualized nature. Much of the same level of difficulty is apparent when trying to define bilingual education. In Section 1.2, it was asserted that integrating language and education is the main feature of bilingual education. On a surface level, it might be said that bilingual education is any programme that incorporates more than one language in the daily instruction for any amount of time. On the other hand, bilingual education might be any programme that includes speakers of two languages. Christian and Genesee (2001) define bilingual education as education involving two languages as media of instruction. This generic definition seems to be the most widely accepted in the literature and is therefore the definition of bilingual education used in the context of the current study. 
The following section will describe the theoretical positions of the various conceptual frameworks within the field for their role in encapsulating philosophies of typologies and models that attempt to define the different understandings of bilingual education and the different populations of children that participate in these programmes.

\subsection{Theoretical Framework}

This section presents a short historical overview of the field of bilingual education, demonstrating how the framework chosen to view and categorize the schools in Qatar is deemed the most appropriate. The 1970s marked the beginning of the academic appreciation of bilingualism and multilingualism as a personal asset not a handicap (see, for example, Mackey 1972, Lambert and Tucker 1972, Spolsky, 1972, Fishman, 1976 and Swain, 1978). In the 1980s, the problem of language achievement within different contexts was much explored. Within this decade, contrasting results on the effectiveness of bilingual education appeared on many fronts in the US and Asia (Tosi, 1990). This emphasis on the context of bilingual education, tempered by the apparently contradictory findings observed in the literature, left the field lacking a strong theoretical grounding. The debate over the effectiveness of bilingual programs found in the studies conducted in the 1980's is documented in Cummins's (1999) critique of Rossell and Baker review of these studies (1996).Later, in the 1990s, significant advances emerged. Hornberger's continua of biliteracy (1989) marked the beginning of theorizing about bilingual education, notwithstanding the seminal analysis introduced by Baker (see, for example, Baker, 1995, 1988). The past and current decades of bilingual education demonstrate an emerging perspective that pays more attention to the context-specific knowledge realized by the learner which has two emphases - one on policy and one on pedagogy. This new outlook is evident from various studies and publications that strive to achieve three aims: 
1. Define the nature of bilingual education and set an overall conceptual framework;

2. Define the political nature and practices of bilingual education using typologies, frameworks or continua that operate on a global basis; and

3. Define the pedagogical and practical realizations and recommendations for the various bilingual education contexts.

This argument can be evident from publications by Maija (2002), Marlin-Martin Jones (2000), Garcia (2004, 2009), May et al (2004), Baker (2001) and Cummins (2000) to name the most prominent. Given the linguistic situation in Qatar with its diglossia and the addition of bilingualism in education, viewing the Qatari context within a model or a conceptual framework that accommodates Qatar's multi-lingual situations will be helpful as a first step to further investigate the realities of these programmes. The following section will discuss a few typologies: Baker (2001), May, Hill and Tiakiwai (2004) and Garcia (2009).

\subsubsection{Models and Typologies of Bilingual Education}

An understanding of the typologies, models and approaches of bilingual education is important in introducing the concepts that the current study will draw on, providing direction and helping make sense of the data. It is customary in bilingual education circles to speak of models. This section will present the most prominent typologies, models and ensuing programmes in the literature, emphasizing those that will be adopted to evaluate bilingual programmes in the present study.

The terms 'bilingual programmes', ‘models' and 'typologies' have sometimes been used interchangeably, but there is a distinction between them. Models of bilingual education are defined in terms of their language-planning goals and ideological orientations in the society (Garcia, 2005, May, Hill \& Tiakiwai, 2004). Models are the broader schemes or 
categories within which different programmes exist. According to Hornberger (1991), bilingual programmes are more concrete categorizations than models, and can be differentiated from one another by an analysis of specific contextual and structural characteristics. By contextual characteristics, Hornberger means the nature of the students and teachers, and by structural characteristics she means the location and facilitation of the bilingual programme in the school. The reason models and typologies are portrayed here, rather than simply a list of programmes, is that a programme could be established in two different contexts and thus be similar only in label, as each will be driven by a different ideology. Moreover, Cummins (2003) establishes that programme typologies serve usefully to highlight specific issues that need addressing in the planning and implementation of programmes. This is especially important in the case of Qatar, as it is not yet definitive because of the lack of a published language policy and empirical research on the country's bilingual education. It is imperative therefore to try to establish where the process of bilingual education is leading to, and what type or model of bilingual education these programmes identify with.

A significant number of different kinds of typologies have been generated in the research literature, depending on the combination of a wide variety of features - programme goals, status of the student group, status of the L1 to the L2 and so forth. It is not possible, nor is it particularly useful, to explore all of these numerous typologies, given the complexities involved. For the sake of clarity, this review will only focus on the most relevant classifications to the context of Qatar.

Baker (2001) identifies ten programme types and divides them into two categories: weak forms or strong forms of bilingualism. 'Weak forms' simply consist of bilingual students, with the educational aim of producing monolingualism or limited bilingualism rather than full bilingualism. In contrast, 'strong forms' aim at producing students who are proficient 
in two languages and are biliterate as well (Baker \& Prys Jones, 1998). The distinction is mainly between support and non-support of the first language. This typology generates 90 varieties of bilingual education.

The support and non-support of the first language seems to prevail as the main criteria to classify the typologies, models and philosophies behind bilingual programmes. May et al (2004) identify three key axes of bilingual education: philosophy of bilingual education, models of bilingual education and the actual programmes. The philosophy of bilingual education refers to the understanding behind bilingual education, i.e. whether the programme will either be value-adding another language to the student's existing language (additive) or replacing one language with another (subtractive).

Models are at the next level, described in terms of educational aims based on Hornberger's typology (1991): transitional, maintenance and enrichment. These have also been discussed widely in the literature (see, for example, Cummins, 2003; Baker, 2001). Transitional models are often models of bilingual programme that have the aim of fostering a language shift from a minority language to a majority one. Maintenance models aim to maintain a minority L1 and are broadly concerned with strengthening the linguistic and cultural identity of a minority group. Enrichment models aim for language development or extension via instruction in a minority language that is an L2 to most students, thus aiming for societal pluralism.

Garcia (2009:115) outlines two ideologies or philosophies for viewing bilingual education: monoglossic and heteroglossic. This marks a departure from abstract notions of bilingualism as either the sum of two languages or the interactions of two or more languages on either a personal, local, societal or global level. Garcia’s bilingual ideology classification builds on the basic dilemma of societal bilingualism: additive or subtractive. 
However, Garcia's model is broader. In a monoglossic view of bilingualism, monolingualism in each of the two languages is the norm, responding to the belief which assumes that desired outcomes would be either proficiency in the two languages according to monolingual goals, or proficiency in the dominant language only. Within the monoglossic view, programmes can then be seen as either additive or subtractive. For example, when the outcome goal is transition into the majority language without continued literacy support for the L1 or minority language, policies enacting transitional bilingual education are established with a monoglossic subtractive ideology in mind.

The breakthrough in Garcia's model is that she adds a whole new dimension to viewing bilingual education, a heteroglossic ideology. Acknowledging the shifting ecology of bilingual education in the twenty-first century, western scholarship has become aware of the vast linguistic complexity of the East, Africa and the developing world. These regions have started their own academic discourse regarding bilingual policies and ensuing practices. A realization of multiple co-existing norms of bilingual speech that might not always adhere to a monolinguistic purists' view have appeared in the field questioning the monoglossic positions used to examine bilingual programmes around the world. This multilingualism - or what Garcia (2009) terms heteroglossic linguistic practices and beliefs - has caused the neat bilingual models developed in the latter half of the twentieth century to leak, producing new frameworks that cannot be seen through the traditional monoglossic lens as either subtractive or additive because of their non-linear nature. The programmes within such contexts cannot be merely dismissed because of their unorthodox nature. Garcia proposes that these new frameworks identified within the heteroglossic ideology are either recursive or dynamic. Although Garcia doesn't provide a hard and fast definition of the two types, it can be said that recursive frameworks operate with the goal of language revitalization, aiming at recapturing a lost language or culture. Classroom 
practices with such goals witness a lot of hybridity, since the teachers themselves might not be fluent in their ancestors' language where bilingualism is not seen as an end-point but at the core of the bilingual process. Dynamic programmes will operate as an all-terrain vehicle for multilingualism or pluralism of languages within a community. A dynamic theoretical framework allows the simultaneous co-existence of different languages, dialects and modes of language in communication.

Garcia does not provide empirical evidence to back up her own framework. Nevertheless, a close investigation in the literature produces various instances of studies that either call for or identify these types of dynamic co-existing or hybridized language use, which are neither subtractive nor additive. They are described as dynamic because the boundaries between the two languages' use and teaching is not so clear cut with more than two languages, dialects or registers involved. Lin (2006) strongly argues for this type of hybridization of linguistic policies that mark a shift from linguistic purists' perspectives. She draws on an analysis of the secondary data of student-teacher interaction transcripts during a Science class. These datasets present evidence for the need for practical bilingual pedagogies that will help students to access the second language discourse by capitalizing on their own indigenous linguistic and cultural resources. Lin uses science lessons transcriptions drawn from a larger corpus data which was collected by another researcher (R .K. Johnson, a professor of Chinese Education). The data only included teacher talk and Lin comments on Johnson's method as not being purely ethnographic since no interviews proceeded or followed the recordings. Lin analyzes these transcripts further drawing attention to the functional uses of Cantonese and English when the teacher code-switches. This practice is considered by the author as a viable pedagogical technique for providing limited English (L2) proficiency students access to the science discourse. Although the methodology is lacking as described by Lin, and is mostly related to teaching content 
subjects not language arts; her work embodies how research in the east is communicating a view that calls for re-inventing new models to suit the linguistic realities of their contexts.

Lam (2007) similarly called for a new perspective for identifying bilingual education in Asia. Lam investigated issues surrounding the trilingual realities of China and the education of Chinese children by examining attitudes of Chinese learners learning Putonghua, the official Chinese language, English as a foreign language and a third local dialect. Within this qualitative study that used interviews with older and younger learners, Lam comes to the conclusion that the linguistic situation in China is multilingual and multidialectal at the same time, which should entail various changes in the language policy in China if trilingualism or multilingualism is to be achieved. Conclusions that relate to the complex and perhaps even dynamic nature of bilingual realities in China are also discussed in a study conducted by Feng and Ke (2003) (cited in Feng, 2007). In their study, the authors evaluated a new experimental bilingual programme, Integrated English (IE) where some content areas are taught in English but not exclusively, as they do not substitute content subjects. Since the failure of immersion programmes in primary education due to the lack of bilingual teachers, resources and material, schools started to lose interest in immersion education. The new IE programme was introduced partly because it did not require as many resources. Statistical data was collected on student English levels and teachers reported on the experiment as a whole. The author stated that the results of these measures indicated that the experiment has achieved a lot and teachers were generally satisfied with the outcomes of these programmes. Other studies confirm this debate over alternative approaches to bilingual education in the Chinese education system and the need to modify the available models and programme types to better suit the multilingual reality of the Chinese context (see, for example, Zhang \& Adamson, 2007). These few examples 
indicate that dynamic multilingual programs do exist and are a part of the current discussion in the literature on bilingual education and bilingualism.

Recent literature arising from western scholarship has also turned to differentiating between the monoglossic/heteroglossic ideologies in bilingual education. Bonacina and Gafaranga (2010) investigated the difference between language of instruction and language of interaction in a French complementary school in Scotland. Bonacina (2012) distinguished between what she terms 'perceived' and 'practiced' policy as opposed to official policy in bilingual schools. She argues that students and teachers construct their own language-use policies in bilingual programs including code-switching which is deemed acceptable by the users even though it is not supported by the school's official policy. This and the previous studies explore code-switching in language schools is a form of flexible language use that is emerging as an area of research interest in recent studies in Bilingual education .

Monoglossic and heteroglossic ideologies and their relation to language choices and pedagogies in language teaching are also seen in the work of Blackledge and Creese (2010) and Creese and Blackledge (2010). They distinguish between "separate" and "flexible" bilingualism as goals of bilingual education. Their study describes 'alternative' or flexible bilingual approach to language teaching and learning in community language schools in the UK. They use the terms 'translanguaging' and heteroglossia to describe languages fluidity and movement in these classes. This means that the teachers and students in the community schools observed in this study were using whatever codes they had at their disposal to communicate. The study consisted of four case studies of four community schools across the UK (Guajarati Schools in Leicester, Turkish Schools in London, Cantonese and Mandarin Schools in London and Bengali Schools in Birmingham). An ethnographic team approach of observation, interviews and field notes, was used following 
two key participants in each. Stakeholders were also interviewed. Their analysis of classroom interaction in these schools identifies bilingual strategies mostly used by the students exhibited in the extracts taken from these interactions. The data depicts that two languages are constantly used in the classes. The authors make a point that both languages are needed simultaneously to convey a different informational message. Secondly they note that the movement between these two languages enables the speakers to engage their audience in order to get the message across. Thus the authors stress that such communication was achieved pedagogically and that flexible bilingualism in these settings was used as an instructional strategy. These flexible language practices are seen as heteroglossia (Garcia, 2009), were teachers often coin new words using an English word followed by a suffix from the first language. The heteroglossia is also seen as pedagogy in and by itself.

Further emphasis on the flexible and dynamic use of languages in bilingual education that aims for heteroglossia and pluralingualism is evident in the work of Bartlett and Garcia (2011) and Garcia, Sylvan and Witt (2011). These studies follow an ethnographic methodology of case studies of bilingual schools in the USA and the Dominican Republic. These two studies also have a common theme of questioning the separate bilingualism approaches, portraying flexible language use and flexible bilingualism in the schools examined. They report on research which responds to a heteroglossic ideology opposed to monoglossic ideology as explained earlier in the section.

To summarize this section, Table 2.1 presents the broad ideologies of bilingual programmes, their varying linguistic goals, the type of programmes associated with each orientation and the types of children participating in such programmes. This scheme provides researchers with a heuristic method by which to examine bilingual education in more detail: 
Table 2.1 Bilingual ideologies, goals, programmes and type of children

\begin{tabular}{|c|c|c|c|c|}
\hline & MONOGLOSSIC & IDEOLOGIES & $\begin{array}{r}\text { HETEROGLOSSI } \\
\mathrm{C}\end{array}$ & IDEOLOGIES \\
\hline \multirow{2}{*}{$\begin{array}{l}\text { Linguistic } \\
\text { goal }\end{array}$} & Monolingualism & Bilingualism & Bilingualism & Bilingualism \\
\hline & Subtractive & Additive & Recursive & Dynamic \\
\hline $\begin{array}{l}\text { Bilingual } \\
\text { programme } \\
\text { type }\end{array}$ & Transitional & $\begin{array}{l}\text { Maintenance } \\
\text { Prestigious } \\
\text { Immersion }\end{array}$ & $\begin{array}{l}\text { Immersion } \\
\text { Revitalization } \\
\text { Developmental }\end{array}$ & $\begin{array}{l}\text { Two-way bilingual } \\
\text { Multiple and multilingual }\end{array}$ \\
\hline $\begin{array}{ll}\begin{array}{l}\text { Type } \\
\text { children }\end{array} & \text { of } \\
\end{array}$ & $\begin{array}{l}\text { Exclusively } \\
\text { minority }\end{array}$ & $\begin{array}{l}\text { Majority } \\
\text { Minority }\end{array}$ & Mostly minority & $\begin{array}{l}\text { Majority } \\
\text { Minority }\end{array}$ \\
\hline
\end{tabular}

Defining such ideologies and orientations is useful in the specific categorization of programmes in any educational context. Since the main issue of concern in Qatar is bilingual education for majority language learners, but without many empirical research to back up the framework this theoretical positioning marks out the terrain necessary for beginning to explore the multilingual context of Qatar, a context which could not have been accounted for under the previous typologies

\subsubsection{Bilingual Programmes}

Defining ideologies associated with bilingual education was useful to address the context of Qatar marking a new terrain in bilingual education. Table 2.1 lists various types of programmes used around the world operating within different ideologies. Pure or generic programmes are rare, especially in multilingual situations, because every community produces its own programmes to accommodate its own specific needs. Bilingual programmes, being context-specific systems, can be differentiated from one another by examining various contextual factors such as curriculum, pedagogy, student population and language distribution. The current study aimed to investigate such contextual factors to differentiate bilingual programmes found in Qatar. The next section discusses Enrichment programmes. 


\subsubsection{Immersion Education}

Immersion education is associated with language-majority students learning through an L2 (Skutnabb-Kangas, 2000) and is therefore potentially relevant to the situation in Qatar. Immersion programmes, which emerged in opposition to the earlier grammar-translation and audio-lingual methods, offer the greatest amount of time for language study and are aimed at producing students with the highest levels of language proficiency (Nunan, 2009). Because immersion programmes are additive in their goals (i.e., they add another language to the children's existing L1) they aim to enable all children to attain functional levels of bilingualism and biliteracy in two languages by the time they finish high school (Hamers \& Blanc, 2000). Johnson and Swain (1997) listed the core features of typical immersion programmes as follows: (a) the L2 is the medium of instruction; (b) the immersion curriculum parallels the L1 local curriculum; (c) overt support exists for the L1; (d) the programmes aim for additive bilingualism; (e) exposure to the L2 is largely confined to the classroom; (f) students enter with similar and limited levels of the L2 proficiency; (g) the teachers are bilingual; and (h) all the students speak the same L1.

Immersion education originated in Canada in an attempt to improve French as a second language (L2) instruction. It assumes that in an environment where language is used for real communication in meaningful, contextually rich settings, immersion education is more productive than traditional second language classes (Cummins \& Swain, 1986). This assumption can be generalized to L2 acquisition instruction in all contexts where the learners speak the majority language of the community. The other assumption is that more exposure to the L2 will lead to greater proficiency. A typical French immersion programme is one in which monolingual (English) children receive all of their instruction in the L2 (French) for the first two years of their schooling. In the third or fourth year of 
schooling English is introduced and then other subjects are introduced gradually. This is termed early total immersion. Different immersion programmes have emerged in Canada (Johnson \& Swain, 1997) including full immersion, referring to immersion with no L1 in the curriculum for a year or more and partial immersion, referring to $50 \%$ or less of the content of subjects taught through the L2.

Immersion education programmes have expanded in the last decade, especially for the early schooling of language-majority children in societies where a global language, especially English, has become increasingly more important. Many adaptations have been made to the original Canadian models, and these contexts need to be investigated in isolation to gain information about their experiences, successes, and failures (Mejia, 2002).

It was acknowledged that the Japanese public education system should mandate that English must be taught as part of the curriculum from junior high level; however, studies on Japanese bilingualism demonstrated that, even after seven years of studying English, the outcomes of these efforts are often modest (Noguchi \& Fotos, 2000). The need for an alternative approach to teaching English in Japan was evident. Bilingual education was proposed as a solution. Bostwick (2000) examined the application of early partial immersion in one private Japanese school and describes the effectiveness of the programme after four years of application. The immersion classes contained 20-25 students. Two thirds of the instruction was conducted through the target language in years 1, 2 and 3. In the fourth year, classes were half in English and half in Japanese. Various instruments measuring reading, writing, grammar, and other linguistic aspects of Japanese and English were administered, as well as normal Japanese academic tests, along with parent and student surveys. The results showed no evidence that immersion in any way slowed down the children's progress in their academic or Japanese language abilities, 
although the language of instruction was very different to their L1. They even scored slightly higher than national norms.

Although these results somewhat mirrored those achieved in North America (Swain, 1997) it is also important to note that the children received revisions of technical terms from Mathematics and Science in their Japanese classes, as well as practicing mathematical story problems in their L1. They also had their Japanese teacher revise the social studies content (which is studied in the target language) to check understanding of concepts. This modified immersion approach reinforces how, in the Japanese context, the schools created their own version of established models. This finding suggests that close investigation into the structure of more immersion programmes might be profitable in discovering alternative bilingual programmes that work for the specific needs of the communities in question.

Other adaptations of immersion education in East Asia were not as successful. Some can be reproductive by the lack of linguistic capital on the part of both students and teachers. Johnson (1997) comments on immersion education in China which results in extensive text translation practices in the classroom. This practice was viewed by the author as counterproductive and constitutes what he calls 'immersion under stress'.

\subsubsection{Enrichment Programmes}

Although they are often confused or used interchangeably, Lasagabaster (2010) differentiated between immersion education and CLIL programmes. The main differences are: (a) the degree of exposure to the L2 in the community; (b) the demographical features of the students; (c) the objectives of the programme; (d) the course-materials used, and (e) the language proficiency of the teachers. 
Enrichment programmes include Content Based Language Teaching (CBLT) and Content and Language Integrated Learning (CLIL). CBLT integrates language and subject matter in both the teaching process and language outcomes (Met \& Genesee, 1989) and also protects the development of the first language (Baetens \& Beardsmore, 2002). CBLT in Europe is termed Content and Language Integrated Learning (CLIL) or dual-focused education, because lessons have two learning outcomes, one related to the subject, and one linked to language (Lasagabaster, 2010). Unlike immersion education, the teachers in CBLT or CLIL programmes do not need to have a native or near native competence in the L2; however, they need to have high levels of proficiency in the language that they teach. CLIL and CLIL-type programmes offer less intensive contact with the target language (Wolff, 2002). According to Wolff a major difference between CLIL and immersion programmes is that CLIL programmes include teaching of the target language as well.

Although the European model of CLIL requires that children be fluent in their mother tongue plus one or more second languages, other enrichment programmes offer variations. CLIL-type programmes were developed in response to the need of developing proficiency in a global language for all in the developing world (Canagarajah, 2005). One way of doing so is to teach one or two subjects via the second language. To classify as a CLILtype a program must include all children in the school and is limited to one or two subjects. For example, Math and Science are taught in English such as the case in Malaysia for example (Gill, 2004).

\subsection{Bilingual Practices within Programmes}

The clarification of issues associated with bilingual teaching practices within programmes is vital to inform the analysis of the bilingual structures and processes being investigated in this study. An observation checklist, as well as a questionnaire, had to be designed to 
describe the bilingual practices identified in the literature to this end; several theoretical prepositions relating to bilingual teaching practices within bilingual programmes were reviewed as follows:

Evaluation models provide a framework for the assessment of effective pedagogy. Such models are indicative of what features to look for when investigating bilingual educational programmes. For example, the model developed by Walqui et al. (2002) was underpinned by research on effective pedagogy when teaching content through a second language. This model incorporates four general principles and introduces six scaffolding techniques built on theories developed by Bruner (1983). Other evaluation models have also been proposed (e.g. Heller \& Martin-Jones, 2001). Because the current study aimed to describe rather than evaluate bilingual education in Qatar, evaluation models are not relevant.

Alternatively items extracted from theoretical prepositions will be incorporated in the discussion of praxis within programmes. Cummins (2000) describes 'traditional' versus 'transformative' pedagogy discussing educational debate surrounding the conflict between conservative and progressive teaching practice. Traditional "transmittive" pedagogy assumes that the teacher's main task is to deliver knowledge and skills to students. The teacher initiates and controls classroom interactions to achieve instructional objectives. The teacher focuses on the surface features of language and literacy and emphasizes correct recall of content using highly structured drills and workbook exercises. Cummins, in contrast, prescribes a progressive "transformative" pedagogical model based on childcentred learning, in which students are perceived to learn by doing, and the teacher is only a facilitator (Cope, 1999). Although there is emphasis on reading extensively in the L1 and L2 in progressive pedagogies in bilingual education (Krashen, 1999) the transformative pedagogy goes beyond this to involve students in their own social community. Critical 
inquiry is used to explore and find ways to develop their realities. This social dimension is what distinguishes transformative pedagogy from progressive pedagogy. The issue of pedagogical orientation in bilingual education becomes more pressing as two codes and cultures become more entwined. Cummins suggested principles of transformative pedagogy include the ones suggested by Bigelow et al. (1994) in which items in the curriculum are academically rigorous, participator, and grounded in the students' lives. August and Hakuta (1997) identify thirteen attributes of effective school practices. These attributes include opportunities for student directed activities, opportunities for practice, and use of instruction strategies that enhance understanding.

The case study aimed to use an ethnographic approach where the data itself will dictate the types of instructional approaches found in the classes to reveal themselves. Thus an extensive account of all relevant instructional practices and pedagogies cannot be listed here. However two main themes are deemed important to discuss in relation to bilingual practices: The difference between conversational and academic registers and the role of scaffolding as a valuable teaching strategy.

Cummins (2000) distinguishes between Conversational and Academic aspects of language proficiency originally termed BICS and CALP. Cummins argues that these will follow different developmental patterns. Cummins emphasizes that "language and content will be acquired most successfully when students are challenged cognitively, but provided with enough support or "contextualization" of instructions required for successful task completion". He posits that language acquisition is associated with higher-order thinking including hypothesizing, evaluating, and classifying. Cummins warned that "automatic transfer of academic skills across languages will not happen unless students are given 
opportunities to read and write extensively in the L2 as well as the L1". He suggests that cognitively demanding content is optimal for developing academic skills in two languages. In addition he highlighted the significant role of the explicit teaching of specific aspects of academic registers in both languages.

The role of scaffolding as a teaching strategy in bilingual education is another source of debate. Scaffolding is the distance between the actual developmental level and the level of potential development required to achieve the required developmental level. Scaffolding is built upon actions such as collaboration, modelling and contextualization (Wallqui, 2006). Accordingly, the prescriptive model of Cummins (2002) supported scaffolding by proposing that the optimal instruction for bilingual education includes content that is highly cognitively demanding, but is also presented in context embedded ways (e.g., supported by cooperative learning or project-based lessons).

\subsubsection{Language Organization and Biliteracy Teaching Approaches}

This section considers bilingual language organization and biliteracy teaching approaches with respect to language allocation, written language provision, and language separation.

\subsubsection{Language Allocation}

One of the aims of this study is to undertake an investigation into language allocation or language distribution in the bilingual schools in Qatar. Allocation refers to the time allotments given to one language or the other. In immersion education students may be immersed up to $100 \%$ of the time in the L2. The most equitable distribution of the languages in the daily or weekly school programme is usually a 50:50 allocation, where half the subjects are taught in one language and half in the other. The most extreme, but 
usually the most popular bilingual programme, is the 90:10 distributions. In transitional programmes, the time allocation changes according to the development of the students' second language skills. Developmental bilingual programmes usually use the sliding bilingual allocation, starting off with 90:10 in the minority language $90 \%$ of the time and gradually balancing out at 50:50. It is perceived, however, that bilingual allocation in multilingual contexts is usually very complex, with languages and dialects often weaved in and out within the school day. In reality, language allocations are much more flexible than described officially. Real teacher-student interactions do not always comply with official policies.

After languages have been allocated in a general sense, schools have to make decisions also about how the language is used in the curriculum. Garcia (2009) differentiates between three different types of language arrangements and separation of the L1 and L2 (Table 2.2).

Table 2.2: Language separation classified by Garcia (2009, pp. 291 - 304)

\begin{tabular}{lll}
\hline Strict Separation & Flexible Convergence & Flexible multiplicity \\
\cline { 2 - 3 } Time-determined & Random code-switching & Responsible code-switching \\
Teacher-determined & & Translanguaging \\
Place-determined & Mono-literate Bilingualism & Preview/view/review \\
Subject-determined & & \\
\hline
\end{tabular}

This three-tire framework translates the monoglossic or heteroglossic ideologies of language teaching. The first type of language arrangement found in schools is the "strict separation" which is usually found in additive bilingual programmes with a monoglossic orientation. The separation of the two languages is either on the basis of time, teacher, 
place or subject. The second arrangement which can be found in schools is the "flexible language use". This type has been little researched. The student's use of the first language in bilingual programmes may be done informally as a deviation from the normal language policy of the school. Flexible language use as a strategy has two directions in the language classes as this framework suggests. In bilingual programmes which aim for convergence or language shift (such as transitional language programmes which develop the second language as the language of the majority) a flexible "convergent bilingual arrangement" may be applied (Baker, 2000). Thus random code-switching may be used to enable children to acquire the majority language. Most of the time code-switching is mono-literate where the majority language is used in literacy, whereas the first language is used orally

The last type of language separation is the "flexible multiplicity" where two or more languages are used in the classroom with a heteroglossic ideology. Within this arrangement, teachers can use one of many practices: (a) responsible/purposive codeswitching, (b) preview/view/review, or (c) translanguaging. Garcia (2009) defined translanguaging as a process in which bilingual students and teachers engage in complex discursive practices in order to communicate in multilingual classrooms. It refers to "any pedagogy that intentionally uses two languages flexibly in an arrangement that promotes bilingualism and biliteracy". This implies that students might develop translanguaging practices to communicate with each other if they come from mixed backgrounds, but it is only when teachers approve and use translanguaging that it occurs as pedagogy.

\subsubsection{Written Language Provision}

Bilingual schools also need to make decisions about how to use languages in literacy practices (i.e., in written language provision). Four models of language literacy use in bilingual schools have been identified: (a) a convergent mono-literate model where only 
one language is used orally and in writing; (b) a convergent biliterate model, where the school uses the L1 in writing as well as orally only to support the development of the L2 and (c) a separation biliterate model, where literacy is being developed in two languages but in separation or (d) a flexible multiple model where the two languages are used to develop each other and support the literacy development of the two languages.

These generic classifications are useful in the analysis of the daily practices of schools and for trying to conceptualize their model of operation in regard to biliteracy practices, both of which form part of this study's aims. These terms will also serve useful for the discussion of the data collected about the schools in the case of Qatar, where in each case, the data might identify the types language arrangement used, as well as the literacy practices adopted. This in turn will shed some light on the types of programmes used in these schools and their ideology towards bilingual education.

\subsubsection{Language Separation}

The language separation arrangements used to teach the L1 and L2 in bilingual programmes have been mainly studied using qualitative methodologies. Although the studies reviewed here are not intrinsically similar to the current study in Qatar, they do demonstrate that language separation has previously been researched.

Lee et al. (2008) explored language separation practices in a dual immersion school in the USA where both the L1 (English) and L2 (Spanish) were given equal status. In this qualitative study where a single school was observed over a period of 12 months, the researchers analysed how the teachers and students interacted to present and implement the school policy. The school creates strict separation of the instruction of English and Spanish by continuously marking the students and teachers as Spanish-speaking or Englishspeaking. The teachers strictly followed a one language-one person model as well as a one 
space-one language rule. In most classes two bilingual teachers are present, but each teacher will speak one language only. Problems arose when the teachers found themselves caught between the rules of language use and the practical accommodations that they must make for students who are not proficient in the L2. These children could not be expected to fully participate in classroom activities if they only speak the second language. These separation practices are also followed by the children in the playground where students are marked either as Spanish or English speakers with little opportunities to interact. Lee and his colleagues concluded that these separation arrangements limited the students' opportunities to socialize and interact with the second language. The strict separation emphasized a division of interactional spaces in the school which did not necessarily end with the development of bilingual speakers. It is acknowledged that the authors question the effectiveness of dual-immersion programmes in general based on observing one school practice. They indicate ,however, that this as an example to demonstrate how a SpanishEnglish code is a legitimate language used in social practices outside the school which was not accommodated for in the interactional spaces, leading to diminished opportunities for using both codes as resources to problem solving or other higher thinking academic skills.

Bonacina and Gafaranga (2010) proposed an alternative position regarding the study of language separation within bilingual education. Using a conversation analysis technique, their empirical study involved 10 students between the ages of 9 and 13 who attended a French Complimentary school in Scotland. Through participant observation, the researchers followed and examined the students' code-switching behaviour in addition to formal interviews with stakeholders. The authors argued that the concept of "medium of interaction" has more utility as opposed to the more widely used concept of "medium of instruction". They argued for two language policy positions to be adhered to when discussing language-in-education, specifically (a) the formally professed language of 
instruction chosen by the school and (b) a less formal policy of language choice and use which they do not refer as code-switching, but rather as an accepted policy of language use. Tis language of "classroom interaction" can be the L1 or L2 of the students. This proposal is supported in their data by investigating patterns of language choice at the complimentary school using Conversation Analysis. They produce a complex argument to legitimize code-switching. Code-switching patterns in their view are not a "deviation" from normative practice, but as part of this normative practice in bilingual classrooms.

\subsubsection{Classroom Interactions}

Table 2.3 summarizes some functional taxonomy of classroom interactions, adapted from Lin (2006). These illustrate how the use of bilingual interactions using the L1 can achieve various useful linguistic, educational, affective and sociocultural functions. Lin combines useful terminology adapted from various resources that she herself used in her analysis of student/teacher interaction study. This terminology also serves to guide the observation checklist devised for the current study.

Table 2.3: Functional taxonomies on bilingual classroom interactions and use of L1

\begin{tabular}{ll}
\hline Students & Teachers \\
\hline To assist one another & To check comprehension \\
To tutor other students & To translate a lesson \\
To ask/answer questions & To explain an activity \\
To use bilingual dictionaries & To provide instruction \\
To write in native language & To interact socially \\
To interact socially & \\
\hline
\end{tabular}


Lin identified (a) micro-functions of code switching in the classroom, which served linguistic or academic purposes, such as classroom management and content transmission. And (b) macro-functions, referring to the socio-educational implications of codeswitching, including retaining national identity, bridging home and school language, and socializing in the wider community.

\subsection{Multilingual Education}

The diversity of the educational systems in multilingual contexts is discussed in this section, with emphasis on empirical research that is similar to the current study and the local context of Qatar.

Within a heteroglossic view that at some level appreciates and actually provides for multilingual approaches, there are many programmes with multiple languages incorporating multilingual education. These include bilingual programmes implemented in the multi-diglossic and bilingual situations found in post-colonial Asia, the Middle East and North Africa. It has been indicated previously that bilingual studies concerned with minority language learners are not exactly useful when discussing the contexts for majority language learners. This section sets out to clarify this minority-majority distinction. In doing so, it incorporates various empirical studies done within regions of the world that bear comparison with the context in Qatar. This section also provides evidence for a gap between observed language teaching practices with the bilingual policies professed by the schools in East Asia and the Middle East, leading to dissatisfaction with the policies and practices of bilingual education. 


\subsubsection{Majority-minority Distinction}

This section aims to establish that the issues, principles and concerns of majority language learners are different from those of language minority learners. It also highlights that there is a difference in the principles governing the acquisition of bilingualism in majority contexts relative to those in minority contexts. The issues surrounding each of these programme types are often very different, with attention towards bilingual education for majority language learners in international settings developing only in the last decade or so. This majority-minority distinction is a critical concept to bear in mind. Most of the U.S. literature on bilingual education is focused on the debate over whether children speaking languages other than English should be educated within two languages instead of being submersed in a totally English-speaking school as minority language learners (August \& Hakuta, 1997; Rossell \& Baker, 1996). This renders much of that research problematic when it comes to generalizing the findings to bilingualism in majority contexts as found in Qatar.

Much research on the language development and academic achievement of majority language students in bilingual education has been conducted in Canada on French immersion programmes for English-speaking students. Baker (2001) and Christian and Genesee (2001) warned, however, that there is a danger in generalizing from the successful Canadian experience to elsewhere in the world, because the factors and variables surrounding the immersion experience are unique to Canada. These include parental involvement, the enthusiasm, commitment, and training of teachers, the provision of material support and resources, and the children's' background and motivation (Genesee, 1994). 
In the context of bilingual/multilingual programmes, various empirical studies have been conducted in the last two decades where a second international language is included in a majority language educational context, including instances where the second language is typologically different to the first. The academic discourse in ex-colonial countries, especially within the Asian context, is different, drawing mostly on the links between a policy of bilingual education and daily practices. The current research belongs to this latter kind, extending the existing literature on bilingual education policy and practices within the context of the Middle East and specifically in the case of Qatar as a new geographical, linguistic and cultural area with typologically different languages. The next section will discuss some of the issues related to bilingual education in these regions that claim to promote some sort of multilingualism within a heteroglossic ideology, with specific focus on Japan and Hong Kong and the Arab Middle East and North Africa.

\subsubsection{Gaps between School Policies and Classroom Practices}

The description of the studies reviewed in this section highlights two recurring themes: (a) that there is a gap between professed school policy regarding the teaching of the two languages in question and actual everyday classroom practice, and (b) that there are varying degrees of dissatisfaction with the policies and practices of the school systems investigated.

Several studies based in East Asia have considered bilingual programmes as a whole and their effect on students' linguistic abilities, focusing on the uneasy shift between Chinese as the medium of instruction in the primary schools to English-medium schools in the secondary stage (Linn, 1999). Tsui (2004) studied student-teacher interactions, comparing English-medium schools to Chinese-medium schools, coming to the conclusion that in Chinese-medium schools different types of questions were asked with more responses 
from the students. It was also concluded that students in Chinese-medium schools were more engaged in the collaborative construction of knowledge. These conclusions were in accordance with the previous research of Yu and Atkinson (1998) who studied students in two different schools (one set government-aided and one private). It was found that most students were much more proficient in Chinese than in English. The authors concluded that this low proficiency could be attributed to the low contact with English outside the schools and students motivation towards learning English as they become concerned about their Chinese identity.

Research with similar aims to the current study explored experiences in a dual language international school in Hong Kong (Fryer, 2009). Stakeholders (parents, teachers and students) were interviewed to elicit responses concerning their views on the success of the school in achieving its goals. The results indicate dissatisfaction with the use of the L1 in the school and that the Chinese culture was under represented. This investigation contrasted the professed aims of a dual language type of school with its outcomes, emphasizing how explorations into a school' realities reflect different manifestations of the school's professed policy.

Johnson (1997) suggested that, although two modalities are generally presented as the case of the dual language education system in Hong Kong, there is evidence that in reality there exists an educational continuum. This justifies the contrast between the policy aims and actual practices in Hong Kong schools, where Chinese schools use English texts because of a lack of appropriate Chinese texts and some Anglo-Chinese schools use Chinese texts for certain subject areas to enable students to understand the content being taught. This dual reality is evident mostly in secondary schools. 
It has been argued that the gap between policy and practice in bilingual programmes in East Asian contexts is sometimes caused by lack of resources, teacher training and student proficiency (Hu 2008). In contrast, within the heteroglossic ideology presented by Garcia and supported by Lin, it could deducted that alternative approaches and policies must be adopted and developed in order for these programmes to operate successfully in these multilingual communities.

The status of bilingual education in Qatar is not directly comparable to that in Hong Kong. The status of Chinese (Cantonese and Mandarin) and English in Hong Kong is different to the status of the two dialects of Arabic and English in Qatar. In Hong Kong, over 90\% of children attend Chinese-medium schools with the remainder attending a few prestigious English medium schools (De Maja, 2002). This is almost the opposite of the situation in Qatar where Arabic-English bilingualism as a goal of the state's education system. The majority of Qatari and Arabic-speaking children attend bilingual independent schools. Nevertheless, the gap between the professed school policies regarding the teaching of Arabic and English languages and actual everyday classroom practice needs to be explored in the Qatari context.

Dissatisfaction with the outcomes of bilingual education in East Asia is mirrored by studies in the Middle East. Shaaban (1997) studied the current state of bilingualism and foreign language learning in Lebanese schools. He also analysed the propagation and the two-tier system of bilingualism in the Lebanese educational system (Arabic-English and ArabicFrench). Although English was studied for over nine years as a second language, only 25\% of students passed the official examination in English at the end of year 12 and only 18\% passed the American University English entrance test. Despite a country promoting bilingualism both through its educational policy and through day-to-day activities (as 
evidenced by the existence of both languages at 'street level' ) biliteracy is not necessarily an automatic product of such bilingualism. Programmes need to be planned carefully to achieve the set goals of the educational system.

\subsubsection{Gaps in the Research}

In this section, the literature covering the current context of the Middle East and other Arabic-speaking countries is outlined. Despite the linguistic dilemma facing language-ineducation policy makers in the Arabic-speaking countries of the Middle East and North Africa, there are very few studies examining bilingual education in that context. A search for publications documenting research of bilingual education in the Arab region generated various studies which, as informative as they might be, do not address the holistic approaches adapted by schools and practices in relation to bilingual teaching and learning as found elsewhere. A few of these studies concentrated on syntactic issues facing adult learners of English. For example, Saeed and Fareh (2006) looked at the difficulties bilingual Arabic learners had in translating "fa" (a linking word) into English. The researchers examined 50 learners of English in the University of Sharjah, UAE and how they translated this word within MSA texts. They came to the conclusion that direct instruction of discourse markers should be incorporated in ESL and translation courses. Fargal and Haggan (2006) investigated Kuwaiti university students' social behaviours in English, detailing compliment behaviour and the English language using corpus analysis, concluding that $80 \%$ of these were culturally oriented. Mallah (2006) investigated the attitudes of Kuwaiti university students towards the English language considering motivational aspects. Similarly Al Khatib (2003) examined social code-switching patterns following three Lebanese-Arabic adolescents looking into their language alternation patterns. None of these studies focused on young learners' language acquisition in 
bilingual (Arabic and English) school systems, emphasizing that there is a gap in the literature that the current study intends to fill. Garcia (2004) concluded that, for the Qatari new experimentation with bilingual education to be successful, various aspects of its bilingual education should be researched, providing a rationale and direction for this study.

\subsection{Summary}

This literature review has been multifaceted because of the complex nature of bilingual education. A researcher with a holistic attitude towards investigating the various applications of bilingual programmes and their components rather than focusing on one small aspect of the teaching learning practice will be overwhelmed by the research in all areas a of concern. To pull this review together, the chapter traced the theoretical history of the field, arriving at the most recent typologies. The framework presented by Garcia (2009) presented a useful ideological perspective within which to place the Qatari context. Zooming in on programmes, programme structure and organization, many empirical studies were discussed. Since the aim of the study is to provide a macro-level description of International and Independent schools in Qatar, it was vital to clarify concepts of language separation and distribution as presented in the literature. The review progressed to examine the studies most relevant to the context of Qatar. Although the US and European studies were excluded, the Asian and Middle Eastern studies were examined, as they bared socio-linguistic similarities to the Qatari situation. Two themes were evident (a) that there is a gap between professed school policy regarding the teaching of the two languages in question and actual everyday classroom practice, and (b) there are varying degrees of dissatisfaction with the policies and practices of the school systems investigated. The chapter ends with studies of bilingual nature conducted in the Arab 
region. It is concluded that there exists a need for more research due to lack of studies in this part of the world.

\subsection{Conclusion}

The lack of empirical studies which focus on schooling and biliteracy provision in bilingual (Arabic and English) programmes has created an academic deficiency in the discipline. Because Arabic school practices are shaping the social realities of current and future generations in Qatar and the wider Arabic-speaking world, the current study might be viewed as the catalyst for further research in the region. It might lead to further investigation of the complex linguistic realities of millions of children in the Arab region. 


\section{CHAPTER THREE: METHODOLOGY}

\subsection{Introduction}

This study sought to gain an insight into the policy and practice of language-ineducation in the Qatari educational system by exploring and describing the organisation and implementation of bilingual education in Qatar. It focused on the bilingual programmes offered to Qatari students and Arabic speaking children at international and independent primary schools in the unique linguistic and socio-economic context of Qatar, where MSA, English and the Qatari dialect are spoken. The other two school types (community and private Arabic) were not included because they mainly cater for children of 'expats'.

I attempted to determine how bilingual education was conceived and carried out in international and independent schools by investigating various aspects of their bilingual and biliteracy practices. I concentrated on arrangements for the allocation, distribution, and separation of two languages (Arabic and English) with respect to fourth grade children. In addition to observing the bilingual methods and biliteracy approaches used in the classroom, and interviewing the teachers, I examined secondary data drawn from a database.

This chapter initially defines the research questions that underpinned the study. The methodology (i.e., the rationale and the philosophical assumptions that underpinned the choice of methods) and the methods (i.e., the strategies and practices) that I employed to collect and analyze the data are subsequently described and justified.

\subsection{Research questions}

The research questions concerned the two prominent types of schools in Qatar, focusing on primary schools where literacy in both languages is being developed. The overarching research question was: How is bilingual education manifested in schools in Qatar? The 
central question is exploratory, in that it investigates a phenomenon that is understudied and on which there is little previous research to guide the inquiry. This question could be addressed in a variety of ways, depending on the focus of the study. The secondary research questions listed below recognized that bilingual programmes vary according to context and practice; therefore, any attempt to understand structures and processes must be grounded in the schools' activities by investigating what was claimed to be practiced (i.e., policy and organization) against what was actually carried out (i.e., implementation):

RQ1: What model of bilingual programme do the schools follow?

RQ2: How are English and Arabic distributed in the school's official policy and official school programme?

RQ3: What content is allocated to each language?

RQ4: How are English and Arabic distributed during the school day/week in classroom practice?

RQ5: Which language(s) do teachers and students use in the classroom?

RQ6: What is the biliteracy teaching method adopted by language teachers?

RQ7: What is the biliteracy approach used most often in the classroom?

The primary research question implied an exploratory/descriptive approach to investigate a phenomenon about which there has been little previous research. It could also be classified as interpretive, because the aim was not only to explore and describe, but also to understand how bilingual education was practiced. The secondary research questions implied a case study approach since they aim to answer "What" or "How" questions. 
The research questions were refined in light of Marshall and Rossman's (2006) typology. All questions were posed in an open-ended manner, evolving from the general to the specific. Moving from the general outlook to the specific situations of schools, the case studies' questions addressed specific topics about the schools under investigation on two levels. For each case, RQ1 to RQ3 addressed organizational aspects of the bilingual programme. RQ4 to RQ7 addressed implementation issues, concerning the languages used by the teachers and students in the classroom, and the teaching method chosen to teach literacy in the two languages.

Tertiary research questions were aligned with the collection of descriptive data which fed into the enquiry. For example, what were the teachers' qualifications? What were the students' achievements in national standardized tests? What were the teachers' awareness and training with respect to to the language policy of the school, the literary environment of the students and the representation of the Qatari culture in the school? These questions are explicated in the case study protocol. These are included in the case study protocol.

This study attempted to use an appropriate research design to investigate bilingual practices and biliteracy provision in countries that are widely using English but without a grounded bilingual policy. The structure of this research design is described in the next section.

\subsection{Research design}

This section delineates the different phases of the research design, and justifies the rationale for implementing a case study. The research was carried out in two phases separated by a pilot study, as outlined in Figure 3.1. The timeline of the three phases is defined in Table 3.2. 

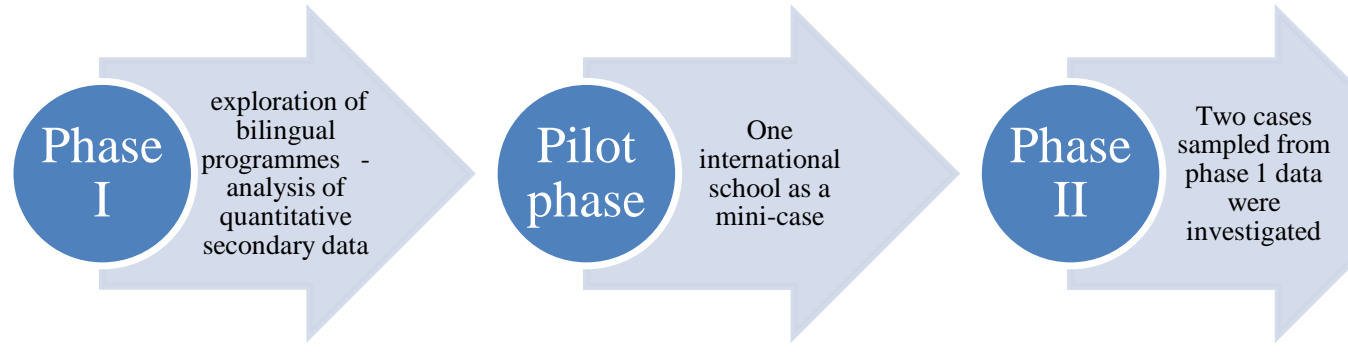

Figure 3.1: Overview of Research Design

Table 3.1 Timeline

\begin{tabular}{ll}
\hline Date & Phase \\
\hline February 2011 & Phase 1 and case selection \\
\hline 15 March - 30 March 2011 & Pilot phase \\
\hline 3 April - 18 June 2011 & Phase 2 data collection \\
\hline
\end{tabular}

\subsubsection{Phase I: Description of bilingual schools}

Phase I established the main characteristics of the two types of schools and their respective bilingual models. It entailed an evaluation of the schools' data relating to their teachers' and students' demographics, as well as their weekly language of instruction distribution. Phase I was necessary to identify the types of bilingual programmes followed by the schools under investigation. The data sets provided by the SEC included a total of 70 schools. Phase I was important to (a) draw a birds-eye- view of the language distribution within the two types of schools; (b) establish variance between the two types of schools; and (c) set a sampling frame from which to select two cases for in-depth study. 


\subsubsection{Pilot Phase: Mini-case study at one school}

I negotiated and gained access to a small international school with which I had connections with the head teacher and the owner. I spent two weeks in the school. On the first visit I introduced myself to the teachers in a staff meeting that was taking place at the end of the first day of that week. The teachers welcomed me and no one had any objection to my observations of the classes and interviews. I obtained the timetable a few days prior to the first visit. There was only one class of grade four. I planned my day so as to attend all of their Arabic and English language classes. I sent out consent forms to the parents before the observations with the help of the administrative staff. The fact that the school had only one form of grade four made it easier as the number was small. I spent 10 school days in this school attending and observing 12 Arabic classes and 12 English classes 2 assemblies, one full day with the year 4 class and interviews with one English Teacher and one Arabic Teacher. I gathered various documents as evidence of school bilingual plans and bilingual practice. Reflecting on the findings of this mini-case study (see Section 3.4) provided useful information to devise the protocols used in Phase II.

\subsubsection{Phase II: Case studies at two schools}

Phase II adopted a multiple case study design to explore and describe the situation at two primary schools in Doha, Qatar which offered different bilingual programmes and biliteracy models. One international school and one independent school were investigated as two cases.

Yin (2003) defined a case study as "an empirical inquiry that investigates a contemporary phenomenon within real-life context especially when the boundaries between phenomenon and context are not clearly evident” (Yin, 2003, p.13). Yin proceeded to elaborate on this definition by relating that the "case study inquiry copes with the technically distinctive situation in which there will be many more variables of interest than data points, and as one 
result relies on multiple sources of evidence, with data needing coverage in a triangulating fashion, and as a result benefits from the prior development of theoretical propositions to guide data collection and analysis.” This definition provided the rationale for implementing a case study design.

Because limited previous research has been conducted on bilingual programmes in the region, and in view of the variation between the different schools’ programmes, a multiple case study was considered to be the most appropriate design to describe and explore this new territory. Each bilingual programme encapsulated many components and variables which would serve as multiple data points. To fully describe the organization of the programme and its implementation at the two schools, multiple sources of evidence had to be collected. The protocols I finally used for the multiple case study design were based on reflecting upon experiences gained in the pilot phase, as follows:

\subsubsection{Reflections on the pilot phase}

The pilot phase encouraged me to think carefully about two aspects of the research (a) time organization and (b) file keeping. To observe Arabic and English classes at two schools needed careful planning, well ahead of the visits. Consequently, I devised a timetable to ensure I spent equal time in the two schools, attending equal amount of classes and other activities. File keeping had to be accurate in order to keep track of every piece of data within its proper case, class and category without undermining confidentiality.

I started by administering a questionnaire which I had designed previously to gather as much data about the school demographics, teaching staff and other information. The main outcome was that this school had no official language policy which was written in a document and made explicit to teachers and parents (a matter that I had foreseen as there was a lack of a documented explicit language policy-in-education in the country). I compensated for the lack 
of such explicit policy by gathering documents such as teachers' guidelines booklets, school brochure, school ads, website texts, newsletters as well as having a short interview with the school principal. The interview with the head teacher had only one question: How do you view your school's approach towards teaching English and Arabic?

I sat and observed classes to obtain information about classroom and teachers' practices. The pilot phase was enlightening in this regard as it appeared that the layout and structure of an observation checklist could not be used efficiently in the real time of classroom interaction. There were too many columns and nowhere to write notes. The observation checklist was adjusted accordingly. The observation of classes also led me to reflect about the best way to answer the research questions. How would evidence that confirm the use of one approach or another be extracted from the data? How would the analysis deal with this complex school structure? This questioning led me to refer back to the literature which guided the development of the analysis framework analysis of the data relating to this question. Further refinement of the framework took place at the end of this phase as well.

I used the interview protocol which I devised prior to coming to Qatar. The semi-structured interview elicited a lot of information and I felt comfortable with the questions. I sent one recording to my supervisors who agreed on the flow of the questions. I also transcribed some of the interviews.

I examined the data obtained from the pilot phase carefully with respect to how it could be used to address the research questions. What do I want to find out? What kind of analysis would be fit for the purpose? Yin (2003) suggested two strategies for descriptive case studies, both driven by theory: (a) devising a descriptive framework before the data analysis, or (b) using a descriptive theory within the field of the case (i.e., bilingual education) and comparing it with a rival theory. Devising a descriptive frame work with enough categories 
to collect data gathered from various levels of the case study seemed to be the most appropriate. It was during the pilot phase that a theory driven descriptive framework was created to present the data and findings in a coherent manner. Based on the literature of bilingual education, this framework is described in detail in Section 3.7. The research strategy that I finally implemented, based on my experiences in the pilot phase, was as follows:

\subsection{Research strategy}

The diagram of the research strategy (Figure 3.2) provides a holistic description of the ascending structure and processes involved in this study and how these were linked to create one complete project with different stages and levels of data sources. 
Demographics of students

And teachers

\section{Quantitative analysis of secondary data sets}

Average teaching time (L1 \&L2)

Sample two schools

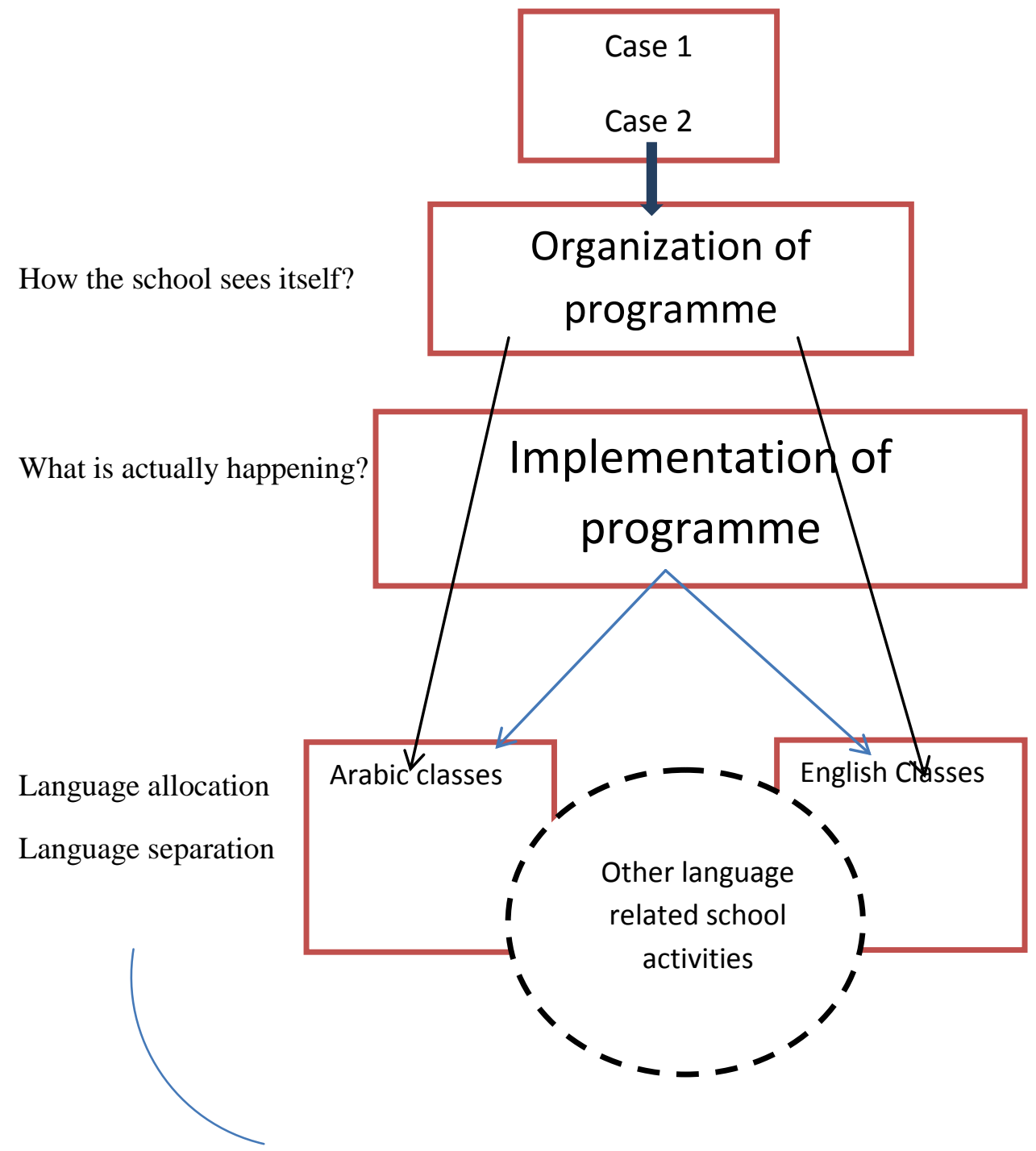

Arriving at a classification of the:

- Biliteracy approach implemented in the classroom

- Model of bilingual programme each school belongs to

Figure 3.2: Research strategy and levels of investigation 
The strategy of this multiple case study depended on two cases in order to explore and describe how bilingual programmes were organized and implemented within the unique linguistics socio-economic context of Qatar during daily processes of teaching and interaction. The research questions asked how were the schools' language policies (if explicitly in-placed) enacted and taken-up by the different players in the setting of the school. The research strategy therefore addressed organizational aspects of the bilingual programmes put forward by the school administration. The implementation of the bilingual programmes was also investigated by observing language distribution during the school day, in addition to the content allocated to each language. This was achieved by observing classroom practice in Arabic and English classes and contrasting this with the language allocation explicitly claimed in the school policy documents. Language separation arrangements were observed in the school programme and classroom practices, for example whether there was a strict separation of the two languages, random mixing, or purposive code-switching. The biliteracy approach adopted by teachers as observed in the classroom practice was determined for each school in order to define the overall biliteracy model used as explained in section 2.4 (the literature review). These types of information were noted and observed to provide a macrodescription of school bilingual structures and processes in actual practice.

The case study approach was chosen because it was the appropriate design to investigate a phenomena 'bilingual programmes' within its context using a variety of data sources It conformed with the three features of a case study described by Yin ( 2003) Stake ( 1995), Miles and Huberman ( 1994) and Merriam ( 1994) i.e., (a) It should be a complex functioning unit; (b) It must be investigated in its natural context with a multitude of methods, and (c) It must be contemporary. The above mentioned researchers stressed different features in their presentation of what case study method is. In general there are two key approaches that guide case study methodology; one proposed by Robert Stake (1994) and the second by Robert Yin 
(2003). Stake pointed out that crucial to case study research is not the methods of investigation but the interest of the object of study stressing that:” as a form of research, case study is defined by interest in individual cases, not by the methods of inquiry used”. Yin on the other hand placed greater emphasis on the methods or techniques that constituted a case study. The current study relied on Yin's approach, because of its ability to deal with embedded cases and embedded units and sub-units of analysis. This approach brought discipline to a wide and complex collection of variables and data sources. I also acknowledged that Yin’s approach brought with it some limitations especially with respect to construct validity. According to Duff (2008) case study research presents at least two conflicting sets of criteria for assessing validity, one set is based on the positivist paradigm (Miles and Huberman ,1994; Yin, 2003), and the other is based on the social constructivist or interpretive paradigm (Merriam, 1994). Yin (2003) included various kinds of validity and reliability as criteria for assessing case studies, closely associated with positivist's quantitative research. In this vein Yin maintained that construct validity can be problematic in case study design in that constructs (theoretical concepts) might be ill-defined or underspecified prior to conducting a case study.

Although this research used Yin's approach to define a case study and his theorization regarding reliability and the triangulation concepts, this study was also drawn to the interpretive paradigm in dealing with various aspects of the data analysis and interpretation (e.g., allowing the data to guide revelation of instructional practices used in English and Arabic classrooms which were not specified prior to the case study.). Therefore it can be said that the study utilized elements of both paradigms: a positivist approach when using enumeration, counting frequencies, displays and matrices in the analysis and report of findings; and an interpretive approach was used to portray school features and link the various elements of the cases when discussing the findings at the macro-level. 
Prior to conducting the case study a case study protocol was devised (appendix i). A case study protocol (CSP) is a standardized agenda for the investigator's line of inquiry (Yin, 2003). A CSP is a valuable source for increasing the reliability of the case study and is growing in popularity in the field of Applied Linguistics (Duff, 2010). The protocol is simply a set of guidelines that can be used to structure and govern a case study. It governs the conduct of the research before, during and after the study. The precise documentation of the process of the case study procedures allow for reliability if the case was replicated. The protocols used in this study to implement the strategy described in Figure 3.2 were devised after consulting with guidelines by Eisenhardt (1989), Yin (2003) and Stake (2005).

\subsection{Sampling}

Silverman (2005) suggested that (given sufficient resources) random samples of cases should be chosen to more thoroughly address issues of validity and reliability. To this end, Stake (2000) recommended that when designing case studies, the researcher should set out typologies prior to embarking on the project so as to choose cases from these typologies. Therefore, it was considered good research practice to work within different phases, with the first phase being in the nature of a general inquiry. In relation to the current study, the first phase helped determine the schools the majority of Qatari children attend, hence purposive sampling strategy was followed in choosing the cases as phase I marked the field.

It was essential that this case study involved both government (independent) schools and international (privately owned) schools. The inclusion of International schools was important to encompass the various types of bilingual education available in Qatar. International schools were included, even though they are not obliged to follow the countries language policy, because they are an important player in the bilingual scene in Qatar. The SEC 
includes both independent and international schools within its yearly evaluations and general decrees. The populations at both types of school have similar socio-economic status; however, independent schools incorporate more of the first language, and many Qatari nationals prefer them. This is not just for SES standards, which are not considered to be a major intervening variable. Some people prefer free public education, regarding it more trustworthy and stable, compared to commercial private education.

\subsubsection{Phase I sampling}

A census of international primary schools and independent primary schools in Qatar was conducted in Phase I, in which the schools, not the students, were the sampling units. Researchers do not always need to collect primary data for a school census, because most government and local authorities have this information stored in their archives/databases (Nortier, 2008). In this study, the SEC database in Qatar (Q-NEDS) provided the secondary data. Phase I was used to determine the sampling frame for Phase II.

\subsubsection{Phase II sampling}

External validity (i.e., the generalization of inferences from a sample to a population) is often possible in quantitative research, due to the use of statistical sampling procedures, which attempt to ensure that samples are representative of populations (Silverman, 2005). Such sampling procedures are not usually used in qualitative research. The number of participants in case studies is often too low to permit generalizability (Yin, 2003). The two cases participating in this case study (i.e. one independent and one international school) were chosen because they encompassed the various types of bilingual education available in Qatar. The use of two cases provided a broader insight with respect to bilingual models, language allocation and biliteracy models within the Qatari primary school context. 
The sample for Phase II of the study was more or less a purposive convenience sample of one case from each type of school to allow for variation in practice to be observed. Thus instead of focusing on only one school, two instances of bilingual experiences were observed, facilitating the exploration of how one phenomenon varied between two cases.

One of the purposes of Phase I was to establish a sampling framework from which schools and sites could be chosen. The problem of selection had two elements: how the two schools should be identified, and by what criteria should they be selected. Since the first phase established a sampling frame the first issue was eliminated. The criteria of selection resided with the purpose and the intention of the study as a whole. Since the study aimed to examine the schools most favourable to Qatari nationals, the criteria was set to choose one international school with the most Qatari students and one independent school with the same criterion. Two more criteria of selection were also set: (a) only schools within the city of Doha should be chosen; and (b) the schools should be in operation for no less than three years.

The variable 'student count' by Nationality-Qatari was examined to extract school IDs which honed the most Qatari students. Initially six schools were chosen for their high number of Qatari students. School IDs were then used to identify school names and contact were established. After sending out letters to the principals and contacting the schools, one of each were chosen that had agreed on the research. The schools selected might not be representative of all Qatari primary schools in general, but they were nevertheless illustrative of the range of schools which were operating with a bilingual programme to enable a thorough description of school organization and implementation of their bilingual programmes.

Three forms in grade four were observed at each school. The average age of the students was between eight to ten years old. Grade four was chosen because it is the level at which 
children have learned the basic reading skills and they use reading to learn. In the current study, the fourth grade was chosen because it was expected that initial literacy skills had been acquired to a certain level as to become a learning tool for both English and Arabic languages. Grade four usually marks the end of the initial literacy stage and various researchers use the same class level to conduct research in the area of literacy (Geva, 2006). Furthermore, this grade level has often been the level where students are assessed in their literacy abilities. For example, the PIRL international comparative assessment study often uses form 4 to convey its assessments (PIRLS, 2006).

\subsection{Data collection}

Different methods of data collection were used for Phase I and Phase II, as follows:

\subsubsection{Phase I data collection}

Data collection for Phase I started by contacting the director of the Evaluation Institute in SEC. The director granted access to the data base and facilitated contact with the head of the Data System. The data belongs to and was accessed by permission from Q-NEDS (Qatar National Education Data System) which is a department within the Evaluation Institute. The Evaluation Institute has full ownership of the data. Data for this phase comprised of all primary schools' data in relation to students' data, teachers' data and languages of instruction. I made three visits to the evaluation institute. By the end of these visits I acquired a soft copy of the necessary data sets for all 70 schools (25 primary international schools and 45 primary independent schools for boys and girls). Data sets contained a multitude of variables of which the following were used in the description of the schools: School name, cohort year, number of students, and number of Qatari students, students' home language, 
number of teachers, teachers' gender, teachers' nationalities, and teachers' native language. In regard to school language of instruction, average class time (per week) all subjects, average class time Arabic, average class time English. The database contained missing data for most of the schools which rendered the data sets useless for display in the description. Alternatively Q-NEDS provided a statistical compendium of tables describing average teaching time for all school types and all grade levels in Qatar. This data will be used to describe teaching time for primary Independent and international schools.

\subsubsection{Phase II data collection}

Phase II started immediately after the Pilot phase and following initial analysis for Phase II to stratify for schools that contained the highest number of Qatari Students. The cases were chosen based on popularity among Qatari nationals. The data indicated that two International schools had more than 40\% Qatari students, and five Independent schools had more than 97\% Qatari students. I sent out letters to all seven as a starting point and depending on access one International school was chosen and one Independent. Schools are within the capital city of Doha. Contact with schools was done parallel to the pilot phase so by beginning of April I was able to start the case studies.

The sampled schools were contacted by an e-mail letter (Appendix iii) followed by a phone call. Two schools agreed and were chosen for the case studies. Prior to the visits I prepared a Case Study Protocol (Appendix i). This was a concise description of all the components of the case study that I could refer to during data collection. On the first visit I met with the principal and explained the study and answered her questions with respect to what I needed to do in the schools. I also presented the questionnaire (Appendix iii) to the school secretary and started to collect school documents such as published policy or equivalent, brochures, 
newsletters, curriculum policy, weekly plans etc. In a second visit I obtained teachers' consent and prepared consent letters for parents along with a brochure that explains the study (Appendix. iii). These were distributed through the administration office. I scheduled the visits so as to spend equal amount of time in both schools (nine weeks). The school day in Qatar starts at 7:00 am with a break at fifteen to ten and then lessons commence from around 10:30 until 1:30. Therefore I attended half a day in each school as displayed in Table 3.2.

Table 3.2 Observation schedule

\begin{tabular}{lll}
\hline Day & First Block & Second Block \\
& 7:00 $-\mathbf{1 0 : 0 0}$ am & $\mathbf{1 0 : 3 0 ~ a m ~ - ~ 1 : 3 0 ~ p m ~}$ \\
\hline Sunday & Salam school & Jazeera school \\
\hline Monday & Jazeera school & Salam school \\
\hline Tuesday & Salam School & Jazeera school \\
\hline Wednesday & Jazeera school & Salam school \\
\hline Thursday & Salam School & Jazeera school \\
\hline
\end{tabular}

In addition I spent a whole day in each school in the last week on alternate days. The schedule was also flexible so as to accommodate for school trips and special events. To obtain consent to observe school wide activities, I asked the principal to introduce me in an assembly. I explained the study in simple terms and informed the children I would be going around the school writing notes.

\subsubsection{Observation procedures}

I devised the observation checklist (Appendix. ii) after reading the Communicative Orientation of Language Teaching (COLT) (Frohlich, Spada \& Allen, 1985), the Early 
Language and Literacy Classroom Observation (ELLCO) (Smith \& Dickinson, 2002) and the English-Language Learner Classroom Observation Instrument (ELLCOI) (Haager, Gersten, Baker, and Graves (2003) as well as consulting with the taxonomies in the literature on bilingual classroom strategies as presented in Lin (2006). The observation checklist was mainly intended to observe language choice, language functions as well as language separation arrangements (i.e. whether teachers applied strict separation of the two languages, random mixing or purposive code-switching). It was used in conjunction with recording the classroom interaction and field notes.

Equipped with the observation checklist, the schedule, the Case Study Protocol, recorders, and note books, I commenced the classroom observations. During the observations I placed three wireless microphones on different parts of the room. I used a mixer to merge the recordings and transcribed the data as soon as I finished the observation.

In each school, I attended a total of thirty lessons, twenty in English and ten in Arabic. I recorded half of the lessons attended and wrote field notes for the rest, because video recording proved to be difficult in the cultural atmosphere of Qatar. I attended classes for three grade four forms in each school. Each lesson was about 45 minutes in length. This accumulated to approximately 24 hours of non-participant classroom observations in each school. During the observations I also collected the daily planning sheets from the teachers, and the students' task sheets. In addition, I observed school wide language practice and activities, such as students' language choice outside the classroom, languages' use in posters, displays and notice boards by photographing items as well as writing field noes. I also gathered evidence for language of school correspondence with parents, teachers and other institutes. 


\subsubsection{Interview procedures}

I conducted semi-structured interviews with six grade four language teachers (Arabic and English). The interviews facilitated further clarification and explanations for the choice of one practice over the other and the functions of any language mixing observed. I interviewed three English teachers, three Arabic teachers and the vice-principal in each school. The interview protocol investigated three areas: awareness of school policy, language choice behaviours, and role of teacher in other activates for language development (appendix iv). All interviews were conducted privately and were audio-recorded.

\subsubsection{Case study conclusion}

On the last week I extended gratitude to the school in the assembly and presented gift cards from a local bookshop to Year four classes to be used for their class library. I also thanked the principal, teachers and administrative staff. In the following week I sent a chocolate basket to the school. The vice-principal asked me to present a workshop on Reading Strategies for English and Arabic. I agreed to do it voluntarily the next term. Some teachers asked me to write reference letters for their teachers' portfolio. I wrote these as well. I also offered to put my name down as a substitute teacher for one term as a good-will gesture. A report of the findings will be available to the principal once the study is thesis is concluded.

\subsection{Analytical Strategy}

The secondary data collected in Phase I, extracted from the Q-NEDS database, was quantitative. A simple descriptive analysis, involving the construction of frequency distribution histograms, was used to summarize up to date information concerning Qatari schools, students, teachers, and teaching hours. Inferential statistics were not considered to be 
appropriate, since the aim was only to describe and summarize, and not to statistically compare the characteristics of independent and international schools.

The analytical strategies applied for the primary qualitative data collected in the Phase II case studies were dictated by the sources and types of data, including interview responses and classroom observations. Multiple data sources were used to compile a case summary, a school portrait, and a descriptive inventory. A more detailed description of the analytical strategies used in Phase I and Phase II follows.

\subsubsection{Analytical strategy for Phase I}

Data describing the demographic characteristics of the students and teachers at 63 Qatari schools (51 Independent schools and 12 International schools) were extracted from the QNEDS database for 63 schools. The raw data were presented in the form of the frequency distributions of nominal variables, including the frequencies of Arabic speaking students, English speaking students, Students speaking other languages, Qatari national students, Students of other nationalities, Qatari national teachers, Arab national teachers, Teachers of

other nationalities, Arab speaking teachers, English speaking teachers, Average weekly teaching hours in English, and Average weekly teaching hours in Arabic.

\subsubsection{Analytical strategy for Phase II}

The data collected in the case studies included field notes, classroom observation notes, classroom interaction recordings, interviews with three English languages teachers and two Arabic language teacher, an interview with the academic vice principal, a questionnaire completed by a school administrator, various school documents, and field notes of observation of school wide activities. The data from every source was filed and organized separately. A data base was compiled using Nvivo9 to store and organize all data sources into internal and external files. Nvivo was used to code and analyse the data concerning school 
policy and related documents. It was also used to code the analysis of interview data and the first level of the classroom observations (utterances). The subsequent analysis of classroom observations was multi-level and performed manually with the help of matrices.

\subsubsection{Descriptive framework}

The multi-level nature of this study necessitated the use of a descriptive framework to deal with the multiplicity of practices associated with bilingual programmes. This descriptive framework underpinned the analysis of data derived from the embedded cases and units of analysis. In an embedded case study design, several subunits of analysis are also necessary (Yin, 2003). The two embedded cases in this study were one independent school and one international school. The units of analysis were dependent on the research questions. The primary units of analysis were the organization and implementation of bilingual programs in each of the two schools. Because of the complexity of defining these units of analysis, they were further partitioned into sub-units, as described in this section. Consequently, the case study was conducted at three levels (a) Bilingual education at the state level and case selection (Phase I); followed by Phase II comprising (b) The organization of bilingual programmes on school level within two cases (one international school and one independent school); and (c) the implementation of bilingual programmes at the classroom level for the two schools. Figure 3.3 outlines the multiple case study design of this study, carrying two embedded cases and further embedded units and subunits. 


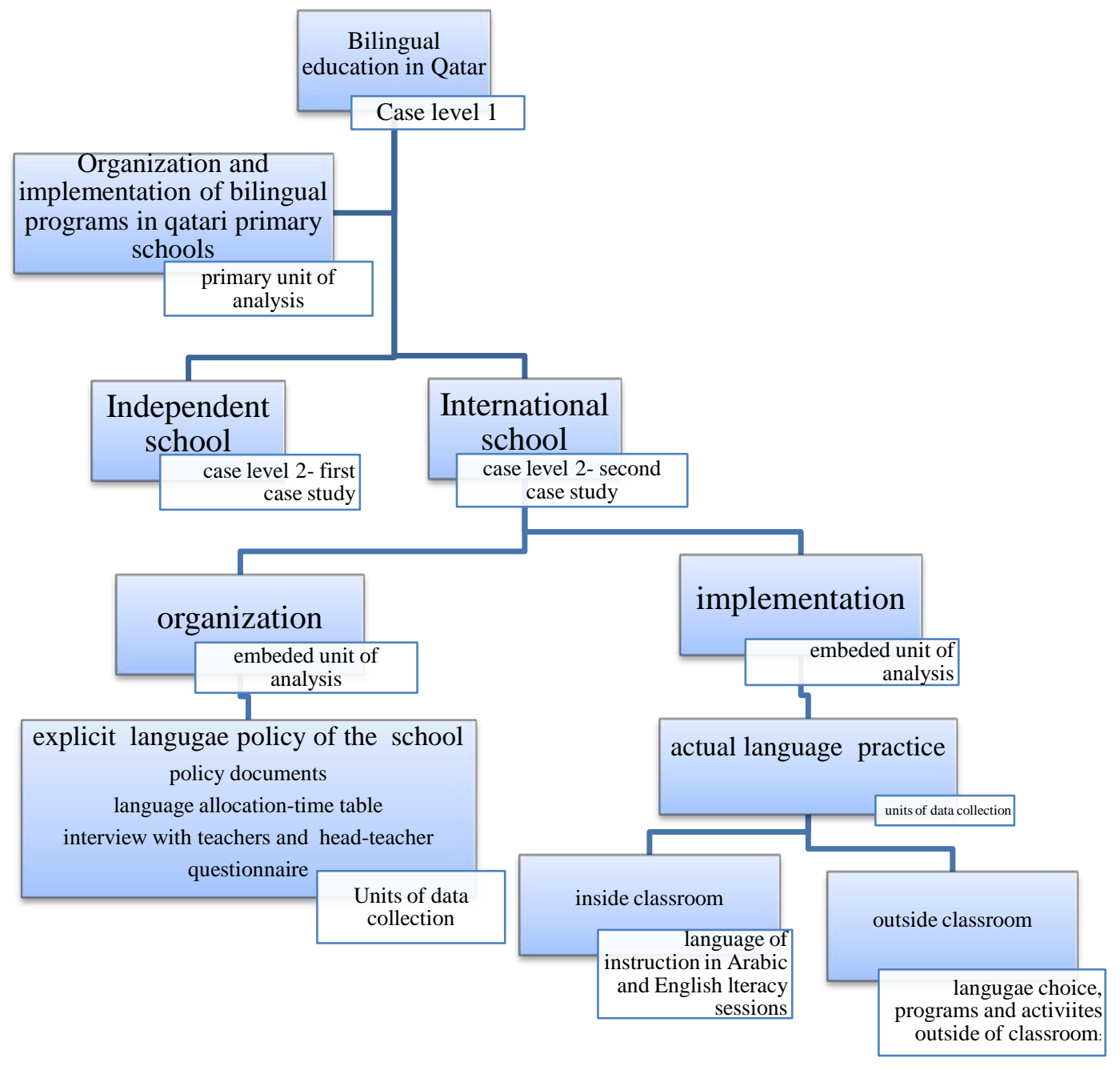

Figure 3.3 multiple case study design including embedded units and sub-units of analysis

Yin (2003) notes that descriptive studies typically fail to specify a priori the critical ingredients of the phenomenon to be described. Within his concept of 'construct validity' data collection then rambles as a result using 'subjective' judgments and the ensuing case study may even contain undesirable circular reasoning. Although defining concepts in the way Yin (ibid) aspires to might not be a reasonable request especially in multiple case design, some aspects of the case study at hand, with the a focus of describing bilingual programs within a set of goals (which have been specified in the research questions) calls for a certain measure of prior specification and description of items to be described. 
Programme organization included the target population, explicit and advertised language policy, percentage of time allocated to each language in the school day, timing of L1/L2 introduction, subjects taught using each language, language separation policy within the classroom and teacher characteristics, whether bilingual or not, the use of teaching assistants, the types of qualifications the teachers have and years of experience as well as resources available to the school related to language teaching. Programme implementation dealt with how the school applied its said organization of the bilingual programme, including pedagogical features of classroom practice and various instructional tools. It was defined under three subheadings: instructional practices, teaching strategies and overall teaching approach with various sub-components.

\subsubsection{Analysis of interview responses}

Using strategies linked to grounded theory, such as axial coding, the interview data were analysed and tabulated. Cohen et al. (2011) defined an axial code as a category label ascribed to a group of open codes concerned with same concept. Axial coding facilitated the classification of similar open codes into new categories. Using axial coding that matched the interview protocol facilitated the analysis and categorization of the interview responses, in order to extract similarly coded themes.

The interview responses were analysed question by question. Separate analyses were conducted for English teachers and Arabic teachers. A table was created to summarize the results (appendix ix) Questions were listed on the right hand side, and the extracted themes were presented in bold type. The evidence was identified by the initials (pseudonyms) of the respondent, followed by the relevant quotation. A three axis sequence was used in the interview protocol (appendix iv). The same categories were used to aggregate responses 
associated with similarly coded themes into a single set of responses. When other themes surfaced a new category was added.

The interpretive analysis of the interview responses followed the approaches described Erickson's (1986) Rubin (1995) and Arksey and Knight (1999) involving the classification of three components or units of data analysis, specifically (a) general description; (b) particular description and (c) interpretive commentary. Patterns among the themes were identified, and the evidence was displayed as 'vignettes' or verbatim quotations, followed by a longer interpretive commentary.

\subsubsection{Analysis of classroom observations}

The classroom observations were the core of the case study, providing an in-depth understanding of what was actually happening inside the classrooms of the schools. Using analytical strategies linked to grounded theory, the field notes and transcripts of classroom interaction recordings were analysed. As pointed out by Cohen et al (2011, p.537) this analysis was "almost inevitably interpretive" and was "less a completely accurate representation (as in numerical positivist tradition) but more of a reflexive, reactive interaction between the researcher and the decontextualized data that are already interpretations of a social encounter". The overall aim of the analysis aimed to discover evidence to determine which language teaching practice prevailed (e.g., a communicative approach, a grammatical approach, a cognitive approach).

The analysis of the classroom observations was conducted following Miles and Huberman's (1994) tactics, as follows: (1) Counting frequencies: event segmentation was used to partition the lesson into different events, and the frequencies of instructional practices with respect to each event were counted, using a code book to classify teacher/ student practices; (2) Finding a patterns: patterns in the instructional process were identified by recording the dominant 
practices in each event; (3) Seeing plausibility: Sense was made of the data using informed intuition to reach conclusions about instructional practices found in each event of the lesson; (4) Clustering: The student/ teacher behaviours were classified into a matrix to display dominant, moderate, and weak practices in the lessons; and (5) Making metaphors: The observations were interpreted using figurative language and linked to theoretical propositions concerning bilingual education.

Rigorous coding was used to classify the transcriptions of the classroom observations. A conversation analysis was undertaken to deal with the density of data from this source, in order to align the data with the research questions. After transcription, the researcher performed inductive data-driven analysis, aiming to find recurring patterns of interaction. The analysis was carried at two levels (1) At the first level of analysis, each utterance (defined as a unit of speech that was capable of being meaningfully understood on its own) was categorized using the code book; (2) At the second level of analysis, teaching events were identified. Each event was defined as a sequence of interactions focusing on a single language task, or a few small tasks with a similar focus (e.g. reading a story, handwriting practice, grammar explanation).

At the first level of analysis, the observed teacher/ student activities were coded using a codebook (Appendix viii) based on the Transition Bilingual Observational Protocol Lara-Alecio \& Parker, 1994) and the Sheltered Instruction Observation Protocol (Short \& Echevarria, 1999) and creating a code book (appendix viii). These two Protocols had similar focus as the aims of the current study compared to others found in the literature. Each utterance was coded, as indicated in the following example (Table 3.3). 
Table 3.3 Extract from lesson 110418_001 INT ENG 09:30

\begin{tabular}{ll}
\hline Teacher student talk & Code \\
\hline T All write today's date and stop talking. Ahmed ... & DIR/PER \\
\hline (pause) & \\
\hline T (00:52) Okay boys, today's unit is compound words. Do you know what the & LEC/LIS \\
meaning of compound words is? & ASK/ANS \\
\hline Okay? For example if we say 'football'- you will see that it is divided into two words & LEC/LIS \\
- foot and ball. And together they are a compound word. Why compound? - Because & \\
it has two words in it & \\
\hline Miss, background. & ANS/ASK \\
\hline Yes, like background & EV/PER \\
\hline Can you give me more examples & ASK/ANS \\
\hline
\end{tabular}

This extract from Observation 7 of an English class demonstrates how the code book was utilized to code the data to prepare it for further analysis, reduction and transformation. The teacher/ student talk is displayed on the left hand side and the code is displayed on the right hand side. In the second row the teacher gives directions to the whole class and the class is performing the directions. Thus a code of DIR/PER means: Teacher directs/ students perform, is attached to the utterance.

At the second level of analysis, three analytical steps were involved. First the the lesson was segmented into different events. Secondly the events were then coded, and finally the data were summarized in a matrix.

For the first level of analysis, the transcript was read to identify the focus of the event and the mode of communication used in the event. For each event the following were reported: (a) Event language focus (reading, writing, copying, listening); (b) Language used (L1 only, L2 clarified by L1, L1 introduces L2, L2 only); (c) Communication mode (oral reception, verbal expression, written communication or reading comprehension). The observed events were displayed using data reduction cards (Table 3.4). The result of this analysis was 30 cards of 
reduced data, one for each lesson, for each school. Each card displayed the observed events with a coded description of the events' communication mode, teachers' language, students' language, physical grouping of the students, and dominant academic activity as apparent from the coding of the teacher / student talk, and the instructional practice being used. Labels were attached to each event where applicable by judging their frequency. The coding considered the focus of the teacher's actions such as the content material, vocabulary items, or a grammatical rule. For example, Table 3.3 provides an extract from a grammar lesson on compound words. Explicit Focus on Grammar was the instructional practice used by the teacher in this event. The utterances indicated that the event was rich in IRF type of interaction. When the teacher asked or signalled a question, a student answered, and the teacher commented on the answer

\section{Table 3.4 Data reduction card}

INT SCH/OBS _ENGLISH/ARABIC

\begin{tabular}{l|l|l|l|l}
\hline Event & 1 & 2 & 3 & 4 \\
\hline Communication mode & & & & \\
\hline T language & & & & \\
\hline S language & & & & \\
\hline Grouping & & & & \\
\hline Dominant academic activity & & & & \\
\hline Other academic activity & & & & \\
\hline Practice labels & & & & \\
\hline Notes & & & \\
\hline
\end{tabular}

For the second level of analysis, more abstract categories of instructional practices used by English and Arabic language teachers were extracted from the data. Following Miles and Huberman (1994) a format for gathering the data from every lesson into one matrix was generated, which summarized the frequencies of different types of instructional practice. Specific practices of bilingual education were included in a checklist format (Table 3.5) 


\section{Table 3.5 Matrix of instructional practices}

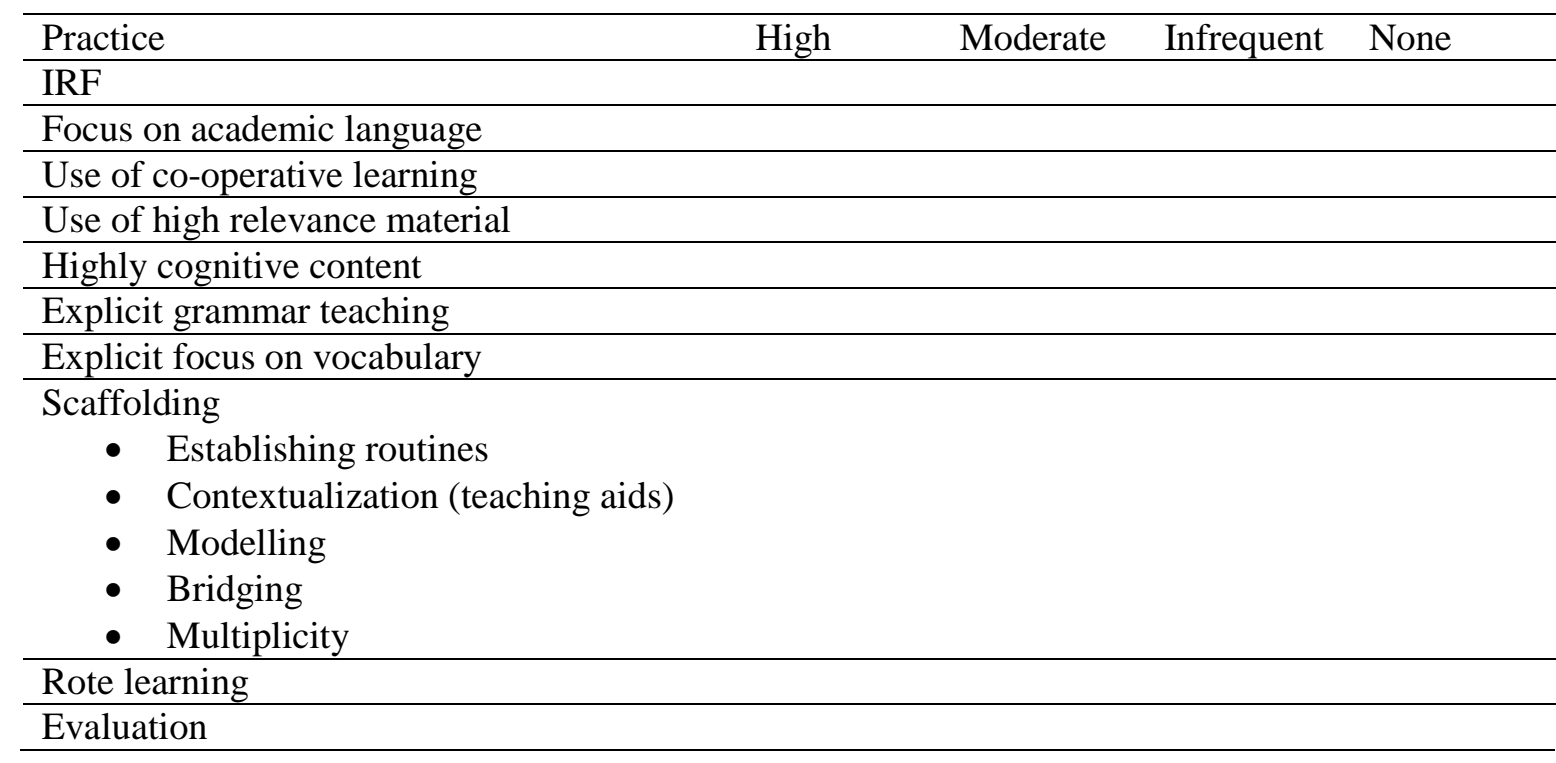

I devised a table where each observed practice was entered into the matrix. If the practice was used throughout the event it was marked as having high frequency. If the practice was used in half of the event it was marked as having moderate frequency. If less than half, it was marked as infrequent and if there was no evidence for the practice it was marked as none. After filling the matrix with check marks for 30 lessons, the data needed to be reduced further. Every ten checks were replaced by an outline of a circle, and every two circle outlines were replaced by a solid black circle. The summed indices not only summarized the data, they also served as a method of interpreting the data. The matrices however, were not interpreted separately to the raw data in field notes and transcripts. The latter described how each instructional practice was utilized in the classroom and how it engaged the students. Therefore the analysis also included vignettes based on the raw data. The evidence from 'vignettes' included in the presentation of the findings were chosen as typical of the data as a whole as advised by Patton (2002) and Merriam (2010). 


\subsection{Findings and Interpretations}

To gain an in depth understanding of the issue 'bilingual education in Qatar' the two cases findings were reported using narrative descriptions to provide contextual aspects of the study. The findings were reported giving summaries of findings at each data point and a brief case summary. Then the report of each case concluded with a school 'portrait' of the findings depicting a contrast between: how the school sees itself (official policy) with what is actually happening (practiced policy) on two features, language use and language pedagogy. Because the study used an interpretive approach this portrait was only devised at the end of each case study report when all issues were clear to present using what is termed 'progressive focusing'(Silverman,2005:178) as items on the portrait only became apparent after the case findings were reported.

\subsubsection{Cross case analysis}

A cross-case analysis involving a comparison of the two cases was conducted. Referring back to the 'big picture' as Yin (2003) stressed, was a key tool in the embedded case study design. A cross-case analysis could only be performed after the analysis of separate cases was completed. Reporting cross-case analysis was done by a synthesis of the two schools portrait into one large display. The cross-case analysis also made use of another display that gave surface description of all elements found in the two cases. This Case-Ordered Descriptive Meta-Matrix 'The Bilingual Programme Descriptive Inventory (BPDI)' is a descriptive framework created for the purpose of this study to display the results of the micro-analysis carried out at different levels. It sketched a systematic picture of the characteristics of the two bilingual programmes.

\subsection{Ethical consideration}

I followed the CUREC Guidelines and Protocol for studies using non-invasive methods with 
typically-developing children in schools. The consent forms I distributed to parents, teachers and head-teachers, and the methods used to recruit the participants adhered to the guidelines of this protocol. Opt-out consent forms and the CUREC approval letter were sent to teachers, parents and children (Appendix iii) to ensure that they understood that participation was voluntary

All the data were confidential and care was taken to ensure the anonymity of all participants. All records were coded and the names of the participants were identified only by pseudonyms. The numbers and the names they represented, as well as any other written material, including school documents, were stored in locked storage files. Electronic versions of the data were stored in separate data storage devices with passwords.

Care was taken to minimize any disruption to the students' daily routine, and to respect the wishes of the participants and participating schools. Schools had the right to withdraw from the study at any time. The schools were fully informed about the purpose of the study and the likely publication of the findings of the research. A report of the study findings will be made available to schools, head-teachers and interested individuals in the future.

\subsection{Limitations}

A criticism of case study methodology in general is that its dependence on a single phenomenon of interest may render the results incapable of generalization to other cases (Yin, 2003). Consequently, the findings of this study may have local significance, but do not necessarily exhibit external validity. Flyvbjerg (2006) criticises this principle in social science. He at first indicates that even if knowledge generated from case study cannot be formally generalized, this does not mean that it cannot enter into the collective process of knowledge accumulation in a given field. He then maintains that 'one can often generalize on the basis of a single case, and the case study may be central to scientific development via 
generalization as supplement or alternative to other methods'. Stating that the "force of the example” is usually underestimated in social research and pointing that formal generalization is often being overvalued. Flyvbjerg supports this argument with the work of Walton (1992) who similarly observed that case studies are likely to produce the best theory. Kupper and Kupper (1985) indicate also that more discoveries have been made from intense observations than from statistics applied to large groups. Notwithstanding Campells work in the area (e.g. 1975)

Another limitation was that the findings may be limited by the timing of the case study, and could be susceptible to local historical events outside the researcher's control; nevertheless, it is suggested that the results are of value outside the boundaries of this case study. The rationale underpinning this suggestion is that the research questions and answers may be identifiable to other teachers and researchers operating in similar bilingual education settings elsewhere.

A case study provides only one person's interpretation of a complex phenomenon, which is shaped by his/her identity, including linguistic competence, ethnicity, gender and age group (Stake, 2005). Reflexivity implied that these and other personal factors could potentially have limited my interpretation of the results and my contribution to knowledge. However the systematic data analysis and reference to literature related to various topics in the thesis meant that bias to one interpretation over another if not supported by the data itself would not be included. Moreover the inherent bias of the case study method as being 'subjective' has been challenged in the qualitative research literature. To continue using Flyvbjerg argument, he also rejects such criticism of the case study method indicating that Campell and others have shown that this critique is fallacious because the case study has its own rigor, different to be sure than other methods, but not less strict than the rigour of quantitative methods. 
According to many researchers in the qualitative field (e.g. Greetz, 1995) researchers who have conducted in-depth case studies have often reported that their preconceived views, assumptions, concepts, and hypothesis were wrong. Accordingly it is the falsification not verification that characterizes the case study.

One final limitation is the fact that a purposive convenience sample was used in this study might have decreased its external validity. This principle has also been rejected by Flyvjberg in the previous argument about generalizing from case study research.

My use of a various theoretical perspectives to discuss the findings might have been eliminated have I used a single factor to examine. The fact that no evaluation or observation instrument was used in favour for analysis and open coding might be considered a limitation. However the rationale for using an ethnographic approach overweighed the benefits of a pre devised observational tool. One of the reasons is to enable the data to guide the findings and not the instrument.

\subsection{Original contribution}

No previous research has been conducted to describe the rapidly changing bilingual education in Qatar and the immediate region. This study is therefore of immediate interest to educational society in Qatar, especially those looking at the new initiative 'Education for a new Era'. Consequently this study represents original contribution to examine bilingual education in the context of change. It examines Qatar's experimentation in bilingual forms of education in a diglossic situation, with little research having been done prior to the 'bilingualisation' venture. The research is grounded in the theoretical proposition of language education put forward by Garcia (2009) who described and categorized the types of bilingual education around the world in different contexts. She classified the situation in Asia and the Middle East as a heteroglossic dynamic language situation. This means that different 
languages and dialects are used interchangeably and for various purposes across the school day/program. Whether or not education in Qatar is heteroglossic remains to be seen from the findings of this study.

In the field of bilingual education research, since the 1990s, significant advances emerged bringing new perspectives to the study of bilingualism in and through education. The emerging perspective pays more attention to the context-specific knowledge realized by the learner which has two emphases - one on policy and one on pedagogy. This new outlook is evident from various studies and publications as related in the literature review. Given the linguistic situation in Qatar with its diglossia and the addition of bilingualism in education, the current thesis investigates the Qatari context within a model or a conceptual framework that accommodates Qatar's multi-lingual situation which is a significant first step and an original contribution to knowledge in the field of bilingual education to further investigate the realities of these programmes. In addition, it has been asserted in recent scholarly work by many researchers (Genesee, 2006; Cummins, 2000; de Maja, 2002) that the issues surrounding bilingual programme types are often very different, with attention towards bilingual education for majority language learners in international settings developing only in the last decade or so. Previously most of the research has been devoted to minority language learners often in the context of the US and Europe. Furthermore, academic discourse in the East presents other interests. Studies in Asia have revealed alternative practices to established bilingual programs. (e.g. Lin 1999, Tsui, 2004Bostwick, (2000) who investigated the implementation of immersion bilingual programme in Japan for example . indicated that close investigation into the structure of different programs in differing contexts is profitable to provide alternative bilingual programs that work with the specific needs of the communities in question. 
Scholars of Arabic-English bilingualism (e.g. Haeri, 2005, Abu-Rabia, 2000) have highlighted the lack of empirical studies focusing on bilingual programmes or considering biliteracy provision. Arabic school practices are shaping the social realities of current and future generations in Qatar and the wider Arabic-speaking world. Therefore, the current study tries to fill the gap in the research of providing an examination of bilingual programmes in novel contexts. It is also viewed as a catalyst to stimulate future research in the region leading to further investigation of the complex linguistic realities of millions of children in the Arab region.

International educators and researchers can use the design and findings to learn more about the different approaches chosen by the State of Qatar to promote bilingualism through education in its public system and the role of other institutes in the process (international schools). This knowledge could be applied to other situations and other societies. In addition, the findings will provide original data on the international nature of the policy and practice of bilingual programmes and biliteracy provision in primary education, extending the current literature on bilingual education for majority language learners. The study will also contribute to the understanding of different manifestations of bilingual programmes intended for majority language learners and of biliteracy within languages that are typologically different. Taken as a whole, the research findings will be able to answer the question of how bilingual education is practiced in this and similar contexts where English is widely used but without a grounded bilingual policy.

In addition the project indirectly sheds some light on bilingual programme evaluation and the lack of a comprehensive evaluation mechanism or battery within bilingual education research to assess in practical terms the practice of bilingual models and types. This study attempted to use the available techniques in investigating bilingual practices and biliteracy provision. Most 
of the analytical tools were devised for this study based on available literature on research methods.

Finally the findings and the discussion steer the thesis towards the study of flexible language use and the examination not only of the L2 but the L1 are also a recent topic of interest in the literature which there has been little research to cover. 


\section{CHAPTER FOUR: DESCRIPTION OF THE SCHOOLS}

\subsection{Introduction}

Quantitative data concerning the students, teachers, and teaching hours at 63 schools (51 independent schools and 12 international schools) were extracted from the Q-NEDS database. Frequency distributions were constructed to describe and summarize these data.

\subsection{Students}

The total number of Qatari national students was 20369 at independent schools and 1483 at international schools. The total number of students of other nationalities was 7372 at independent and 1450 at international schools. The frequency distributions (Figure 4.1) indicated that the majority of independent schools served 400 to 700 Qatari nationals and fewer than 300 students of other nationalities. The majority of international schools served fewer than 400 Qatari nationals and fewer than 200 students of other nationalities.

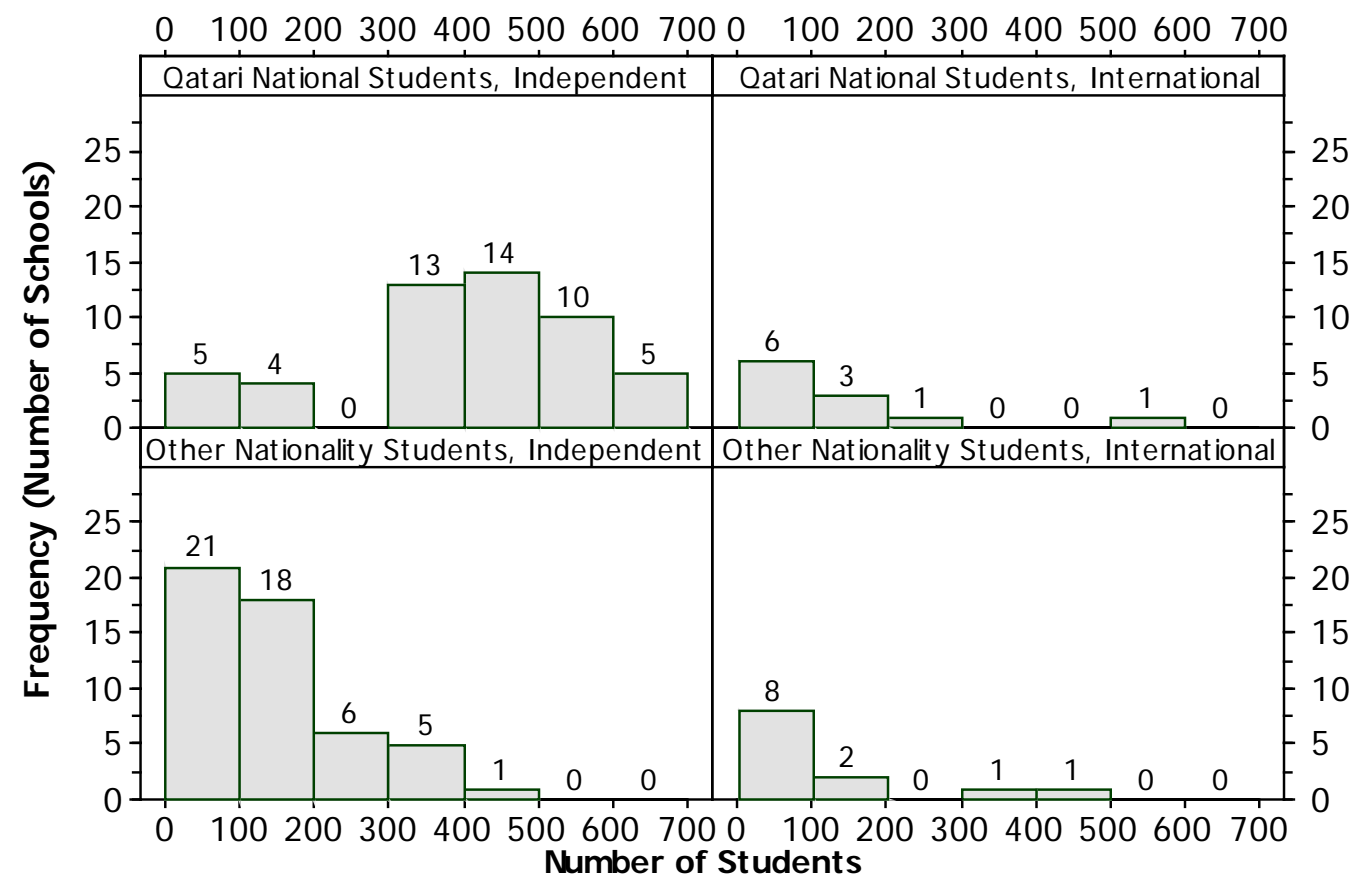

Figure 4.1 Frequency distributions of students by nationality and school type 
The total number of students with Arabic as L1 was 20369 at independent and 3877 at international schools. The total number of students with English as L1 was 1965 at independent and 353 at international schools. The total number of other students was 1334 at independent and 378 at international schools. The frequency distributions of the students' L1 are illustrated in Figure 4.2. The majority of the independent schools served 500 to 700 Arabic students and less than 100 students whose L1 was English or another language. The majority of the international schools served less than 300 Arabic students and less than 100 students whose L1 was English or another language.

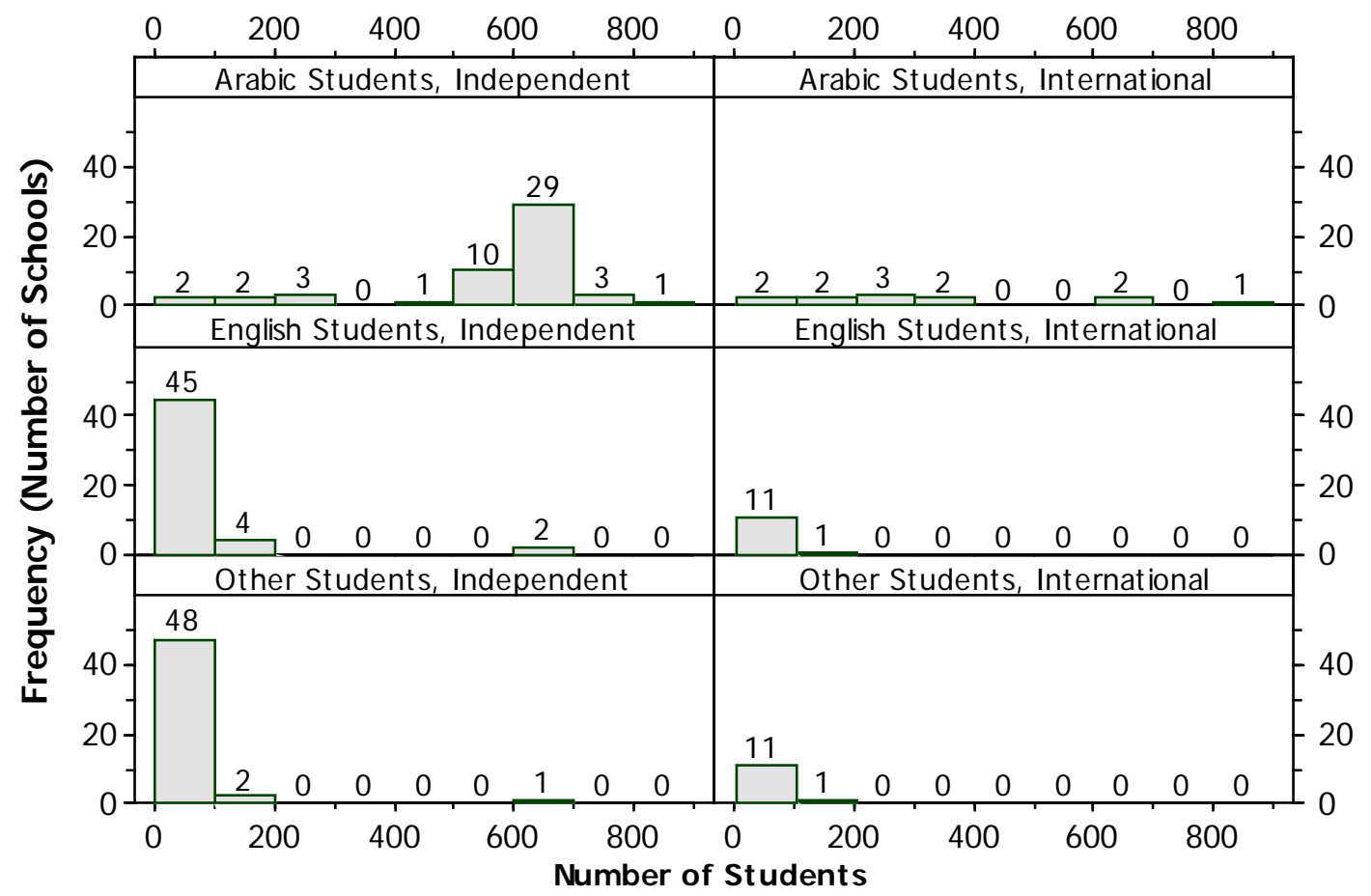

Figure 4.2 Frequency distributions of students by language and school type

\subsection{Teachers}

The total number of male teachers was 24 at independent schools and 43 at international schools. The total number of female teachers was 2644 at independent schools and 381 at international schools. The frequency distributions of the teachers' gender across the two 
school types are illustrated in Figure 4.3. The majority of the independent schools employed less than 10 male teachers and 50 to 70 female teachers. The majority of the international schools employed less than 30 male teachers and 10 to 40 female teachers.

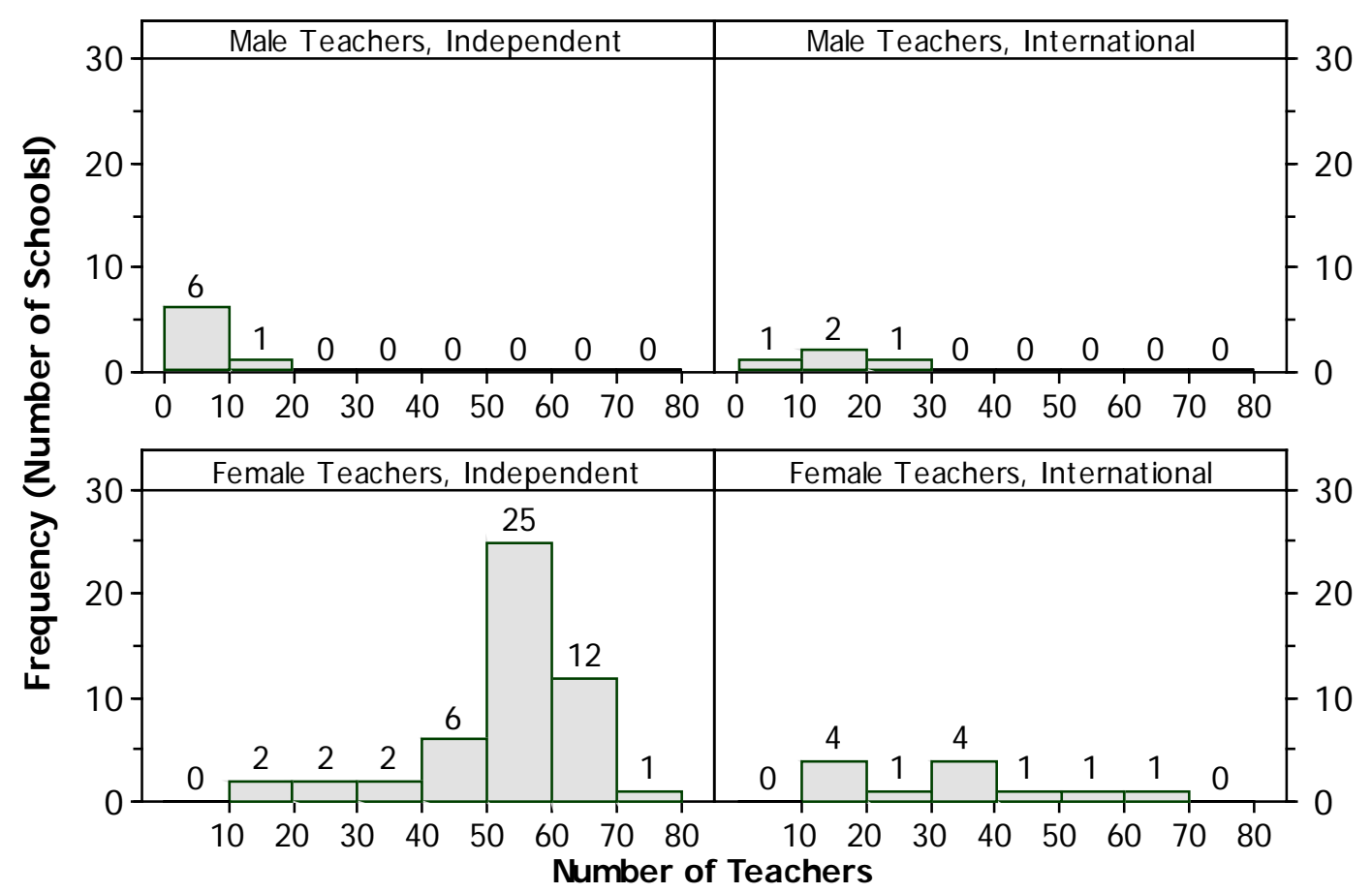

Figure 4.3 Frequency distributions of teachers by gender and school type

The total number of Qatari national teachers was 1051 at independent schools and 18 at international schools. The total number of Arab national teachers was 1361 at independent schools and 151 at international schools. The total number of teachers of other nationalities was 266 at independent schools and 277 at international schools. The frequency distributions of the teachers' nationalities across the two school types are illustrated in Figure 4.4. The majority of the independent schools employed less than 40 Qatari nationals, 20 to 40 Arab nationals, and less than 10 teachers of other nationalities. The majority of the international schools employed less than 20 Qatari nationals, Arab nationals, or teachers other nationalities. 


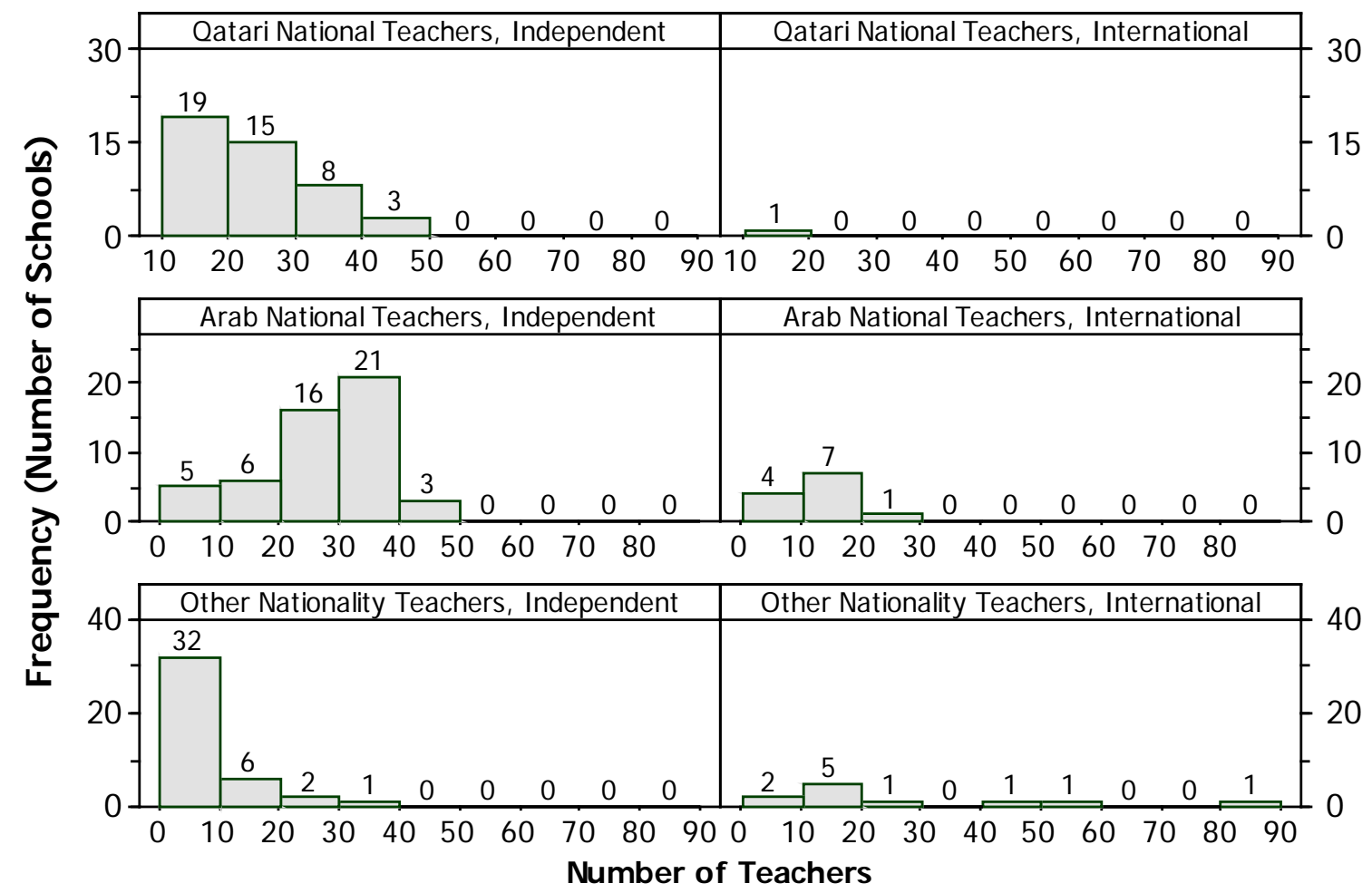

Figure 4.4 Frequency distributions of teachers by nationality and school type

\subsection{Teaching hours}

Separate tabulated data was used to provide description of teaching time in the schools. The average number of teaching hours in English or using English as a medium of Instruction per week was 20.0 at independent schools compared to 12.1 at international schools. The total number of teaching hours in Arabic per week was 4.8 at international schools compared to 13.3 at independent schools. Average class time in hours per week for all subjects across the two school types are illustrated in Table 4.1. The majority of schools taught in English for $50 \%$ to $90 \%$ of the time, with an average of $52.0 \%$ in the independent schools and $82.0 \%$ in the international schools as figure 4.4 depicts: 
Table 4.1 Average class time in hours per week per language allocation and school type

\begin{tabular}{llllllllll}
\hline & Overall & English & Mathematics & Science & $\begin{array}{l}\text { Social } \\
\text { science }\end{array}$ & Arabic & Religion & $\begin{array}{l}\text { English } \\
\text { subjects }\end{array}$ & $\begin{array}{l}\text { Arabic } \\
\text { subjects }\end{array}$ \\
\hline $\begin{array}{l}\text { Independent } \\
\text { Schools }\end{array}$ & 25.4 & 4.6 & 4.4 & 3.1 & 1.3 & 4.4 & 2.7 & $\mathbf{1 2 . 1}$ & $\mathbf{1 3 . 3}$ \\
\hline $\begin{array}{l}\text { International } \\
\text { schools }\end{array}$ & 24.8 & 6.1 & 4.7 & 2.7 & 2.0 & 3.1 & 1.7 & $\mathbf{2 0 . 0}$ & $\mathbf{4 . 8}$ \\
\hline
\end{tabular}

Figure 4.5 Percentage of language allocation per school type

\section{Independent Schools}

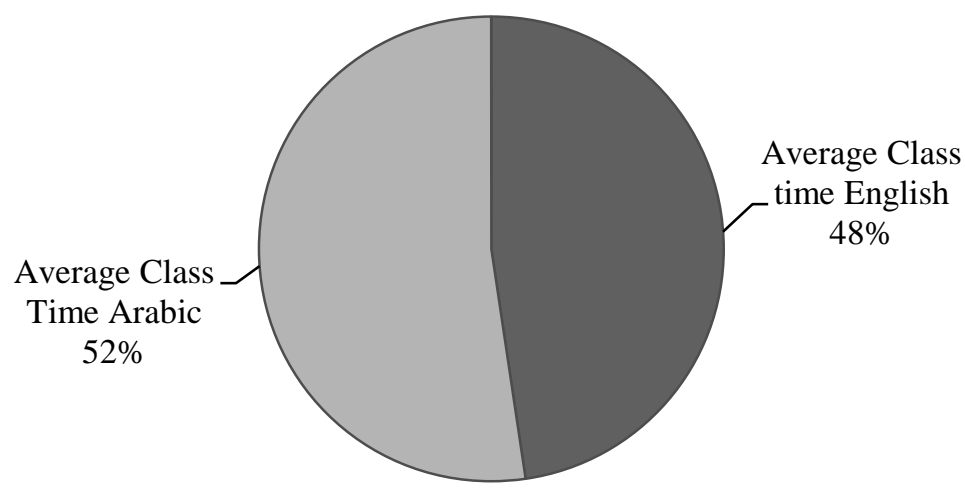

\section{International Schools}

Average Class

Time Arabic

$18 \%$

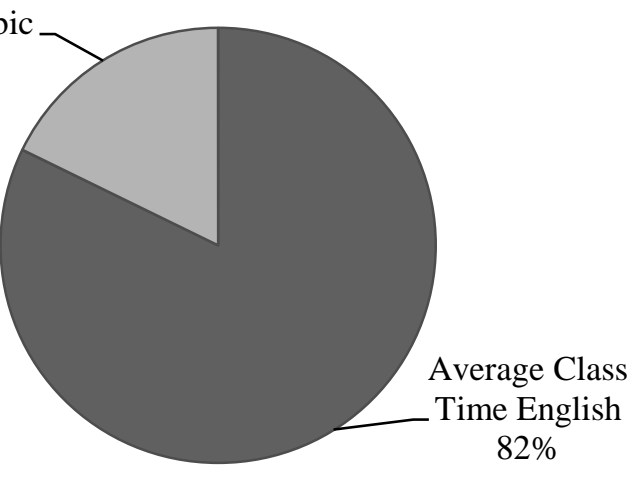




\subsection{Conclusion}

It was deemed necessary to start this exploratory study with a quantitative examination of the two school types involved (independent and international schools). The Q-NEDS data base provided adequate data to view the schools from afar and to set a sampling frame from which to draw the cases. The first aim was achieved as the data provided the following information:

1. There are more Qatari students in independent schools than International schools. The data also indicate that the majority of students in Qatar attend independent schools. There are more students who speak English or Other Languages in independent schools compared to international schools. However international schools attract English students and students who speak other languages more than Arabic speaking students.

2. In both International and independent schools female teachers numbers surpass the numbers of male teachers. There are very few Qatari teachers in international schools. Both types of schools attract teachers from Arabic nationalities.

3. An investigation of average teaching time per week reveals that independent schools present almost equal teaching time for subjects that use Arabic as the medium of instruction and the ones that use English as a medium of instruction. International school on average have an 80-20 language allocation. In relation an examination of the raw data and reference to the Supreme Education Report (2010) reveals that some school have a 90-10 allocation while other can have less.

In conclusion, results of the Phase I data analysis portrayed a sketch of the type of students that attended the independent and international schools and the characteristics of the teachers who were employed there. The results were also crucial to provide preliminary information on how Arabic and English language interplayed within the school week with respect to the 
hours spent studying each language. This quantitative review, however, did not provide a solid understanding of the structures and processes of how Arabic and English were taught. Answering the research questions required other methodologies such as interviews, observations and questionnaires, to elicit information that enabled the researcher to gain a more comprehensive understanding of the daily activities relating to the teaching and learning of the L1 and L2 within bilingual school programmes in Qatar. The next two cases' reports along with the cross-case analysis provided deeper analysis of the issues related to bilingual programmes in Qatar. 


\section{CHAPTER 5: CASE STUDY 1 - SALAM SCHOOL}

\subsection{Introduction}

The international school which was the focus of the first case study is described briefly before the presentation and analysis of the data. This ethnographic description includes location, size and nationality composition extracted from field notes, and profiles of the teachers elicited by questionnaire or interview. The school and teachers' names are identified by pseudonyms to preserve their anonymity. Following the descriptions of the school and its teachers, the results of the case study are presented in two main sections (a) the organisation of the bilingual programme and (b) the implementation of the bilingual programme.

\subsubsection{Profile of Salam school}

Salam is an international privately owned school set in two large rented villas in different locations in the city of Doha. Both villas have large shaded open spaces in the front area. Both buildings are surrounded by equally large villas in their quiet residential areas. I was not allowed entry into the walled premises before negotiation with the security guard. Upon entry I heard the sounds of children echo from afar, and a few appeared out of the front door in their shirt and trouser uniforms. Uniformed cleaning ladies were noticed in their bright blue

attire. A whistle blew and I could see the only male teacher shouting at the boys to line up to go to the PE lesson in the side outdoor play area.

Salam school is of medium size, in a central location, and teaches boys and girls in separate premises. The boy's premises are identical to the girls' except that there are more decorations in the girls' premises. It has a large population of Qatari students with an equally large Arab national student population (Egypt, Syria, and Palestine, Jordan) but only four non-Arabic- 
speaking students. The school has been in operation for four years and follows a British based curriculum. The Arabic and Islamic studies are supervised by the SEC education and evaluation institutes.

\subsubsection{Profiles of the participants}

The teachers employed in Salam school included 11 Arabic bilinguals, 12 Arabic nonEnglish speakers, 14 English speaking Asians, and one English speaking European. Ten teachers were qualified by a Master's degree, 29 by other university degrees, and four with a post high school diploma.

There are three Arabic teachers for grade four at the school. Two Arabic teachers were observed during this study. The same two teachers agreed to be interviewed and one refused. I tried to persuade her later in the term but was unsuccessful. The profiles of the two Arabic teachers are as follows:

Ameera: An Iraqi teacher in her 50's. She has extensive experience teaching Arabic language in Iraq and in Qatar. She has been working for Salam school for three years. Her degree is in Arabic language. She has some teaching qualification in the form of teaching courses woven into the bachelor degree she holds. This is an old degree in which the extent of modern pedagogy training is not clear to the researcher. The teacher did not mention any recent training or workshops.

Jasmine: Jasmine is the youngest teacher of the three teachers in year four (she is in her early 30’s). She refused to have her classes recorded so I had to rely on observational notes. She also holds a degree in Arabic language from Jordan. There is teaching training courses included in this qualification. She has also been teaching in this school for almost 3 years. 
Three fourth grade English teachers were interviewed. Their profiles are as follows:

Hurria: This was the only teacher whose L1 is Arabic. She is very proficient in English and this is because of her schooling, since she attended English speaking schools in Egypt all through her education. Hurria is a young teacher (27 years old). She has not been teaching in this school for long since this is her first year but she has got approximately four years of teaching experience in her own country. This is the first school she has worked with in Qatar. Her first degree is in Fine Art with no formal teaching training or qualification.

Ruby: Originates from Malaysia, holds a Master's degree in statistics from the United States along with a bachelor degree in Mathematics, also from an US university. This gives her excellent proficiency in English, although she speaks very little Arabic. She is also in her30's. She has more experience teaching in this school, at approximately 3 years. She also has 5 years of teaching experience in another school in Qatar as well. Similar to the previous teacher Ruby doesn’t hold any formal teaching qualification.

Nazeem: This teacher is also Asian. She speaks several Asian languages such as Urdu, along with English, but with very little knowledge of the students L1 (Arabic). She is in her 30's. Nazeem also has some teaching experience in this school, as well as other schools in Qatar (3 years in this school and approximately 4 years in another school in Qatar). She holds a bachelor degree in English from India. Teaching English as a second language was one of the subjects she studies for her degree so it can be said that this is the only teacher with some formal teaching qualification.

The vice-principal also agreed to a short interview in which I had a chance to ask about the school policy. Her profile is as follows: 
SA: The academic vice-principal is from Australia. She has a bachelor degree in Communication Technology. She also has an MBA. She worked as a teacher abroad and in Qatar. She worked as a curriculum supervisor in a school in Qatar before taking this position. She has been working in this school for two years. She is married with two children.

\subsection{Organisation of the bilingual program}

This unit of analysis encompassed all that was advertised and believed by management and operators of the programme. It included information published in the policy document or other documents explicating the mission and aims and objectives of the programme. Findings related to this unit of analysis answered in part the overarching question of 'how is bilingual education manifested in international and independent primary schools in Qatar'. The organization of the bilingual programme was described from three sources (a) the school bilingual policy document; (b) language allocation and distribution in the programme, and (c) interviews with English and Arabic language teachers and the academic vice-principal.

In general it was expected that a school policy towards the bilingual programme, and its aims and objectives related to the teaching and use of L1 and L2, should be clearly stated for all stakeholders to apprehend. In the schools' questionnaire item 13: “Do you have a written school policy regarding language use and teaching Yes/No.” The answer was no. In the absence of an officially published policy for the school as a whole, or a policy relating to its bilingual programme, other sources were used to obtain information about how the school views its programme for direct interpretation: school brochures, school advertisements in the local newspaper, school website material, and school curriculum policy. Analysis of these documents led to three main themes that the school communicates publically through these documents which explicate its policy: Each of these is described under the headings of (a) school linguistic goals (b) educational goals (c) school identity. This section will also describe the school's language of communication, and language allocation, as follows: 


\subsubsection{Linguistic goals}

The school views itself as an 'English School', teaching mainly through the medium of the English language. This is highlighted by the school's name which indicates its main purpose being defined as an 'English school'. This phrase is part of the school name and thus apparent in all literature about the school. Explicit and clear indication of the school's bilingual programme is noticed in one place in these documents: 'the school provides internationally acknowledged English medium program' (school website mission). The rest of the statements related to the school programme and language teaching is apparent in the four documents examined. The school published an advertisement in the local newspaper which defined the school as an English school offering the British curriculum: 'X English School is proud to offer a British curriculum'، .to establishes a sound syllabus based on the British curriculum' 'quality in teaching English and Arabic'

The previous statements describe the type of curriculum used. Moreover, references to languages taught are apparent in the extensive description of the course material chosen for teaching English as is explained in the curriculum policy and school brochure. The content of the school curriculum policy is identical to the content of the school brochure. It seems that the curriculum policy was embellished and reproduced as a brochure. These two documents also contain some reference to the school's language policy, or the approach of the school, but present different ideas. Consider the following vignettes:

'We have chosen an excellent scheme of work in English called X. Being the first international English course book to be informed by English lessons taught in native speaker classrooms. Designed for second language learners...but uses many of the approaches to reading, writing, and speaking that underpin the teaching of English to first language children'. 'The course does not assume first language English as the 
early stages...the exposure to the language though is more extensive than in traditional second language courses' and 'as the children move into upper levels, they experience more first language teaching methods_covering the same aspects of English as do first language learners, however the needs of the second language students_are always taken into account'.

The above extracts present a clear emphasis on 'English as a first language', 'native speakers' and 'second language learners'. This emphasis can be viewed as an acknowledgment on the part of the school management that the school aims to produce native-speaker-like skills without forgetting the needs of the children as second language learners. Further examination indicated that this is a direct quote from the description presented by the course book publishers in the introduction to the course material. The school chose this particular material because they identified with the aims of the course. In other words, the aims of the course material fit with the school founders' aims, and it remains to be seen in the implementation analysis whether the school actually translates these aims in the school programme.

\subsubsection{School identity}

In addition to its English language goals, statements in the school advertising literature and documents emphasize its 'Islamic' identity. Examples of these statements are quoted in Table 5.1. These statements paint a picture of a moderate Islamic school, asserting an Islamic identity, adhering to the wider society with awareness of global traditions and value, drawing it away from Islamic extremism by emphasising on 'society', various cultures', and' mutual respect'. This in turn sets the school apart from other international schools in Qatar that are more western-oriented following a more secular standard within the school (anecdotal evidence). 
Table 5.1 Evidence reflecting the school identity

\begin{tabular}{ll}
\hline Statement & Source \\
\hline 'Teaching the British curriculum excellently in an Islamic atmosphere' & School ad \\
\hline 'Teaching the Holy Quran and Islamic studies' & School ad \\
\hline 'Segregated boys and girls buildings' & School ad \\
\hline '...plus Islamic/Arabic studies... transforming young individuals into God- & Mission \\
conscious citizens' (Mission statement on website) & statement \\
\hline 'Instilling in each child the importance of putting God in the centre of his/ her & Mission \\
life' & statement \\
\hline '..the formation of youth as its service to Islam and society' & Brochure \\
\hline '..to develop God-conscious individuals' & Brochure \\
\hline '...is a growing community of students, personnel, and faculty, all united in & Brochure \\
the mission of contributing to Islam and to the society' & \\
\hline 'our personal, social and humanities education curriculum...is based on & Brochure \\
$\begin{array}{l}\text { Islam... prompting both self-respect and mutual respect according to Islam' } \\
\end{array}$ & \\
\hline
\end{tabular}

The school brochure, advertisement and website were very graphic including pictures of students and symbolic pictures. On the school website there are two pictures portrayed in the heading of the web page and a picture of a western looking boy wearing glasses and pouring some liquids into glass tubes as if he is performing a chemistry experiment. The other picture is of two girls wearing head scarves and holding up certificates. The use of these photographs indicates that the school projects an identity of being an 'English school' and a 'scientific' school as well as an Islamic school that focuses on achievement, as success is symbolized by the certificates. It is a school that espouses English education, success and Islamic values. The three other pictures on the web page depict students wearing Qatari clothes and engaging in entertainment activities: blowing a balloon and bouncing on a castle and showing their painted faces. These photos communicate an education which is taking place within an atmosphere of 'fun'. It also communicates that this is a modern school. Whether the pictures were 
deliberately chosen by the school administration or randomly chosen by the school webmaster is unknown. Presumably they were approved by the principal.

\subsubsection{Educational goals}

The school's documents described the educational goals of the school, including a description of the general purpose of the curriculum, and its ideology. The school paints a picture of an institute that aims to provide a quality education while enhancing total progress of the child and pushing each student to their full potential. Its educational goals were coded and categorized into three categories: (a) child-centeredness; (b) academic excellence and (c) providing an enjoyable learning experience.

The following statement reflected a child-centred approach: 'Salam English School was established with one goal in mind: to inspire young individuals to be the best they can be'. (Curriculum policy, p.1) This approach 'concentrates on the individual learning of every student' and aims at 'helping children reach their full potential through an educationally stimulating environment with the best of resources'. Academic excellence was aimed for by using internationally approved assessment and highly qualified teachers. It was also emphasised that only children with the highest ability will be admitted. Within this atmosphere of educational excellence the school provided a unique programme, as described in the school brochure: 'It contains opportunities for children to participate in class, to contribute to school life and put their learning into practice'. All of this is stressed to be provided using 'positive approach' with ‘enjoyable' and 'attractive material' 


\subsubsection{Language of communication}

There was a lack of any information in the school's literature regarding the use of English as a medium of instruction when describing the curricula. The documents also failed to describe any bilingual support that students receive during these lessons. In all the school documents, however, some ideology was communicated, reflecting the role of language in the curriculum. Moreover the place of the Qatari Dialect was also not specified inside and outside classroom provision.

The clearest evidence that the school was bilingual came from communications with the SEC, other institutes and parents. An examination of the communication files (photocopying of which was not allowed except for a few parents' letters) revealed that communication is achieved in both Arabic and English. In letters that were one page long, Arabic was set on the right and English on the left, exemplified by the bilingual letter to parents in Figure 5.1. In longer communications, one side was in English and the other in Arabic, which works well because Arabic and English are directionally opposed. 

theme of Reading is Fundamental, is proud to announce the Third Annual Read a Thon for its students. The goal for the Read a Thon is to make reading enjoyable and fun all the while reemphasizing the importance of reading in general language ability.

The Read a Thon will consist of each student reading books, books, and more books and the parents, family and caregivers pledging a certain amount of money to be donated to the school library book fund.

The students will read often and record how many blocks of 15 minutes they have read (either alone or with a parent) and the parent will initialize beside this daily tally. We also kindly request either the parents to pledge a donation (at least QR $10)$ for the entire week of reading, or to donate a specified amount of money for each block of 15 minutes the student has read. At the end of the two weeks we will collect the tallies and donations. We will present certificates to all who return the tally sheets to their class teachers.

The Read a Thon will be from Wednesday $12^{\text {th }}$ of January 2011 through Monday $24^{\text {th }}$ of January 2011.

The tally sheets are due on $25^{\text {th }}$ Tuesday to all class teachers.

Since reading ability, fluency and vocabulary only improves with practice, please encourage your children to read, read and read!

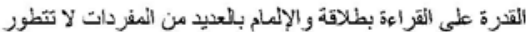

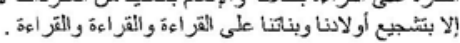

\section{Figure 5.1 Example of a bilingual (English and Arabic) letter to parents}




\subsubsection{Language allocation}

Language allocation was identified through the language distribution in the weekly program, with reference to content and time and language separation arrangements, the questionnaire, and the school timetable attached to the questionnaire. Salam school spent approximately $70 \%$ of the total weekly hours of instruction (30 hours per week) doing English as a subject or using English as the medium of instruction. The remaining 30\% was spent either doing Arabic as a subject or other subjects using MSA as the medium of instruction. In comparison, Phase I revealed that the percentage of English language teaching hours per week for international schools was $82 \%$. The $70 \%$ allocated to English at Salam school, which is somewhat lower than the average, reflected the school's ideology and how it viewed, practiced, and allocated the teaching of the two languages in the bilingual programme.

The school documents revealed that Salam is a school with an Islamic orientation or identity characterized by (as indicated from their weekly timetable) a noon prayer break, extra Quran sessions where long verses of Quran are memorized and recited by the students with specialized teachers. Consequently, a little extra time was devoted to Arabic as a subject resulting in a $70 \%$ time allocation to English compared to the $80 \%$ to $90 \%$ allocation to English found in some Western-style international schools in Qatar. Western-style in this sense refers to schools that follow an American or British curriculum standard (SEC International schools booklet, 2010) with more or less a secular orientation that can cater for

a variety of students. These schools have western management with native speakers of English as principals and higher administrators. 
With regards to the content allocated to each language, evidence from the weekly timetable of the school revealed that the school followed a subject-determined language separation policy (Figure 5.2).

$\underline{\text { Term1,283 - 2010/2011 }}$

$\underline{\text { Year 4-3 }}$

\begin{tabular}{|c|c|c|c|c|c|c|c|c|c|c|}
\hline DAY & 7:00-7:30 & 7:30-8:15 & $8: 15-9: 00$ & 9:00-9:15 & $9: 15-9: 30$ & 9:30-10:15 & $10: 15-11: 00$ & 11:00-11:45 & 11:45-12:15 & 12:15-1:00 \\
\hline SUN & \multirow{5}{*}{$\begin{array}{l}\text { Reading \& } \\
\text { Writing } \\
\text { Activities } \\
\text { (English) }\end{array}$} & English & Islam & \multirow{5}{*}{$\begin{array}{l}\text { SNACK KS-1 } \\
\text { PLAY KS-2 }\end{array}$} & \multirow{5}{*}{$\begin{array}{l}\text { SNACK KS-2 } \\
\text { PLAY KS-1 }\end{array}$} & Maths & ICT & Science & $\mathrm{s}$ & Arabic \\
\hline MON & & English & Islam & & & Maths & PSHE & Science & A & Arabic \\
\hline TUE & & English & Islam & & & Maths & Quran & Hum & L & Arabic \\
\hline WED & & English & Science & & & Maths & Library & Art & A & Arabic \\
\hline THU & & Quran & English & & & Maths & English & P.E & $\begin{array}{lll}T \\
T\end{array}$ & Arabic \\
\hline
\end{tabular}

Figure 5.2 Copy of the weekly time table for grade 4-3

This timetable is an example of how the subjects are distributed in the weekly programme. It can be seen that most subjects such as: mathematics, science, humanities, PSHE, Art, IT, as well as English as a subject were taught using English as a medium of instruction. Arabic, Islamic studies and Quran were taught in Arabic. It was unclear from these documents whether PE was taught in English or Arabic. It should also be noted that this school introduces the L2 simultaneously with the L1 literacy from the lowest levels (kindergarten 1 at 3 years old).

It was important to include the weekly teaching plans because they formed an important component of how the school organized its bilingual program. A weekly plan, exemplified by the extract in Figure 5.2, is a one page per day schedule that is pre-designed by the school management. For each day there are six columns under the headings: key vocabulary, lesson objectives, main activities, homework, and dialogue practice listening and resources. The use of weekly and daily plans reflects a mechanistic model of organizing the school (Davidson and Tesh, 1997). 


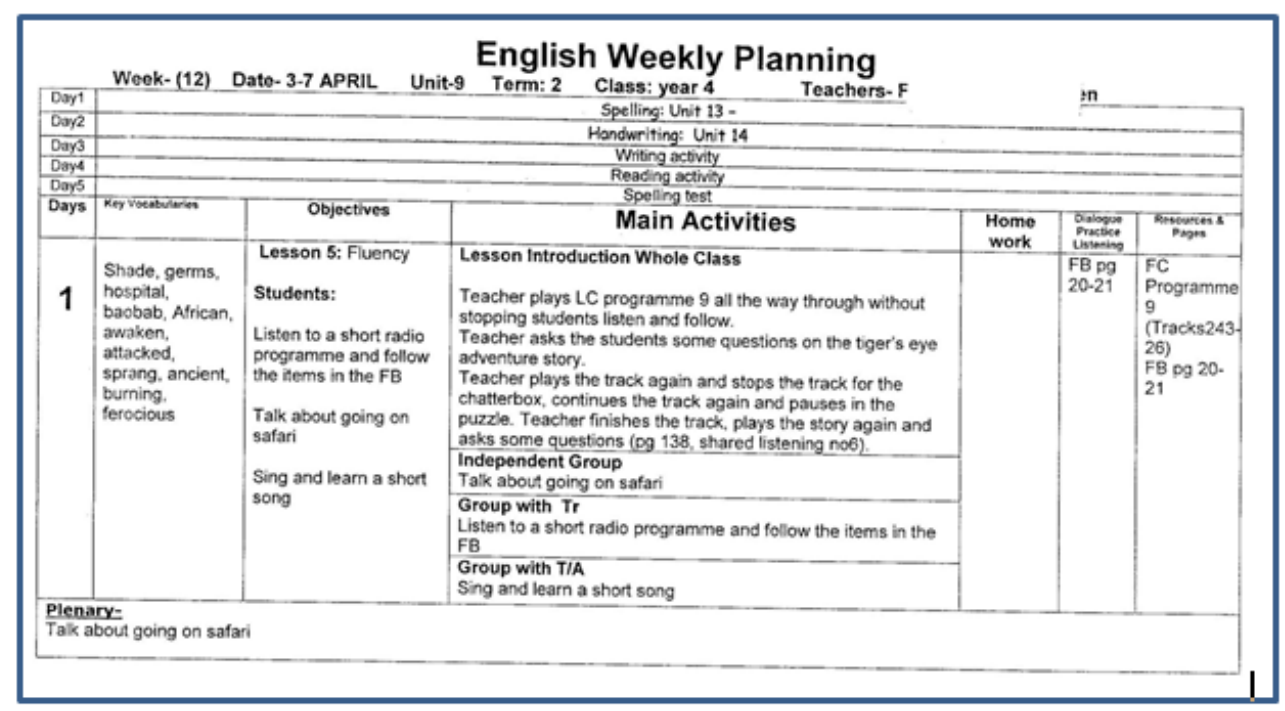

Figure 5.3 Extract from English weekly plan

Because the teachers were given a pre-devised plan and the books and materials were provided by the school administration, a bureaucratic approach that stressed authority, hierarchy, and control was highlighted. Teachers were not only provided with a course curriculum but also with a daily syllabus plan indicating which pages should be covered and which exercises to include. The weekly plan for grade four included a division of the main activities of the lesson into (a) whole class activities and (b) independent group activities. Some activities are performed as a whole class and others in independent groups, with teachers or teaching assistants. The plan also included many opportunities for speaking and group discussions indicating an emphasis on co-operative learning and the importance of output and interaction. The English weekly plan was therefore in alignment with the school's advertised English instructional practice. It emphasized high quality language education and the use of a student-centred curriculum, incorporating group and collaborative work.

The format of the Arabic weekly plans was similar to the English. They were divided in the same manner, providing details of lesson objectives, activities, homework and teaching aids; 
however, the Arabic teaching plan did not provide key vocabulary, as exemplified by the plan in Table 5.2 (a translation of the original plan in Arabic about 'family')

\section{Table 5.2 Translated Arabic lesson plan}

\section{Main objectives}

At the end of the lesson students are expected to :

1. read the lesson silently and answer the questions

2. recognize what constitutes a 'family'

3. recount how Islam focuses on families and the roles of the wife, husband and children

4. recognize family values

5. explain the importance of keeping families together in Islam

6. deduct main ideas of the text

\section{Activities}

The students will read the text silently

The teacher asks some comprehension questions about the text

Teacher reads the text out loud and then choses one of the excellent students to read the lesson

Teacher asks students to identify the features of 'family'.

Teacher asks students to identify the ways in which Islam values families

Ask the students more comprehension questions

Ask students to repeat main ideas of the text

\section{Homework}

Copy the text

\section{Resources}

Pictures of happy families

Text book exercises

The Arabic teaching plans prescribed different instructional practices concentrating on higher teacher control and less student participation than in the English plans. 


\subsubsection{Interview responses}

The interview questions explored, among other themes, the perceptions of the participants with respect to the language separation policy in the school. Evidence from the interview data fed into an understanding of the organization of the bilingual programme and how the staff viewed and understood school policy and the structure of the programme. The evidence is presented in alignment with interview protocol (Appendix iv). Questions are listed on the right hand side, themes are presented in bold type, and the evidence (relevant quotations) is presented next to the interviewees' initials (pseudonyms).

Following the three axial category sequence used in the interview protocol (appendix iv) the same categories are used to group similar themed answers into a single set of responses. When other themes surfaced, another category was added. A separate analysis was conducted for English teachers and Arabic teachers. A cross-analysis was used to compare recurring themes across the two groups of teachers. The interview responses and evidence are displayed using a theme oriented table, (Appendix ix) that relates the three axes of the interview protocol, specifically (a) awareness and training according to school bilingual policy; (b) language choice behaviour; and (c) bilingual development practices outside the classroom.

Appendix i presents the ultimate themes that emerged from the interview data following a three axis category sequence. The responses of the teachers are subsequently presented, following the three axes of (1) awareness of school bilingual policy; (2) language choice behavior, and (3) Role of the teacher in the bilingual development practices. Within each axis, the responses of the English teachers are considered first, followed by the Arabic teachers. 


\subsubsection{Awareness of school bilingual policy}

One English teacher (HU) was eager to explain in chronological sequence every step of her experience of teaching in her own country and in Qatar, whereas the other teacher who did not have any teaching experience before arriving in Qatar only gave a brief description of her long teaching experience there. All three teachers did not talk at length about their qualifications since none had a teaching qualification other than their graduate and postgraduate academic qualifications. Aside from the subject coordinator guidance the school does not offer any type of professional development as was indicated by the teachers.

Teaching experience in the school was discussed in terms of 'culture and behaviour' of the students. One teacher (RU) perceived that:

"Since the mix of children that I have over here, they are mostly middle east kids. It's a good mix...Because when children from different countries, they come from different culture and with different culture it's also different on how they perceive their education. Children from certain countries have more serious parents, not serious parents, but their parents are more interested in their education, so they will push their children to be on top of the class all the time"

Then she continued:

"What I find a bit difficult, you know things I have to tackle... it's the children's behaviour" "I have a few students who do not take their studies seriously ...They are not into... its okay not to do their homework, it's ok for them to forget books... It is not a priority. They come to school unprepared"

Since the teacher comes from a different cultural background, she commented:

"But this is something like ...it's not something common; I mean I am not used to it." 
When the teachers were asked about the school policy, they answered that the school was an English school and stressed the importance of a text book approach. Their comments concurred with the school formal documents about the emphasis on a textbook approach; however, no reference was made to a formal published policy document, a school meeting, or a school circulation of rules. For example:

“.. Ok the policy here is mainly you have to speak English all the time during the... especially in English lessons” (HU)

“..I think we have a good approach. Um... the thing that I like about the school approach is the textbooks that we're using, it's Macmillan, and they're using these textbooks that are geared for non-native speakers.”(RU)

The extent to which the teachers related to their understanding of the school policy in their own teaching was apparent by their statements that they opt for strictly L2:

“Because I don't speak Arabic, so I speak to them in English, and they are required ... of course they have to answer to me in English. Being an English school, as a class teacher I sit with them during break. So during break they tend to talk to each other in their own language, which is Arabic over here. And I always correct them, because I told them you get to speak Arabic at home with your parents, with your family, and you get to ... and we have Koran lesson, Arabic lesson every day, an Islamic lesson ... Arabic and Islamic every day ... so it's like ... you have enough practice of that language. So when I'm with them I require them to speak in English. Even during break. The only time that I can't control them is when they play outside, because they're with their friends and ... you know. “(RU) 
We notice how this teacher 'corrects' her students language choice almost perceiving using Arabic (their first language) as an 'error' to be corrected. Keeping languages separate is the norm and any deviation is regarded as a mistake. The other English teacher data (NA) indicated that she held the same beliefs about the importance of the 'English only policy'. The teacher who spoke Arabic stated that she rarely used code-switching to the L1, only to clarify in extreme circumstances, or for discipline...

When the interview questions explored how the policy or school rules were communicated to the students and how the teachers dealt with children referring back to their L1 the answers were varied between 'rules implied' and 'rules explained'. One teacher (RU) said that she explained the rules of the class in the beginning of the school year, including the rule that they should speak with her and the rest of the class in English only. The rules she reported are not written but communicated verbally. The other two teachers reported that the students understood that they should only use English. For example, one teacher stated:

$$
\text { “They know ...they understand” (HU) }
$$

Unlike the English language teachers, the Arabic language teachers presented very few comments on their experience in the school. The two Arabic teachers displayed opposing views on the policy and of their teaching practice.

One teacher (AM) reported how she was unsure if the children would acquire equally strong skills in the two languages, stating:

"But in a school that teaches English and Arabic, students will not be proficient in Arabic” (AM)

She elaborated on this view continuously throughout the interview noting the lack in time and resources for the development of Arabic skills, as follows: 
"We would be fooling ourselves if we said that a child will acquire both languages proficiently, No. because Arabic is taught once a day .Arabic needs more time, we have reading skills, writing, poetry, grammar, and various language exercises... I mean even today's lesson I could have given it in more elaboration, but we have to rush because of the weekly plan and the curriculum, so one lesson a day is not enough... and the students studies are all done using English so when we come to the Arabic..[Shakes her head in disapproval] (AM)

"We do not have listening material, no CDs, Arabic needs more care"(AM)

The second Arabic teacher presented an opposing view. She emphasised the role of the teacher in developing the Arabic linguistics skills of the students, stating:

"Basically the teacher is obliged as a teacher and it is her duty in front of Allah before anything else, because I am an Arabic teacher” (JA)

Both teachers acknowledged the role of the teacher in instilling an appreciation of Arabic in a predominantly English speaking school, for example:

“Now I am happy because in grades 5 and 6 they are starting to like Arabic, I am happy because at the start of the year they came very weak in Arabic, and today I gave them an oral task and they were excellent. I felt they enjoyed it” (AM)

When asked about how they related to their understanding of the school policy in their own teaching they responded in ways that matched their initial views about the policy. One teacher reported that she opts for a strictly MSA and "forbids" her students from using their colloquial dialect, as follows: 
"I forbid them to speak anything but Standard Arabic inside the classroom. Whether they know how or not, any student that doesn't know how I tell them try, try once, twice and again , and any one of us as a matter of fact makes mistakes, and now they find it natural"(JA)

She reported that by this time of year all students are used to addressing her and speaking to each other in MSA. This teacher's enthusiasm was apparent in her choice of words such as 'I forbid' and 'it is a crime against the child', as well as the pride in her accomplishments when she concluded:

"[Now] they got used to speaking in standard Arabic. I mean for a child in the third and fourth grade to speak in standard Arabic, I mean not an easy thing.”

The second teacher reported that she speaks MSA most of the time with some code-switching to the colloquial dialect of Qatari for clarifications and to explain difficult concepts. She also reported that she allows the students to speak in their own dialect. She related how it's difficult for them to gain proficient skills in Arabic to be able to read and understand the texts and completes the required tasks, as follows:

"If I oblige them to speak only in MSA no one will answer... Their language is almost English. I am happy that they do the tasks correctly, if I ask them to speak in MSA... No that will be too difficult for them"

It was evident that the two Arabic language teachers had opposing views on the use of MSA in classroom interaction from 'successful use', to 'too difficult to use'. One teacher's responses indicate using ‘flexible language choices’ opting for purposive code-switching, but approves of random mixing from the students.

The academic vice-principal also spoke with ambivalence about the school bilingual policy. In the following interview extract, she stressed the importance of communication first and English second, and the importance of instilling Arabic, as follows: 
“Okay, we're an English school so ... (interruption) because we're an English school we focus firstly mainly on the English, so we try and keep the communication more English. But because of our children being Arabic from their homes, we try and promote as much Arabic communication as possible in an English school. So it's almost bilingual, okay, because we just encourage communication as much as we can. And some children will not communicate if it has to be English all the time. So communication is the first objective, and then we try to encourage the English, but we also encourage the Arabic where the English is maybe lacking. And also for the home ... you know the home language to still keep that instilled in them.” ACA V.P.

\subsubsection{Language choice behaviour}

Themes elicited within this category about teachers' own behaviour in the classroom were in line with the findings from the first category. The English teachers all agreed that they applied a strict separation policy in their classrooms with rare use of L1:

“No. Because I think if you are teaching English you should stick to English. I think it is faster for the children to pick up on languages if you have a pure ... a person who doesn't speak Arabic.”(RU)

“I mean 99\% I don't use Arabic during the class” (HU)

One English teacher (HU) said that she uses Arabic only for explaining very difficult concepts which cannot be conveyed by other means, or for discipline. The answers of Teacher NA were short as she appeared to be intimidated that I was interrogating her, regardless of my constant assurance. Consequently, most of the quotations are taken from the other teachers. Her answers were in line with the other teachers nonetheless. 
Themes concerning the Arabic teachers' language choices and behaviour were in line with findings about their awareness and understanding of the school policy. One teacher (JA) maintained that she strictly used MSA in her own teaching, not her own dialect, as follows:

I So you do not use your own dialect?

$R \quad$ of course not. This is a huge crime and a violation of the child right because in this age they acquire it naturally not knowing if this is a specific vernacular or MSA. I believe that it is best that the teacher speaks SA because we are teaching SA.

This teacher concluded that:

"The Arabic language should be taught and spoken in SA"

The other teacher commented on falling back to code-switching for explaining difficult concepts, for example:

"There are vocabulary terms that from time to time I use their dialect” (AM)

She elaborated about code-switching after reading the main text in MSA and explained that was important to relate the lesson in their dialect to facilitate understanding:

"I was explaining Islamic family values to their level of understanding because the text... can be above their level, but if you explain it in their dialect they... they understand” (AM)

\subsubsection{Role of the teacher in the bilingual development practices}

This category explored other programs that the school offered for developing bilingual skills and how the teachers were involved in these practices. The teachers talked about the extracurricular activities offered by the school. These included origami, clay, gardening, speech and acting clubs. The teacher also reported that they were involved in the library sessions as 
well. The teachers viewed these as supportive of teaching English since English was used as the medium of instruction in these sessions. Their responses were:

"It's an English lesson in its own, because we have to give instruction in English, and they have to follow our instruction. “ (RU)

"I also did speech and acting activities ...helping students write their own words and say them out loud one way or another" (NA)

“Having fun... pleasurable activity, knowing steps... but mostly in speech and acting they gained English skills” (NA)

There were no Arabic extra-curricular activities (conducted out of school hours), however the Arabic teachers talked about their involvement in the library session which is part of the weekly program given every other week. One teacher was eager to explicate her self-initiated Arabic typing activity. She talked in reference to her pride in students work and parent initial objection and later appreciation of her efforts, as follows:

"Kids these days know how to type in English because of the technology... my own kids do not know how to type in Arabic.so I send tasks to be typed as homework. At first mothers were complaining now they thank me.”(AM)

Another teacher also referred to her personal efforts in promoting reading skills since library sessions this year were less than last year. She therefore encouraged the children to borrow books on their own and read them. Their efforts were rewarded in the rewards chart. The teachers also talked about their involvement with the book fair and their wall displays titled 'my favourite book'. The teachers expressed that these activities were important in developing Arabic language skills. 


\subsubsection{Summary of interview responses}

Analysis of the interview responses led to the following conclusions (a) English teachers have some awareness of the bilingual policy of the school but with no training on policy implementation; (b) Teachers view their language choice as one of strict separation of L1 and L2 characterized by minimal code-switching (code-switching is only permitted to clarify difficult concepts); (c) English teachers emphasise the role of course material, reading and library sessions; and (d) English teachers also believe that extra activities aim at developing language skills in a pleasurable atmosphere, with adequate extra-support for the development of the L2. The same protocol was used with the Arabic language teacher as with English language teachers. The findings from tabulating the data indicate the following (a) There is great variability in how the teachers understanding of the school policy towards bilingual education and the role of Arabic; (b) Teachers have little awareness of the school policy and report no training in this area (c) Their language choice behaviour range from strict use of MSA to flexible use of SA and the Qatari Dialect.

\subsection{Summary of the organization of the bilingual programme}

Information about the organization of the bilingual programme was procured by means of a questionnaire, school documents, interviews with language teachers and the academic vice principal. The following is a summary of the findings:

Analysis of school published documents presented three main themes: (a) The linguistic goals of the school as an English school interested in achieving native-like skills without forgetting the needs of the students as second language learners. (b) The educational goals concentrated on learner-centeredness aspiring to develop all aspects of the child, including academic excellence through use of internationally standardized resources and highly qualified teachers. The educational atmosphere was one of fun and enjoyment which appears in the 
content and graphics of these documents. The school also projects a contemporary atmosphere. (c) The school projects a strong Islamic identity that respects cultural plurality with a stress on social involvement.

The school maintained a language allocation of about 70\% English and 30\% Arabic. There was a subject-determined strict separation of the two languages promoting a monoglossic bilingual education. Literacy in the two languages was introduced simultaneously. Most of the English language teachers were not bilingual in English and Arabic, but spoke English and their own mother tongue. Only a few teachers spoke Arabic because it was their L1. Few teachers had qualifications in education but were qualified in other specialties. The school did not offer any special training or professional development opportunities to the teachers.

There was no orientation or policy document defining the bilingual policy of the school, and no clear verbalization of the school policy from the administration to the teachers, or from the teachers to the students. There was a limited verbal presence of a policy statement stipulating the use of the first language in the school grounds. There was also limited verbalization of the school policy towards the second language goals. Some teachers communicated their understanding of the policy to the students explicitly, others communicate it implicitly. The academic vice principal communicated a clear policy regarding teaching and use of the first and second language. However, it is unclear whether this was a school-wide adopted policy set by the school founders or the vice-principal's personal understanding of what the policy is. There was no comment on Arabic language teaching policies and standards.

Both English and Arabic teachers reported that they apply strict separation of the L1/L2 and MSA/CA in their teachings indicating the importance of speaking and using the target language only to achieve proficiency in that language. This view was opposed by one teacher who allowed students to speak their own Qatari dialect and referred to CA herself 
occasionally to clarify difficult concepts. Her reported purposive code-switching and the students random mixing present a view of flexible language use opposing the strictly L1 view. The teachers also reported different policy assumptions about communicating rules to the students from implied to directly communicated.

The daily and weekly plans projected the schools mechanistic model of administration. The plans stressed group work, interaction, collaborative learning and the use of teaching assistants. The extent of how these findings are practiced in the classroom and around the school will be evident after analysis of the implementation data in the subsequent sections.

\subsection{Implementation of the bilingual programme}

The following sections describe the application and practice elements of the bilingual programme following the descriptive framework. The implementation of the bilingual program is explored within two areas (a) classroom practice and (b) other out-of-class activities and programs. The classroom observations are analysed separately for English and Arabic lessons. Information is also included regarding the course materials and resources used in these lessons.

\subsection{Observations in English language classes}

The analysis generated from the classroom interaction data cards was used to obtain findings concerning four areas: communication mode, student and teacher language choice, student grouping and instructional practice most used. The first three are important in the description of the programme; however, the analysis of instructional practice dominates this section. The classroom observations provided most of the evidence to compare how the school advertised and organized the bilingual programme against what was implemented in practice. 


\subsubsection{Language Choice}

Analysis of the language choice in 20 lessons revealed that strict separation of English and Arabic was performed almost 99\% of the time. Students used more Arabic than teachers especially when assisting each other or asking for clarifications. Code-switching rarely occurred, except when the teacher tried to explain a difficult English term or concept. The remaining code-switches were done either for disciplinary acts, socializing and other nonacademic activities such as taking the attendance. It was illuminating to observe the teachers' use of English. They rarely relied on Arabic, even when it was easier to code-switch to give input and clarify content and task procedures. I reflected on this in the field notes querying whether this was a display put on only for me as a researcher; however, I considered that this type of reactivity to the presence of a researcher (commonly known as the Hawthorne effect) could not be maintained consistently for 8 weeks of observations. It was difficult for the teachers to react abnormally for such a long period of time.

An example is provided of how one teacher referred to Arabic translation asking the children for the Arabic word for plan since this teacher does not speak Arabic. In this session teacher RU was eliciting answers about a writing task where she was doing a whole class activity to write notes in the form of phrases on the board that describe pictures in the students workbook where later these notes will be joined to make a story:

T(21:50) No. It's just... plan. You're planning for something. Okay right. So what do you say... do you know the word 'plan'... what do you call plan in Arabic? When you plan for something? Go home, find out and then Sunday come and tell me. Right.

$P \quad$ Come and tell (inaudible) 
Yes. On Sunday, come and tell me and I'll find out. Because I don't know what it's called in Arabic but I want to know. So on Sunday I can Google, you can Google, it's a learning process... if I tell you, you won't learn... you go home, find out, ask your mum, ask your dad, ask the computer, ask the dictionary... and the first person to come and tell me the correct answer will earn a point... two points. Not for the group, for you... for you and for the group, right. Section 2. Mariam... oh you be quiet... yes.

In most observations students used slightly more Arabic than the teacher, mostly to each other. The teacher mentioned the word scarecrow as she was talking about the movie 'Wizard of Oz’. One student asks:

23 S: Teacher what the meaning of scarecrow?

24 S: Fazza'a, Fazza'a, Fazza'a, Fazza'a, Fazza'a, Fazza'a, Miss Fazza'a (Arabic for scarecrow)

25 Teacher doesn't comment and continues her explanation...

The student was saying the Arabic word for scarecrow to his friend seven times with the other student paying attention to the teacher who was explaining the rest of the input until finally he turned to look at his friend. The teacher was watching but did not comment. This was not a frequent activity, but it occurred at least once during every lesson. The teacher often ignored Arabic communication without reproach which does reflect the separation policy of the L1 and L2 in this school. This was typical of all the observation data.

\subsubsection{Communication mode}

Most of the time, the students were engaged in listening to directions, demonstrations and input from the teacher as $32 \%$ of teaching events were coded as oral, where students were listening to the teacher or audio materials (Figure 5.4). The other frequently observed 
communication mode (30\%) was writing; either copying from the board, writing dictated material or answering exercises in their text books or task sheets.

Figure 5.4 Communication Modes Used in English Classes

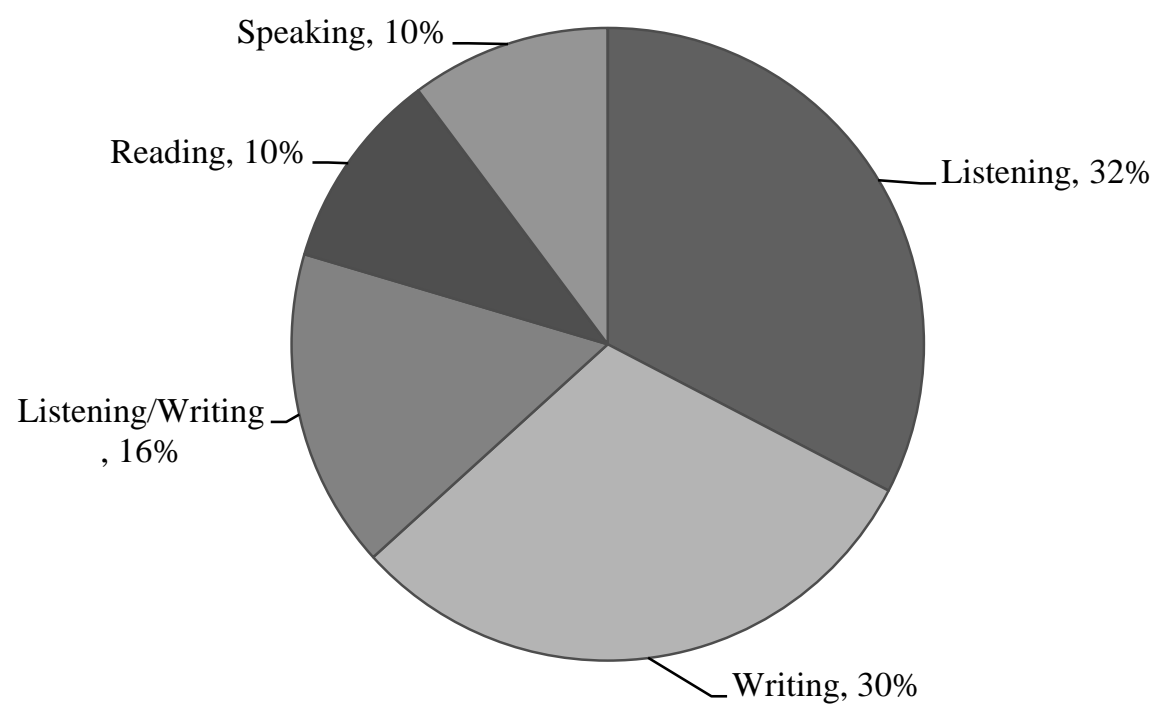

In $16 \%$ of the events students were observed to be engaging in a combination of listening and writing mode. This was not part of the original code book. However the events that contained this attribute were coded as AU/WR. This type of communication was observed in $16 \%$ of 
the events. The other two communication modes of reading aloud or individually and speaking were used sparingly (10\% verbal communication and $10 \%$ reading).

\subsubsection{Grouping}

The classroom observations included inspection of physical grouping during the defined teaching events as well as grouping according to tasks. The frequency distribution (Figure 5.5) indicated that almost $60 \%$ of tasks and teaching events were performed in a whole class manner. Thirty-five per cent of the events and related tasks were conducted individually (each child working alone on the same task). Only about 5\% of the events utilized a grouping method, involving five or more students, for performing tasks or following teaching events.

\section{Figure 5.5 Grouping of Students in English Classes}

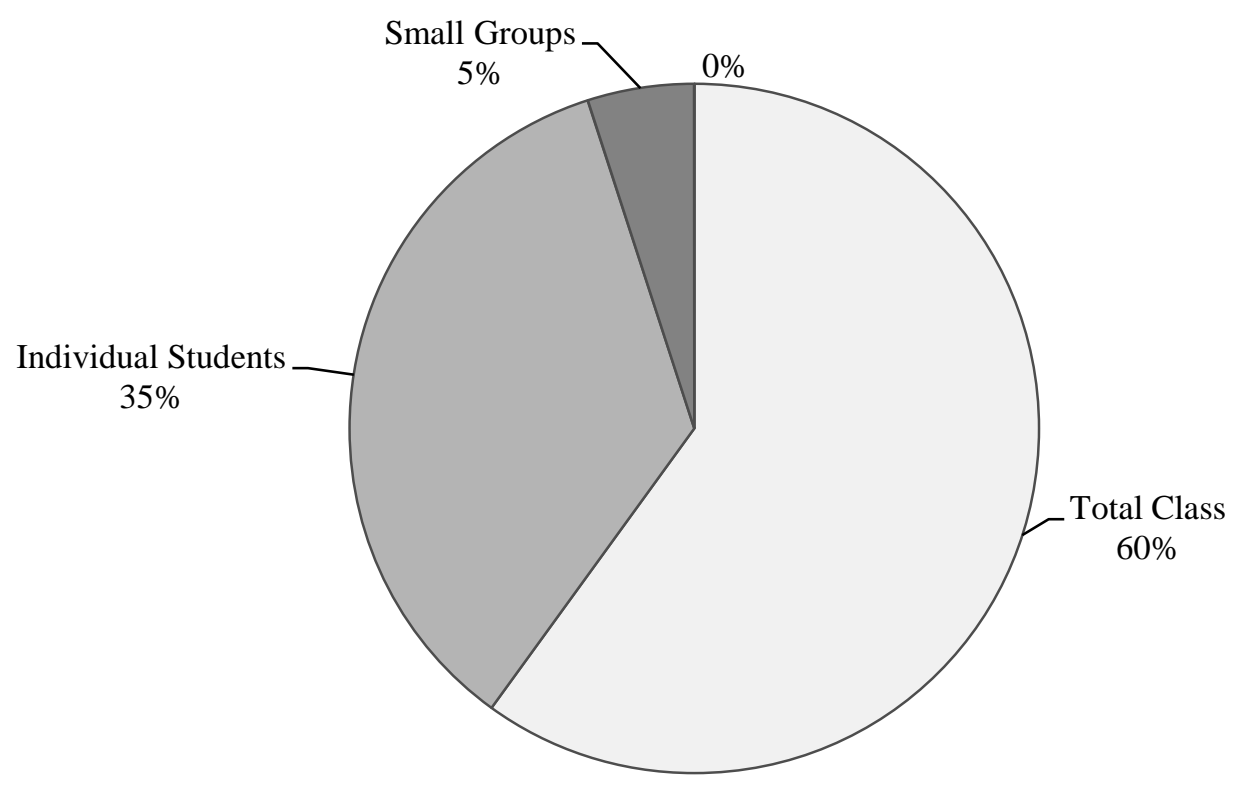

The students were arranged either in groups of four (Figure 5.6) or in pairs (Figure 5.7) in the classroom; however, the teachers usually taught the whole class, or the students worked 
alone. The grouping of the students according to tasks was not in line with their physical grouping in the classroom, nor with the designated grouping in weekly plans.

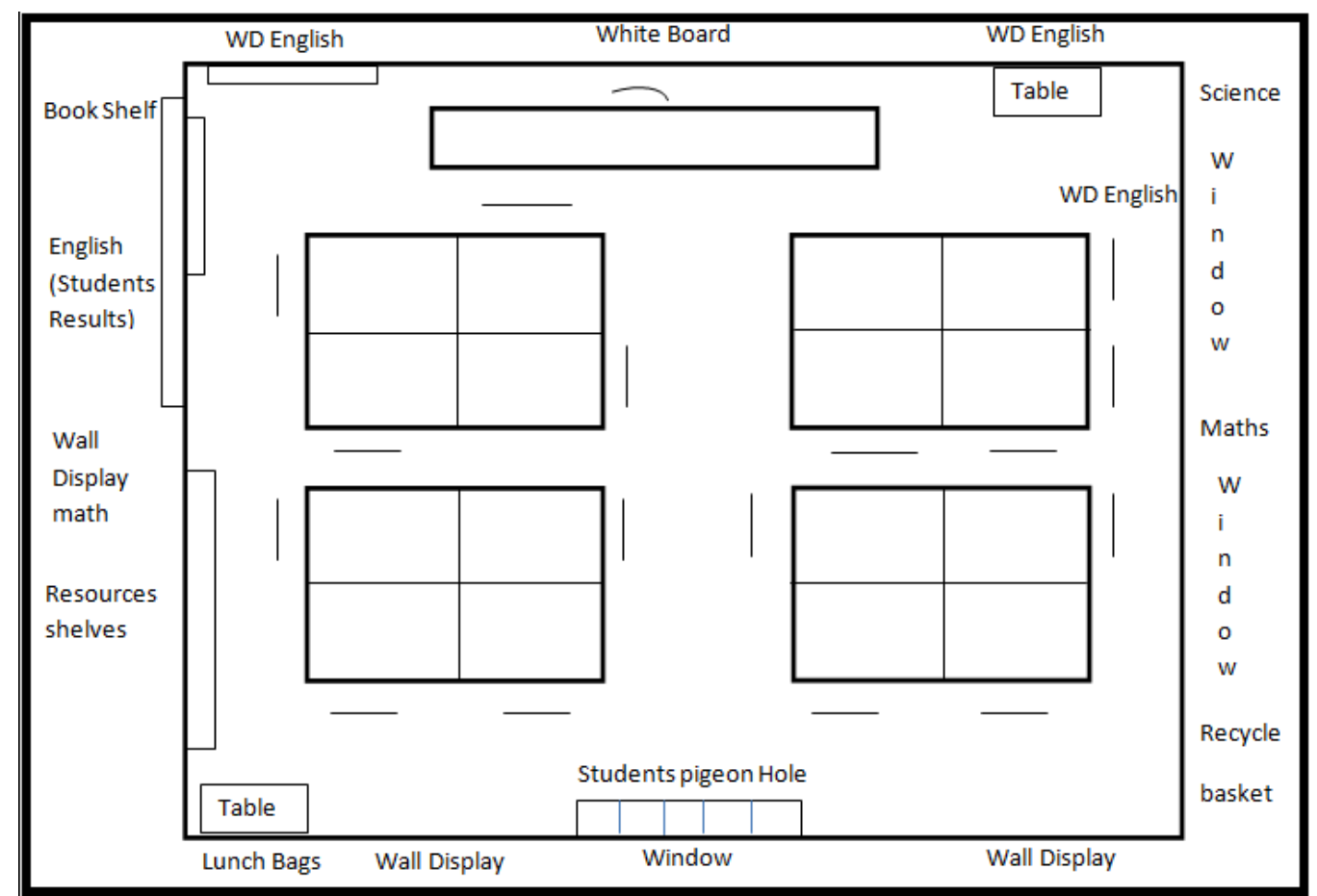

Figure 5.6 year four - form 1 classroom diagram (groups of four)

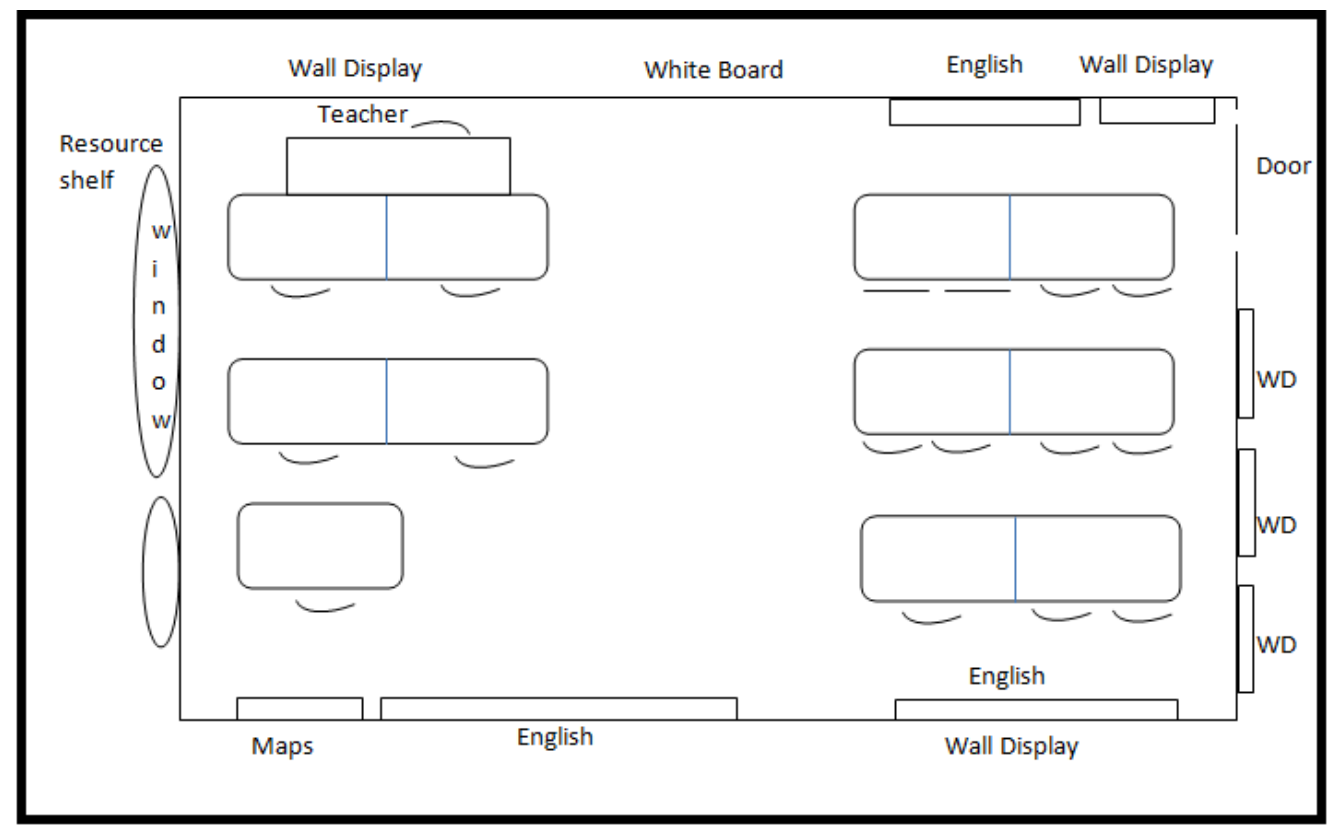

Figure 5.7 Year four- form 2 classroom diagram (pairs) 


\subsubsection{Instructional practices}

Table 5.3 presents the frequency of use of different instructional practice as observed in the classes, based on the sum of the practices of three teachers.

Table 5.3 Frequency of use of instructional practices used in English classes

\begin{tabular}{l|c|c|c|c}
\hline Practice & High & Moderate & Infrequent & None \\
\hline IRF sequence & $\mathrm{X}$ & & & \\
Focus on academic language & & & & $\mathrm{X}$ \\
Use of co-operative learning & & & $\mathrm{X}$ & \\
Use of high relevance material & & & $\mathrm{X}$ & \\
Highly cognitive content & $\mathrm{X}$ & & & \\
Explicit grammar teaching & $\mathrm{X}$ & & & \\
Explicit focus on vocabulary & $\mathrm{X}$ & & & \\
Scaffolding & $\mathrm{X}$ & & & \\
- Establishing routines & & & $\mathrm{X}$ & \\
- Contextualization (teaching aids) $\quad$ Modelling & & $\mathrm{X}$ & & $\mathrm{X}$ \\
- Bridging & & & & \\
- Multiplicity & $\mathrm{X}$ & & & \\
Rote learning & & & $\mathrm{X}$ & \\
Evaluation & & & \\
\hline
\end{tabular}

The teachers were given a pre-devised teaching plan and books and materials are provided by the school administration, following what can be termed a mechanistic model according to Davidson and Tesh (1997). Such model is described as a 'bureaucratic' approach that stresses the need for authority hierarchy and control providing teachers not only with a course curriculum but also with a daily syllabus plan indicating which pages to be covered and which exercises to include. Consequently, there was little variability in practices across the three teachers. It was a school practice rather than the teachers' practice. Thus, Table 5.3 displays a pattern of distribution that was typical of all teachers’ practice (Erickson, 2001). In the following each of these practices will be described in relation to the raw data. 


\subsubsection{IRF sequence in classroom interaction:}

The IRF sequence was first identified within applied linguistics by Sinclair and Coulthard (1975) as the most identifiable 'teaching exchange' in their account of classroom discourse. They identified a three move exchange involving an 'initiation move' followed by a 'responding move' and a 'follow up move'. According to Ellis (1994) this became known as the IRF sequence. The system was not developed for language lessons; however it fitted well in SLA. Ellis (ibid) also stresses that this structure is only likely to arise in classroom discourse which is highly teacher-controlled which is the case of the current classroom as the discussion in the case summary reveals. On the other hand Interactive instruction as defined by Lara-Alieco and Parker (1994) is 'teaching with active students responding typical of direct instruction where the teacher models, leads, tests students and where students perform or orally respond to questions as an integral part of instruction'. In such interactive instruction an exchange of turns (either voluntary or by teacher's choice) and a sort of negotiation of meaning is taking place. This interaction and negotiation of meaning are important components of second Language instruction as mostly facilitative of acquisition (Ellis, 2003) which are also characteristic of task-based pedagogy (ibid).

Accordingly, the coded data were searched for evidence of interactive teaching focusing on student-teacher interaction or student-student interaction Most utterances (64.2\%). were coded as teacher asks/ students answer (ASK/ANS). Teacher lectures students listen (LEC/LIS) occurred in a significant portion of communication modes suggesting conversation and discussion. The utterances were lacking with respect to students discovering teacher evaluates, (EV/DIS), or students perform teacher evaluates (EV/PER). This also ties in with evidence from the communication mode mostly used in the previous section. Students were mostly engaged in writing or listening. This may lead one to speculate that students were passive listeners or respondents to teachers' questions. Consequently the 
interaction evident from all three teachers' data in all lessons and teaching events, can be described as mostly using an IRF sequence of initiation-response-feedback (Cazden, 1988), or initiation-response-evaluation (IRE). These were the most common type of interaction observed in the data. This sequence have often been criticised (see for example Hall and Welsh, 2002) as unproductive for most of the time since the interaction is used to elicit answers that the teacher is expecting rather than a tool for substantive conversation in productive pedagogy.

The following extract provides an example of using IRF. At the beginning of an English lesson I observed the students sitting in groups of three facing the teacher who was standing at the white board pointing to the vocabulary items which she had previously written. The topic was compound words. The teacher was trying to elicit answers about the language items after explaining what compound nouns are. The interaction in this extract is typical of IRF routine, which was observed in many lessons:

T(00:52) Okay boys, today's unit is compound words. Do you know what's the meaning of compound words? Compound words are words divided into two words. Okay? For example if we say 'football' - you will see that it is divided into two words - foot and ball. And together they are a compound word. Why compound word? - because it has two words in it.

P Miss, background.

T (1:38) Yes, like background. Can you give me more examples?

P Paintbrush.

T Paintbrush, what else?

P Toolbox.

(Several pupils speaking)

P Toolbox.

T Good answer all of you at the same time. Yes, Faysal. 


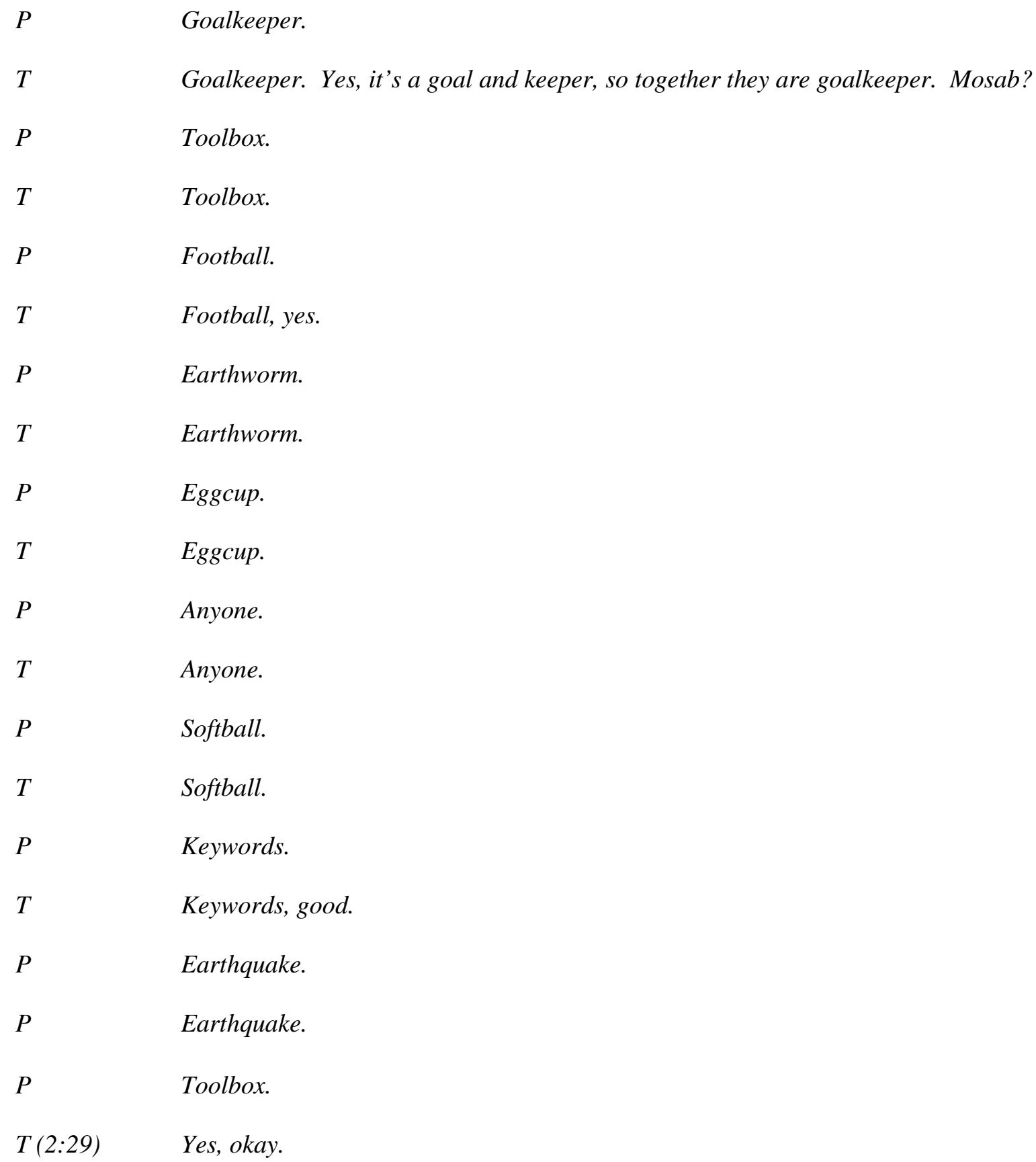

Although in this extract IRF was used for opening the lesson about compound nouns, it was typical of the classroom observations as a whole. Total class activities, even with written tasks, were performed with the teacher asking and the students answering, followed by the teacher providing positive or negative feedback. It is concluded that IRF was characteristic of all three teachers' instructional practice dominating most of the classroom interactions.

IRF sequence is linked with high teacher control. In addition the amount and type of teacher talk and student talk also determines who controls the class time (Foster, 1996). In the data 
teacher talk was mostly devoted to asking questions, lecturing and giving directions, whereas pupil talk was mostly devoted to responding to teacher talk and little pupil initiated talk. Teacher talk was substantially higher than pupil talk. This is evident in most observations and field notes. I found myself writing these comments on teacher control in various occasions. For example in the previous lesson I commented in the reading event:

'High teacher control with little chance for students' participation 'Obs. 4

Similarly in Obs. 2, event 2, the teacher was engaged in a reading event involving the whole class. She was sitting at the desk holding the book, facing herself, with the book cover facing the students

T: I will read a book for you... Football. The teacher reads the story aloud. It is a non-fiction information book about football. A student asks about the meaning of 'chest'. The teacher ignores his question so another student points at his own chest. The teacher keeps reading asking: do you understand? Teacher continues reading. In the middle she asks: why do your muscles get tired? A few students answer: because when you play you are tired so your muscles are tired if you play too much. The teacher agrees. A student starts to talk about his own experience playing football. Teacher says: we don't want to hear about your life story. Other students want to share their own experience but are dismissed by the teacher. The teacher continues reading the book. The book ends. Another student starts an anecdote but the teacher asks him to stop talking. Some other students ask questions of how can you stay healthy by playing football (what is the relation). The teacher answers at length giving little opportunity for student participation.

I noted that during the reading session the teacher often sat at her desk away from the students who were sitting at their groups and there was no chance to engage the students with the pictures. Mostly the teacher did the reading or chose one student to read. Other teachers engaged the students slightly more but with high control. 
I was in Ruby's class when she was doing a writing task that involved the whole class. I noted at the time that:

This teacher tries to give equal chances by asking: Who did not answer? Who was quiet? throughout the activity (Obs. 4, event 1 )

This particular teacher also rotated the groups weekly so the students who are sitting at the back would get a chance eventually to sit at the front of the class nearer to the whiteboard since the groups are arranged to face the board. However, the overall description reflected the most frequent of practices.

In relation to the interactive teaching it was observed that teachers offered little guidance on tasks after a whole class discussion. To illustrate further the following observation (Obs.2) students were directed to come up with phrases to make up a story using pictures as a prompt for the story events. This sort of exercise should elicit discussions and provide an opportunity for speaking and writing. The teacher however was discussing the exercise in a whole class manner and writing the phrases on the white board in note form. Later the students individually were asked to connect the phrases to make up a story.

Obs. 2 Event 3:

Then the students were to connect the phrases to make sentences and a story based on the notes they copied from the white board. I was going around the groups looking at the students work. Some students were doing ok, but many had no clue what to do to transform the notes into full sentences or whether this is what the teacher was asking them to do. They had no clue how to connect the phrases to make a story using connecters like: then, after that, finally, at the end, but and so on. The teacher did not model writing the sentences or did not even go around to check their work. She sat on her desk to correct some note books with her red pen. The student I was nearest to was a girl with some learning difficulty. 'She did not speak' the girl sat next to her told me. I was not sure of her disability 
but she seemed to 'refuse' to speak and not a mute. I sat next to her to look at her writing. She was copying the notes from the white board.

This sort of practice was common in most classes observed. The teachers will give input, briefly describe the activity and leave the students to complete the task independently. Here is another example in another class with teacher Hurria. One boy in this class had a muscular disability:

Obs. 7, event 3:

The teacher was giving guidance about the writing task while sitting at her desk. The students sitting at the front nearer to her desk benefitted most from this guidance. I went around the groups. I observed that many students didn't know what the task involved. Students with disability received no support. One boy had motor disability. He was scribbling the answers in large print across the page.

This was typical of the three teachers practice. Ruby is an active teacher; the following extract is taken from one of her lessons, where she bounced the questions between herself and the students, moved around a lot and wrote on the board providing some interaction in the classroom.

Obs.13

$T$

Please be with me, please pay attention. Yes, Dalia wait... you've had a go... (inaudible)

$P$

When Pete Sands hit her in her face she fainted. When she woke up she saw herself in the match.

$T \quad$ Ah, that's nice. Let's change the story, because all right you've been writing (inaudible) now I like this one.

$P \quad$ (inaudible)

T (26:59) Wait a second, Bana, be patient, wait wait. Can I say something, girls, I like this one. Somebody said she fainted, yes, in the third part, part 3, she fainted, and then she woke up and she found (inaudible) she's at the stadium. Where do people play the match? Where do you go for a tennis match? Which stadium? 
Several Pete Sands.

$T$

Signed by him. In tennis... do you know tennis game?

Several Yeah.

$T \quad$ Look... this is tennis but if you double, double... it's a double (inaudible) two people play on it. Pardon.

$P$

(inaudible)

$T$

Pardon?

$P$

Can I say something? It can be 10.

$T$

It can be?

$P$

10.

$T$

10.

Several No...

$T$

never.

P

This is the most. Go home and Google... and read about tennis. All right now... I want you to write this... for three minutes. Everybody write this story on the next page. When I write a capital letter you must write capital letter. Huh? You begin your sentence with a...?

P $\quad$ Capital...

T Capital... letter.

P Letter.

The teacher comments on her own teaching style as there was much commotion in the class since she was doing the talking and the writing students were not paying attention: learn from each other, this is a group work. I can let you write on your own, but I 
think you still need guidance, so we are doing this together... do you understand? Yes? All right. Nora, can you read a sentence paragraph again?

At the end of the interaction and the teaching event she instructs students to do the writing task and then she sits quietly at her desk correcting math notebooks.

\subsubsection{Focus on grammar}

Most lessons observed had a grammar focus in one of the teaching events of the lesson. In a lesson about volcanoes the focus was on grammar rather on the topic itself. The lesson was about joining two phrases using a 'conjunction'. In this event of the session the interaction becomes frustrating as the teacher discusses the questions with the students as a whole class; one question proves to be challenging:

Q9: Use the words below to make a sentence. Begin with the word written with a capital letter. Make the last word of your sentence 'town'

Italy buried once in A a volcano town

The students answer one by one with the teacher feedback only as 'no'. Only after eight attempts does student number nine answers correctly and the teacher completes the rest of the sentence. This type of initiation in the form of a question, response from students, and limited feedback is characteristic of the teaching approach used by the English language teachers in this school. In addition in grammar lessons the teacher gave directions before the task, with little demonstration or modelling and no evaluation. All explanation was oral and the teacher did not write on the board or go round to check answers.

In some instances the teachers performed smooth transition from the story reading event to the grammar topic. In this extract the teacher was finishing reading a story out loud to the whole class with the help of a student in their daily reading event. She ends with a question tag which is the focus of the grammar lesson in the next event: 
Here you are...

$P$

Here you are at last, Sid.

T (27:13) Here you are at last. Nice story isn't it?

Several Yes.

$T$

Is it or isn't it?

Several Yes.

$T$

Okay, so... now when I asked you...

$P$

$T$

A nice story.

It is a nice story, isn't it? So...

Several Yes.

$T$

This is called... (Teacher writes on the white board: Question Tag)

$P$

Question tag.

T (28:08) A question tag is a question, comes at the end of the sentence is like to... as if you are making sure that this sentence is correct. Again, question tag comes at the end of the sentence. Why it comes at the end of the sentence? - To make sure that the sentence is correct, or that you agree on the sentence. Like we did now... I am sure that the story is nice, but I want to make sure that it's nice. How can I do it? So I just ask a question tag, it's just a small question, okay, and it comes at the end of the sentence. And when the sentence is positive, the question tag comes in negative. What means positive? Positive that it's...

Table 5.3 (above) indicated that focus on grammar was one of the strongest practices used by teachers in all events of the 20 lessons attended. Figure 4.8 illustrates a grammar exercise done with the aid of the text book. Teachers explained, asked for repetition and copying of structures. Many exercises in the text book and task sheets focused on various grammatical forms. Focus on form is crucial in SLA and is of relevance and importance to a bilingual programme. 


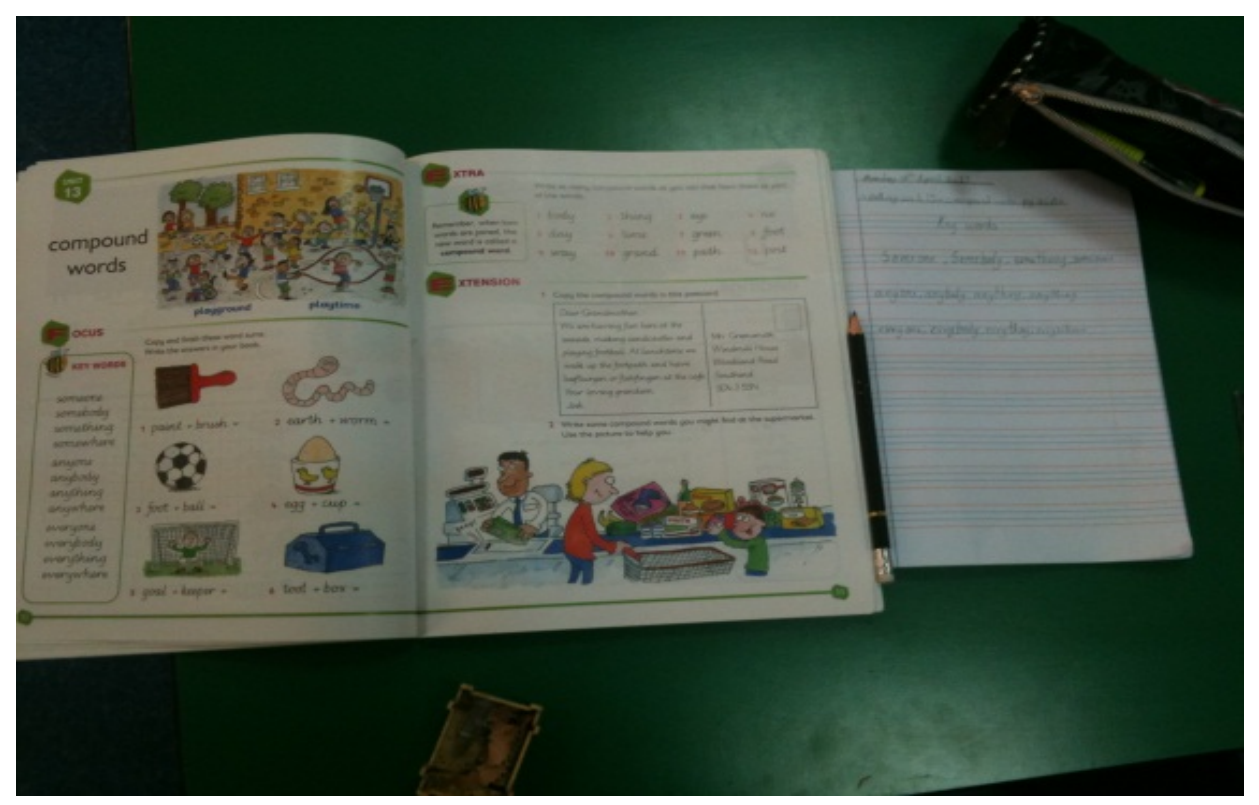

Figure 5.8 Grammar exercises from the text book

\subsubsection{Focus on vocabulary}

It was observed that explicit focus on vocabulary was a most common feature of the instructional practices used in year four classes in Salam school. Almost every lesson involved teaching of new vocabulary items which are written, copied, repeated orally, explained and later used for spelling tests. The picture (Figure 5.9), exemplifies how vocabulary is taught. In this lesson (Obs.1) the teacher wrote nine vocabulary items on the white board with their definitions. She explains the meaning of these in English, ask the students to repeat it out-loud as whole class, and copy it in their copy book. 


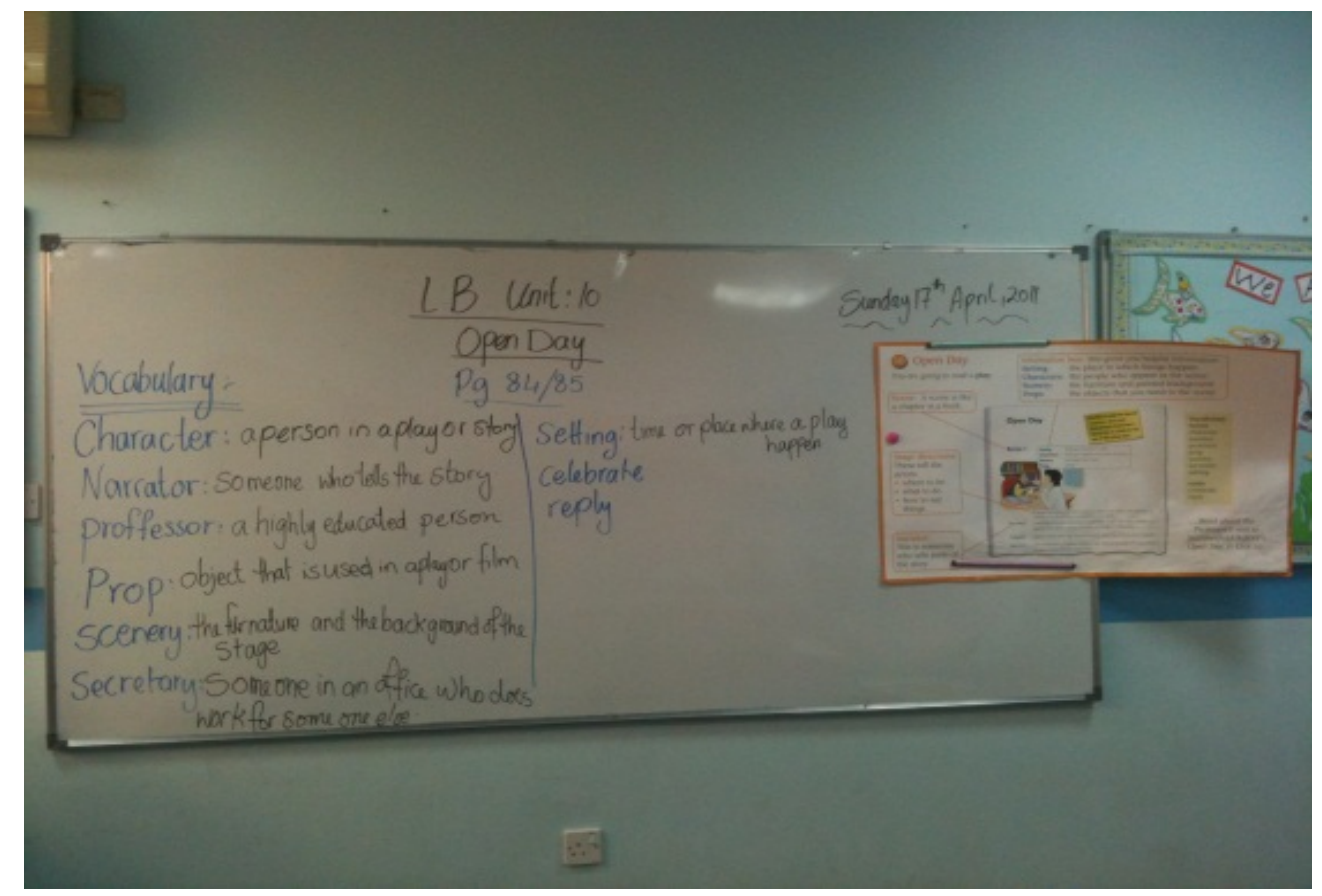

Figure 5.9 Focus on vocabulary

\subsubsection{Scaffolding structures}

Garcia (2009) lists five components of scaffolding structures in language education that I used to analyse the data. They are: establishing routines, contextualization, modelling, Bridging, and multiplicity.

It was observed that English language teachers established routines consistently throughout their classes. The teachers always began the lesson with a language focus session either in vocabulary, grammar, copying or handwriting practice; this was followed by a reading event. Stories are chosen from the class library. The teacher begins reading the story and sometimes chooses one student to finish. The lesson then begins from the text book. The students have spelling tests on certain days.

Contextualization in this analysis refers to the use of teaching aids. It was observed that the text book was rich in illustrative pictures which teachers used. The teachers used the white 
extensively as well as posters and CD's that accompanied the course material. In addition teachers used paraphrasing and body language to explain vocabulary items.

Modelling was observed to be infrequent. Teachers rarely modelled language structures, tasks and exercises. It can be noted from the rare code (DEM/LIS) where a teacher demonstrates a desired procedure, and the little evidence for (LED/PER) where the teacher leads the students through the desired tasks. It was observed in the previous section that teacher practice was lacking in this area as evident from observation data.

Bridging new and old knowledge was used moderately as a strategy in the observed classes. Teachers in some occasions used phrases such as:

"Do you remember when we did the Wizard of Oz play last term, we did not use any props" Obs.1. Event 2

Preview of previously studied material was not the only bridging strategy used. Teachers also relayed on students' knowledge of the world and own schemas to explain new vocabulary terms, and in writing tasks. We observed in the interaction analysis that teacher Ruby was doing a writing task with the whole class. In this same lesson the teacher was asking about tennis and asked the students if they know about tennis and asked about the Tennis and Squash Complex in Doha. All through this lesson she asked about several themes that relate to students own knowledge to elicit ideas for writing such as:

"What do you use if someone fainted to wake them up?"

Multiplicity refers to the use of multilevel tasks in the classroom pertaining to the different linguistic levels of the students. It was observed earlier in findings concerning classroom interaction that children with disability were left unattended. The use of this strategy was observed to be missing since in all lessons the tasks was the same for all students. 


\subsubsection{Rote Learning}

The concept 'rote learning' was used when coding the data to include all events in which oral whole class repetition of structures and vocabulary items, handwriting practice, memorization copying, and dictation are cited. It is acknowledged that this is a controversial term in pedagogies literature however in this project it refers to any practice that relies on memorization and repetition as a learning technique (Mayer, 2002).

The teachers demonstrated high focus on handwriting practice. The picture in Figure 5.10 shows how the teachers used the fluency book as a guide for copying cursive writing. Students usually copied a page at the beginning of every lesson. Additionally, teachers always used oral repetition of new vocabulary items and new grammatical structures. The copying of vocabulary items and grammatical structures was frequently observed as well as oral repetition.

There was high focus on activities of this type in all teaching events. Every session began with a copying activity or dictation of vocabulary items. Teachers go around and give a lot of feedback on penmanship and handwriting skills making sure that students write correctly.

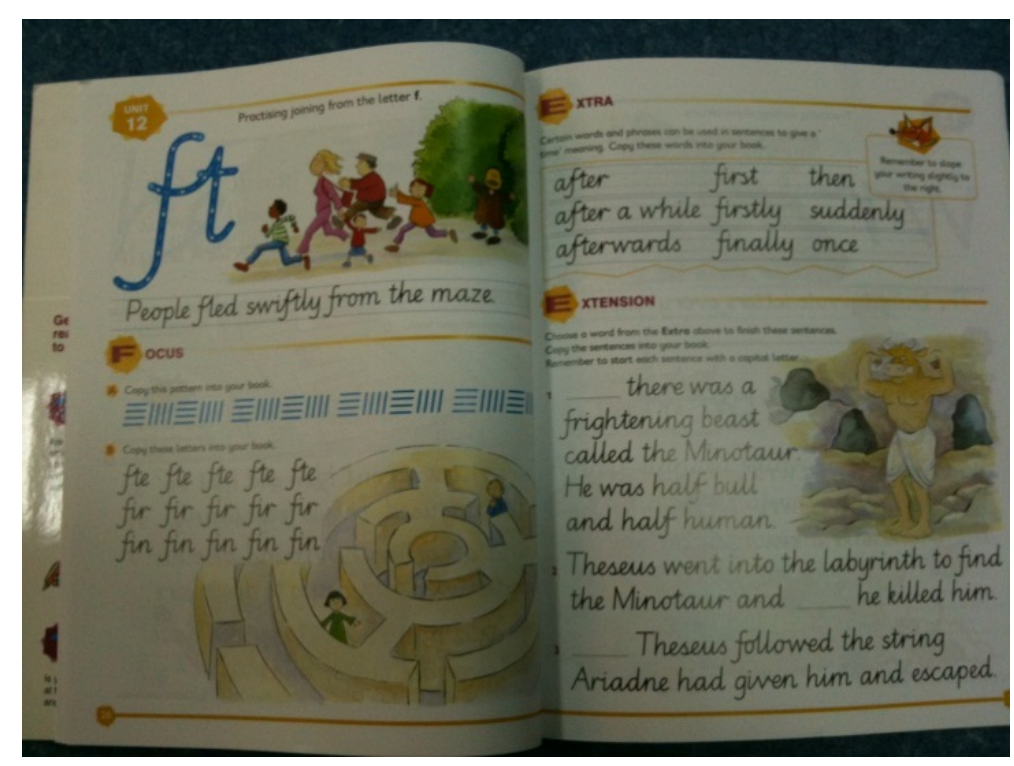

Figure 5.10 Fluency book 


\subsubsection{Highly Cognitive Material}

This item was created responding to Cummins (2002) pedagogical model which emphasises the importance of cognitively demanding content for optimal instruction in bilingual programs, offering content that is academically challenging. Although written input was used daily in the observed classes, the type of input was usually non-authentic low-cognitive material from the textbook. Only in one of the twenty lessons I attended could be considered dense cognitive content used. This session was about Volcanoes.

\subsubsection{Academic language}

The observations did not identify focus on academic language, difference between L1 and L2 in written genres, or language functions for various disciplines. There was no evidence of teaching vocabulary items related to other subjects students study using English, such as Math and Science. As identified in the literature review Cummins (2000) distinguishes between academic and conversational language proficiency stating that with bilingual children and within bilingual education arises the need to foster academic language explicitly using specific curricula such as the CALLA (Cognitive Academic Language Learning Approach). There was no evidence of using aspects of this approach in the lessons observed.

\subsubsection{High Relevance Material}

Books chosen were mainly western oriented stories such as 'Jack and the Bean Stalk' (Figure 5.11) and stories about dogs, wizard of $\mathrm{Oz}$ and so on. Only in two occasions was a story with an eastern reference used including 'The Ant and the Wheat Spike' where the boy in the story had an Arabic name. Almost all other books were western books. 


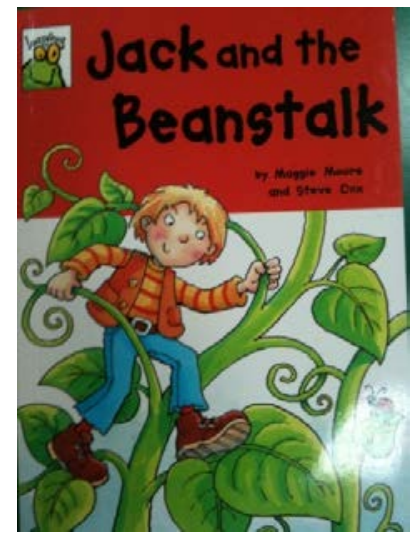

Figure 5.11 'Jack and the Bean Stalk’ cover.

In a few events teachers tried to engage the students in a discussion following an activity or story regarding the moral and trying to connect the story at hand with what they had read before. For example, after the teacher finished reading 'Jack and the Beanstalk' she started a brief conversation about an alternate ending of the story and whether the students read this version. This however did not elicit much discussion because the students seemed not to be familiar with the story.

\subsubsection{Co-operative learning}

Co-operative learning was found to be infrequent. Evidence from findings related to students grouping support this finding. Teachers presented the lessons in a whole class manner allowing for little opportunity for students to discuss and co-operate in finishing the tasks. There was no pair work and little evidence of guided tasks in small groups of six or less. Although the teachers used read-aloud as a reading strategy which is a technique in cooperative reading this technique did not stimulate any student support since the teacher was doing the reading in most of the evidence with a few exceptions.

\subsubsection{Evaluation}

There were very few utterances in the transcribed lessons and field notes coded as (EV/PER), (EV/COP), (EV/DIS) (code book, appendix ii). These involved the teacher overtly judging 
correctness or quality of students work giving further directives in tasks. Students in such codes would be cooperating, discovering or performing tasks. The lack of such codes leads to further examination of the data. The only feedback was the ones given during IRF sequence in whole class grouping. In written tasks students got very little feedback on their work and received little guidance on how to do the exercises or tasks.

\subsubsection{Summary of observations in English classrooms}

English classroom observation provided findings to populate the descriptive framework. Teachers implemented a separation policy of language and an L1 only strategy was used throughout the observations. Teachers very rarely relied on code switching. The communication modes were mainly listening or writing activities. The grouping was mainly the whole class or single students. Teachers occasionally grouped students in small groups of six or less.

With respect to instructional practice, there was a high focus on explicit grammar teaching, vocabulary learning using repetition and copying. Some scaffolding techniques were used such as bridging old and new information, as well as contextualization through use of audio material and posters. Interactive instruction characterized by IRF sequence was prevalent in the teaching of the three teachers. One teacher (HA) used more dense cognitive material whereas (RU) used more co-operative learning. Both teachers used these techniques only rarely. There was low occurrence of expressive language-related communication. It was observed that the teachers provided little opportunities for co-operative learning where students might be able to scaffold one another. There was low learner participation with little opportunities or techniques to elicit responses from a lot of learners.

In a related vein, I was surprised with one teacher's comment: 
Noor pay attention, yeah? Or you can sit at the back with Miss Fatma over there, she's lonely.

It seems that I was perceived as a punishment and therefore I will be used as a punishment!

L1- L2 differences between two languages that are typologically different (different scripts and directionality) such as Arabic and English were not indicated during the English classes I observed. This included print directionality, differences in orthography, grammar and stories and texts structures. The description of the instructional practices in this way does not ignore various contextual facts such as teacher training and the type of teaching and pedagogy knowledge they have. This area was described when interview analysis was carried out and will be connected with the teaching practice in the discussion chapter where further interpretations and explanations are presented.

\subsection{Observations of the Arabic language classrooms}

Arabic teachers refused to have classes recorded. I wrote observational notes for the ten

lessons I attended. Similar to the analysis of English classroom practice data, the analysis of Arabic classroom practice generated from the classroom interaction data cards was used to obtain findings concerning four areas: communication mode, student and teacher language choice, student grouping and instructional practice most used. Findings from this data source are slightly different than findings obtained from English classroom data.

\subsubsection{Language choice}

The classroom observations reflected variations of language of instruction between the teachers of Arabic. The students and teachers switched frequently between Modern Standard Arabic (MSA) and a Colloquial Arabic Dialect (CA) according to teachers and student nationality. Using the classification put forward in the BPDI, in most lessons teachers used 
MSA clarified by a colloquial dialect where the lesson input is given in MSA while explanation, instruction, clarifications and definitions were given in the Arabic dialect. This finding however is not consistent with all teachers as some used more colloquial Arabic than others and in some lessons more than others. The observations also revealed that one teacher used MSA strictly in the classroom; another used MSA with some CA and one teacher was almost translating the lesson from MSA to her own dialect (Iraqi) which is very close to the Arabic dialect used in the Arab Gulf region. This teacher used MSA for the lesson input where she was reading a passage from the text book titled 'family'. After reading each line she would look up to the students and explain the meaning of the line in CA. This engaged the students as all were listening to her input. The same technique was used in answering the exercises that followed the passage. This technique fits with what can be called: convergent mono-literate model of bi-literacy (Garcia, 2009) where the written language doesn’t match the language of instruction which is usually a dialect that is not written. The other two teachers used separation bi-literate model of bi-literacy where the language of instruction matches the language of the written text.

Students in all lessons observed followed the language choice of the teacher and used MSA when directed to use MSA and CA when the teacher used the CA or allowed its use. Evidence from the Analysis cards indicated that student's code switches served mainly two functions: Asking questions when they started to ask in MSA but could not finish the sentence, and clarifications about tasks from colleagues.

On reflection, I believe that the strict separation observed between Arabic and English in English classes and between MSA and the Qatari dialect in Arabic classes was not induced by highly disciplined students, but rather a consequence of the teachers' high control and the minimal chances students were offered to produce speech or contribute to classroom discussion. More often than not, students were engaged in teacher led IRF sequence. 
Alternatively, the students were engaged in individual silent reading, writing, copying, or listening activities, where strict discipline is inflected on them. The data revealed very few instances of classroom talk in the Qatari Dialect.

\subsubsection{Communication mode}

The Arabic teachers used similar communication modes to those observed in English classroom practice. Figure 5.12 illustrates that students were mostly engaged in aural (Au) communication where they were listening to the teacher. This was observed in $44 \%$ of events, next comes reading which took up $25 \%$ of students communication mode either reading aloud or silently. Verbal communication where the students were speaking either answering a question, discussing or asking a question took up $19 \%$ of the teaching events and writing took up $12 \%$ of type of communication mode used by the students. This draws a picture about the types of activities the students engaged in. This in turn, when connected with all other detail gathered about the classroom practice in Arabic lessons, describes the learning culture of the students and the context of their bi-literacy education within this school, this grade and as much as the case study can provide.

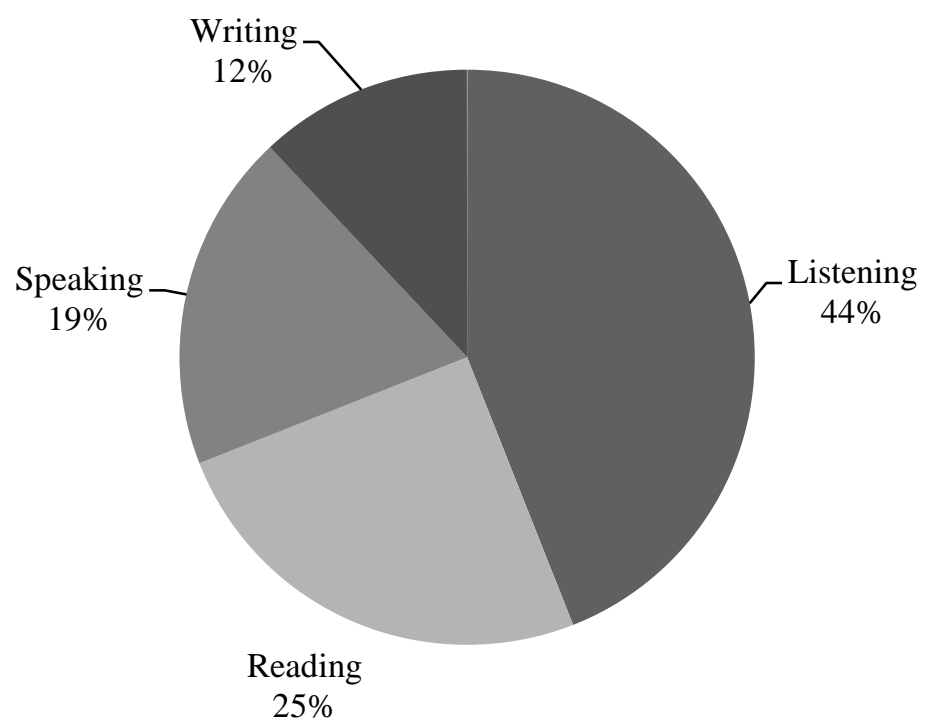

Figure 5.12 Communication Modes in Arabic Classes 


\subsubsection{Grouping}

The students in Arabic language classes usually engaged in tasks in total class grouping or as single students. Similar to the English classes, the physical grouping of the students was either in rows of three or groups of six. The students were engaged in tasks and activities as a whole class (TC) in $75 \%$ of total events observed. The remaining $25 \%$ of observed teaching events activities and tasks were conducted in single student manner (Figure 5.13). The Arabic teachers were not observed to use pair or group work, and did not support the use of cooperative learning as a learning strategy or teaching technique.

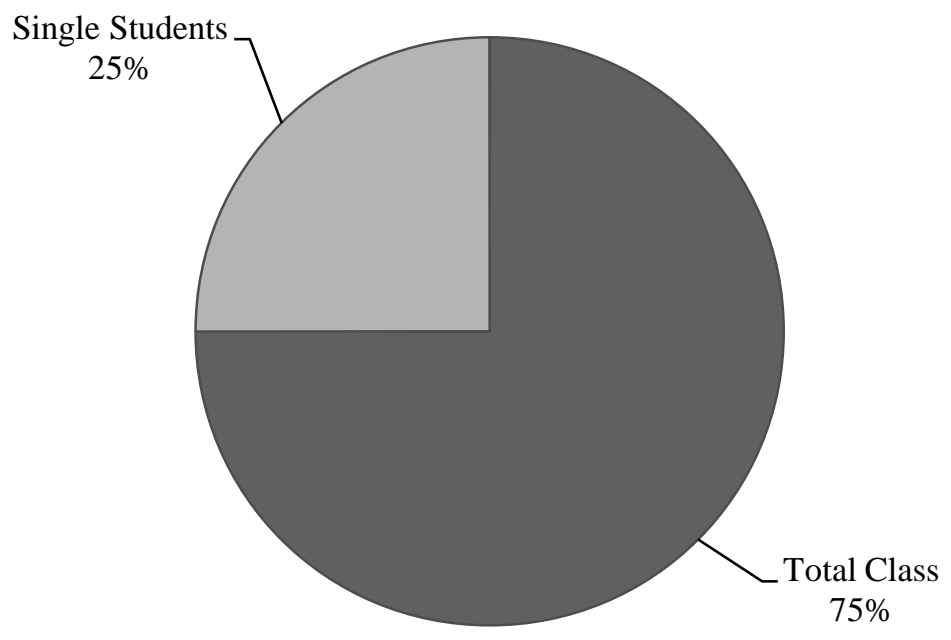

Figure 5.13 Grouping of Students in Arabic Classes

\subsubsection{Instructional practices}

The instructional practices in Arabic language classes were similar to the English classroom practice in many aspects. Each of these practices will be elaborated as evident from the data in Table 5.4. 
Table 5.4 Frequency of Use of instructional practices in Arabic classes

\begin{tabular}{lrccr}
\hline Practice & High & Moderate & Infrequent & None \\
\hline IRF sequence & $\mathrm{X}$ & & & \\
Focus on academic language & & & & $\mathrm{X}$ \\
Use of co-operative learning & & $\mathrm{X}$ & & $\mathrm{X}$ \\
Use of high relevance material & & $\mathrm{X}$ & \\
Highly cognitive content & $\mathrm{X}$ & & & \\
Explicit grammar teaching & $\mathrm{X}$ & & \\
Explicit focus on vocabulary & & $\mathrm{X}$ & \\
Scaffolding & & $\mathrm{X}$ & \\
- Establishing routines & $\mathrm{X}$ & \\
- Contextualization (teaching aids) & & $\mathrm{X}$ & $\mathrm{X}$ \\
- Modelling & & & \\
- Mridging & & $\mathrm{X}$ & \\
Rote learning & & $\mathrm{X}$ & & \\
Evaluation & & & \\
\hline
\end{tabular}

\subsubsection{IRF sequence in classroom interaction}

The Arabic teachers used interaction extensively in the form of an initiation-responsefeedback (IRF) sequence. They used this sequence to elicit answers that the teacher was expecting, by either checking understanding of the text, or answering comprehension questions. This practice was characteristic of the entire teacher's practice in Salam school. In Arabic classes most utterances were coded as (ASK/ANS), (LEC/LIST), and (DIR/LIS). This is exemplified by the following extract in which an Arabic teacher was revising Arabic grammar at the beginning of the lesson. It was midmorning and there were twenty girls in this class sitting in groups of fives:

T A Salam Alike, (commotion)

Books and note books in front of you Mona, Nawal.

What are the types of phrases in Arabic?

$P \quad$ (answer)

T Why the noun phrase is called that?

Teacher answers 
Who can give me an example?

A pupil comes up to the white board and writes a sentence. Grammar explanation proceeded to revise parts of the words in Arabic; Noun, verb, and particle. Students asked to repeat it as a whole class. What are the types of verbs? Present, past, and order. Teacher explains: It is about an action happening in a certain time. Teacher asks students to give examples one by one. A student next to me says, in a low voice, "everybody is cheating from the book, why not me?” and takes a peek into the book to find an example to say.

T What are the types of nouns?

She writes the types on the boards after getting a few correct answers.

T Who can define what a verb is?

$P \quad$ I have a question. There are verbs that begins with ' $A L$ ' how do we put it in the order form?

The teacher keeps asking questions about Arabic grammar and students answer individually, and mostly orally, by a show of hands. The teacher continues revising verb inflections and types of particles orally and sometimes using the white board to write examples.

This type of interaction was characteristic of all three teacher's practice and was prominent in all observations. It was observed that teachers would choose only the students who raise their hands to answer without checking understanding of the students who do not raise their hands. Consider this extract from the lesson about Arab Nations. The teacher asked the students about the difference between two words that have the same spelling, slightly different pronunciation, and different meaning:

Obs.15. Event 1

T girls look. Teacher writes two words in Arabic on the white board:

\section{AL DEEN}

Al DAIN 
The teacher uses words from her Levant dialect to explain difference. The word the teacher is using to paraphrase in her own dialect has a different meaning in Qatari dialect. The teacher asked if the girls understood and the Levant girls said yes. The teacher was satisfied with this. I heard a Sudanese student asking, “what is it, what is it?” Another student who was Qatari replied, "I do not understand". This is one example of many where the difference in dialects can become a communication barrier.

Teachers often dismiss student initiation of interaction. Consider this extract in OBS.6. The lesson is about families. The teacher was explaining the lesson by reading a line from the text while sitting at her desk, and then she would paraphrase in her own dialect:

Ob.6 Event 1:

P $\quad$ my family is... (A class discussion starts about students families)

The teacher interrupts and asks the students to listen.

T we do not want to hear about your own life, we will discuss first the position of women in Islam.

The teacher explains the roles and duties of women as mothers, sisters and daughters. The teacher explains in MSA for a few minutes then she uses Iraqi dialect for a while. One student stands to tell a story about parents' rights in the middle of the teacher's explanation. The teacher shouts at the students, saying they should listen. The teacher starts a class discussion about marriage and family life in a Muslim culture. Teacher asks student to underline some sentences in the text.

Students' initiation of discussion was usually dismissed as in English lessons. Most explanation was done orally and with the use of the text book. No task sheets were used. The 
only exercises students were observed to engage with are the ones offered in the text book. Mostly the children were asked to read the questions silently then the teacher started asking the questions aloud and doing the exercises with the whole class. It was observed that often students were given less than a minute to try to answer the questions on their own before they are answered in whole class manner. At the end of an explanation of a text the teacher extracted the main ideas of the text, wrote these on the white board and asked the students to repeat them and copy them in their note book.

The English lessons had more organization in their division with a fluency half hour, reading session and the textbook session. Arabic classes were less organized. They mainly revolved around the texts in the text book as the weekly plan indicates (see Table.5.2 above). Teachers often chose the same students who always volunteered to answer. Lecture form was very common where the teacher stood and explained for extended amounts of time.

\subsubsection{Focus on Grammar and Vocabulary}

Explicit focus on grammar was found high in frequency. Every lesson had at least one event in which grammar was the focus of the event. Many lessons opened and closed with a grammar focus and had grammar exercises during the explanation of the texts. Most grammar explanations were done orally on the white board in whole class and students were supposed to listen, copy and remember.

The focus on vocabulary was highly frequent as well. Vocabulary items were explained and paraphrased usually from MSA to a CD. Grammar and vocabulary did not have their own events but were integrated throughout the lessons and form a main component of teaching the Arabic Language. 


\subsubsection{Scaffolding Structures}

Teachers in Arabic had fewer structured lessons and thus less reliance on routines in the daily presentation. The lessons usually were focused on studying written texts from the text book and explain them in detail with emphasis on grammatical forms and vocabulary items. Since there was no variability in the tasks there were no set routines. The teachers however asked students to do silent reading of the text on the first encounter with the text, but this was not carried out by all teachers.

Teachers referred to contextualization as a technique only rarely, relying mostly on the text book and writing of text on the whiteboard and no use of other techniques such as audio material, posters, or story books to present linguistics input and tasks. In one lesson the teacher used the globe in the classroom to show students the location of Qatar and the Arab countries on the global map.

Arabic teachers referred to modelling only in their read aloud. They often read the text aloud before they asked the students to read it individually. Other than modelling reading with emphasis on pronunciation, most tasks in the text book were not modelled and there were only a few times when the codes (DEM/LIS) or (LED/PER) was used when the teacher would be demonstrating or leading the students into a task.

Occurrence of use of bridging techniques; of either old knowledge or students' knowledge of the world; was found to be infrequent in the teaching events observed. As seen from the previous extracts students own experiences where not incorporated as a learning source in the class discussions. Teachers often embarked new knowledge on students in the form of lecturing.

Multiplicity as described in the literature was missing from the Arabic teachers practice much the same as the English practice. 


\subsubsection{Evaluation}

Very few tasks were provided in Arabic classes. Consequently there were infrequent occurrences of evaluation techniques. Evident evaluation was oral and in the form of back channelling and feedback to evaluate correctness of answers.

\subsubsection{High relevance material}

The material presented had some relevance to the students as topics such as the Arab nations and Families are related to students’ lives. However teachers as mentioned above dismissed student's discussion of own experiences related to the topics studied.

\subsubsection{Co-operative learning, Focus on academic language and cognitive material}

These three instructional practices or strategies were all missing and no evidence was found of use to these techniques in the Arabic classes.

\subsubsection{Rote learning}

Focus on oral repetition and copying were main elements in Arabic classes. In every class there was an event where the students read aloud to the teacher one by one while the rest of students are copying the lesson. Grammatical rules were memorised and repeated almost daily, including reciting and memorizing poems.

\subsubsection{Summary of classroom observations}

Table 5.5 compares the instructional practices in English and Arabic classes. Teacher's language choices varied among the two teachers from strict separation using MSA only to random code-mixing of MSA and CD. Students often followed teacher's language choices. 
Table 5.5 Comparison of instructional practices in English and Arabic classes

\begin{tabular}{|c|c|c|}
\hline Practice type & English observations & Arabic observations \\
\hline IRF Sequence & High & High \\
\hline Focus on Academic language & Infrequent & None \\
\hline Co-operative learning & Infrequent & None \\
\hline High relevance materials & Infrequent & Moderate \\
\hline Highly cognitive content & Infrequent & Infrequent \\
\hline Explicit grammar teaching & High & High \\
\hline Focus on vocabulary & High & High \\
\hline \multicolumn{3}{|l|}{ Scaffolding } \\
\hline \multirow{5}{*}{$\begin{array}{l}\text { - Establishing routines } \\
\text { - Contextualization } \\
\text { - } \text { Modelling } \\
\text { - Bridging } \\
\text { - } \text { Multiplicity }\end{array}$} & High & Infrequent \\
\hline & High & Infrequent \\
\hline & Infrequent & Infrequent \\
\hline & Moderate & Infrequent \\
\hline & None & None \\
\hline Rote learning & High & High \\
\hline Evaluation & Infrequent & Infrequent \\
\hline
\end{tabular}

Students code-switched more than teachers and these were for asking clarifications from each other. Students often engaged in Listening or Writing activities. These are mainly receptive skills with little use of speaking or writing tasks. Students engaged in these tasks either as a whole class or individually with no use of co-operative learning in the form of group work or pair work. Instruction practices were similar to those observed in English classes. Arabic language classes are characterized with high reliance on IRF sequence of teaching and high focus on explicit grammar and vocabulary instruction. There was infrequent use of scaffolding techniques and evaluation of students work with little contextualization, bridging and modelling techniques. Relevance of material was moderate. 


\subsection{Course Materials}

The course materials I observed in use in the classrooms included English text books, Arabic text books, and other resources.

\section{7 .1 English text books}

The course material was described in the previous parts as a main source of organizing and implementing the English language teaching in the bilingual program of the school. The scope and sequence of the lessons as presented in the contents pages of the textbook provide a structure and a pre-designed syllabus for the program. The course material include a set of learning resources such as posters related to the topics, audio material in the form of CD's for listening practice, as well as reading fluency book that contains readers that are level appropriate for the students. The advantage of having textbooks (e.g. Figure 5.14) as the main resource of the program is that they helped standardize instruction so all students received the same content.

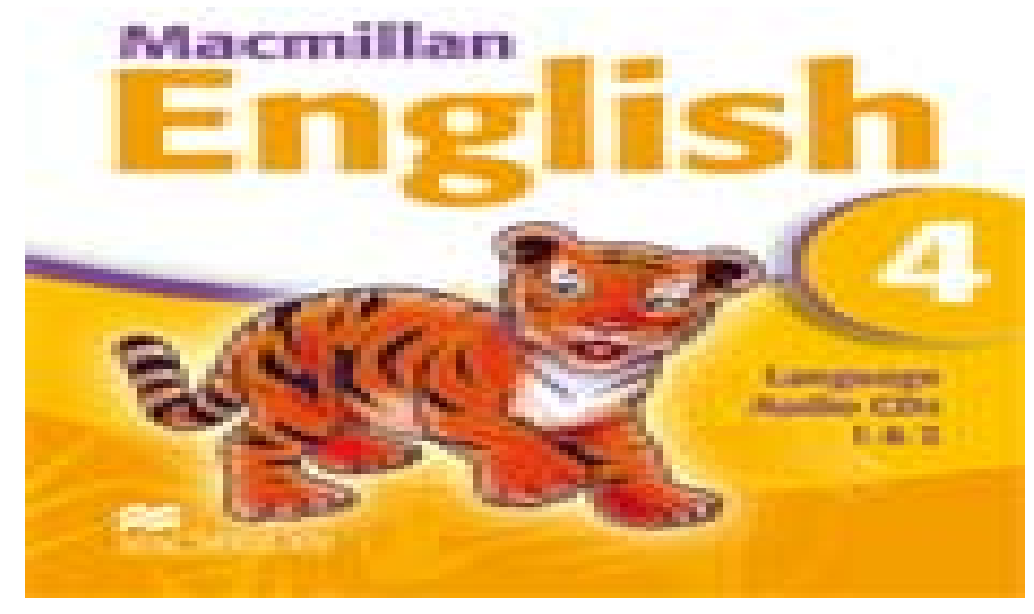

Figure 5.14 English Text books: language book and practice book covers.

They also provided effective language input which teachers of different proficiency levels might not be able to achieve. The books in this school are visually appealing, which is the case in most commercial textbooks. There are many criteria for evaluating textbooks and 
course materials such as the ones offered by Stein, Stuen, Carnine and Long (2001). However this is not the aim of the case study at present. The language book is organized around twelve themes distributed on eighteen units. The material covers all four skills and offers a lot of grammatical and vocabulary exercises. Pronunciation is also a part of each unit. Each unit contains a main text called stimulus, vocabulary items, language building facts, grammar focus, spelling exercises, writing focus, and a reading extension. Additional exercises' are offered in the accompanying practice book and extra reading material is offered in the fluency book which contains eighteen stories corresponding to the units in the language book.

\subsubsection{Arabic text books}

Arabic text books were also the main source of organizing and implementing the Arabic program of the school. The contents reflect the sequence of topics to be studied. It also provides structure and a set syllabus for the program. The course only provided a language book without any other material to accompany the book. The pictures in the book are not of a high quality, mostly hand-painted and old. The presentation of the book is not as visually appealing as the English books. Each of the twelve units contains a main text, comprehension questions, language skills exercise, a grammar rule and an evaluation sheet. There is some pronunciation work which was not used in the lessons observed.

\subsubsection{Other resources}

English language teachers used task sheets occasionally for different purposes such as an additional language skill task or for revision. Arabic teachers never used extra task sheets apart from the text book and the note book. Wall displays in the class were mostly in English, with only one board dedicated to the Arabic language. Each subject has a board for display. Displays included students work in maths, science, and English, a Star chart, class 
rules and story posters made by the students (figure 15) as part of their activities in the book fair week.

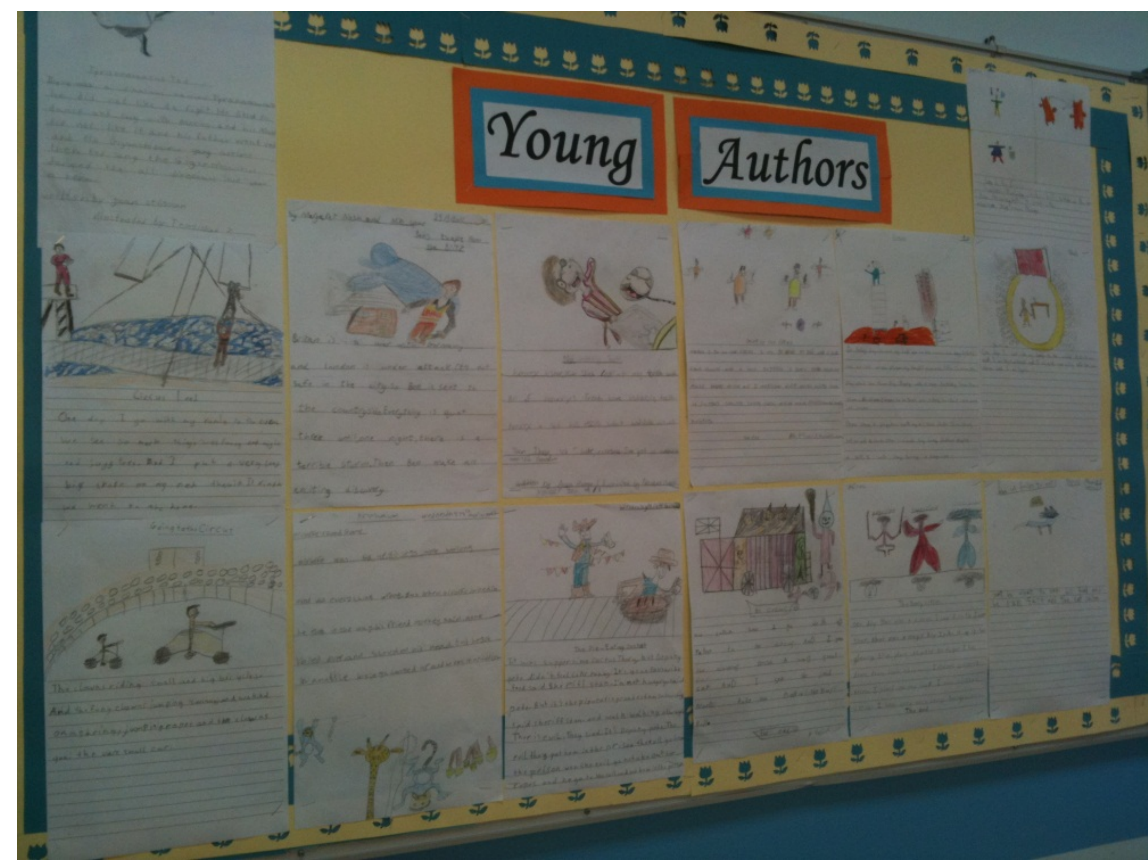

Figure 5.15: Book posters made by students

Each class has a few shelves which contained around twenty books to make up a class library. These were mainly English books with two or three Arabic stories. Every class had around 5 dictionaries as well.

\subsection{Language outside the Classroom}

Examining only the language classes does not provide the full picture of the sort of 'languaging' that was taking place. Students engaged in various out-of-class activities that aim at language development or support language use such as ESL sessions, assemblies and library sessions. These will be recounted in what follows in some detail. 


\subsubsection{Assemblies}

An assembly was organised once a week at the end of the week before the first period. Typically a class gives a performance and then the vice principal presents certificates, acknowledgments, announcements and a house trophy. The assembly was conducted in English except when the Arabic language teacher had a turn in the students’ performance.

\subsubsection{ESL sessions}

These were daily pull-out classes where the weak students in English were taken out of the main English lesson to attend these small group sessions which follow the same curriculum as the main English sessions but offer extra support. The main class teacher assessed the level of the students at the beginning of the school year and sends students to ESL. The students were provided with more time to perform tasks. The teacher in ESL sessions often, explained the lesson in simple ways and repeated the explanations. They are re-evaluated at the end of each term to decide whether they need more support or if they can return to the main English sessions. The ESL program included students' collaborative project. The stated aim of the project was to engage ESL students and 'give them a push'. The ESL program also included a reading fluency session every Thursday. The group met in the library for the reading session. ESL students usually sat for spelling tests and other assessments with the main class.

The type of interaction in ESL sessions was found similar to the ones observed in the main class but done in small group of five students and the teacher. There was low occurrence of student to student interaction. Since the group was small usually all students got a chance to participate in discussions. The teacher gave extra time to check each student's comprehension. The focus of these sessions was still on grammar. The structure, planning and content of ESL lessons followed the main lessons but without the story reading event. There was great focus on vocabulary as well. 


\subsubsection{Library sessions}

The school has a modern fully equipped bilingual library where books are organized according to titles and had a bar code classification and computerized filing. Students attended a weekly library session with the English teachers and an Arabic library session every other week. Both English and Arabic sessions were organized in much the same way. The session would start with the teacher reading from a big book to the students in a corner then each student will presume reading at the level chosen by the teacher. At the end of the session students are encouraged to take stories home for extra reading. Individual reading is evaluated by the teacher in a library notebook that each child keeps (Figure 5.15).
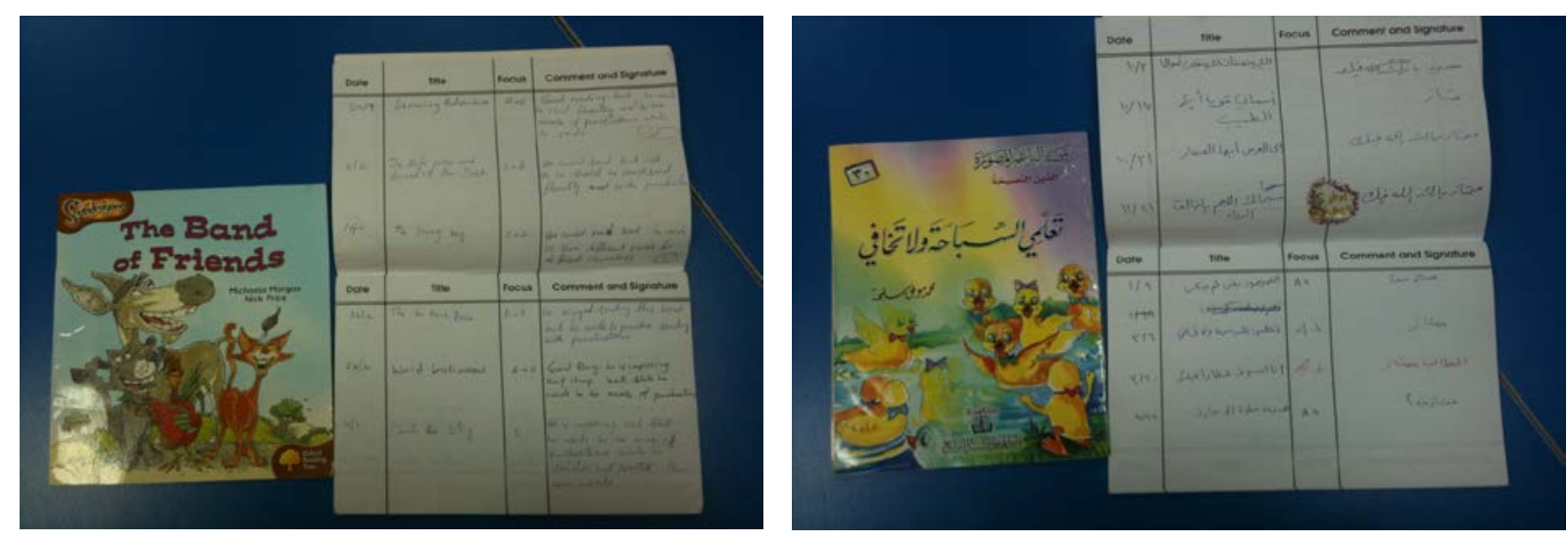

Figure 5.16 Reading log for English and Arabic stories

\subsubsection{Extra -curricular activities}

The school offered various extracurricular activities in the form of clubs and workshops convened out of school hours. They included sports, arts, science and cultural orientation ranging from a gardening club, a debate club to a computer club with the resources available to the school. Two teachers were responsible for ach workshop and no more than ten students in each activity except for the sports as the football club was the most popular among the boys. 


\subsubsection{Book fair}

In addition to having a classroom library and the weekly library sessions where children are encouraged to practice individual reading, the school has organized three book related events: the Book Fair, a Read-a-Thon, and the library week. The book fair took place in January, before visits to the school started. Meeting with the administrator in charge of the book fair however allowed information relating to this event to be gathered.

\subsubsection{Read-a-thon}

The aim of the Read-a-thon was to encourage extensive reading and involve parents with this important skill in second language acquisition, in learning new concepts and practicing reading in both languages. The school issued a letter to the parents in both Arabic and English inviting parents to the Read-a-thon. Every student was given a tally sheet to record with the help of their parents the book being read and a donation for either every fifteen minutes spent in reading or a random amount for the whole week of reading. The letter did not specify whether the books to be read should be from home or the school library and there was no specification for the language that the student should choose books in. All students that participated (regardless of the amount donated or the number of time/ books read) were presented with a certificate. The letter ended with this sentence: 'Since reading ability, fluency, and vocabulary only improves with practice, please encourage your children to read, read, and read!'

I noted various grammatical and spelling mistakes in both the Arabic and the English versions of the letter. The first two lines of the letter were written in excellent Arabic style, but translated poorly in English. The rest of the letter was directly translated from the English version into Arabic with wrong translations. For example, the sentence: 'the parent will initialize beside the daily tally’ was translated to mean that the parent will initiate. Mistakes 
and errors similar to this one are all over the letter. Similar mistakes were found in various documents all along the case study as mentioned in discussing the school policy and describing the school related documents.

In general language representations and activities outside the classroom portray weak Arabic representation and strong English one. It responds to the school overall policy of a 70-30 approach towards L2 and L1. Language outside the classroom represents the English language with no representation of Arabic in most of the activities.

\subsubsection{Summary of language outside the classroom}

Language activities outside the classroom are rich and versatile. However they mainly support English language development, with some support of Arabic. Library sessions provide a strong support to reading fluency. ESL sessions provide strong support for weak students and are done in a supporting environment that might be lacking in the main classes. Extra-curricular activities provide opportunities for task-based learning that support the development of the second language in an enjoyable atmosphere. These also indicate that what is lacking in the classroom can be provided elsewhere in the program. In regard to language choice out of classroom time, it was observed that as soon as students were alone, between classes, in corridors or during free play they speak mostly Qatari dialect or their own CD, with a few instances of English.

\subsection{Case summary}

It was stated initially that a descriptive approach would be adopted in the analysis and display of findings of this case study. In light of the analysis presented above, aligning the research questions to the findings, and thinking about the ideas posed, and observational data, the case 
is summarized using two displays: the BPDI matrix and the school portrait. These provide the evidence for visual structured and detailed cross-case comparisons that is later discussed and interpreted against related literature and theoretical prepositions. The BPDI is presented in Chapter Seven as part of the cross-case analysis.

\subsubsection{School portrait}

Table 5.6 presents the school portrait, with the claimed programme features on the right hand side, the second column display the evidence from this data and the third column presents either a practice that agrees or contrasts with the claimed practice as evident from the data: 
Table 5.6 Salam School portrait

\begin{tabular}{|c|c|c|}
\hline \multirow{2}{*}{$\begin{array}{l}\text { Claimed Programme features } \\
\text { Native speaker skills }\end{array}$} & \multirow{2}{*}{$\begin{array}{l}\text { Organization evidence } \\
\text { Mission } \\
\text { Curriculum Policy }\end{array}$} & \multirow[b]{2}{*}{$\begin{array}{l}\text { Implementation evidence } \\
70 \% \text { of daily activities done } \\
\text { through medium of English } \\
\text { Little opportunities for } \\
\text { communicative experience } \\
\text { during English lessons }\end{array}$} \\
\hline & & \\
\hline Second language learner needs & $\begin{array}{l}\text { Mission } \\
\text { Curriculum policy }\end{array}$ & $\begin{array}{l}\text { ESL classes } \\
\text { Focus on vocabulary } \\
\text { Focus on grammar } \\
\text { Course materials and text books } \\
\text { geared towards developing L2 } \\
\text { skills } \\
\text { Teachers are not bilingual in } \\
\text { Arabic/English } \\
\text { Library sessions and book } \\
\text { reading }\end{array}$ \\
\hline Learner-centeredness & $\begin{array}{l}\text { Educational goals expressed in } \\
\text { the school official documents }\end{array}$ & $\begin{array}{l}\text { IRF sequence with } \\
\text { High teacher control } \\
\text { Most utterances are coded as } \\
\text { teacher ASK /student Answer } \\
\text { Little guidance in tasks as } \\
\text { evidence shows } \\
\text { Infrequent modelling of tasks } \\
\text { High frequency of using rote } \\
\text { learning }\end{array}$ \\
\hline Communication & $\begin{array}{l}\text { Vice principal stresses } \\
\text { importance of communication } \\
\text { first, language second }\end{array}$ & $\begin{array}{l}\text { Infrequent learner participation } \\
\text { in whole class discussions, } \\
\text { little opportunities for students } \\
\text { discussions in discovery tasks, } \\
\text { in most events students were } \\
\text { either listening or writing }\end{array}$ \\
\hline Academic excellence & Curriculum policy & $\begin{array}{l}\text { Infrequent focus on Academic } \\
\text { language, infrequent use of high } \\
\text { cognitive material } \\
\text { Science and Maths follow } \\
\text { British based curriculum } \\
\text { standards } \\
\text { Modern resources, bilingual } \\
\text { library modern text books }\end{array}$ \\
\hline Highly qualified teachers & Mission, school brochure & $\begin{array}{l}\text { Most teachers do not have } \\
\text { teaching training or a degree in } \\
\text { education }\end{array}$ \\
\hline Enjoyable learning & $\begin{array}{l}\text { Educational goals , curriculum } \\
\text { policy ,School Mission }\end{array}$ & $\begin{array}{l}\text { Book Fair } \\
\text { Extracurricular activities } \\
\text { Assemblies } \\
\text { Other school celebrations }\end{array}$ \\
\hline Islamic identity & School documents & $\begin{array}{ll}\text { Separate girls and boys } \\
\text { premises } \\
\text { Noon prayer Break } \\
\text { Quran recitation session } \\
\end{array}$ \\
\hline Strict separation of L1 and L2 & $\begin{array}{l}\text { Interview with teachers } \\
\text { Strictly English and Variability }\end{array}$ & $\begin{array}{l}\text { English only in English lessons } \\
\text { minimal code-switching, }\end{array}$ \\
\hline
\end{tabular}


in Arabic classes, one reports Variability of teachers practice use of MSA only another in Arabic lessons, some MSA reports difficulty to apply and only others flexible use of MSA says that she uses CD rarely but students use QD often and CD.

Students follow teachers' language choice. Qatari Dialect is only used minimally during both class times. Out of class free play and students socializing is in Qatari Arabic or students own Colloquial dialect.

\begin{tabular}{lll}
\hline Collaborative learning & $\begin{array}{l}\text { Opportunities for participation } \\
\text { (curriculum policy) }\end{array}$ & $\begin{array}{l}60 \% \text { of events conducted as } \\
\text { whole class or individual } \\
\text { Group work (weekly timetable) }\end{array}$ \\
& $\begin{array}{l}\text { students. No pair work or group } \\
\text { work }\end{array}$ \\
\hline
\end{tabular}

The Salam school portrait (Table 5.6) indicated that although the school projected a bilingual programme stressing the importance of developing native like skills; it offered little opportunities in the daily program for commutative experiences. The school catered for students' second language needs with ESL support classes and library sessions to encourage reading as well as focusing on grammar and vocabulary teaching. There was, however, little observable evidence for the implementation of other features such as learner centeredness, collaborative learning and use of highly qualified teachers. The elements of offering learning in an enjoyable atmosphere were evident in the data. Communication as a school policy was not part of the teaching practice as in Arabic lessons the students mostly were engaged in receptive skills. In English classes the practice focused on writing and listening. Academic excellence as a theme could be traced in the school attempts such as use of modern text books, using international curricula in Maths and Science. The school Islamic identity was prominent in the school practice. The strict separation and the immersion in L2 were also evident in the school practice. 


\subsubsection{Conclusions}

This study identified a case of a school that generally used a separation bi-literate model, as defined by Garcia (2009) where two literacies were being developed in the school but in separation. In English sessions L2 only was allowed. In Arabic lessons L1 was taught using MSA, with some tolerance of CD. This, however, was not the case all the time. One teacher applied her personal own model according to her perception of the school policy. For this teacher, a convergent mono-literate model operated, where the vernacular was used to explain the written language (MSA) using two languages in oral mode but only MSA in the written mode. The findings indicate more focus on grammar and vocabulary in both Arabic and English lessons than other literacy related skills like reading comprehension or academic writing.

With respect to the question of the bilingual education approach used by the school, it can be concluded that a grammatical approach was mostly used. There was limited evidence for the use of communicative language teaching, and no evidence of using cognitive approaches to bilingual education.

With respect to the type of bilingual education, strict subject determined separation of the two languages where all subjects were taught in English, except Arabic and English. English was used all day except for recess, and was opposed to time determined (alternating days programmes) or teacher determined separation (alternating teachers). Because of the separation nature of the programme (70\% English and 30\% Arabic) and the early immersion approach to teaching L2, as well as the demographics of the students (98\% speak the same L1), the programme in this school can be classified as immersion bilingual program.

As an individual case Salam International School presented rich data in regard to the different aspects investigated such as teachers' and students’ language choices and how teachers kept 
languages separate, viewing code-switching as an error to be corrected. The data also indicated how the diglossic situation in Arabic can be a barrier in communication where words can mean different things for students from different parts of the Arab world. Salam school described itself as an English speaking school and indeed it was an English speaking school where no place for the Arabic or Qatari culture was evident in the texts used in the L2 classes, the extra-curricular activities, stories or wall displays. 


\section{CHAPTER 6: CASE STUDY 2 - JAZEERA SCHOOL}

\subsection{Introduction}

Jazeera school, the focus of the second case study, is described, including its size, location and composition, together with the self-reported profiles of the teachers who participated in the case study. The findings of the case study are then presented in two sections: (a) the organization of the bilingual program and (b) the implementation of the bilingual program. Finally, the school portrait, a tool for viewing the various explored features from the two perspectives of organizational evidence and implementation evidence, is presented.

\subsubsection{Profile of Jazeera School}

Jazeera is an Independent school funded by the Supreme Education Council (SEC) in Qatar. The SEC, formerly known as the Ministry of Education for the State of Qatar, is responsible for the administration of all publicly-funded schools and higher education. Jazeera school became independent five years ago under the new reforms of the educational initiative "Education for a new Era". It has about 800 registered students, of which over three quarters are Qatari nationals who do not pay any fees. Non-Qatari students of many other nationalities, including Sudan, Egypt, Algeria, Syria, Jordan, Oman, Palestine and Pakistan, are also eligible to register if one of their parents works for a government organization or for the school itself; however no data on the proportions of each nationality are available.

Jazeera school is set in a large, purpose built modern building, in a new urban development. All the school furnishing, including floors and chairs, are modern and new. When I visited the school, entrance was very easy. There were no security guards, and I just walked into the building without being apprehended. The receptionist was the first gate-keeper that I met in 
the administration area. I saw no students in the administration area, but when I looked through a large glass window into the hall, I saw about 400 students running around wearing the Qatari white "Thoub" school uniform, monitored by five teachers. After the ringing of the bell all the students were ushered back to their classrooms.

A total of 61 teachers are employed in Jazeera school, comprising 28 English-Arabic bilinguals, including 25 Arabic nationalities, and three Arab-Canadians, and 33 who only speak Arabic. All of the teachers have an undergraduate degree qualification, and two have a postgraduate degree. All teachers specialize in teaching one subject, except for the teachers of grades 1 and 2 (6-8 year olds) where each class has one class teacher and one assistant. The class teacher is bilingual and the assistant only speaks Arabic.

\subsubsection{Profile of the Participants}

I interviewed three Arabic-English bilingual teachers (given the pseudonyms: Sana, Amal, and Maya) and two Arabic speaking teachers with limited English language skills (pseudonyms: Suad and Omaima) who taught grade 4, and the Vice-Principal of the school (Mona). Their profiles, self-reported at the interviews, are as follows:

Sana (SA): Is an Arab-Canadian teacher, 24 years old, with a Bachelor's degree in Communication Studies. She moved to Qatar four years ago when she joined Jazeera school to take her first job as a teacher. Sana is young and enthusiastic about teaching, speaking at length about education. As an Arab-Canadian her English-language skills are excellent.

Amal (AM): Is a Qatari teacher in her late 20's with a Bachelor's degree in language teaching from Qatar University. She has been teaching for eight years since her graduation and is also involved in administration. She has the role of English subject co-ordinator in Jazeera school. 
She supervises, advises and oversees the teachers' planning and ensures that all SEC standards for the subject are being met.

Maya (MA): is a Jordanian teacher in her early 40's with a Bachelor degree in Science who vaguely described her English language skills as "moderate". She said that her own children go to an English speaking school because she believes that independent schools do not offer enough English language tuition.

Suad (SU): is an Egyptian teacher in her 30's with a Bachelor's degree in Arabic language and literature. She taught Arabic for 14 years in Egypt and Qatar, six of which were at Jazeera school. Consequently she was a teacher before the "Education for a New Era" reforms were implemented in Qatar. Suad participated in many workshops/seminars that were organized by the SEC for teachers at the beginning of the reforms. She taught preparatory and primary levels from grades $1-9$.

Omaima (OM): is a North African teacher in her 30's with a Bachelor's degree in Arabic who taught for eight years in primary schools, and four years in an international school, before joining Jazeera school four years ago.

Mona (MO) is in her 40's and has a degree in Islamic studies. She was a teacher at Jazeera school for three-years, and a subject coordinator for another three years. Mona has been the academic vice-principal at Jazeera school for two years, and does not teach anymore. She agreed to do an interview because the principal was unavailable.

\subsection{Organisation of the Bilingual Program}

The information provided about the organization of the bilingual program at Jazeera School encompasses all that was advertised and perceived to be true by the school management and operators of the program. The findings relating to this unit of analysis address the main 
research question of the study : "How is bilingual education manifested in international and independent schools in Qatar?"

The original intention was to base the information about the organisation of the bilingual program at Jazeera school from three sources: (a) the school bilingual policy document ; (b) the observed language allocation and distribution in the program; and (c) the interviews with English and Arabic language teachers and the academic vice-principal.

In order to provide evidence for the organization of the bilingual program, Item 12 in the questionnaire asked: "Do you have a written school policy regarding language use and teaching ? Yes/No" The questionnaire also asked that a copy of this document should be attached and returned with the questionnaire; however although the answer to Item 12 was "Yes", no policy document was provided, and so it could not be interpreted for the purposes of this study. In the absence of this document, other available sources were used for direct interpretation, specifically Jazeera school's " Students' and Parent's Guide" (SPG) and the school's website material. The SPG is a booklet containing various materials directed to students and parents, including the school's goals and rules for expected behaviour.

Three main themes emerged which related to how the school communicates its policy publically. The themes are described in three sections, namely (a) Linguistic goals (b) Educational goals and (c) School identity. A subsequent section also describe the school's language of communication as it appeared in the documents, in addition to the observed language allocation and distribution in the program in the weekly plans of the two languages.

\subsubsection{Linguistic Goals}

The "Students and Parents Guide" (SPG) including the educational plan was the main sources of evidence to identify the linguistic goals of the Jazeera school. Out of the 15 items 
in the school's educational plan, reference to language teaching is cited in three places, two of which are part of the special education section. There is no reference to literacy teaching in a first or second language. Some implicit indication of the school interest in language teaching is evident in Section Three (p.3) of the guide titled "Educational goals" as follows:

“4. To develop students skills, so as to be able to operate in a multi-cultural society"

"12. To create a motivating and safe learning environment, that focuses on knowledge and skills”

There are also other places where the word 'skills' is used in the SPG that could be interpreted to include all types of skills including first and second language skills. These statements imply that Jazeera schools seeks to develop second language skills, along with other skills, but the explicit nature of the skills are not defined.

Explicit reference to language and literacy is evident in Section Six (p.6) and Section Seven (p.7) of the guide entitled "Students' support and learning difficulties" as follows, but it is not stated in which language the referred to language/learning difficulties are supported:

"Facilitate understanding and using written and spoken language in the following processes: listening, thinking, speaking, reading, writing (including spelling and handwriting)”

"Speech therapy department: Duties of speech therapy department"

The school's website material consists of pages with a link to the SEC website (www.sec. gov.qa). It summarizes the educational goals of Jazeera school, where language and literacy are mentioned implicitly in the following two statements:

"Educational goals : An alignment of Qatari National Standards of learning to the teaching and learning of students" 
"All students receive the support they need to access the curriculum. This includes students with special education needs and students who need support in learning both Arabic and English”

The "Qatari National Standards" are issued by the SEC for four core subjects (Arabic, English, Mathematics, and Science). They are a set of goals indicating the requirements students need to achieve in each grade level as criterion reference for teaching and learning in independent schools (www.sec. gov.qa). The only evidence to indicate that Jazeera school teaches in both English and Arabic is found in the part referring to students' support and students with special needs. The two extracts listed above are not explicit, but only imply Jazeera school's goals for teaching Arabic and English and having a bilingual orientation.

In summary, the available evidence to determine the exact linguistic goals of Jazeera school, with respect to the relative roles of Arabic and English in the curriculum, is not explicit. It is concluded that either (a) the available information is too vague and difficult to interpret; or (b) an implicit approach is intentional, to give the impression to prospective students and parents that Jazeera schools' language policy is discreet; or (c) there is, in fact, a lack of a clear linguistic policy at Jazeera school, with no obvious goals, and little awareness of bilingual issues in the curriculum.

\subsubsection{School Identity}

Statements in the SPG and the school website emphasize the "national" identity as well as an "Islamic" identity of Jazeera school. The school vision is used as a footer in every paper printed and distributed to staff , students, parents and the public, and is also displayed on the wall of the school, outside the school gate (Figure 6.1) as follows: 
"Our overall aim is to create an Islamic, originative, and epochal generation, achieving the vision of Qatar future 2030”
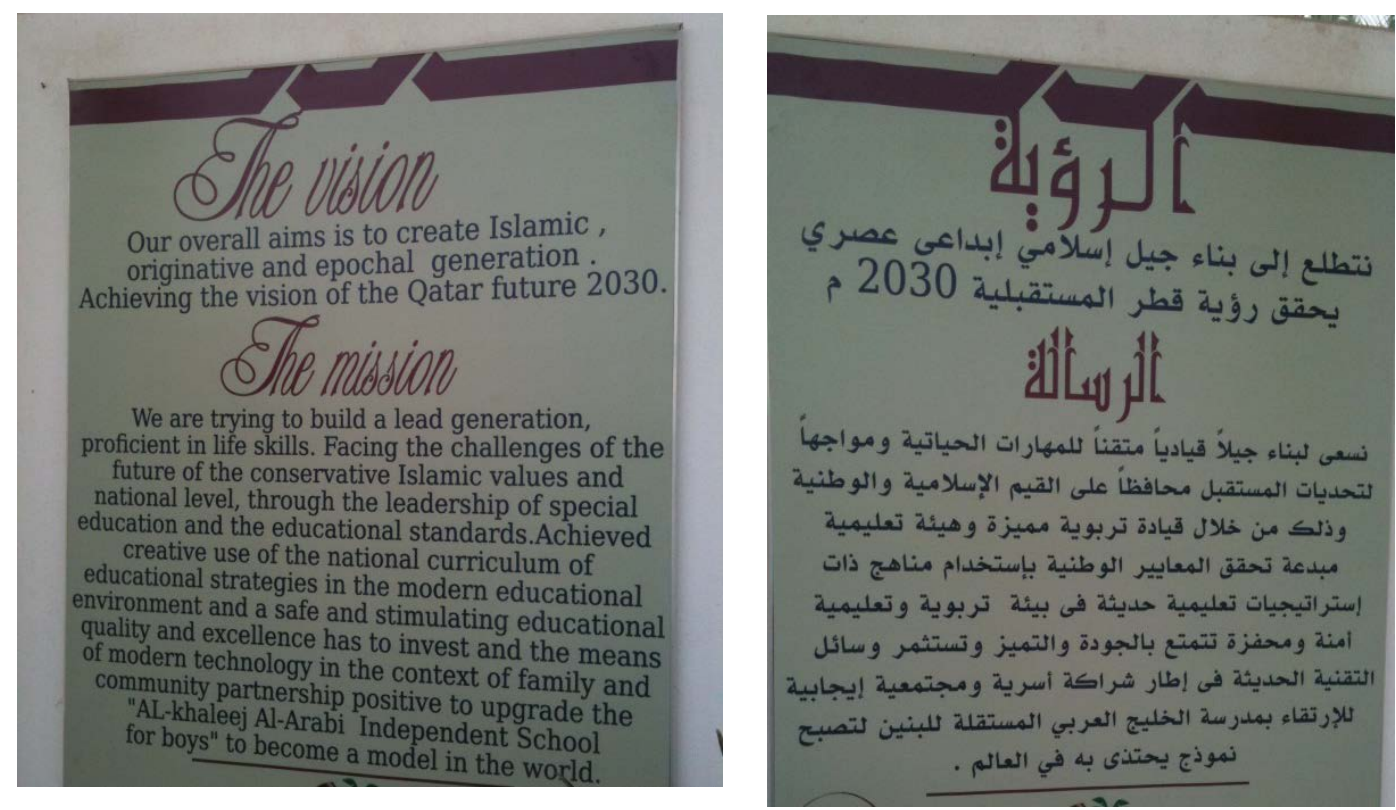

\section{Figure 6.1: School Vision}

Examples of statements regarding the Islamic identity of the school are quoted in Table 6.1. These present evidence that identify the implicit goals of the school to promote Islamic values and morals. These statements portray a picture of a school which asserts its Islamic identity, but adheres to the values and morals of others aiming for a peaceful co-existence.

\section{Table 6.1 Statements Reflecting the Islamic Identity of the School}

\begin{tabular}{ll}
\hline Statement & Source \\
\hline 'Facing the challenges of the future of the conservative Islamic Values' & School mission \\
\hline 'A curriculum that embraces Islamic traditions and beliefs' & Website \\
\hline 'The school aims to develop citizens who embrace Islamic traditions and & Website \\
behaviour, who respect the beliefs and attitudes of others and work & \\
together to create a better and more peaceful world & \\
\hline
\end{tabular}

The information in the SPG concerning the school's national identity emphasizes the Qatari culture and its values. The first page in the SPG is a fact sheet with pictures about the state 
of Qatar including its geographical position, language and major cities. A cartoon character wearing the Qatari costume giving advice is depicted. The third page contains the lyrics of the national anthem, and the fourth page has a picture of the Emir of Qatar. Table 6.2 displays further examples of evidence for the school's goals in promoting patriotic values of Qatari nationalism in the school mission statement and SPG.

Table 6.2 Statements Reflecting the National Identity of the School

\begin{tabular}{ll}
\hline Statement & source \\
\hline "The school aims to contribute to the development of loyal Qatari citizens" & $\begin{array}{l}\text { School } \\
\text { Mission }\end{array}$ \\
\hline "To reinforce the values and culture of the nation" & SPG \\
\hline "To instil a national identity" & SPG \\
\hline "Support a patriotic and national awareness among students" & SPG \\
\hline
\end{tabular}

The SPG also displays the school logo, containing the Qatari flag, a palm tree and a book. Its cover displays six pictures of the school's students engaged in various activities. The first is of a student using a computer, the second portrays students during prayer time, one is of a school play with students wearing old Qatari costumes, the fourth displays students making paper masks, another shows four students with a policeman, and the last displays students in the library. These pictures communicate the school's educational goals of being a modern school with IT facilities and a large library.

\subsubsection{Educational Goals}

The school's mission, vision, website and SPG define the educational goals of Jazeera school The school clearly presents itself as an institution that aims for "academic achievement and success" which is achieved by four elements: (a) a focus on teaching and learning strategies; (b) professional staff development; (c) providing a modern and motivating environment; and (d) careful curriculum planning. 
Several statements reflect the school's aim of promoting academic achievement, such as "We are committed to the provision of a quality education' and 'Enabling students to achieve at a level that will maximize success" (website) which are achieved by the school focusing on various teaching and learning strategies including 'A variety of ways to learn including working as teams that will seek to develop essential skills" (p.17, SPG); and "Learning experiences that are relative to real life in areas of leadership, decision making, tolerance, independence in learning, negotiation, and analytical critical thinking skills" (p.24,SPG).All of this is provided in: "A stimulating and motivating environment which develops the students desire for knowledge" using "An education model that incorporate interactive, cooperative, enquiry based and ICT focused environment". The SPG also identifies the school's commitment to professional development, by developing a "Dynamic, high performance team of dedicated teachers and support staff" and it emphasizes that the school embraces "Innovation and change in curriculum planning, delivery and assessment' .

\subsubsection{Language of Communication}

The observed documents lacked information concerning (a) which languages are used to teach different subject areas; (b) the use of English as a medium of instruction in the school curriculum and (c) the place of Qatari dialects or other dialects. The documents, however, indicated that the school provides extra support for students' educational needs including learning both Arabic or English, indicated by 'All students receive the support they need to access the curriculum. This includes students with special education needs and students who need support in learning Arabic and English"

All the school documents were in Arabic, apart from the website, which has the option of opening an English version containing the school mission and school educational aims. The 
school weekly timetable is also in English. The SPG and all other school communication with the parents, SEC, and media is in Arabic only.

\subsubsection{Language Allocation}

Language allocation was identified through the language distribution in the weekly program, with reference to content and time and language separation arrangements, the questionnaire, and the timetable attached to the questionnaire. Literacy in Arabic and English are introduced simultaneously in lowest grades (kindergarten level at four years old). According to these sources, the students spend approximately $60 \%$ of their total weekly hours of instruction (25 hours per week) learning English as a subject, or using English as the medium of instruction. The remaining $40 \%$ is spent either learning Arabic as a subject or using MSA as the medium of instruction. In comparison, Chapter four revealed that independent schools in general have a 52:48 English to Arabic language allocation. The 60\% allocated to English at Jazeera school is therefore above average, and reflects the school's approach towards English, and how it viewed and practiced its bilingual program. The use of English as a medium of instruction in IT classes is reported to increase the amount of time that English is used.

With regards to the content allocated to each language, evidence from the school questionnaire and weekly timetable revealed that the school followed a subject-determined language separation policy (Figure 6.2)

\begin{tabular}{|c|l|l|l|l|l|}
\hline Period & Sunday & Monday & Tuesday & Wednesday & Thursday \\
\hline First & Math & Social science & Science & Arabic & Math \\
\hline Second & English & Arabic & Arabic & Arabic & English \\
\hline \multicolumn{7}{|c|}{ Break } \\
\hline Third & Science & English & Islamic & English & Islamic \\
\hline Forth & P.E & IT & Math & Science & Arabic \\
\hline Fifth & Islamic & Math & IT & Math & P.E \\
\hline & \multicolumn{7}{|c|}{ Pray Break } & \\
\hline Sixth & Arabic & English & English & Social science & Math \\
\hline
\end{tabular}




\section{Figure 6.2 Copy of the Weekly Timetable for Grade 4-4}

The timetable in Figure 6.2 describes the distribution of subjects in the weekly program. According to the school questionnaire, English is the language of instruction for four subjects, Science, Mathematics, English and IT. The remaining subjects of Arabic, Social Science, Islamic Studies and PE are taught using MSA. There is also prayer break, but only for grades 4,5 and 6 .

It is important to include the findings relating to the teaching plans of Arabic classes and English classes because they formed an important component of the school's organization of its bilingual program and how literacy (reading and writing) and other language skills were planned to be taught in grade four. Extracts (Figures 6.3 and 6.4) display the two-page daily teaching plan.
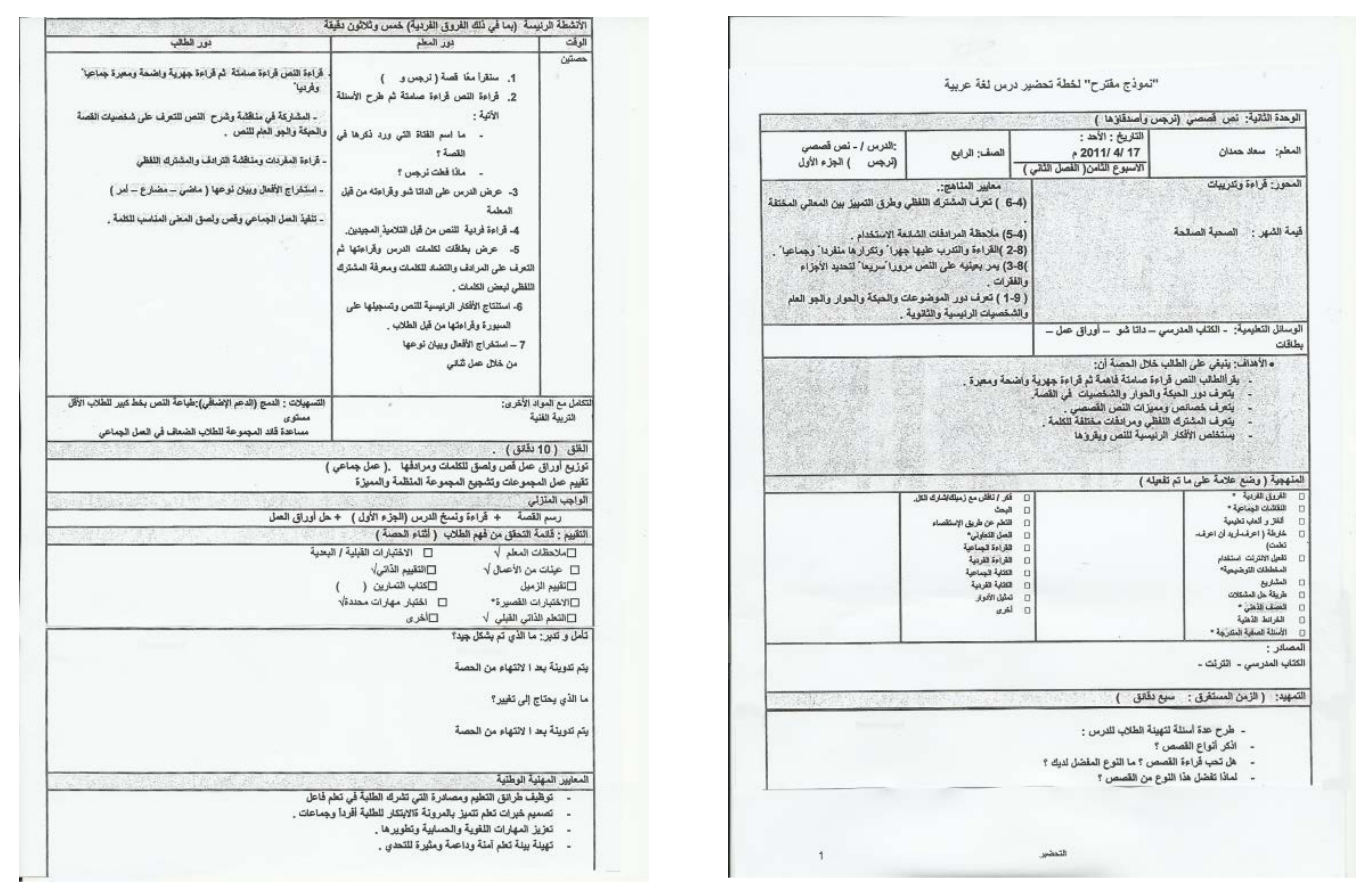

\section{Figure 6.3 Arabic Weekly Plan}

The layout and headings in the weekly lesson plan for English and Arabic classes are identical. The plan layout is a sample provided by the SEC on which teachers base their own 
teaching plan; however, it is used as the default layout for both Arabic and English lesson teaching plans in Jazeera school. The plan is a two page schedule that depicts the unit title, curriculum standards, school's theme of the month, objectives, methodology, resources and lesson sequence. Each lesson has a starter activity, a main activity and a closing activity. The plan also displays the key vocabulary to be taught, assessments used as well as the homework. There is a place at the end for the teacher's comments on the lesson and the professional standards applied during each lesson.
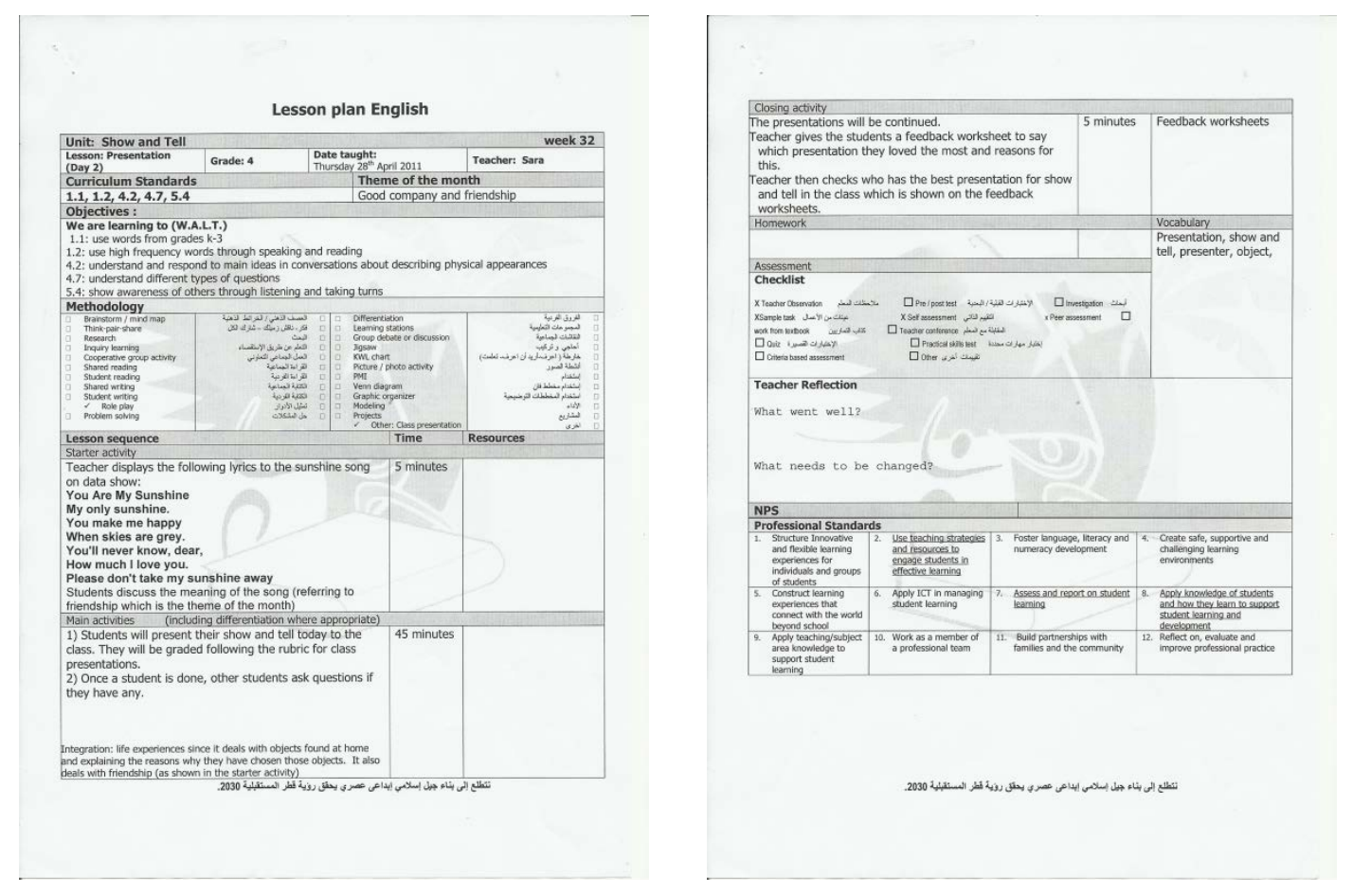

\section{Figure 6.4 English Daily Lesson Plan}

As indicated in the first case study, dependence on a fixed layout of weekly and daily plans reflects a mechanistic model of organizing the school (Davidson and Tesh, 1997). There is, however, evidence that Jazeera school is organized using a more flexible organic model. In this model, teachers, and the subject co-ordinator decide on the content of the lesson plan and align the lessons to the Qatari National curriculum standards as distributed to schools from the SEC. Although a centralized approach is evident, the model gives freedom to the teachers 
and subject co-ordinators to work with the lesson plan layout and provide their own input. There is also space in the lesson plans to indicate where skills learned were being applied in the lesson. The objectives themselves are competency-based outcomes as reflection of the use of the SEC standards. The use of standards began as a movement in the 1990's in the United States. They are descriptions of the targets students should be able to reach in different domains of the curriculum, with benchmarks describe students' competencies at each stage (Richards, 2001).

An examination of the format of the Arabic and English teaching plans present certain suggested teaching strategies. The plan begins with a list of methodologies to be used presented as a checklist comprising various teaching and learning methods such as cooperative learning structures (e.g., think-pair-share, brain storm, cooperative activities, projects, group discussions), differentiation, shared reading and writing, and problem solving. An assessment checklist suggests a variety of versatile assessment techniques at the disposal of the teachers. The self-reflection section of the plan provides space for teachers to think about their lessons by answering two questions "What parts of the lesson went well?" and "What parts need to be changed? This can be viewed as a tool for the continuous professional development of the teachers. The plan ends with a checklist of 12 professional standards that the teacher can use to apply in each lesson as another tool to activate teachers professional skills. The plan also suggests an operative model of teaching which requires teachers to meet the requirements of a centralized system (e.g., the delivery of a text book as planned in a set time scale).

\subsubsection{Interview Responses}

The interview questions explored the perceptions of the teachers with respect to (a) their awareness of the bilingual policy of the school; (b) their practices to support the bilingual 
policy; and (c) their involvement in any developmental programs that support the bilingual policy. The interview responses are recorded in a theme oriented table (Appendix ix) based on the three axes of the interview protocol. In the following three sections the findings are presented. Within each axis, the responses of the English teachers are considered first, followed by the Arabic teachers.

\subsubsection{Awareness of School Bilingual Policy}

The three English teachers described their bilingual teaching experience in Jazeera school as a" learning process". To one teacher this process was difficult, whereas the other two talked about their experience as a quick process of learning and adapting to the school system, justified by the differences in culture:

"So I started here, the first year was very difficult for me because I came from Canada straight to Qatar and the students are very different, and the teaching system is very different "(SA)

When the teachers were asked about the school language policy, they discussed it in terms of "balance" and "integration"; however, they appeared to have low awareness and mixed feelings about the school bilingual policy either in relation to the time devoted to English or the objectives of the policy. For example:

"You know, the school is teaching two languages. It's .. uh. Balance... yes balance. It's a balance with the subjects - English, Maths, Science. We have integration between subjects, we have integration with other subject ... like computer, like art, like sport” (MB).

“Um ... that's a good question, I haven't really thought of that. I know that ... I mean science ... the terminology used .. I mean even doctors, they use a lot of English terms. So they need ... I feel they need like for English ... I mean Science needs English, but for Math ... some 
students don't know the numbers in English, but they know Math ... I don't know I have mixed feelings” (SA).

The extent to which the teachers related their understanding of the policy in their own teaching can be traced in their statements that they code-switched to Arabic whenever needed. This is an extract of one response to this item in the interview. This is not a translation but her own words describing her English language proficiency level as well as the extent of her use of Arabic in the classroom:

"I use Arabic for low achievers if they don't understand the meaning of new words I told them to use dictionary for different ... for difficult words. I also give them the meaning of the word if they didn't know the meaning 'Bilarabi' (in Arabic)” (MB)

When the interview explored how the bilingual policy was communicated to the students and parents, and how the teachers dealt with students language choices, it was stated that these rules were "mentioned" to the students and they were encouraged to try to speak English as much as possible. One teacher reported that she informed the parents at the beginning of the year that almost 80 per cent of the each lesson will be in English and this was difficult for the students at the beginning of the year. Teachers reported that they do not discourage students' code-switching but they encourage them to try and speak English as much as possible.

The two Arabic teachers presented opposing views on the bilingual policy of the school. One implied that the bilingual policy appeared to be imposed on schools by the SEC, but it was not the school's, as follows:

"You mean the SEC policy of teaching English and Arabic in schools , not the school policy" (SU). 
She also suggested that the bilingual policy and its impact on student learning needs further consideration. She believed that the time given for Arabic classes is much less than the time devoted to teach English.

The other Arabic teacher, in contrast, showed acceptance of the bilingual policy :

"I do not think there is any harm in teaching two languages at school...Teaching English is a great thing, as one has to know the language of other societies, and gain their knowledge" $(\mathrm{OM})$

The two teachers reported that they abide by a strict separation policy and use only MSA in the classroom because this is a requirement from the SEC, for example:

"I believe that speaking and using MSA in the classroom is obligatory, it has been a requirement for teaching Arabic since the new system of education started, the SEC demands it” (SU)

When asked about how they related their understanding of the policy to their own teaching, both teachers reported that although they opt for strictly MSA, they sometimes code-switch to a colloquial dialect to explain difficult concepts. In relation to how they communicate the language rules to students, teachers responded that using MSA is a classroom rule, and this is stated on information sheets on classroom notice boards. One teacher added that instead of attempting to force the students to use MSA, they try to encourage them, as follows:

"I do not oblige them to speak in MSA, but if I speak with them in MSA I must correct their language, I must teach them and warn them and play with them to achieve my goal, as these things cannot be achieved by obligations and rules only, they must love this language” (OM)

The other teacher agreed with this approach and she reported that she uses games to correct students' speech, indicated by: 
“We have this nice game called 'Say ..and don't Say' ... when they answer or say a word in their own dialect we stop and the whole class shouts 'say and don't say' and then I give the equivalent in MSA" (SU)

The teacher explains that the aim is to correct students' mistakes in a routine fun way. For example if a student gave the wrong plural form the teacher will correct it with "Say $\mathrm{X}$ and don’t say Y".

The interview responses indicated that the Arabic language teachers opted for strict-language separation when it came to their own language use, but use positive encouragement to get the students to use MSA themselves.

The academic Vice-Principal presented a different view with regard to the bilingual policy of this school and independent schools in general. She stated that she believes it is better for students to study Mathematics and Science in their first language:

"Honestly I believe that for students to understand and achieve they should study mathematics and science in their mother tongue, all the leading countries that reached a place in the world development study these subjects in their mother tongue" (MN)

She also added that achieving excellent English and Arabic language skills is determined by individual differences among students, depending on their academic ability, as follows:

"I think .. In order to accomplish adequate ..good standards in English ..and Arabic.. we must differentiate between weak students and gifted students, in ..the excellent students are receiving excellent education but the low achieving students need continuous support...We also have students who are non-Arabic speakers... We are asking them to attain high standards in a second and a third language? I believe bilingual education is not suitable for all students” (MN) 
The Vice-Principal also complained that there is a lack of qualified teachers and support staff which presents a continuous challenge for the school.

\subsubsection{Language Choice Behaviour}

The responses of the teachers toward questions relating to their own behaviour in the classroom indicated that, although it is ideal to only use English they frequently used purposive code-switching from English to Arabic, for example:

"Yeah, there is some of Arabic involved. I mean you can do so much with like acting, but then there's words you just can't act, you have to just translate you know. It will be easier for them and the teacher just to translate in Arabic” (SA)

"I know that it's best just to speak English all the time ..I know that it's best and it's recommended, but I feel like it's ... yeah if everyone was the same level,” (SA)

Code-switching can be either random or responsible (Garcia, 2009). I termed responsible code-switching as "purposive" because it indicated that the recurrence of code-switching has a specific purpose. In the case of SA, the purpose of code-switching was to explain vocabulary items. The purpose of code-switching was also identified as a learning tool, for example:

"In the [Curriculum]Standards it's written that we can ... we can use this kind of teaching. It says if you tell the students what's this in Arabic, what does this mean, or I say an Arabic word, what is this word in English.” (AB)

The Arabic teachers reported that they code-switched only on very few occasions, either to explain a word, or for other activities such as checking attendance, or for social purposes. The Arabic teachers rarely used their own dialects because they were required to speak in MSA. One teacher's response is given as an example: 
"It is a beautiful thing to speak MSA and I have a passion for this language since my childhood, and the local dialects of the teachers and students are forbidden to use in the classroom, but we also understand that these are children and we try to reach their understanding as much as possible, and as you may know we have different dialects" (OM)

\subsubsection{Role of the Teacher in Bilingual Development Practices}

The interview protocol explored other programs that the school offered to develop students' language skills. The English teachers talked about a reading program in English whereby students were required to read one story and then be tested on it. They viewed this program as good practice because it helped to develop students reading skills. The Arabic teachers spoke about their role in developing students' language skills using the Arabic reading program, which is similar to the English program, except that it is voluntary, and the students read and are tested on a different book every week. The Arabic teachers also reported their involvment in assemblies and school-wide competitions related to Arabic language skills, for example:

"The Arabic language department is very active in organizing assemblies. Last week the students performed a play...We also participate in the break activities and provide Arabic quiz posters for the whole school to participate” (OM)

\subsubsection{Summary of Interview Responses}

The English language teachers (a) provided no clear evidence to confirm the existence of a formal school bilingual policy; (b) reported frequent purposive code-switching from English to Arabic, and considered that code-switching was justified as a learning tool; (c) reported few out-of-class activities for developing language skills.

The Arabic teachers:(a) also provided no clear evidence to confirm the existence of a formal school bilingual policy; (b) presented conflicting views about the use of a strict separation 
policy of using only MSA in the classroom, because student code-switching was tolerated; and (c) reported many contextual activities for the development of Arabic language skills, such as assemblies and school-wide competitions that helped to connect students with the Arabic language.

\subsection{Summary of the Organization of the Bilingual program}

Data about the organization of the bilingual program in Jazeera school was collected by means of a questionnaire, school documents, interviews with language teachers and the academic Vice-Principal. The following is a summary of the findings:

Analysis of school documents presented three main themes: (a) The school displays vague linguistic goals providing only implicit indications of the aim to develop first and second language skills. (b) The school projects a strong national identity focussing on Qatari values and traditions, clearly apparent in the content and graphics of the documents. (c) The educational goals are directed towards academic achievement and success, by focusing on teaching and learning strategies, curriculum planning, and professional development in an inspirational environment. The documents also highlighted (a) the support given to students in their first or second language learning and (b) a monoglossic subject-determined separation of the first and second language, with an allocation of 60\% English and 40\% Arabic. Literacy in the two languages was introduced simultaneously at the kindergarten stage. All English teachers are bilingual in Arabic and English. Language teachers had no formal educational qualifications, but the school provided professional development program as required by the SEC. No information was provided as to the extent to which the teachers participated in this program. There was an absence of documents defining the bilingual policy of the school and guidelines regarding the teaching and use of English, Arabic and local dialects. There was no evidence that the school provided any verbal or written orientation for students and teachers 
alike on language use in the school. The teachers provided limited information for students on language use policy inside the classrooms. Some teachers communicated their own perception of language of instruction use to the parents and students. The academic Vice Principal presented an opposing view of the school policy, reporting that she believed students should study Science and Mathematics in their first language and that bilingual education is not suitable for all students. The extent to which she communicated these views to her staff is unknown.

English teachers reported using frequent purposive code-switching between L2/L1 in their classrooms. This code-switching was justified as a legitimate teaching strategy and that it is easier for students of differing abilities. This practice presents what is termed flexible language use (Garcia, 2009). Arabic teachers on the other hand reported a strict separation of MSA/CA, opting to speak only MSA, and rarely using their own dialect; however, they reported that they tolerated some code-switching from students for error correction. Language was also corrected using games and positive encouragement.

Daily teaching plans indicated mechanistic model of educational organization. The focus on flexibility, professional development, and self-reflexivity also indicated some aspects of an organic model of educational organizations. The use of standards and competency related objectives reflected an operative model of teaching which focuses on achieving centralized outcomes. The plans included focus on values and morals, reflecting another aspect of the school's policy.

\subsection{Implementation of the Bilingual Program}

The practice elements and application of the bilingual program are described in the following sections. Following the descriptive framework put forward in the methodology chapter, the 
implementation of the bilingual program will be explored within two areas (a) classroom practice and (b) other out-of-class activities and programs.

\subsection{Observations in English Language Classes}

The information contained in the classroom interaction data cards was categorized into four themes (a) communication mode; (b) student and teacher language choice; (c) student grouping, and (d) instructional practice most used. The classroom observations provided most of the evidence to compare how the school advertised and organized its bilingual program against what was actually implemented in practice.

\subsubsection{Language Choice}

Analysis of the language choice in twenty lessons revealed that flexible language use of L1 and L2 (Blackledge and Creese, 2010,Garcia, 2009) was performed in the English classes. Teachers used L2 only in 45\% of the total number of events observed, whereas, L2 clarified by the first language, was used almost $50 \%$ of the time. The English teachers used Arabic more than the students, but the English language proficiency of the students was not evaluated. Code-switching occurred almost routinely to state the Arabic equivalent of new or unclear vocabulary items. Arabic was used by all three of the English teachers, to clarify new or difficult concepts. The English teachers rarely tried to paraphrase or use visual aids to explain the meaning of new words. The following extract is provided to illustrate how one teacher refers to Arabic constantly to explain the meaning of English words. In this session teacher is revising vocabulary items that have been studied some time ago:

T: $\quad$ "And Thursday your Ali-baba Story test. You will have some questions, and bring the books to me tomorrow. Let's do a quick review of the vocabulary words. It is not dictation, I didn't say it's dictation. No. You have to know the meaning of these words. I have the flash cards here, let's do a quick re- ... excuse me, don't speak .... 
Okay. Which word ... I will give the definition, you tell me what word is it if you remember.

T: $\quad$ Okay. Look at Majid, he is sitting ...

Several: $\quad$ Alone.

T ... alone. What is the meaning of 'alone'?

P $\quad$ waheed $\{$ alone $\}$

T Waheed\{alone\} Okay.

P Waheed $\{$ alone $\}$

T Okay, my house is nice and comfortable. I feel ...

Several: $\quad$ Safe.

T $\quad$... safe. Bil-aman $\{$ safe $\}$ is safe?

$P \quad$ Aman $\{$ safe $\}$

T Majid, \{safe\}Aman Okay. Excellent. When there is danger, I need to ...?

Several Hide.

T ... hide. Yakhtaby\{ to hide\} hide?

Several Yakhtaby\{to hide\}

Students used L2 about 75\% of the time. Except for social talk, students spoke Arabic (their Qatari Dialect rather than MSA) only when prompted to do so by the teacher, to give the Arabic translation of a word, to check understanding, or to elicit answers from less proficient speakers. The students used L2 clarified by L1 about 25\% of the time. When students used their L1 to talk amongst themselves they were not reprehended, but when asked to address the teacher or discuss a topic out loud they used L2 or L2 clarified by L1. For example, in the following extract, students are reading a text about different cultures, and the teacher is prompting a discussion about the pictures in the book and the concept of culture. 
T "Say it in Arabic, the students will help you how to say it in English - go ahead.

$P \quad$ Fe amakin yadrsoon bil Englizee \{In some countries students study in English\}

T Okay Hammad, this is about work. Okay. Not studying. Work (pointing to the picture on the board) Some countries ... Hammad, listen ...

$P \quad$ In other schools..

T But we're talking about all over the world.

$P \quad$ (pointing at a picture) what is this?.

T The bus station.

P Fe baadh il buldan yerohoon il sheghil bil bas \{in some countries people go to work using buses\}"

\subsubsection{Communication Mode}

The communication modes observed in English classes (as percentages of the total number of observations of listening, reading, writing, and speaking) are illustrated in Figure 6.5 


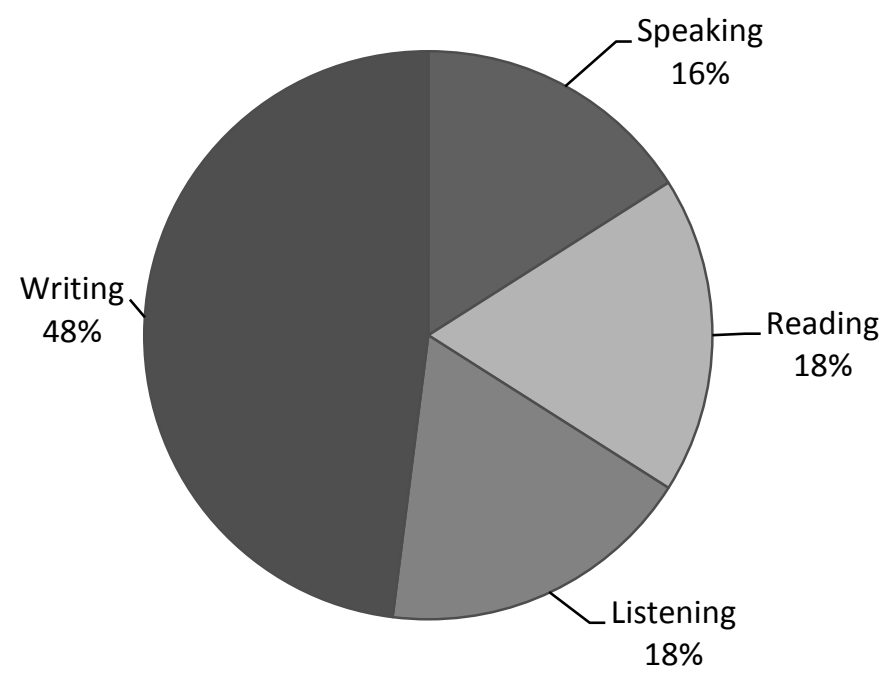

\section{Figure 6.5: Communication Modes in English Classes}

The most frequent (48\%) of the observed activities in the English classes involved writing, including answering task sheets, filling in gap exercises, or writing sentences in response to a visual prompt. Less frequent (18\%) activities included listening to directions or explanations from the teacher, or reading prescribed texts in silence. Verbal activities, including reading out aloud or speaking, were the least frequent communication mode (16\%).

\subsubsection{Grouping}

The percentages of three types of physical grouping observed in the English classes are compared in Figure 6.6. $44 \%$ of the observed tasks and activities were performed by all students in the class (referred to as Total Class in Figure 6.6). 30\% of the tasks and activities were carried out by individual students. $26 \%$ of the observed tasks and activities were performed by students in small groups of four to six, including writing and answering task sheets and text book exercises. No working in pairs were observed. 


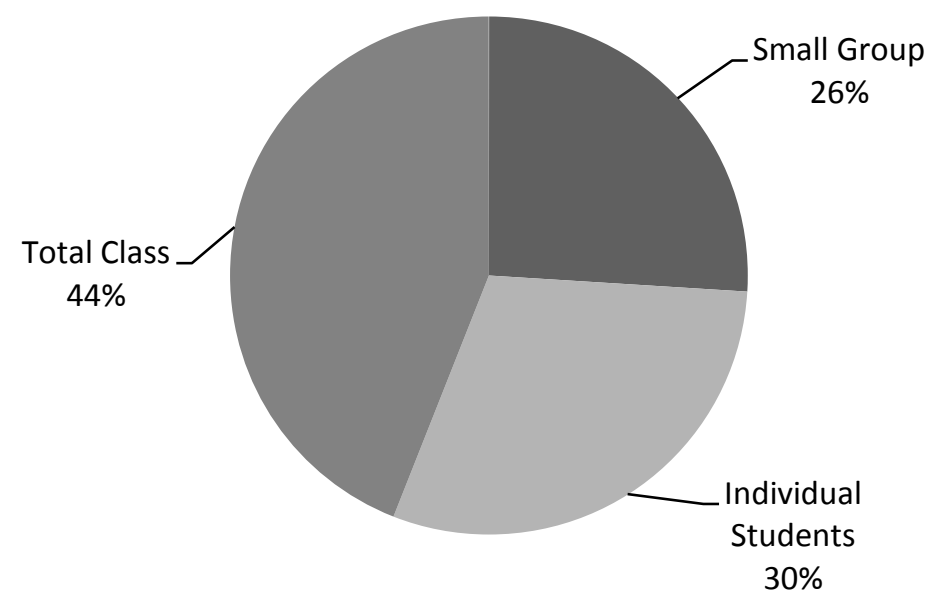

Figure 6.6 Grouping of Students in English Classes

The students' seating was arranged in groups of four to six students; however, except when they were performing group or individual tasks and activities, the teachers usually delivered the lesson by addressing the whole class. The teachers were not observed to move around the class to work with small groups or individual students.

\subsubsection{Instructional Practice}

The School management, provides the English language teachers with the curriculum standards for grade four, as published and stipulated by the SEC. These are then translated into the use of text books and course material and converted into teaching plans following a pro-forma distributed by the SEC as well. Although this reflects the a centralised operative model of school organization, there was evidence of an organic model operating as well, reflected by the ways in which the teaching plans did not strictly follow the text book material, and other content matter was incorporated. The teachers had an opportunity to utilize their own professional capacities as the plans indicated. Because of the domination of the operative model, however, the style of teaching of the three teachers was similar, because 
they all used the same content and techniques. These instructional practices, can be identified as the school practice. In the following sections each of these practices will be described in detail reporting on the actual classroom implementation of the school policy and any other aspects as well.

Table 6.3 records the relative frequencies of different instructional practices observed in the English classes, categorized as High, Medium, Infrequent, or None, based on an analysis of the sum of the observed practices among the instructional practices of the three teachers. The most frequent practices were use of high relevance material, explicit teaching of grammar and focus on vocabulary, establishing routines and multiplicity. The least frequent practices were focus on academic language, highly cognitive content, and bridging.

Table 6.3 Frequency of Use of Instructional Practices in English Classes

\begin{tabular}{|c|c|c|c|c|}
\hline Practice & High & Moderate & Infrequent & None \\
\hline Initiation-response-feedback (IRF) sequence & & $\mathrm{x}$ & & \\
\hline Focus on academic language & & & $\mathrm{X}$ & \\
\hline Use of co-operative learning & & $\mathrm{x}$ & & \\
\hline Use of high relevance material & $\mathrm{X}$ & & & \\
\hline Highly cognitive content & & & $\mathrm{x}$ & \\
\hline Explicit grammar teaching & $\mathrm{X}$ & & & \\
\hline Explicit focus on vocabulary & $\mathrm{X}$ & & & \\
\hline \multicolumn{5}{|l|}{ Scaffolding } \\
\hline Establishing routines & $\mathrm{x}$ & & & \\
\hline Contextualization (teaching aids) & & $\mathrm{x}$ & & \\
\hline Modelling & & $\mathrm{x}$ & & \\
\hline Bridging & & & & $\mathrm{x}$ \\
\hline Multiplicity & $\mathrm{X}$ & & & \\
\hline Task based instruction (TBI) & & $\mathrm{X}$ & & \\
\hline Focus on reading & & $\mathrm{x}$ & & \\
\hline
\end{tabular}


Using the activity codes listed in Chapter 3, a wide variety of instructional activities were observed, with no clear prevalence of one activity over another (Figure 6.7).

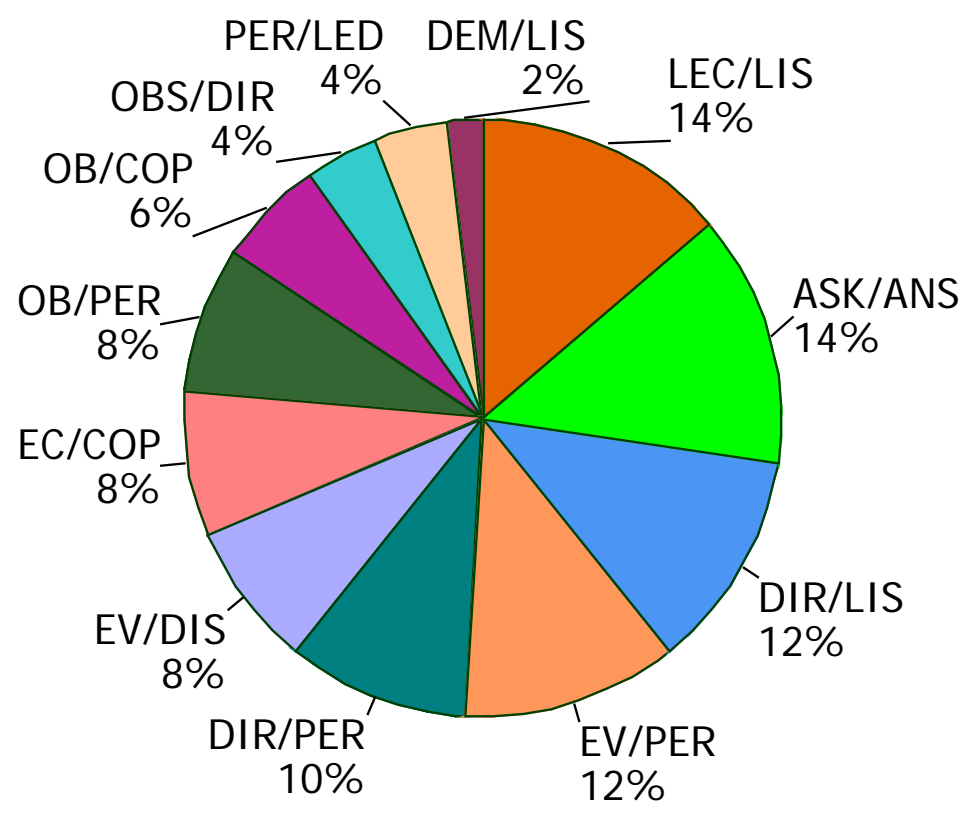

Figure 6.7 Instructional Activities in English Classes

\subsubsection{IRF Sequence}

There was a moderate use of the IRF sequence. The sum of activities coded as teacher asks/students answer (ASK/ANS) and teacher lectures/students listen (LEC/LIS) made up about $28 \%$ of the activities, reflecting two-way interactions. An exchange of turns, either voluntary, or chosen by the teacher, reflected a type of negotiation of meaning that is essential to second language acquisition and understanding of language content in general. This sequence of initiation-response-feedback, however, has been criticized as unproductive, because it produces the language the teacher is expecting, rather eliciting novel output from the students (Welsh, 2002). 
The following extract provides an example, taken from an English lesson where students were learning about culture. The teacher was showing some pictures and the students were answering questions about differences in cultural behaviour. It reflects that the IRF sequence was used in a portion of the lesson, but did not dominate instructional practices. The main focus was on vocabulary and grammar.

"My religion is Islam. Some religions are ..

$P$

Christian.

$T$

Christian. So ... Christian, Faysal?

$P$

\{speaking Arabic\}

$T$

Different religions okay. Clothes .. you know what's clothes? And food. Go down Ali. Slowly slowly slowly. Slowly. What do you see here? You see here how many pictures?

$P$

Two.

$T$

Two. Look at the pictures below and describe the different cultures of the people. Look at this man, he is a ...

Several Businessman.

$T$

And this guy is a ...?

Several Farmer.

$T$

So how is it different? Look at it, what can you say is the difference between the two? What's the difference in jobs, or culture, the way of living here. Nobody? (inaudible) yes?

$P$

Miss, the businessman rich and live in a big house. The farmer is poor and live in a small house.

Okay. Can you talk about the jobs? The jobs. Mohammed, yes.

$P$

Miss, the farmer cuts the trees and the businessman working on the computer.

$T$

Okay yes. Businessman, look how he dresses - he wears a suit, tie, pants, he has a briefcase, and he goes to work in a nice clean place, and he works indoors, (inaudible) indoors.

$P$

(speaking Arabic) 
Out.

$T$

Outdoors. And he gets dirty and he cuts and he'll ... you understand. Next page. Now look here, you have food. What's this one?"

\subsubsection{Explicit Focus on Vocabulary}

A focus on vocabulary was one of the strongest instructional practices observed in the English language classrooms. In every lesson there was at least one vocabulary related activity. These included the introduction of new vocabulary items, with explicit teaching of English words, and their Arabic meaning, and vocabulary quizzes or a vocabulary worksheet to be answered. The following extract presents a teaching event when the teacher was reviewing a vocabulary item with students using contextualizing and acting. This extract is representative of many instances of explicit vocabulary teaching used by the English teachers to explain word meaning, and also to check the student understanding/comprehension.

$\begin{array}{ll}T & \text { "When there is danger, I need to ...? } \\ \text { Several } & \text { Hide. } \\ T & \text {... hide. (Arabic) hide? } \\ \text { Several } & \text { (Arabic) } \\ T & \text { So can you hide somewhere in the class? Find a place to hide } \\ & \text { quickly. Quickly. Who wants to hide? } \\ P & \text { Me, me! } \\ T & \text { Ahmed Aman hide. Slow. (pupil goes to hide) } \\ T & \text { Where is Ahmed Aman hiding? } \\ P & \text { Under the table. } \\ T & \begin{array}{l}\text { Under the table. Look how you spell 'hide' - H I D E. When } \\ \text { something is funny, what do you do? }\end{array} \\ \text { Several } & \text { Laugh. }\end{array}$


Several (spell out word)

T G G G G laugh for me now." (pupils laugh)

Figure 6.8 illustrates an example of explicit focus on vocabulary, in the form of a short quiz. This type of quiz was used as a routine activity, several times a week.

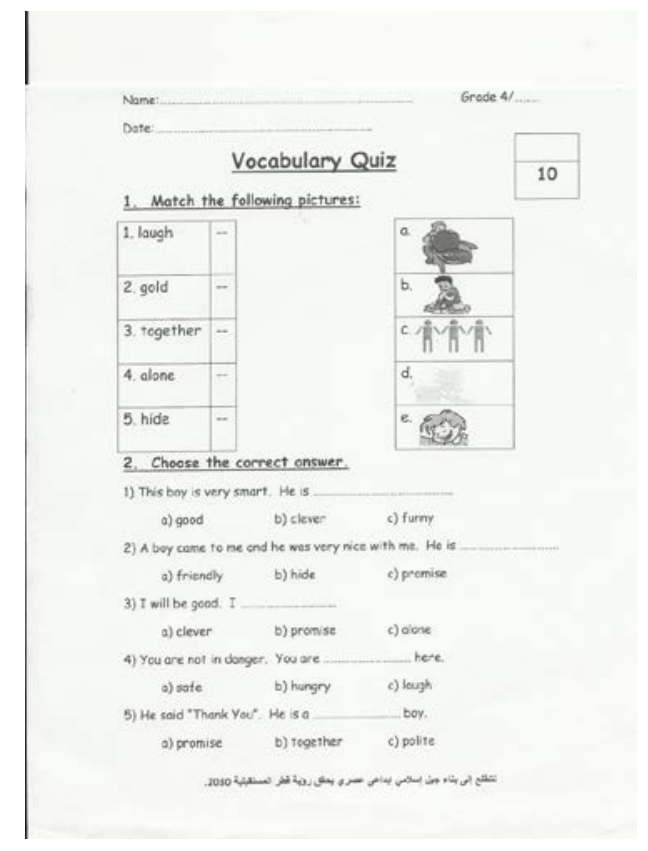

Figure 6.8 Vocabulary Quiz

The quiz displayed in Figure 6.8 was devised by the teacher and was not copied from a published text . The students were presented with this quiz as a test of words that were studied in a previous lesson.

\subsubsection{Explicit Focus on Grammar}

An explicit focus on grammar was a strong instructional practice in the observed lessons. Figure 6.9 illustrates some typical students’ worksheets, related to grammatical structure. 


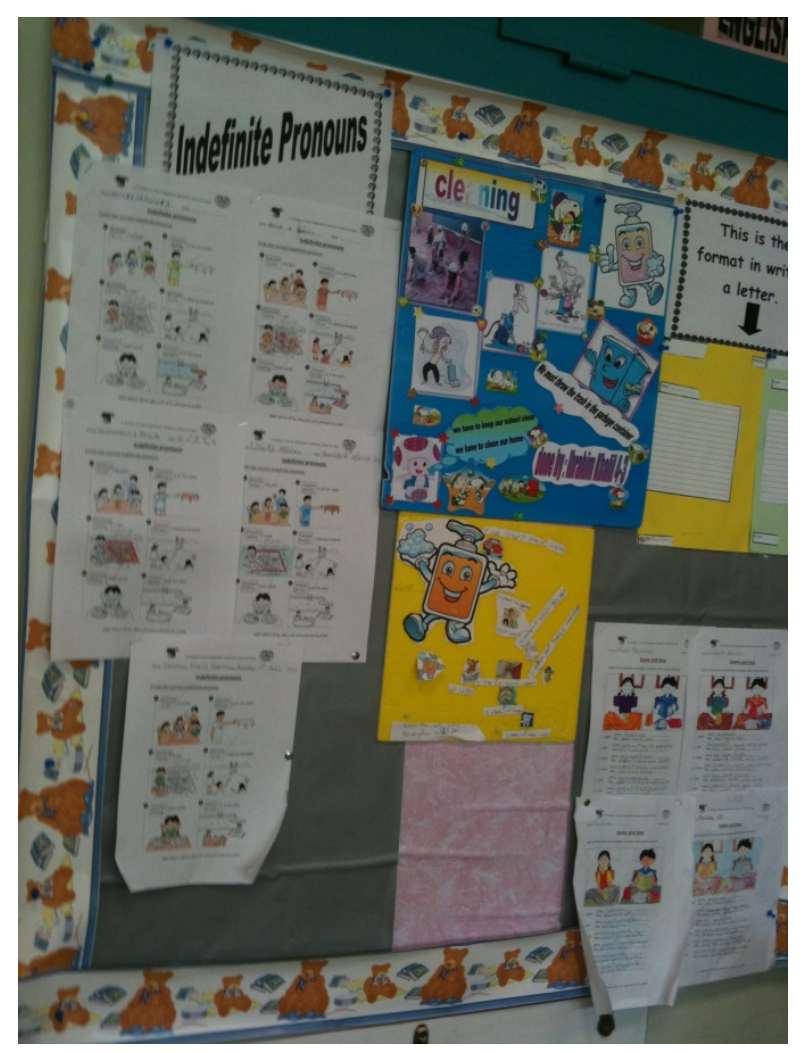

Figure 6.9 Grammar Practice Worksheets

Grammatical structures were explained by the teacher, and memorized by the students, as the following extract exemplifies. The teacher spent 15 minutes reviewing subject and object pronouns and then asked the students to review these at home because they will be tested the following day on subject and object pronouns. This type of exercise was a frequent part of lessons, and pupils were given daily lessons relating to grammatical practice:

P $\quad$ "The balls are yellow, put the balls the box.

$T \quad$ Okay, what's the problem in this sentence? Why is the balls written underlined and bolded? Hamad Rashid can you answer this question? Listen to my question ... I said why is this one underlined and bold? Why do we need to change this one? 'The balls are yellow, put the balls in the box.'

$P \quad$ (inaudible)

T Listen to what the boys will say. Tell me why?

P $\quad$ Because balls are .. them.

$T \quad$ Them is correct, okay. But you're not answering my question. The balls are yellow, put the ball in the box ... why is this word ... what's the problem with these two sentences? Ali? 
$P \quad$ It's repeated twice.

$T \quad$ It is repeating. The word 'the balls' is said again in the second sentence. It's said twice - you don't need that, you can make it better, easier to read. Take the balls out ... 'the balls' is that one or many things.

Several Many things.

T Many things, because there's an S here. So when it's many, is it 'them' or 'it'?

$P \quad$ Them, them.

T Them because it is plural"

This is a typical practice where the students were 'drilled' to practice use of various grammatical forms and structures. This is usually done as a whole class where the teacher managed solving the exercise sheet. In this and other observations few students participated while the other listened and filled out their sheets with the answers as instructed by the teacher.

\subsubsection{High Relevance Material}

Effective pedagogy for bilingual students should be relevant to their identities (Cummins, 2006). This means that the teachers should capitalize on the student's backgrounds and view their L1 and culture as a contextual resource. Contextualized content empowers students and enables them to relate the content of the curriculum to their individual or collective experiences. I observed that the lesson content was usually highly relevant to students, and interconnected with their daily lives. In writing tasks, the teacher often chose topics which were related to their everyday lives. One example is when the teacher asked students to bring pictures of themselves as babies into class, as part of a writing exercise about growth and change over time. In another writing task, the students were asked to write a paragraph responding to the following question about what they like to do with their families:

" I want the homework of writing about your family, this homework - what you like to do with your family" 
It was obvious that the teacher often connected the content to students' daily lives, as exemplified by the following extract:

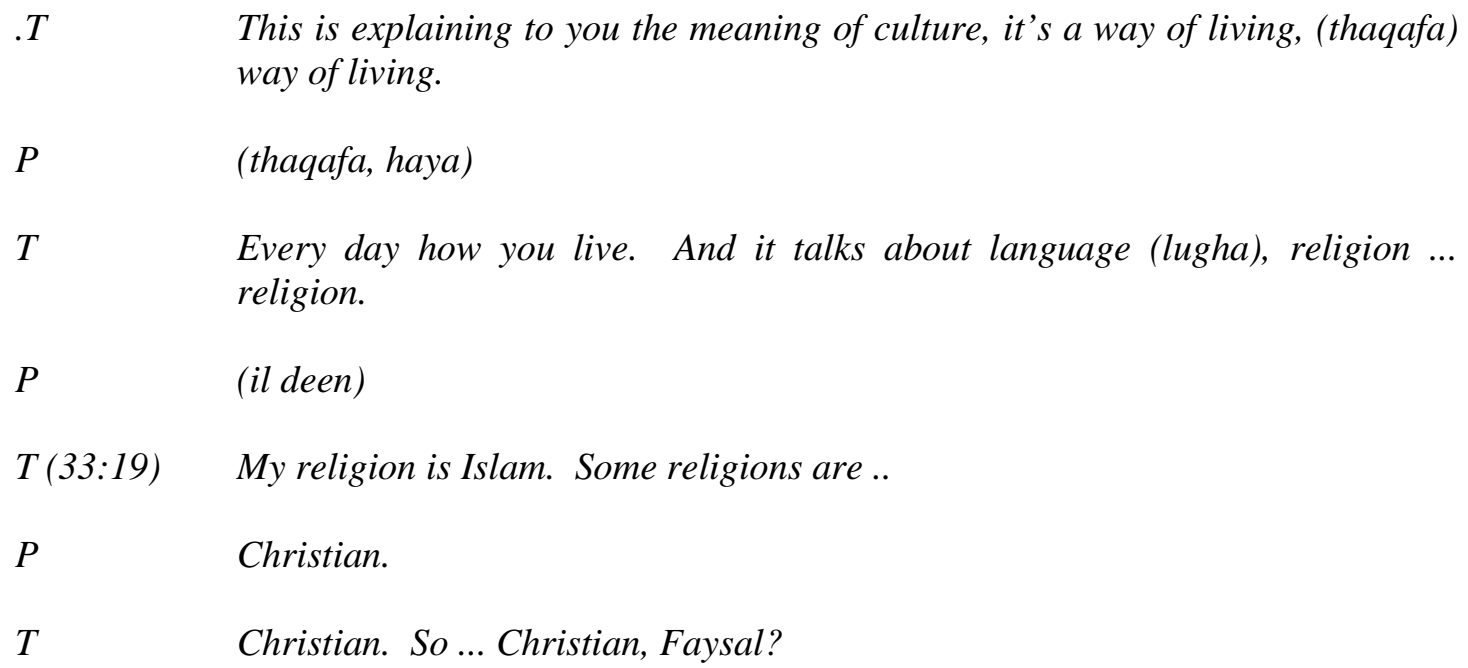

Then the teacher asks about food :

$\begin{array}{ll}T & \text { What kind of food do we eat in Qatar? } \\ P & \text { Salad and rice. } \\ T & \text { Salads ... everyone eats salads. }\end{array}$

These examples, which are representative of the majority of activities observed, indicate a strong focus on using material that is relevant to the students daily living experiences, thereby linking the curriculum content into the context of their own world.

\subsubsection{Focus on Academic Language}

Meaningful pedagogy in bilingual programs usually focus on disciplinary and academic language. Halliday (2001) prescribes that lessons should engage students in discussions of how specific written and spoken texts are structured. These might include vocabulary that is specific to the discipline, writing mechanics, and research abilities. Although the school teaches mathematics and science through the medium of English, the English classes were 
observed to offer little support to develop decontextualized language skills needed to study math and Science in the language classes. It is also characteristic of academic conversation where meaning is conveyed via linguistic cues, such as cohesion devices, that are independent of the immediate communicative context where comprehension depends significantly on knowledge of the language used. This is opposed to contextualized language which is Meaning can be negotiated by participants, such as via feedback from listeners about how the message was understood (Cummins,1994). These two concepts are central to Cummins (2000) differentiation of conversations/academic language proficiency. Discipline related language skills are important to develop academic language. In the lessons, focus on academic language was classified as "Infrequent" (see Table 6.3) because it was rarely observed. A rare example of focusing on academic language is the way in which one teacher drew attention to the way poetry as a genre is presented in written form:

$T \quad$ "The house will be so noisy as we all like to speak. There'll be laughter and singing for the whole of next week. And when they all go home I know they'll stay in touch, but the house will be so quiet and I'll miss them all so much. (inaudible) stop. Excellent. Do you know what's this in English? In English this means it's a poem.

P $\quad$ (several pupils speaking) (in Arabic) Po-em ?

T Poem. P O E M. they rhyme. There are words that sound the same. Hat, cat (?) door - floor, like that.

\subsubsection{Highly Cognitive Content}

A cognitively undemanding task is one in which the student has access to a range of visual and oral cues; for example looking at pictures of what is being talked about in a foreign language by the teacher, describing a simple object, or asking questions to confirm his/her understanding. A cognitively demanding task is one such as understanding grammatical structure, where there are no external sources or cues to help, other than the language itself. Cummins (2000) argues that effective bilingual education involves cognitively demanding 
tasks that are context embedded in the curriculum, and that students need to develop cognitive academic language proficiency in the L2 to achieve success in studying through the medium of a second language. In all of the observed English lessons, the use of cognitively demanding material was limited. For this reason, high cognitive content was classified as "Infrequent" (see Table 6.3).

\subsubsection{Cooperative Learning}

Gibbons (2002) defines cooperative learning as an approach where students must work in groups to complete tasks collectively towards an academic goal. Such practice, Gibbons suggests, encourages focus on form and function of language. Based on my observations of the frequency of use of different instructional practices in English classes, the use of cooperative learning was classified as "Moderate" (see Table 6.3). Some examples are provided.

During some but not all English lessons, the students are assigned into small groups of five or six and a leader, and the students must work on tasks within their assigned group. Group leaders delegate responsibilities for some tasks. Within the groups, the students ask one another for information, explanations, and evaluate each other's ideas and work. It is not known if the teachers offered guidance at the beginning of the year in relation to cooperative group work.

Cooperative work was used in the unit about "show-and-tell" described in the previous section. Groups of students were asked to present ideas and talk about certain objects In the reading comprehension task students were asked to read and answer questions together as a group. The teacher may also evaluate group work by using points which a group can earn after successfully completing a task before the other groups. One creative teacher used marbles and boxes to motivate cooperative learning, as indicated in the following extract: 
$T \quad$ Leaders, I want the homework of writing about your family, this homework - what you like to do with your family. Leaders, give me this one first.

T Ahmed Majuhed, did you do anything? No you didn't fix anything. Next, leaders ... give me the worksheet of 'Big city noise'. Leaders you tell them. (?) (pupils speaking among themselves)

T Okay, but you all did it?

$P \quad$ Yes.

$T \quad$ So we're going to have to wait for him to bring it. Leaders, let's go. Five marbles for E. Okay, five marbles for A. (pause)

T Five marbles for $F$.

Getting points on a group basis is assumed to reinforce learning because it presents a form of peer pressure and motivation to finish tasks in order to earn marbles. When they reach 25 marbles they receive a reward, such as having special access to a place, having a picnic that the teacher pays for, playing a group board game or watching a movie in the auditorium. Other popular collaborative techniques, were not used in any of the observed English lessons, such as the use of jigsaw tasks or dictagloss (a procedure that encourages students to reflect on their own language output).

\subsubsection{Scaffolding}

The use of five scaffolding structures in the English lessons was examined (see Table 6.3). A high frequency of establishing routines was observed. All lessons started by arranging the seats and tables. The class objectives, curriculum standards, date and vocabulary of the day were displayed on the white board. Other established routines included how the homework was collected. A high frequency of multiplicity was also observed, because all the task sheets had two versions, an easy version for the less able students, and a complicated one for the more able students, whilst a support teacher was assigned for the low achieving students. Contextualizing in the form of teaching aids was used with moderate frequency, for example, incorporating pictures, objects, texts and videos shown on the data show as well as acting, 
paraphrasing and body language. Modelling was also used moderately. The teacher sometimes modelled reading, presentations and other tasks as a way of guiding the students into the tasks and to demonstrate how it is done. Bridging old and new material was not observed. There was no evidence of linking old material to newly studied content.

\subsubsection{Task Based Learning}

Ellis (2003) defines task-based language learning and teaching as an approach that gives learners tasks to transact rather than items to learn, providing an environment promoting a natural language learning process. The focus of task based learning is on speaking and interactive tasks that involve other skills such as writing, mostly in the planning or the preparation of the task. All the teachers' lessons contained examples of task based learning.

Show-and-tell is an example of using task based instruction, because it involves communicative strategies and a focused task ( Ellis, 2003). The teacher introduces the task by showing a video of students in a western school presenting an item from their home environment and speaking about it. The teacher speaks about how to present the item including the reason for choosing it. The teacher then provides a written text describing an item and asks each student to bring an object from home and speak about it in front of the class, after preparing a written text. The students discuss in groups the object they might bring from home as their show-and-tell, and are then presented with planning sheets containing questions that guide them to plan their presentation. Students used the questions to individually write a first draft in the classroom and then to go home and finalize it as homework.

Other task based learning activities observed with moderate frequency in the English lessons were (a) the students were given short stories, a question sheet and had to answer the questions after reading the story and present answers orally to the class; (b) a sheet was filled 
in, requiring information about the students as babies, providing a picture and presenting these to the class after discussing in groups. I observed that task based learning could lead to confusion, because some students were not sure about the task given to them. For example, in one class, the students were not sure whether they needed to erase the worksheet and re-do it, or to write a new paragraph in their notebook, or to draft the paragraph from their guided writing worksheet. The children with learning difficulties were grouped together but did not seem to understand what the task was. The teacher, after distributing the corrected worksheet, went back to her desk and called individual students to come to her to check. After a while the students were hesitant to come to her alone, so she called them by groups.

\subsubsection{Focus on Reading}

A focus on reading fluency and reading comprehension was sometimes observed in the lessons, and its frequency of use was therefore classified as "moderate" (see Table 6.3). The students are assigned a book to read for the semester which they read in their own time, and are subsequently tested via a reading assessment in which the teacher often corrects students' pronunciation. In one week all students have read out aloud at least twice. The students are guided to use reading strategies, such as the one used in the following extract, when teacher reminded the student of how to read long words out loud by cutting them into separate syllables. The student knew about cutting a word into syllables, providing evidence that this strategy had been explained in a previous lesson:

T Okay thank you for this information. Down here. Excuse me. Hammad Abdullah would you like to read? 'T U R E' is 'chur' ... 'culture'

$P \quad$ Culture is defined ...

T $\quad$ Defined ...

$P \quad$ (inaudible) the people's way ...

T Way 


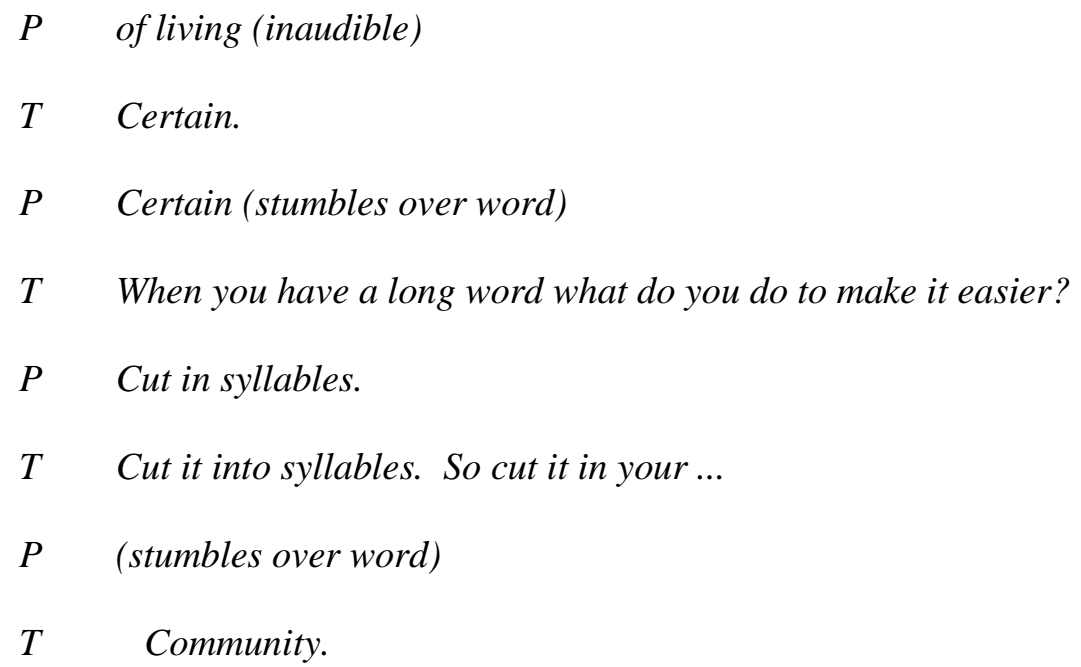

\subsubsection{Summary of Observations in English Classrooms}

The English classroom observations led to a description of the frequency of use of different current teaching practices.

All the teachers in English classes employed a flexible use of language, opting for a convergence model. Purposive code switching from English to Arabic occurred in almost $50 \%$ of the interactions between teachers and students. The communication mode that the students mostly engaged in was writing. The grouping of students according to task was primarily done with the whole class, with less frequent assignment of students into small groups of five or six.

There was a high focus on explicit grammar and vocabulary teaching, and the use of high relevance materials. Scaffolding techniques such as establishing routines and using multiplicity in the form of graded material for different levels of proficiency were used very frequently. The frequency of use of the IRF sequence, contextualization, multiplicity, and cooperative learning, was classified as moderate. There was infrequent use of explicit teaching of academic language and using highly cognitive material. The only practice not observed was bridging, since there was no evidence of teachers trying to connect old and new 
material. Differences between English and Arabic, such as directionality and structural differences were not explained in grade four.

\subsection{Observations of the Arabic Language Classrooms}

The observations of the Arabic language classrooms followed the same protocol as used in the English lessons. Data reduction cards were were completed to identify four key areas: communication mode, student teacher language choices, students grouping and frequency o use of instructional practices.

\subsubsection{Language Choice}

A flexible use of MSA and colloquial dialects (CA) was observed in the Arabic classes. The observations were similar for both teachers in all three classes. Students and teachers switched between these two codes frequently. Students often followed the lead of the teacher. However this was not a consistent observation. On a number of occasions the entire lesson was delivered using MSA and the teacher would correct all CA use. On other occasions the same teacher would refer to her own CA, and CA was primarily used to give directions, instructions for tasks, or for discipline. Lesson content was never provided in CA or for explaining vocabulary items

Code switching was only used to direct tasks and keep discipline, but the teachers were not observed to use colloquial Arabic to explain the lesson's content, vocabulary or grammatical structures. This took place in MSA only. The colloquial dialect used by the teacher was always their own. One teacher spoke an Egyptian dialect and another a Jordanian dialect whereas students used their own Qatari dialect in response. With their flexible use of two languages or dialects, their teaching can be termed convergent mono-literate (Garcia 2009). 


\subsubsection{Communication Mode}

The communication modes observed in Arabic classes (as percentages of the total number of observations of listening, reading, writing, and speaking) are illustrated in Figure 6.10. In $30 \%$ of the observations, the students were engaged in total class discussion (listening /responding) or 30\% they were reading (including reading out loud). Students listened to the teacher's instructions in $18 \%$ of the observations, and in $11 \%$ they were speaking alone. Writing was the least frequent communication mode, comprising only $6 \%$ of the observations, in which the students undertook text-book exercises or copied from the board into their notebooks.

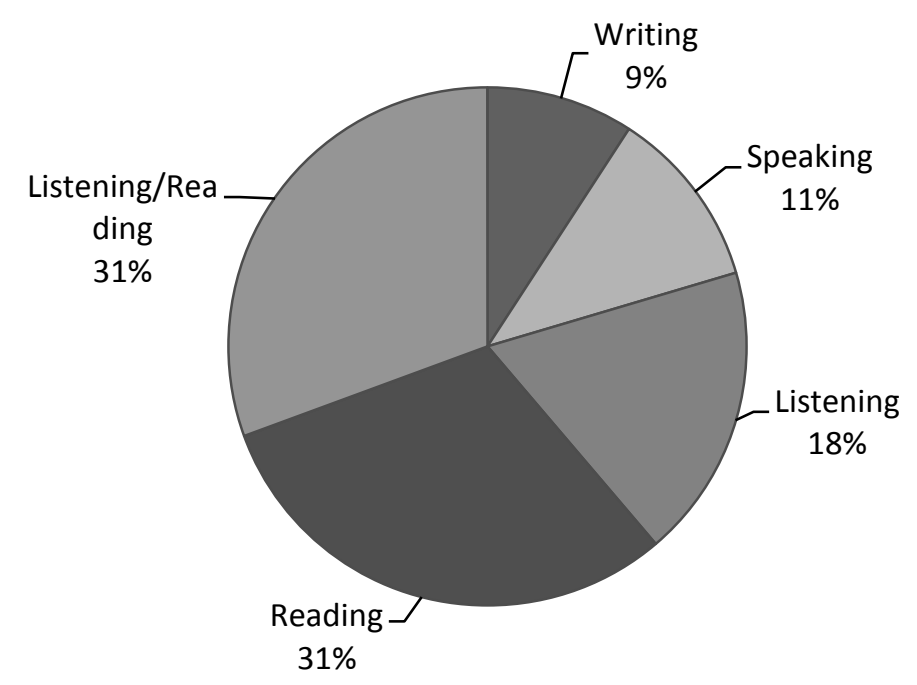

Figure 6.10 Communication Modes in Arabic Classes

\subsubsection{Grouping}

The grouping of students in Arabic classes is illustrated in Figure 6.10 . In $50 \%$ of the observations, the students were spatially organized in single rows and engaged in tasks or activities as a total class, or as single students (30\%). No pair work and limited group work was utilized. In only $20 \%$ of the observations did the students work in groups of five or six. 


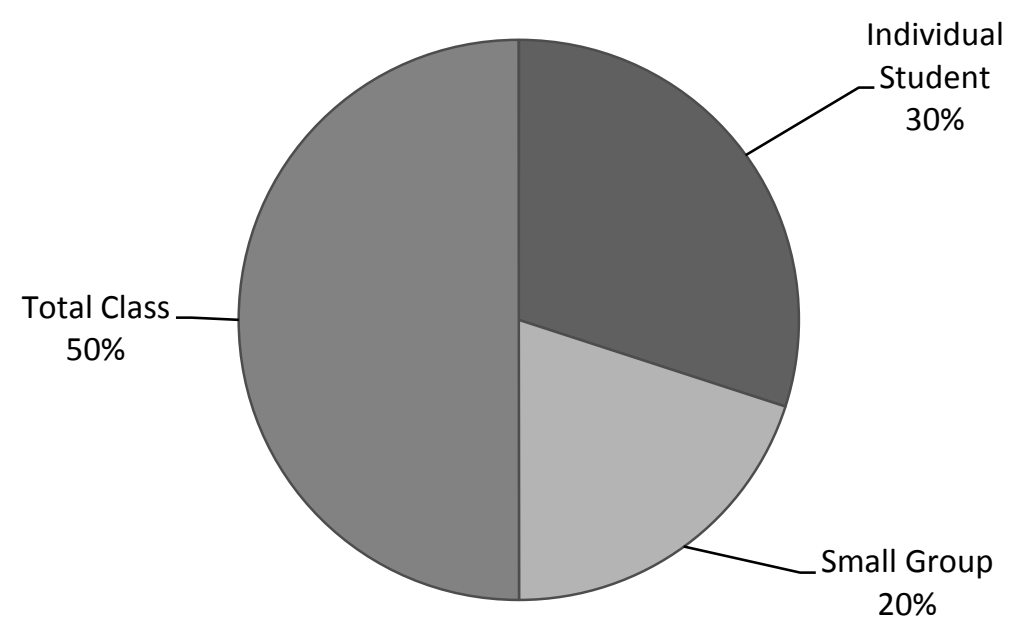

Figure 6.11 Grouping of Students in Arabic Classes

\subsubsection{Instructional Practice}

Table 6.4 records the relative frequencies of use of different instructional practices observed in the Arabic classes, categorized as High, Medium, Infrequent, or None, based on an analysis of the sum of the observed practices among all the teachers.

Table 6.4 Frequency of Use of Instructional Practices in Arabic Classes

\begin{tabular}{|c|c|c|c|c|}
\hline Practice & High & Moderate & Infrequent & None \\
\hline Initiation-response-feedback (IRF) sequence & $\mathrm{X}$ & & & \\
\hline Focus on academic language & & $\mathrm{X}$ & & \\
\hline Use of co-operative learning & & & $\mathrm{X}$ & \\
\hline Use of high relevance material & $\mathrm{X}$ & & & \\
\hline Highly cognitive content & & & $X$ & \\
\hline Explicit grammar teaching & $\mathrm{X}$ & & & \\
\hline Explicit focus on vocabulary & $\mathrm{X}$ & & & \\
\hline Scaffolding & & & & \\
\hline Establishing routines & & $\mathrm{X}$ & & \\
\hline Contextualization (teaching aids) & & & $X$ & \\
\hline Modelling & & $\mathrm{X}$ & & \\
\hline Bridging & & $\mathrm{X}$ & & \\
\hline Multiplicity & & & & $\mathrm{X}$ \\
\hline Task based instruction (TBI) & & & & $X$ \\
\hline Focus on reading & $\mathrm{X}$ & & & \\
\hline
\end{tabular}




\subsubsection{IRF Sequence}

There was a high frequency of use of the IRF sequence by the Arabic teachers. Controlled discussions frequently followed a lecture whereby the teacher presented information or content to the students either visually or verbally. $35 \%$ of the total number of interactions were coded as ASK/ANS when the teacher asked questions and the students responded. $23 \%$ of the interactions were coded as LEC/LIS when students listened to the teachers delivery of content or explanation of material. In $14 \%$ of the interactions the students were also listening to directions ( DIR/LIS). The students were listening about 58\% of the time, whereas teachers where speaking $52 \%$ of the time.

The majority of observations of instructional practices in the Arabic classes used the IRF sequence, as the example below demonstrates. It is concluded that the IRF sequence is characteristic of Arabic language instruction:

T Saad, did you write [the paragraph]?

$P \quad$ No, but I looked up the topic.

T only searched, speak SA Saad. What about you Ibrahim?

(pupil stands up)

P I wrote six (seet) lines

T $\quad$ six (seet) or six (seeta) [correcting his grammar]

$P \quad$ let me remember.... seeta (the correct form)

T What did you read about tide Nasser?

$P \quad$ high tide when the waves come near to the shore and low tide when it is away from the dirt.

$T \quad$ what do you mean by dirt?[teacher prompting the student to use the term she is expecting which we then realize it is sand. All this was done in MSA] (pause)

$P \quad$...sand

$T \quad$ Sand is a more accurate expression Ibrahim did you read about the tide yesterday

$P \quad$ (reading from his note book) Two phenomena that take place in the waters of the seas and oceans influenced by the moon. The high tide is the gradual raising of the sea level. Low tide is the gradual fall of the sea level. 


\subsubsection{High Relevance Material}

The observations indicated that the Arabic lesson content was usually highly relevant to students, and so the frequency of use of high relevance material was classified as "High" (see Table 6.4). The examples and materials used either related to their individual or collective experiences, or was relevant to their identity. High relevance material enables students to relate the content of the curriculum to their daily experiences (Cummins, 2000). For example, one lesson was about families, and pictures of Arabic families were displayed in the textbook. On another occasion, the teacher used student experience to exemplify content. In this lesson about information texts the teacher was discussing ocean tides and asked students about their own experience on the beach:

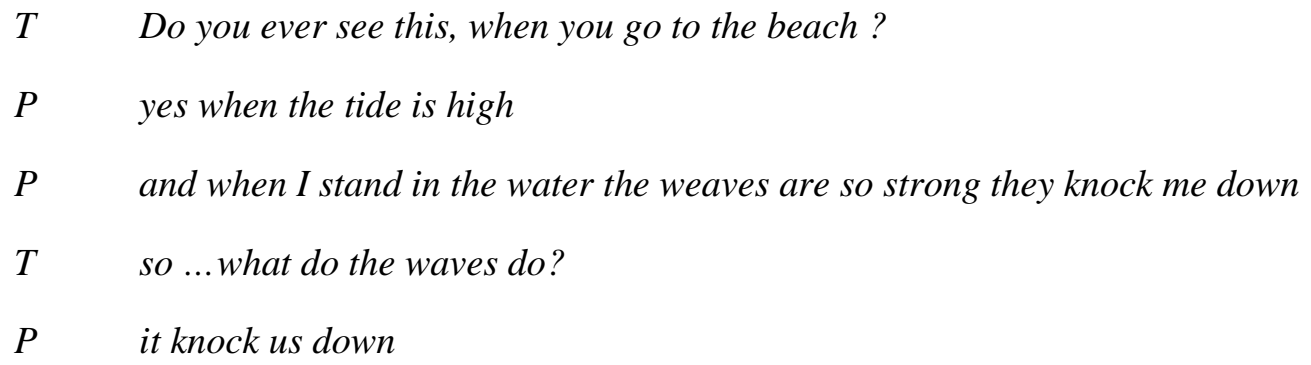

In another lesson, the teacher asked the students to describe herself first, and then to give a description of some of the students to highlight the difference between physical description and personality traits. However, at other times this high relevance to students culture or identity or immediate learning environment is missing. For example, in their reading program the book that was given for students to read was a western story (Gulliver's Travels) translated into Arabic.

\subsubsection{Highly Cognitive Content}

Cummins (2000) defined a cognitively demanding language task as one such as understanding grammatical structure, where there are no external sources or cues to help, 
other than the language itself. The use of highly cognitive content was classified as "Infrequent" in the Arabic classes (see Table 6.4). Lara-Alico and Parker (2007) distinguish between light cognitive content (e.g. discussing community news) and dense cognitive content entailing conceptually demanding specialised vocabulary and critical thinking (e.g., speaking about a chemical experiment in a science class). An example of dense cognitive content is an Arabic class where the topic was explaining how volcanoes work. Figure 6.13 displays part of the students' homework on researching and writing a one-page piece about volcanos to enable them to understand explanatory scientific information.

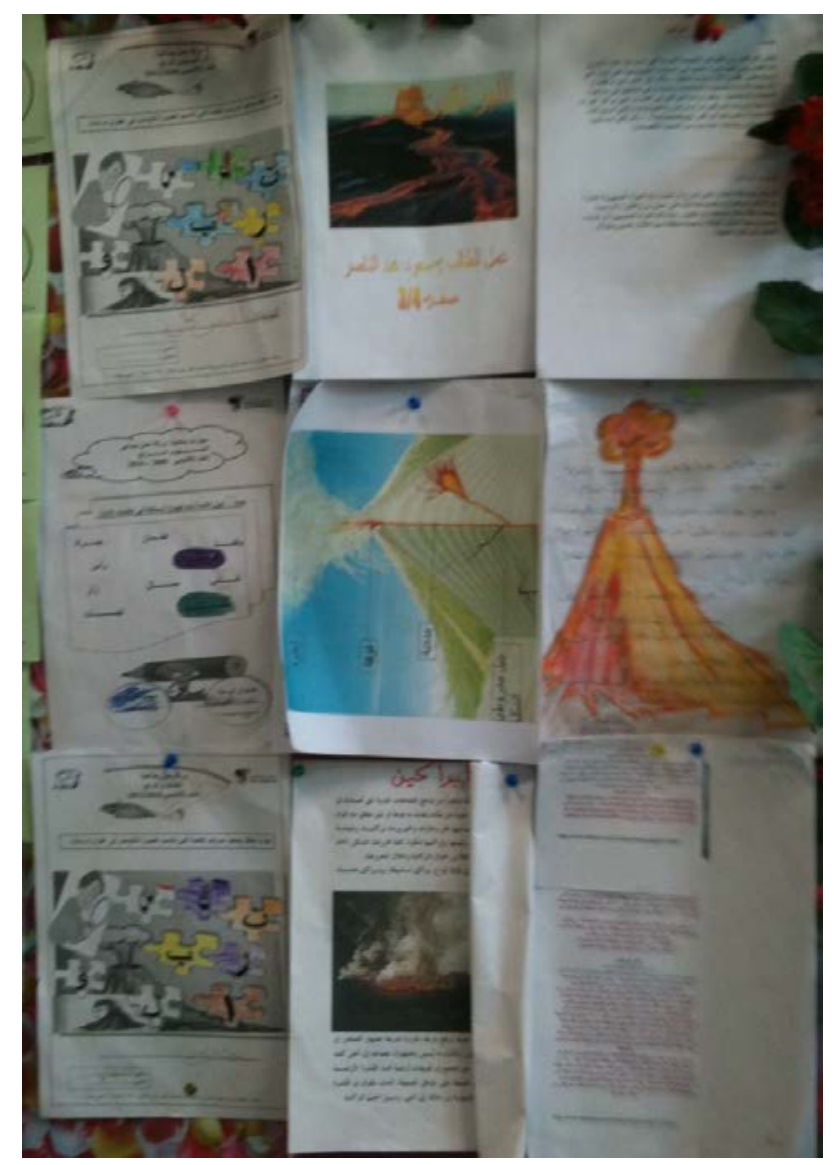

Figure 6. 12 Homework about Volcanoes in Arabic

\subsubsection{Academic Language}


The frequency of use of academic language in the Arabic classes was classified as "moderate" (see Table 6.4). The previous section indicated how academic language, concerning how volcanoes work, was taught using an explanatory text, and was part of the curriculum standards published by the SEC. The following extract emphasizes the way in which the teacher explains the difference between information texts and explanatory texts:

$T \quad$ These eight lines that you wrote can we call it an information text? Or an explanatory texts?

$P \quad$ (several)information

$T \quad$ When I ask a question and say: How does tide occurs? And you respond explaining that it is a phenomena which is affected by the moon gravity. And when you go to the science laboratory and your science teacher asks you how something works, how does the eye see for example? What is she asking?

$P \quad$ pause

T She is asking you to EXPLAIN HOW something works so a text responding to a how question is an explanatory text. Did we study an explanatory text before?

$P \quad$ (several) How the snow forms

It is evident that academic language was taught explicitly, with academic texts as the central focus. Different ways that texts are written, and their inherent characteristics, were distinguished. The extract also indicated that the teacher was bridging the old and new experiences of the students.

\subsubsection{Explicit Focus on Grammar and Vocabulary}

The frequency of focusing on grammar and vocabulary in the Arabic classes was classified as "High" (see Table 6.4). Every unit in the textbook contained grammatical structure and vocabulary items. Every lesson contained some instruction of grammatical structures and related written exercise to be completed by the students as homework. For example, Figure 6.14 presents a homework display of three types of pronouns in Arabic: 


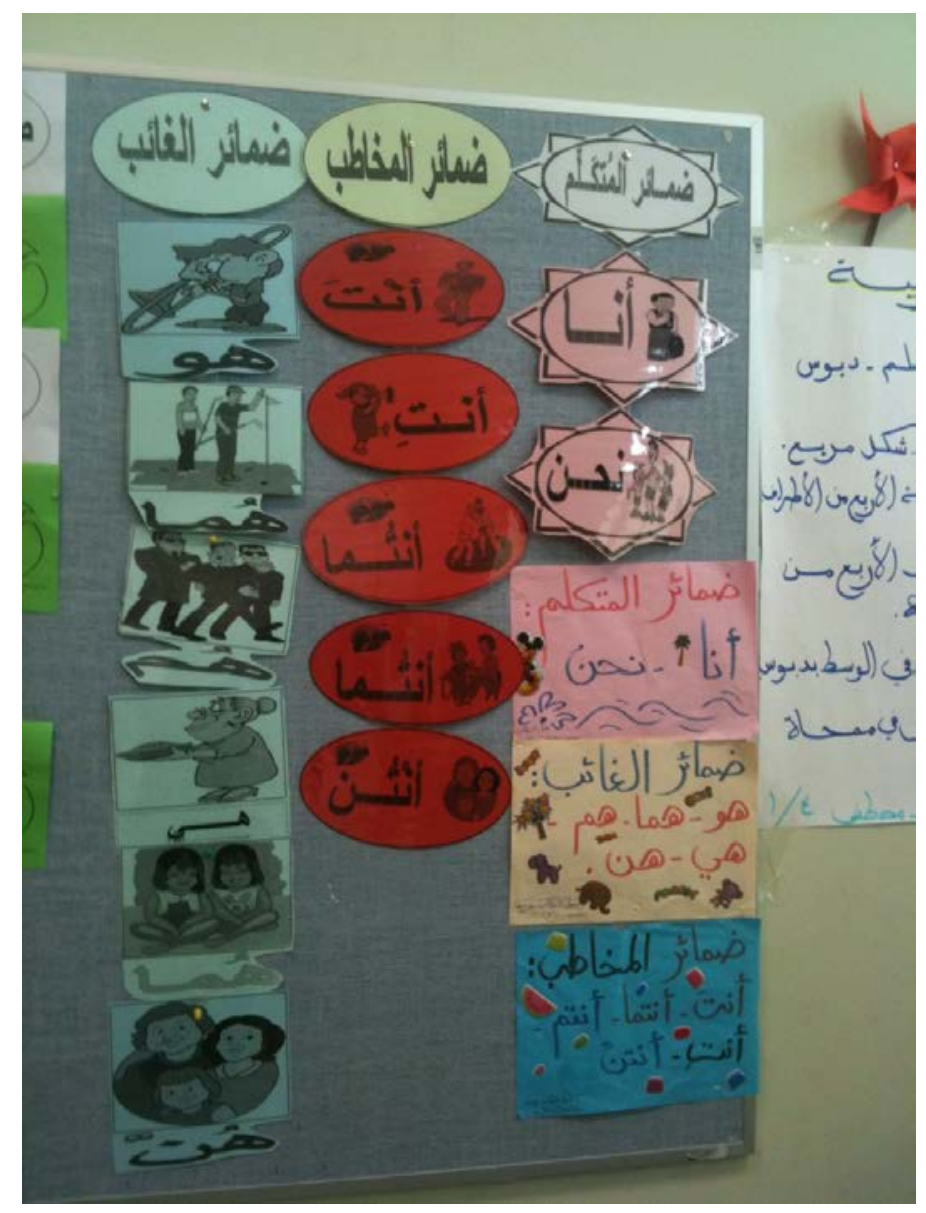

Figure 6.13 Display of Grammatical Structures in Arabic

Explicit focus on syntactic structures and lexicon was observed in the Arabic classes, such as the synonyms and the antonyms of Arabic words and the inflection of verbs, either to clarify meaning or to enrich vocabulary awareness. For example, Figure 6.15 displays student's work on Arabic words and their synonyms posted as a wall display in one grade four class.

Vocabulary is an invaluable element to be added to bilingual education (Gibbons (2002). When there are various lexical differences between children speaking colloquial Arabic (the Qatari dialect) then the words encountered in written texts and standard Arabic explicit lexicon differences must be highlighted in Arabic classes. 


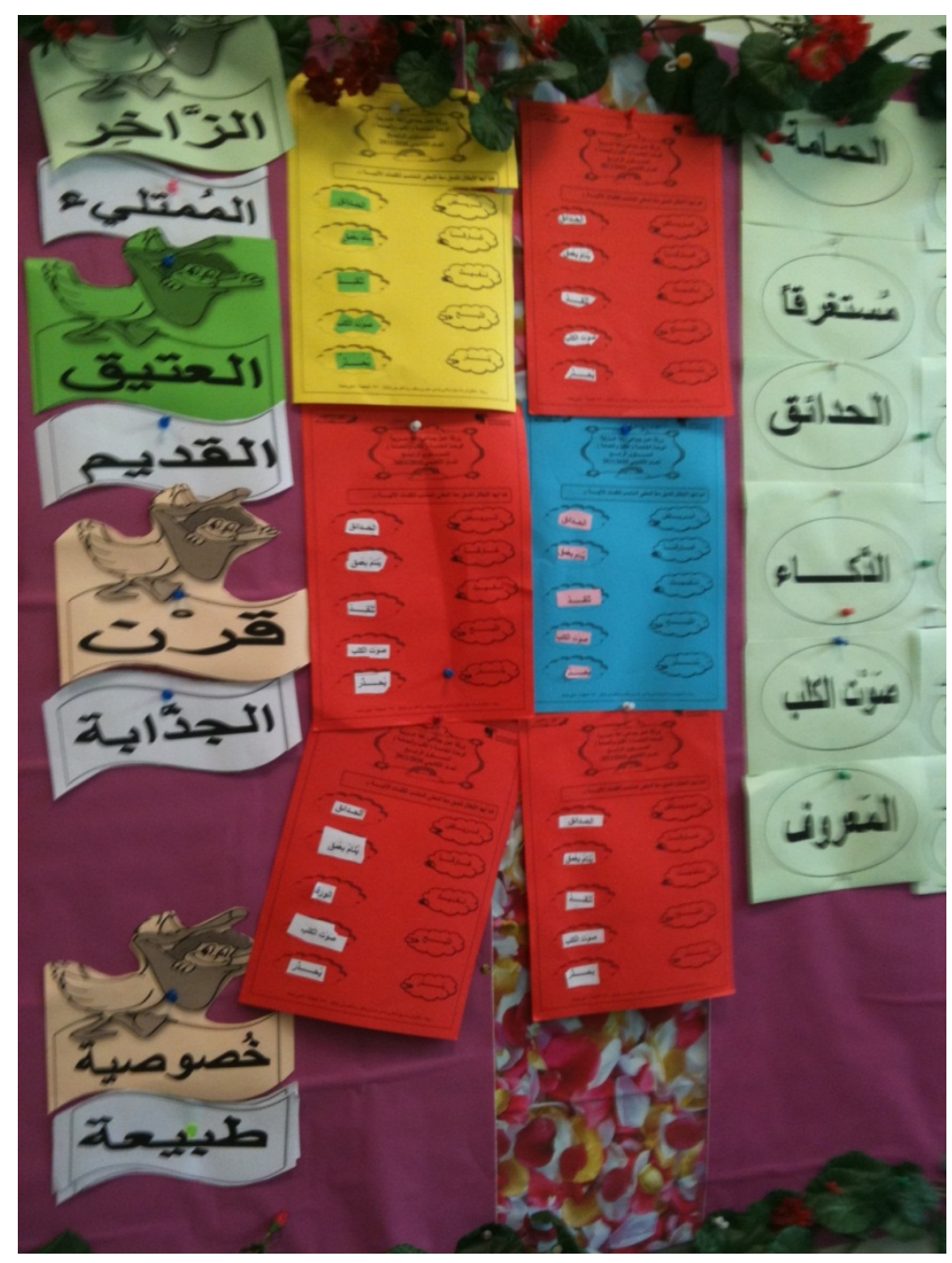

Figure 6.14 Display of Synonyms in an Arabic Classroom

\subsubsection{Scaffolding}

The use of five scaffolding structures in the Arabic lessons was examined (see Table 6.4). The frequency of establishing routines was classified as "Moderate". Lessons usually followed a similar pattern, starting with a review of the previous lesson or checking homework. Teachers then either reviewed some previously studied structures or finished the lesson started the previous day, so that each lesson could take up to a week to finish. One teacher used a bell to indicate her wish for the class to be silent or to correct language errors. She established this routine from the beginning of the year. Students needed to raise their hand to answer. 
The frequency of modeling was also classified as "Moderate". The Arabic teachers often modelled answers before asking student to produce their own sentences with newly studied structures. It was also observed that teachers often modelled reading to the class. There was infrequent use of contextualizing by using teaching aids. The Arabic teachers relied heavily on oral explanations and textbook material. In the observed classes, frequency of use of bridging was classified as "Moderate". Bridging was used to explain new concepts by referring to previous lessons or trying to relate the words to other subjects taught at the school. There was no evidence for multiplicity in the form of using multi-level tasks. All students in the Arabic classes received the same level of instruction.

\subsubsection{Task Based Instruction}

There was infrequent use of task based instruction in the Arabic classes (see Table 6.4). Very few tasks were given to students to transact and perform either individually or in groups. The tasks observed were often given as homework to be handed in to the teacher without much discussion of how it was performed.

\subsubsection{Focus on Reading}

The frequency of focusing on reading in the Arabic classes was classified as "High" (see Table 6.4). The teachers often concentrated on teaching reading fluency. The students were frequently asked to engage in reading aloud to the whole class. Most of the texts used were previously studied texts that the student encountered several times. On no occasion were these read aloud activities performed on new material, nor were they performed with authentic texts. The teachers often corrected the students' mistakes and asked them to repeat the word again before continuing their reading. Eventually over a few days every student would get a chance to read. 


\subsubsection{Summary of Classroom Observations}

The teacher's language choices were flexible. Most teachers used code-switching from L2 to L1 and from MSA to Arabic dialects. Communication modes varied across the two language classes. There was a focus on writing in English classes contrasted by a focus on listening and responding verbally to the teacher in Arabic classes. Group activities were more frequent in English classes. The frequency of use of instructional practices in English and Arabic classes are compared in Table 6.5.

Table 6.5 Comparison of instructional practices in English and Arabic classes

\begin{tabular}{|c|c|c|}
\hline Practice & English Classes & Arabic Classes \\
\hline IRF sequence & Moderate & High \\
\hline Focus on Academic language & Infrequent & Moderate \\
\hline Co-operative learning & Moderate & Infrequent \\
\hline Use of high relevance material & High & Moderate \\
\hline Highly cognitive content & Infrequent & Infrequent \\
\hline Explicit grammar teaching & High & High \\
\hline Explicit focus on vocabulary & High & High \\
\hline \multicolumn{3}{|l|}{ Scaffolding } \\
\hline Establishing routines & High & Moderate \\
\hline Contextualization & Moderate & Infrequent \\
\hline Modelling & Moderate & Moderate \\
\hline Bridging & None & Moderate \\
\hline Multiplicity & High & None \\
\hline Task Based Instruction & Moderate & Infrequent \\
\hline Focus on Reading & Moderate & High \\
\hline
\end{tabular}

Differences between the instructional methods used in Arabic English classes were identified. The frequency of use of the IRF sequence was moderate in English classes but high in Arabic classes. Focusing on academic language was less frequent in English classes than in Arabic 
classes. English teachers used co-operative learning and task-based instruction more frequently than Arabic teachers. In both classes high relevance material was frequently used, but more frequently in the English classes. In both classes infrequent use of cognitively demanding material was observed. There was a high frequency of use of the explicit teaching of grammar and vocabulary in both English and Arabic classes. The teachers practiced a variety of scaffolding techniques. Establishing routines and contextualization were more frequent in the English classes. Bridging was frequently used in the Arabic classes, but not in the English classes. Multi-level tasks were always used in English classes but never in Arabic classes. Given the differences in languages taught and standards to be covered in each subject, this comparison only described similarities and differences.

\subsection{Course Materials}

The course materials used in Jazeera school varied between locally devised SEC approved text-books, commercial material and school prepared booklets and worksheets. Some examples are depicted in Figure 6.16 and 6.17. The Arabic text books were prepared by another school and approved by the SEC, explaining the addition of the SEC logo on the text book covers. The textbooks are aligned with curriculum standards as issued by SEC and contained many topics to be covered in lessons. The text books, however, did not prescribe a formal sequence of lessons nor were they the sole source for organizing and implementing Arabic language teaching. 

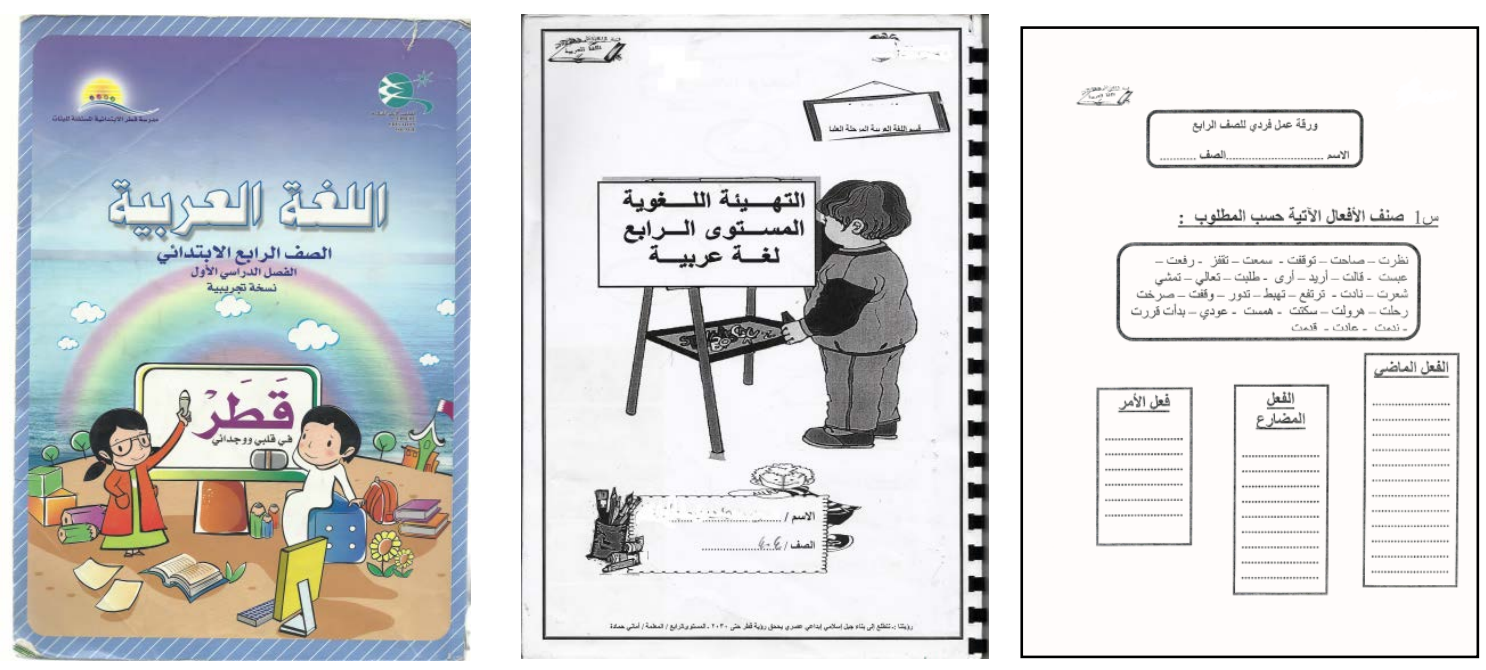

\section{Figure 6.15 Arabic Course Material}
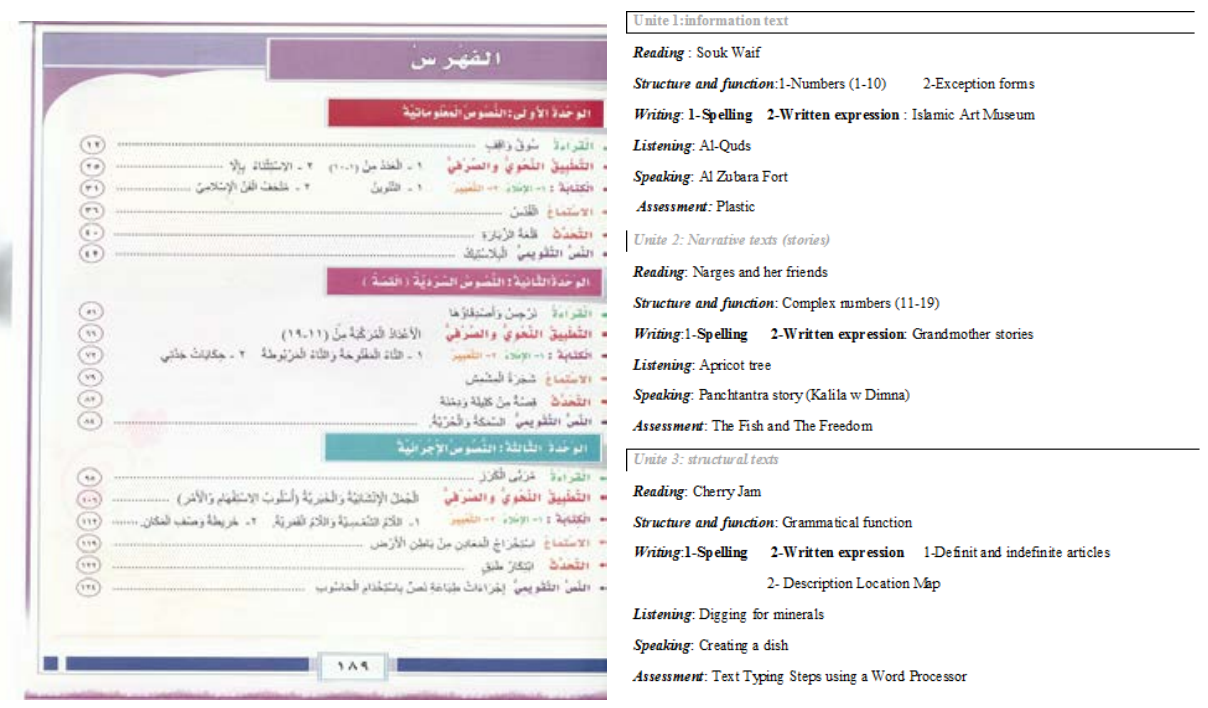

Figure 6.17 Contents Page from Arabic Text Book and Translation

The curriculum standards are displayed at the beginning of of every unit and before each set of items to be studied. This is followed by desired outcomes for each unit. There are five units in the year four text-book. These are organized around types of written texts. The units also included spelling content, phonetics, grammar, and writing exercises. Usually there is a main text that is the centre of the unit bearing the features of the text genre to be studied followed by comprehension questions, grammatical exercises and vocabulary topics such as synonyms. 
The English course material is a commercial set, including a student class text book, teacher book, work book and a CD. The covers of the workbook and class book are depicted in Figure 6.18. The teachers however did not abide by the scope and sequence of the text book but used other material such as worksheets and other task-based lessons to follow curriculum standards.

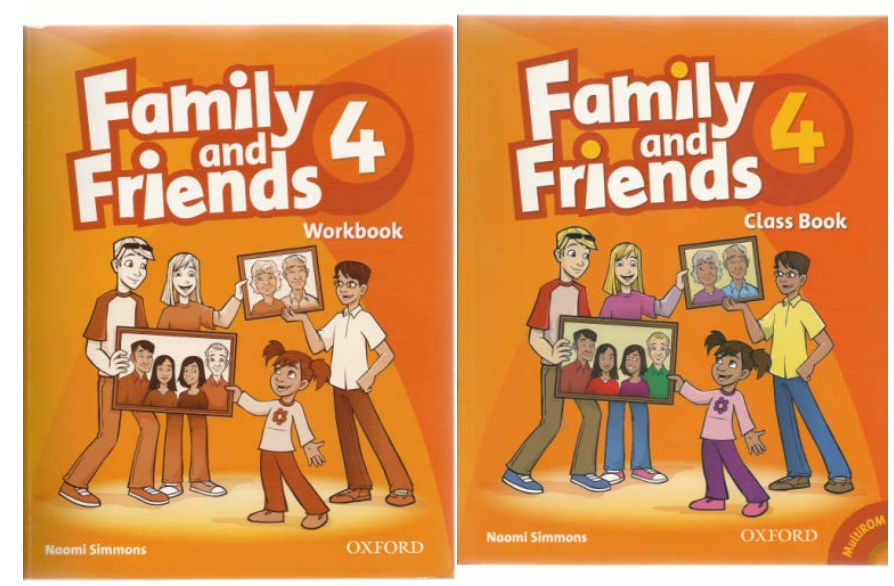

\section{Figure 6.17 English Course Material}

Besides course material teachers use wall displays and a classroom library to support students learning. A place is assigned for each subject to display students' work. Most of the work is done at home as part of students projects. Some of the wall displays are students worksheets and other display classroom rules and important topics studied. The classroom library hones very few Arabic and English books that students can borrow to read at home or in class. There were a few English-Arabic dictionaries in each class as well.

\subsection{Language Use Outside the Classroom}

Field notes of students language behaviour outside the school and in other classes revealed similar findings to those observed in English and Arabic classes. Classes that use English as the medium of instruction such as Math and Science, contained evidence of flexible language use similar to the one observed in the English classrooms. Teachers used Arabic to explain 
new concepts and clarify ideas. In Math and Science, more Arabic was used than observed in the English classes. Between classes, in breaks and at other times students mainly spoke mostly Qatari dialect. It was very rare to observe any English or MSA used except for joking and name calling. Other activities observed were the daily assembly, reading program, integration projects and extra-curricular activities which will be described in detail below.

\subsubsection{Assemblies}

Jazeera school held a daily morning assembly before the beginning of the first lesson. At exactly 7 o'clock the bell rings and all students gather in rows according to their grade level and class. MSA is used by teachers and other staff to communicate daily announcements, guidance and other activities. Each week a group of teachers co-ordinate the assembly activities. There is a week for each subject. During Arabic language subject week, Arabic language teachers organized a play about the 'Arab Spring' that was performed by students which was performed using MSA. There were singing performances, information and wisdoms presented to the whole school by the students. During the English week teachers organized the whole assembly to be delivered in English and it was presented by students. There was also a weekly break assembly in which each group of subject teachers organized games and competitions. This is usually on the last day of the week. The language used was also MSA for Arabic subjects and English in the week designated for the English language teachers. As an example the Arabic teachers in one of their morning assembly announced a 'who is the poet' competition. They read a few lines of Arabic poetry and displayed posters of the poem extract around the school (Figure 6.19) indicating that answers should be written along with the student name and dropped in a special box. At the last assembly of that week a winner was announced. 


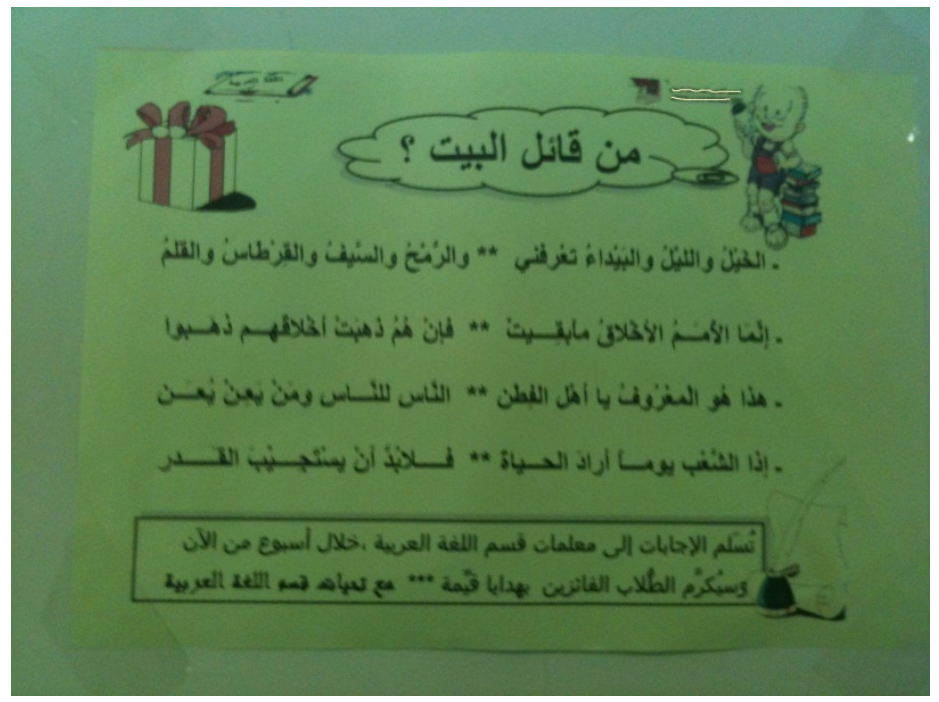

\section{Figure 6.19 Who Is The Poet Competition (Displayed On The School Walls)}

\subsubsection{Reading}

The school has a large modern fully equipped library and educational resources for students and teachers comprising fiction and non-fiction books, audio library, video library, teaching aids, and books on educational topics for teachers. All students were issued a library card and had a weekly library session; however, not many students borrowed books. In most observations students were looking at titles or reading, but they were not encouraged to borrow out of library area. I later found out that they were not allowed to borrow books. There were no group readings similar to those observed in the international school.

Jazeera school has two reading programs, one for Arabic, and one for English. For each grade and each language two books were chosen, one at an easy entry level, and the other is more advanced. Students were given a couple of weeks to read the book, and it is discussed and read in the classroom at least once, after which the students are tested on their comprehension of the book. When they pass another book is given of an advanced level. Tests are performed at the IT room using reading assessment software. 
Titles varied between Ali-baba and Heidi for the English reading, and Gulliver's Travels for the Arabic reading. It was an interesting choice from the Arabic teacher since the story was a translation from the English version especially in the abundance of Arabic titles and literature available. The English teacher often encouraged students to borrow books from the few available in the classroom library.

\subsubsection{Curriculum Integration Projects}

In Jazeera school and within the English languages classes curriculum integration projects were conducted. Some examples of posters made by students are depicted in Figure 6. 20.

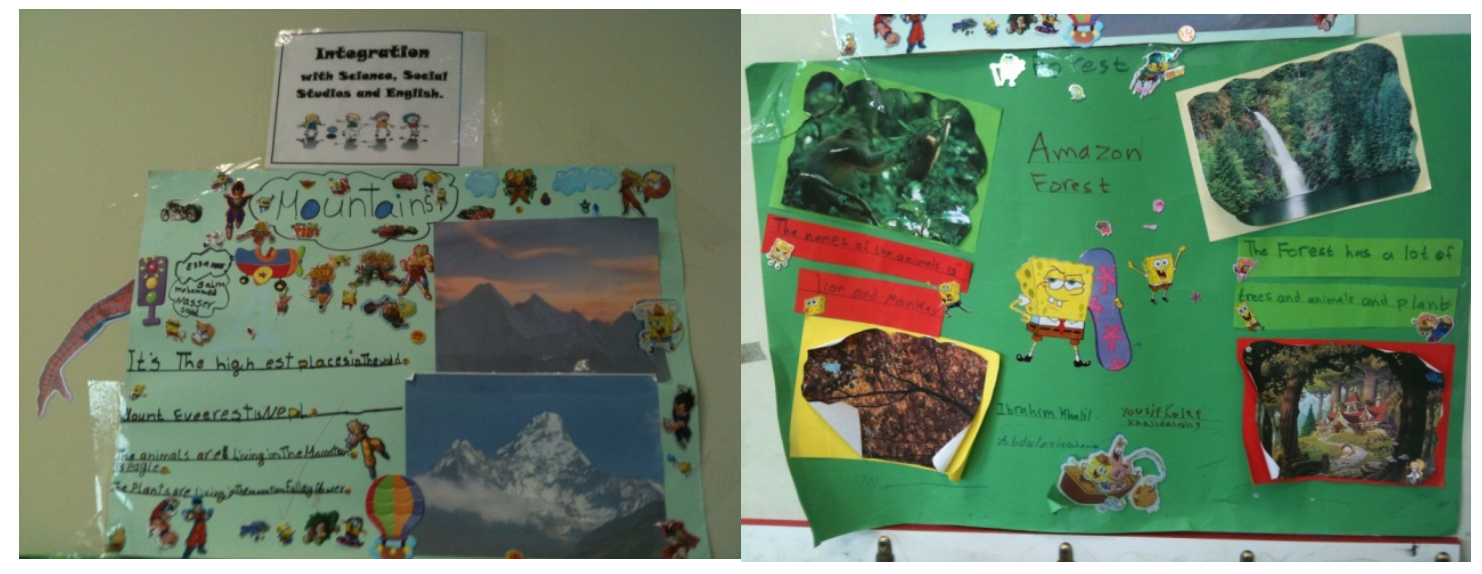

Figure 6.20 English, Science and Social Studies Integration Posters Made by Students

Curriculum integration aims to build on restructuring learning activities to help students build connections between topics they studied, and helps in building schemes for language learning. The projects in the English lessons involved a group of children poster making that integrated three subjects: Science, Social studies, and English (Figure 6.20). These were done out of English lessons but with the English teacher as the facilitator. There were five posters displayed in the classroom, one for each group. 


\subsubsection{Extra-Curricular Activities}

Jazeera school offers a wide range of extra-curricular activities for students. Only the language related activities are considered here. Students can join various clubs and activities but not everyone can join, because the students are chosen by the teacher, possibly because it is not possible to accommodate all the students.

The Arabic language division in the school was responsible for the journalism club. Students in grades 3, 4, 5 and 6 could join. The English language division encouraged students to participate in a writing competition between primary schools. They also chose students to participate in the Human Dictionary competition against primary schools in Qatar to memorize words and their meanings. In addition the school organized its annual book fair encouraging students to buy books from various publishers.

These activities present the school attempts to develop language skills outside the organized instruction within classrooms. Moreover, the activities altogether portray a balance representation of English and MSA in activities out of the classroom. This in turn responds to the school language policy of $60-40$.

\subsubsection{Summary of Language Outside the Classroom}

There were few language activities outside of the classroom. Because of the large number of students in the school, not all children had the opportunities to participate in these out-ofclass activities from borrowing books to signing up for clubs and competitions. These activities nonetheless offered a range of opportunities for language use and development out of classes. It must be noted that the school did not offer any support for students with low language proficiency or any other type of learning difficulties. In regard to language choice outside classes, students and teachers always opted for their own CD which was mostly the 
Qatari dialect between classes, in breaks and play time. The use of curriculum integration was a good approach for language development which included other areas of the curriculum, however it was used in limited ways.

\subsection{Case Summary}

A descriptive approach was used in exploring the organization and implementation of the bilingual program at Jazeera independent school. In alignment with the research question the case summary will be presented using a school portrait. In the next chapter, a cross-case analysis will display the findings using the matrix format described in Chapter 3.

\subsubsection{School Portrait}

The school portrait is a tool for viewing the various features explored from two perspectives: (a) organizational evidence and (b) implementation evidence. Consequently, the school portrait strives to compare what is claimed and what is practiced. The claimed program features and the sources of the organizational evidence are presented in the left and central columns. The implementation evidence is presented the right column.

\section{Table 6.6: Jazeera School Portrait}

\begin{tabular}{|c|c|c|}
\hline Claimed program feature & Organization evidence & Implementation evidence \\
\hline \multirow[t]{2}{*}{$\begin{array}{l}\text { Aim to develop } 1^{\text {st }} \text { and } 2^{\text {nd }} \\
\text { language skills }\end{array}$} & SPG & $\begin{array}{l}\text { Lack of policy document that } \\
\text { specify linguistic goals }\end{array}$ \\
\hline & & $\begin{array}{l}60 \% \text { of daily time done through } \\
\text { medium of English }\end{array}$ \\
\hline \multirow[t]{3}{*}{ National identity } & Vision, Mission & Uniform are the Qatari costume \\
\hline & SPG & National anthem sang daily \\
\hline & & $\begin{array}{l}\text { Not many material studied bear } \\
\text { high relevance to students national } \\
\text { culture }\end{array}$ \\
\hline
\end{tabular}




\begin{tabular}{|c|c|c|}
\hline Academic achievement & \multirow{3}{*}{$\begin{array}{l}\text { Mission } \\
\text { Educational goals- Website }\end{array}$} & Curriculum standards for Arabic \\
\hline & & Modern text books \\
\hline & & Qualified teachers \\
\hline \multirow[t]{7}{*}{$\begin{array}{l}\text { Teaching and learning } \\
\text { strategies }\end{array}$} & \multirow{7}{*}{$\begin{array}{l}\text { SPG } \\
\text { Website- educational goals } \\
\text { Lesson plans }\end{array}$} & $\begin{array}{l}\text { Use of read-aloud techniques for } \\
\text { modelling reading. }\end{array}$ \\
\hline & & $\begin{array}{l}\text { Use of task-based learning and } \\
\text { some co-operative strategies in } \\
\text { English classes only }\end{array}$ \\
\hline & & $\begin{array}{l}\text { Differentiation of levels also used } \\
\text { in some worksheets in English } \\
\text { classes }\end{array}$ \\
\hline & & Use of integration projects \\
\hline & & Focus on student reading \\
\hline & & $\begin{array}{l}\text { Other strategies mentioned were } \\
\text { not employed }\end{array}$ \\
\hline & & $\begin{array}{l}\text { Communication mode indicate } \\
\text { focus on filling written exercises in } \\
\text { English and oral activities in } \\
\text { Arabic lessons }\end{array}$ \\
\hline
\end{tabular}

\begin{tabular}{ll}
\hline Curriculum planning & Website \\
& $\begin{array}{l}\text { Use of mechanistic model of } \\
\text { organizing the school }\end{array}$ \\
& Using SEC curriculum standards \\
& Same plan sheets for all teachers
\end{tabular}

\begin{tabular}{lll}
\hline Professional development & SPG & $\begin{array}{l}\text { Lesson planning sheet provide } \\
\text { checklist to ensure use of learned } \\
\text { strategies are employed }\end{array}$ \\
\hline Lesson plans & SPG & Limited class library \\
& Interviews & $\begin{array}{l}\text { Lack of learning aids and stimulus } \\
\text { in classes }\end{array}$ \\
& $\begin{array}{l}\text { Little opportunities to borrow from } \\
\text { school library and sign up for } \\
\text { school clubs. }\end{array}$
\end{tabular}




\begin{tabular}{lll}
\hline $\begin{array}{l}\text { Strict separation of L1 and L2/ } \\
\text { MSA and CD }\end{array}$ & Timetable & School website \\
Arabic teachers interview & $\begin{array}{l}\text { English Teachers report use of } \\
\text { frequent code switching } \\
\text { Classroom data indicate frequent } \\
\text { purposive code-switching in Arabic } \\
\text { and English classes indicating } \\
\text { flexible language use }\end{array}$ \\
\hline Support learning difficulties & SPG & $\begin{array}{l}\text { No support staff or teaching } \\
\text { assistant }\end{array}$ \\
& Website - educational goals & $\begin{array}{l}\text { No special pull-out classes or } \\
\text { programs for supporting children } \\
\text { with LD }\end{array}$ \\
\hline
\end{tabular}

The school portrait highlights that although the school aims to develop first and second language skills, there is little documentation to guide and govern how the school will do so. The school presented a national identity by the presence of national costume as uniform, use of national flag in all school logos, and singing the anthem daily in the morning assembly. The school stressed the importance of teaching and learning strategies and employed many of these mostly in English classes; however, there was little observable evidence for the implementation of other techniques indicated in the document such as group discussions, shared reading and writing, jigsaw, or critical thinking. The school provided very little support for individualized learning. Other than use of multiple level worksheets in English classes, students with low proficiency in English were not supported, neither students with other learning difficulties. The school provided some extra-curricular activities in the form of school clubs, but there were little spaces in these to accommodates the huge number of students in the school. The library used an in-school borrowing system so students could not take books home.

The school presented evidence for careful curriculum planning that was aligned with the SEC curriculum standards with use of modern text-books and other resources that are school made. The student environment was lacking of objects to stimulate students minds. The 
classroom library contained less than ten English books and less Arabic ones. Professional development of the staff could be traced in how the teaching plans included a checklist to ensure use of learned teaching strategies. The teachers attended regular professional development workshop conducted by the SEC. The school professed a strict separation policy which was subject-determined. However teacher and students often engaged in purposive code-switching in English and Arabic classes.

\subsection{Conclusion}

This study identified a case of a school that used flexible multiple model of biliteracy as defined by Garcia (2009). Arabic was used in English classes either in CD or MSA, to clarify word meanings and give some explanations. CD was also used in Arabic classes for the same function.

With respect to the question of the bilingual education approach used by the school, it can be concluded that a grammatical approach was mostly used. There was little evidence for the use of communicative approach features and no evidence for using a cognitive approach.

With respect to the use of flexible multiple model of biliteracy teaching, it was difficult to classify the conduct of the school as a partial immersion program. Although teachers were bilingual and strict separation was professed, the flexible language use was part of the daily practice and was even promoted in the guidelines of the curriculum standards. Thus the closest type of bilingual education that fitted the features of the program used in Jazeera school was the CLIL-type programs where one or more subjects were taught in the second language, but code-switching was permitted, because the first language was viewed as a resource (Gajo, 2007, Serra, 2007; Lasagabaster and Sierra, 2010). 
Moreover, in the literature review differences between the immersion, and CLIL and CLILtype programs were listed as(a) degree of exposure to the L2 in the community,(b) demographical features of the students and whether they all share the same L1, (c) objectives of the programme,(d) course materials, and (e) type of teachers. Clearly the type of children and the social context does resemble that of an immersion program where all children speak the same L1 and there is little exposure to the second language in the community. However, the objective of the programme, materials used, and type of teachers all resemble those of a CLIL program. According to Lasagabaster and Sierra (2012) CLIL immersion programmes usually have an aim to reach native like proficiency in the L2 whereas other bilingual programmes have less optimistic goals since they are part of a public education system. Most of the time immersion programmes use materials that are aimed at native speakers, while CLIL (in Spain at least) the teachers and school administration opt for bridging material that is either modified or designed for L2 learners. Lasagabaster and Sierra also comment that teachers in immersion education in Spain are mostly native speakers of the second language while teachers in CLIL program are bilingual. These differences as well as the use of Codeswitching discussed previously indicate that the programme followed by Jazeera independent school is a CLIL-type of programme rather than an immersion programme. 


\section{CHAPTER SEVEN: CROSS-CASE SYNTHESIS}

\subsection{Introduction}

This chapter will begin by presenting case summaries for each of the two schools according to the units of analysis: curricular organization and implementation. Then a cross-case synthesis will be presented, using a cross-case conceptual display. This display is the result of clustering case portraits from the previous two chapters. A brief discussion of the topics that arise from the synthesis will follow, reporting on the match/mismatch relationship that appears between programme features, as presented on the organization level with the classroom and school praxis. The chapter also includes a display of comparison, which aim to present all of the two schools' characteristics in one complete display. This matrix was useful for summarizing facts and data about the two schools.

\subsection{Salam International School}

With regard to curricular organization, the school had a 70-30 L2-L1 language allocation. Thus subjects were mostly taught through the medium of English, with only two subjects taught using students' first language. Throughout its documents the school maintained that it used a subject-determined language separation policy between L1 and L2. Literacy in the two languages (teaching reading and writing) in this school was introduced simultaneously from pre-school grades. Teachers were mostly non-native English-speaking, but they do not speak the L1 of the students (Arabic).

The interview data reveal that English teachers have some awareness of the bilingual policy of the school, but without any explicit orientation or training on this policy. Teachers also reported a strict separation of language use in the classroom. Teachers put a great emphasis on the course material and textbooks used in the school and noted the importance of extra-curricular activities in developing students' language skills. Arabic 
teachers have a great variability in their views, with little awareness on language use policy in the school.

When classroom praxis was examined it was observed that strict separation was indeed implemented, as English alone was used for the subjects that were taught using English as the medium of instruction. MSA was used in other Arabic classes with minimal codeswitching. Examining pedagogical features, it was noted that there was a strong focus on IRF-style classroom interaction, particularly explicit teaching of grammatical structures and lexicon. Learning by rote was prevalent. Instructional practice was characterised by little use of co-operative learning, no direct teaching of academic language and no use of cognitively demanding materials. Teaching resources were mostly commercial ones. In

regard to language choices, students were observed using Qatari dialect out of classes. English was the language of communication in formal school activities such as assemblies. Library sessions mostly focused on both L1 and L2.

\subsection{Jazeera Independent School}

Formal documents in Jazeera School indicated 60-40 L2-L1 language allocation. Thus, almost half the subjects were taught using Arabic and the other half using English as the medium of instruction. In these documents, strict separation of the two languages was communicated. Literacy was also introduced simultaneously from the pre-school level. Most language teachers were bilingual in Arabic and English. Other teachers spoke Arabic only.

Similar to Salam International School, teachers at Jazeera Independent School showed low awareness of school bilingual policy. English teachers report using frequent purposive code-switching to guide students' learning. They reported little involvement in extracurricular activities. Arabic teachers in this school also present conflicting views regarding 
school language policy. They reported use of strict separation, opting for MSA only, but tolerating students' code-switching. Arabic teachers reported their involvement in many activities that aim at developing Arabic language skills outside the classroom.

When classroom practice was examined, it was noticed that a flexible convergent model of biliteracy was used, characterised by frequent code-switching from English to Arabic in English classes and from MSA to colloquial dialects in Arabic classes. It is called convergent because the main language was used orally and in written form while the other language was only used orally. Code-switching was used to clarify concepts and word meaning but never to provide input. Regarding instructional practices, the observations indicated a strong focus on IRF-style interaction and an explicit focus on grammatical structure and lexicon. L1 classes also focused on academic language and reading fluency, while there was some focus on co-operative learning and TBI in L2 classes. There was a balance between use of commercial textbooks and school-devised material. Outside classes students mostly spoke in Qatari dialect. MSA was used to manage assemblies and formal gatherings. The school reading programme focuses on both languages.

\subsection{Cross-case synthesis}

Meta-matrices are master charts assembling descriptive data from the cases explored in a standard format (Miles and Huberman, 1994). The following table (7.1) produces a novel chart to present at the simplest level a 'squint' view of the features of the programs on the two axes of investigation. The conclusions drawn from the description and the contrast between the two types of school provide some insights to frame further discussion on bilingual education in Qatar. The following is a descriptive Meta-Matrix (ibid), which I titled the Bilingual Programme Descriptive inventory (BPDI). 
The BPDI, which was described in Chapter Three, is presented here to describe both school features in a single display. Because of the richness of data presented in the analysis, and to ensure that the reader is not overwhelmed by the masses of detail, this instrument is useful in displaying the data in one table where all the detail can be seen, serving the two units of analysis in examining the bilingual program offered by this school. It gives a visual summary that contrasts the independent with the international school. It also describes in simple terms the observed structures and processes of the two schools in a comparable fashion. 
However the matrix in Table 7.1 and the previous case summaries provided only the surface contrast of the two programmes. There was a need for a better display to synthesize the complex and rich data found in the two cases that takes findings displayed in the case portraits into account. To achieve this goal, the Nvivo 9 software was used to cluster programme features into larger categories, producing metaphors as themes that are recurrent in both cases. This display will increase understanding of the features of both programmes on common grounds. Hopefully this in turn will raise the chances that the two cases represent recurring types which accord with other existing typologies.

The school discourse communicated through documents and interviews convey the following six key concepts: Language Provision, Pedagogy, Students' Support, Staff Enrichment, Affective Aims, and School Ethos. These are displayed in the Case-ordered Descriptive Matrix (Table 7.2):

\section{Jazeera Independent School}

1. Language Provision

$2^{\frac{\text { nd }}{2}}$ language skills

Lack of policy document that specifies linguistic goals $60 \%$ of daily time done through medium of English

Communication mode indicates focus on written exercises in English and oral activities in Arabic lessons
Strict separation of L1 and L2/ MSA and CD

English teachers report use of frequent code switching

Classroom data indicate frequent purposive code-switching in Arabic and English classes indicating flexible language use

\section{Salam International School}

Native Speaker Skills
done through medium of English

Little opportunities for communicative experience during English lessons

\section{Communication}

Infrequent learner participation in whole class discussions, little opportunities for student discussions in discovery tasks; in most events students were either listening or writing

2. Pedagogy Curriculum planning

Use of mechanistic model of organizing the school

\section{Teaching and} learning strategies

Use of read-aloud techniques modelling reading.
Academic Excellence

Infrequent focus on academic language, weak use of high cognitive material

Science and Maths follow British based curriculum
Strict separation of $\mathrm{L} 1$ a L2

English only in Engli lessons

minimal code-switching, Variability of teache practice in Arabic lesson some MSA only, othe flexible use of MSA, a CD.

Students follow teache language choice. Qat dialect is used minimal during both class times. $\mathrm{O}$ of class free play a students' socializing is Qatari Arabic or student own colloquial dialect. 


\begin{tabular}{|c|c|c|c|c|}
\hline & $\begin{array}{l}\text { Using SEC curriculum } \\
\text { standards } \\
\text { Same plan sheets for all } \\
\text { teachers }\end{array}$ & $\begin{array}{l}\text { Use of task-based } \\
\text { learning and some co- } \\
\text { operative strategies in } \\
\text { English classes only }\end{array}$ & $\begin{array}{l}\text { standards } \\
\text { Modern resources, } \\
\text { bilingual library modern } \\
\text { text books }\end{array}$ & \\
\hline & $\begin{array}{l}\text { Academic achievement } \\
\text { Curriculum standards for } \\
\text { Arabic and English } \\
\text { Modern text books } \\
\text { Qualified teachers }\end{array}$ & 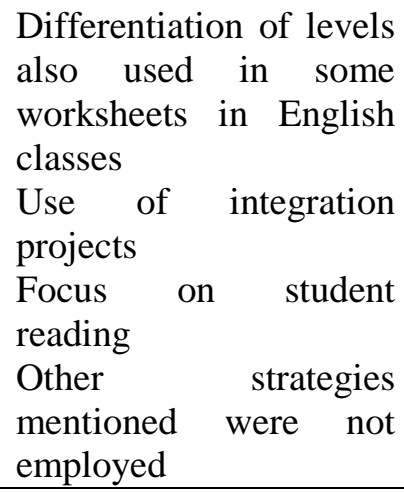 & $\begin{array}{l}\text { Collaborative learning } \\
60 \% \text { of events conducted } \\
\text { as whole class or } \\
\text { individual students. No } \\
\text { pair work or group work }\end{array}$ & \\
\hline $\begin{array}{l}\text { 3. Students' } \\
\text { Aid }\end{array}$ & $\begin{array}{l}\text { Support } \\
\text { difficulties } \\
\text { No support staff or } \\
\text { teaching assistant } \\
\text { No special pull-out } \\
\text { classes or programmes for } \\
\text { Students with low L2 } \\
\text { proficiency }\end{array}$ & & $\begin{array}{l}\text { Second language learner } \\
\text { needs } \\
\text { ESL classes } \\
\text { Focus on vocabulary } \\
\text { Focus on grammar } \\
\text { Course materials and text } \\
\text { books geared towards } \\
\text { developing L2 skills } \\
\text { Teachers are not bilingual } \\
\text { in Arabic/English } \\
\text { Library sessions and book } \\
\text { reading }\end{array}$ & $\begin{array}{l}\text { Learner-Centeredness } \\
\text { IRF sequence with } \\
\text { High teacher control } \\
\text { Most utterances are coded } \\
\text { as teacher ask /stude } \\
\text { answer } \\
\text { infrequent guidance in tas } \\
\text { as evidence shows infreque } \\
\text { modelling of tasks } \\
\text { High use of rote learning }\end{array}$ \\
\hline $\begin{array}{l}\text { 4. Staff } \\
\text { Enrichme } \\
\text { nt }\end{array}$ & $\begin{array}{l}\text { Professional development } \\
\text { Lesson planning sheet } \\
\text { provides checklist to } \\
\text { ensure learned teaching } \\
\text { strategies are employed }\end{array}$ & & $\begin{array}{l}\text { Highly Qualified } \\
\text { Teachers } \\
\text { Most teachers do not have } \\
\text { teaching training or a } \\
\text { degree in education }\end{array}$ & \\
\hline $\begin{array}{l}\text { 5. Affective } \\
\text { aims }\end{array}$ & $\begin{array}{l}\text { inspirational environment } \\
\text { Limited class library } \\
\text { Lack of learning aids and } \\
\text { stimulus in classes } \\
\text { Little opportunities to } \\
\text { borrow from school } \\
\text { library and sign up for } \\
\text { school clubs. }\end{array}$ & & $\begin{array}{l}\text { Enjoyable learning } \\
\text { Book Fair } \\
\text { Extracurricular activities } \\
\text { Assemblies } \\
\text { Other school celebrations }\end{array}$ & \\
\hline $\begin{array}{l}\text { 6. School } \\
\text { ethos }\end{array}$ & $\begin{array}{l}\text { National Identity } \\
\text { Uniform is the Qatari } \\
\text { costume } \\
\text { National anthem sung } \\
\text { daily } \\
\text { Material studied often } \\
\text { bears little relevance to } \\
\text { students national culture }\end{array}$ & & $\begin{array}{l}\text { Islamic Identity } \\
\text { Separate girls’ and boys' } \\
\text { premises } \\
\text { Noon prayer break } \\
\text { Quran recitation session }\end{array}$ & \\
\hline
\end{tabular}

Table (7.2) Case-ordered Conceptually-clustered Meta-Matrix of themes and praxis 
Items displayed in the matrix have been described previously in the separate case reports of findings. In the discussion of the findings of the study as a whole, these features will also be discussed in more detail in the light of the research questions, and the current research debate and literature about bilingual education. The following section discusses the different items on the matrix. Although it creates repetition, this synthesis is needed to guide the reader through the matrix. In Table 7.2 the underlined phrases refer to items found in the organizational evidence concerning each title. Evidence from the school practice is presented under each organizational concept.

\subsubsection{Language provision}

Between design and practice, the social act of language education in the two settings described reveals various 'gaps' between what is claimed and what is practised. Language provision in both schools was not organized by a well circulated discourse in the form of a policy document. The international school did abide by its claimed separate bilingualism approach, while the independent school used a more flexible approach incorporating the first language and different oral dialects of Arabic in its language provision. What is interesting is that the two academic vice-principals expressed their own 'perceived' language policy, but the extent of staff knowledge of their views is unknown. However, the teachers expressed alternative views. These policies also contrast with the school's advertised material in the websites and other documents.

\subsubsection{Pedagogy}

Lave and Wagner (1991) view instructional practices in language education as a collaborative social practice that mediates ideas, actions and concepts through an additional language. It is within this view that Garcia (2009), as well as Ellis (2007), suggest an action-based pedagogy or task-based learning, where language teaching and 
learning activities are infused with concepts such as collaborative dialogue, scaffolding and 'heteroglossia'. In the two schools investigated there was infrequent use of these instructional methodologies. The data from the independent school indicate more use of these strategies than the international school.

Cognitive (academically challenging) content, that is context-embedded using various scaffolding techniques which bears high/moderate relevance to student culture and identity, was found to be rarely used in the international school. The literature indicates that such content was facilitative of academic success (Cummins, 2000). The independent school utilized these methods in moderation, especially in Arabic classes.

\subsubsection{Student and Staff Support}

Close examination of the two schools' organizational and practice evidence reveal interest in providing a type of support to students, and some aims relating to staff development. The international school offered support for students in the form of pull-out ESL groups. Despite its claim of learner-centred education, practices supporting this type of teaching approach were only used rarely. The independent school claimed to focus strongly on students with learning difficulties and students with speech problems: however, the classes observed did not reflect any such policy. Students with special needs in the international school were often un-aided.

The independent school did offer some in-service training for the staff, but that was not the case in the international school. Professional development also appears as an aim in many of the independent school's documents, while it was rarely mentioned in the documents examined in the international school. 


\subsubsection{School Culture}

The international school portrayed an Islamic identity, perhaps because in international schools in Qatar children come from different backgrounds, but most speak Arabic and are Muslims. The independent school presented a national identity focusing on the Qatari culture. Both schools expressed the desire to foster various 'affective' aims. The main aim of the independent school was to create an inspirational learning environment. The practice inside and outside language classes indicate a weak focus on practices that might create such an environment. The international school expressed the aim of providing an enjoyable learning experience. The evidence from the classroom did not back this up, although there were many extra-curricular activities, fairs and various school-wide activities and celebrations.

\subsection{Summary}

In general a gap between what the schools advertised and its implementation was noted. The two schools presented different types of bilingual education with early partial immersion employed in the international school and a CLIL-type programme implemented in the independent school, characterized by flexible language use and teaching language through content.

Daily plans of the international school indicated a reliance on collaborative work, but none was evident in the observations. Similarly there was no focus on academic language skills or developing teachers' skills. The independent school followed Curriculum Standards and the centralized management from SEC, which provided various methodologies to be followed in the school.

A lot can be said about the contrast and comparison between the two schools. On the one hand, the international school has fewer students in each classroom than the independent 
school. They focus a lot on extensive reading with weekly library sessions, book logs and rewards, in addition to school-wide programmes for extensive reading. The English text books are of a higher level than those in the independent schools. The obvious difference between the two schools was studying more English but with moderate focus on the first language (30\% of weekly school time was devoted to teaching Arabic or through the medium of Arabic). Bilingual education literature (e.g. Cummins, 2000) shows that support of L1 - which by definition means less time on L2 - actually yields similar or superior performance in L2. The international school follows British curriculum standards, which have been in existence longer and have been stabilized over the years. There are also lots of ready-to-use resources available for teachers. Because international schools are only partially supervised by the SEC there is less bureaucracy in its management and practice.

The independent school, on the other hand, has the benefits of a large budget as a part of major developments in the public education system and the initiative launched ten years ago ('Education for a new Era'); so it can be said that this is a richer school with modern classes, equipment and resources. However, there is less use of such resources since classrooms are crowded, students are not allowed to borrow from the school library, and they do not have teacher assistance or support for learning difficulties. The classroom can be described as more dynamic than the international school, with a focus on collaborative work and task-based learning. There is more focus on the first language and developing academic language skills in the first language, which is missing in the international school. The independent schools offer plenty of professional development as required by the SEC.

The overall comparison between the two cases includes consistencies and variations. As the discussion above indicated, there are variations in the types and numbers of students, types of teachers, time allocation of L1 and L2 and language use decisions. However, there are also similarities. The schools share similar pedagogies, focusing on traditional drills 
and artificial interaction in the form of IRF sequence. There is a great focus on the surface features of language such as grammar and vocabulary, and little use of individualized or ability differentiation in teaching approaches in the language classrooms. In a few instances (such as Arabic classes in the independent school) there was a focus on the teaching of academic language skills. These features, and the findings, will be further interpreted in the next chapter, addressing directly the research question in relation to the theoretical perspectives found in the research literature on bilingual education. 
Table 7.1 Case-Ordered Descriptive Meta-Matrix (BPDI)

\begin{tabular}{|c|c|c|c|c|c|c|c|c|c|}
\hline \multicolumn{10}{|l|}{ ORGANIZATION OF PROGRAMME } \\
\hline 1. Target population & $\begin{array}{c}\text { Mostly Qatari } \\
\text { Some Arabs } \\
\Delta\end{array}$ & $\begin{array}{l}\text { Mostly Arabic } \\
\text { Some Qatari }\end{array}$ & $\begin{array}{l}\text { Mostly Other } \\
\text { mixed } \\
\text { nationalities } \\
\text { Some Arab } \\
\text { Some Qatari } \\
\quad \\
\end{array}$ & & & & & & \\
\hline 2. Language policy & Published & & $\begin{array}{c}\text { Not available } \\
\bullet \\
\Delta\end{array}$ & & & & & & \\
\hline $\begin{array}{l}\text { Language allocation } \\
\text { percentage } L 1 / L 2\end{array}$ & $10 / 90$ & $20 / 80$ & $\begin{array}{r}30 / 70 \\
.\end{array}$ & $\begin{array}{r}50 / 50 \\
\Delta\end{array}$ & $70 / 30$ & $80 / 20$ & $90 / 10$ & & \\
\hline Timing of $L 2$ introduction & $\begin{array}{l}\text { Early } \\
\text { simultaneous } \\
\bullet \\
\Delta \\
\end{array}$ & Early subsequent & Late introduction & & & & & & \\
\hline Language separation policy & $\begin{array}{c}\text { Strict separation } \\
\bullet\end{array}$ & $\begin{array}{c}\text { Flexible } \\
\text { convergence } \\
\Delta\end{array}$ & $\begin{array}{l}\text { Flexible } \\
\text { multiplicity }\end{array}$ & & & & & & \\
\hline Subjects taught in L2 & $\begin{array}{r}\text { English } \\
\bullet \\
\Delta\end{array}$ & $\begin{array}{c}\text { Math } \\
\dot{\Delta} \\
\dot{\Delta}\end{array}$ & $\begin{array}{r}\text { Science } \\
\bullet \\
\Delta\end{array}$ & $\begin{array}{ll}\mathrm{IT} & \\
& \bullet \\
& \Delta\end{array}$ & PE & Art & $\begin{array}{c}\text { Social Studies } \\
\bullet\end{array}$ & & \\
\hline Subjects taught in $L 1$ & & & & & $\Delta$ & $\Delta$ & $\Delta$ & $\begin{array}{r}\text { Arabic } \\
\bullet \\
\Delta\end{array}$ & $\begin{array}{c}\text { Islamic studies } \\
\bullet \\
\Delta\end{array}$ \\
\hline 3. Teachers & & & & & & & & & \\
\hline $\begin{array}{l}\text { Teachers } \\
\text { Language }\end{array}$ & $\begin{array}{l}\text { Arabic speaking } \\
\text { only } \\
\quad \Delta\end{array}$ & $\begin{array}{c}\text { Bilingual } \\
\bullet \\
\Delta\end{array}$ & $\begin{array}{l}\text { English Speaking } \\
\text { only }\end{array}$ & & & & & & \\
\hline $\begin{array}{l}\text { Teachers } \\
\text { Qualifications }\end{array}$ & Postgrad & $\begin{array}{c}\text { University } \\
\text { degree } \\
\bullet \\
\Delta\end{array}$ & College diploma & $\begin{array}{l}\text { High school } \\
\text { diploma }\end{array}$ & $\begin{array}{l}\text { Teacher training } \\
\Delta\end{array}$ & & & & \\
\hline 4. School Resources & $\begin{array}{c}\text { School Bilingual } \\
\text { Library } \\
\bullet \\
\Delta\end{array}$ & $\begin{array}{c}\text { Classroom } \\
\text { Library } \\
\bullet \\
\Delta\end{array}$ & $\begin{array}{c}\text { Classroom } \\
\text { Computer } \\
\Delta\end{array}$ & $\begin{array}{c}\text { Dictionaries } \\
\bullet \\
\Delta\end{array}$ & $\begin{array}{c}\text { Smart Board } \\
\Delta\end{array}$ & $\begin{array}{r}\text { IT lab } \\
\Delta\end{array}$ & $\begin{array}{c}\text { Cafeteria } \\
\Delta\end{array}$ & $\begin{array}{l}\text { PE hall } \\
\text { Outdoor play } \\
\text { area } \\
\dot{\Delta}\end{array}$ & $\begin{array}{c}\text { Auditorium } \\
\Delta\end{array}$ \\
\hline
\end{tabular}




\begin{tabular}{|c|c|c|c|c|c|c|c|c|c|c|}
\hline \multicolumn{11}{|c|}{ IMPLEMENTATION OF BILINGUAL PROGRAMME (PEDAGOGY AND PRACTICE) } \\
\hline 5. & $\begin{array}{l}\text { Language of } \\
\text { instruction }\end{array}$ & & & & & & & & & \\
\hline & English classes & L1 & $\mathrm{L} 1$ introduces $\mathrm{L} 2$ & & $\begin{array}{l}\text { L2 clarified by L1 } \\
\Delta\end{array}$ & & $\begin{array}{r}\text { L2 only } \\
\bullet\end{array}$ & & & \\
\hline & Arabic classes & QA & $\begin{array}{l}\text { QA introduces } \\
\text { MSA }\end{array}$ & & $\begin{array}{l}\text { MSA clarified by } \\
\text { QA } \\
\Delta\end{array}$ & & $\begin{array}{c}\text { MSA only } \\
\bullet\end{array}$ & & & \\
\hline \multicolumn{11}{|c|}{$\begin{array}{l}\text { 6. Code-switching } \\
\text { functions }\end{array}$} \\
\hline & Teachers & Lesson input & $\begin{array}{l}\text { Giving } \\
\text { definitions }\end{array}$ & $\begin{array}{l}\text { Explaining an } \\
\text { activity }\end{array}$ & $\begin{array}{l}\text { Provide } \\
\text { instruction }\end{array}$ & Translate lesson & Discipline & $\begin{array}{l}\text { Checking } \\
\text { comprehensions }\end{array}$ & $\begin{array}{l}\text { Social } \\
\text { interaction }\end{array}$ & \\
\hline & English Teachers & & $\begin{array}{l}\bullet \\
\Delta\end{array}$ & $\Delta$ & & & $\dot{\Delta}$ & $\begin{array}{l}\bullet \\
\Delta\end{array}$ & $\begin{array}{l}\bullet \\
\Delta\end{array}$ & \\
\hline & Arabic Teachers & & $\dot{\Delta}$ & $\Delta$ & & $\bullet$ & $\dot{\Delta}$ & $\dot{\Delta}$ & $\dot{\Delta}$ & \\
\hline & Students & $\begin{array}{l}\text { To assist each } \\
\text { other }\end{array}$ & Ask/answer Q & Write in L1 & Use dictionary & Interact socially & & & & \\
\hline \multicolumn{2}{|c|}{ In Arabic classes } & $\Delta$ & $\dot{\Delta}$ & & & $\dot{\Delta}$ & & & & \\
\hline \multicolumn{2}{|c|}{ In English classes } & $\dot{\Delta}$ & $\Delta$ & & $\Delta$ & $\dot{\bullet}$ & & & & \\
\hline & $\begin{array}{l}\text { Instructional } \\
\text { practices }\end{array}$ & $\begin{array}{c}\text { Interaction (IRF) } \\
\bullet \\
\Delta\end{array}$ & $\begin{array}{l}\text { Focus on } \\
\text { Academic lang. }\end{array}$ & $\begin{array}{l}\text { Co-operative } \\
\text { learning }\end{array}$ & $\begin{array}{l}\text { High relevance } \\
\text { materials }\end{array}$ & $\begin{array}{c}\text { Explicit grammar } \\
\text { teaching } \\
\bullet \\
\Delta\end{array}$ & $\begin{array}{c}\text { Focus on } \\
\text { vocabulary } \\
\bullet \\
\Delta\end{array}$ & Scaffolding: & $\begin{array}{c}\text { Focus on } \\
\text { Reading } \\
\Delta\end{array}$ & \\
\hline 8. & $\begin{array}{l}\text { Teaching } \\
\text { approach }\end{array}$ & $\begin{array}{l}\text { Mostly } \\
\text { Communicative } \\
\text { approach }\end{array}$ & $\begin{array}{l}\text { Mostly } \\
\text { Grammatical } \\
\text { approach } \\
\dot{\Delta} \\
\dot{\Delta}\end{array}$ & $\begin{array}{l}\text { Mostly Cognitive } \\
\text { approach }\end{array}$ & Mixed approach & & & & & \\
\hline
\end{tabular}

- Salam International School

$\Delta$ Jazeera Independent School 


\section{CHAPTER EIGHT: DISCUSSION}

\subsection{Introduction}

Overall the study reveals that the Qatari bilingual schools context explored is a heteroglossic context, with three codes in operation: Modern Standard Arabic, Colloquial Arabic dialects and English. These three codes are used differently in the two schools observed. Teachers and students in the international school adopt a strict separation policy between the two languages following a monoglossic belief. Language teachers and students in the independent school applied a flexible language pedagogy inside English and Arabic classrooms. Flexible language use was applied by the participants for both classroom management and content transmission.

International schools have a reputation for offering cutting-edge learning and teaching methods and end-of-line resources, whereas independent schools are often criticized in the local media (Carder, 2007). That reputation was contradicted by the findings of this study, because the independent school was observed to offer more versatile and modern teaching methods and strategies than the international school. It is not known, however, if this distinction can be generalized to all international and independent schools in Qatar.

The discussion which follows seeks to address the research questions in the light of the findings reported in the earlier chapters. The chapter is thematic in nature, and also explores the extent to which the methods employed were fit for the purpose of answering the research questions.

One main research question and seven sub-questions were designed to explore the programs in depth, focusing on features of bilingual programs: namely, language distribution in the school day, language allocation, bilingual arrangements, language choices in the language classroom, pedagogical strategies in language classes, models of 
bilingual teaching, the bilingual approach, and finally, the model of bilingual program adopted. The fourteen tertiary questions, attached in the case study protocol (Appendix I), which were used to collect data for the two cases, were essential to build a coherent answer to the main research question.

The case study was not designed to make value judgments, but rather as a fact-finder, to compare the school's perceived and practised language policy, as opposed to its official language policy (Bonacina, 2012). In addition, an underlying concern of the present study is that the school's stakeholders (administrators, teachers, students, and parents) should be aware of the need for an explicit bilingual policy, and the need to implement effective instructional practices in order to achieve the goals of such a policy.

The research questions (RQs) are answered in ascending order: that is, the sub-questions are answered first before the main research question is discussed. The sub-questions address the case studies of the two schools specifically, whereas the main research question addresses a more general argument. RQs 2-5 are grouped together and discussed in section 8.2. RQs 6 and 7 are discussed in section 8.3. The type of bilingual program, addressed by RQ1, is discussed in section 8.4. Section 8.5 directly addresses the main research question (RQ1) in light of the two case studies, the description of schools in Qatar as presented in Chapter Four, and appropriate literature on bilingual education, especially the theoretical framework presented by Garcia (2009).

\subsection{Perceived and Practised Language Policy}

The following research questions are addressed:

RQ2: How are English and Arabic distributed in the school's official policy and official school programme? 
RQ3: What content is allocated to each language?

RQ 4: How are English and Arabic distributed during the school day/week in classroom practice?

RQ5: Which language(s) do teachers and students use in the classroom?

RQs 2-5 are addressed in one section, because answering these questions in separate sections would produce dispersed arguments with much repetition. The findings related to these questions support each other, with many overlaps between issues.

All decisions about how languages in bilingual classrooms are allocated, arranged, and used in the curriculum are language policy choices. They adhere either to an official or an agreed-upon policy of language use. The two cases at hand present examples of separate and flexible bilingualism in the language classroom, as described by Blackledge and Creese (2010). This finding is also in line with Garcia's (2009) classification and description of the two types of language arrangement in bilingual programs.

In the international school, the data gathered from the variety of sources -questionnaire, interviews, classroom observation and field notes- indicate that the school abides by its perceived language policy of separation of the three codes used (MSA, English and Qatari Dialect). The school's claimed language allocation of 70:30 was supported by the school's implementation data. Teachers and students rarely rely on code-switching as a tool for communication. The cross-case synthesis indicates a matched relationship between claimed organizational evidence and implementation evidence regarding the linguistic aims of the school. The school's claim to promote native speaker skills in their course material, as well as the 70:30 distribution of the second language in the weekly program, was confirmed. 
The international school supports the use of English language only, with minimal codeswitching, and MSA is used only in Arabic classes. This separation policy was advocated by the teachers in the interviews. It was perceived that it is better for the teachers to be monolingual, because the students will learn the language faster through maximizing exposure to L2. Blackledge and Creese (2010) record similar findings in their observations of some community schools in the UK where a separation policy is maintained. This is also the case in most international schools, as documented by Cummins (2000) in his description of international schools. A separation policy is encouraged and commended as the norm in international school practice, whether in minority or majority language contexts. Some prominent examples are the Vienna International School (Carder, 2007) and the Canadian immersion programs (Swain and Lapkin 1982). In the Asian research literature, separation policies are also apparent. For example, Lin (2006:287) questions such practice in schools in Hong Kong, advocating more flexible language policies in Asian contexts. The language ideology of an official, perceived and practised, policy of separation will be discussed further in Section 8.3.

The data gathered from the independent school was different to that from the international School. The organizational evidence indicates a 60:40 language allocation. Other evidence also points to a subject-determined language arrangement, where subjects such as maths, science and technology are taught in English and other subjects are taught using the first language. This subject determined separation is in line with practice in many countries; for example the Philippines (Garcia, 2009) and Malaysia since 2003 (Martin, 2000). In practice, bilingual allocation, especially in multiple multilingual education, is often more complex than the implementation of fixed distribution percentages calculated from weekly timetables and indicated in policy documents. This is because L1 and L2 are weaved in and out during interactions inside and outside the classroom. 
The findings of this study indicate that the actual ratio of L1 to L2 among the teachers and students is not exactly the same as the percentages claimed by the schools. Although I spent only two months in the schools, classroom observations demonstrated how codeswitching was frequently used by the teachers, and local dialects were used as a resource, as pointed out by Ferguson (2003). O’Neill and Valesca (2007) also consider that codeswitching is a useful pedagogical technique, one of the uses of which is to provide definitions of words: this was observed in the independent school. Research in CLIL in Europe suggests that code-switching, if properly understood and suitably applied, can enhance cognitive skills for the content matter in non-language subjects (Duverger, 2005). Code-switching, in itself, can be viewed as a scaffolding technique (Bloom, 2008) making the additional language more comprehensible.

The responses of the teachers in the interviews and the classroom observations at the independent school indicated that code-switching was a practised policy, using the first language in English classes and the local dialect in Arabic classes in order to give definitions of words - providing what Duverger (2005) terms micro-alternations. Microalternations occur when a subject which is taught through the medium of one language makes use of elements of another language. This type of code-switching happens naturally in bilingual communities, but is often considered taboo in language-education communities (Cook, 2000). I observed how in (supposedly) English-only classes, Arabic was used to support the development of L2. In the case of Arabic classes, the CA dialect was used to support the development of the dominant language MSA. Mostly, CA was used in order to allow students to make sense of the vocabulary used in the lessons.

When examining current typologies of bilingual education, it can be seen that no one type of bilingual education admits the importance or the occurrence of this type of codeswitching. Although code-switching as a practice in L2 acquisition has been the topic of a 
multitude of research studies, flexible use of languages in bilingual classrooms have been little considered and researched. Jacobson (1981) and Jacobson and Faltis (1990:4) presented one of the early arguments for this type of teaching. Recent consideration of the topic is found in Bartlett and Garcia (2011:116), who discuss such flexible language teaching policies in schools in the Dominican Republic. In their description of one school: Luperon "languaging" or "translanguaging" is used overtly as a learning tool and a reality which is put to use to improve the students' linguistic calibre. Garcia (2009:44) also uses the term "translanguaging" and identifies it as a type of bilingual instructional practice in the classroom.

In the current study, the practice in Jazeera independent school might not be one of "translanguaging" as defined by Garcia: however, flexible language use is certainly apparent in the form of frequent code-switching. The absence of a pre-determined agreement between the management and the teachers about this alternation and use of languages makes it a subtle arrangement devised by teachers to deal with the complexity of language teaching in the classroom. It is an example of what Bonacina (2012:230) terms "perceived" and "practised" policies, which can be the same as or different from the official language policy of the school.

In the international school, an ideology of separate bilingualism has been constructed, establishing routines and practices that aim to keep languages separate. On the other hand, the flexible bilingualism apparent in the independent school must be viewed as heteroglossia rather than code-switching. Although at most times students followed the language choice of the teacher, the use of two codes in the same classroom is more than simple code-switching: it is better classified as a "hybrid alternation of two codes" (Garcia, 2009:45). This classification puts the learner at the centre of the practice, and contextualizes the practice within the wider multilingual context of the school where 
students use MSA, English and their own dialects to communicate during the school day. This is a distinct context, separate from the practice of L2 learners referring back to their L1 to fill in the blanks of an unknown lexicon during a second language class. It is a flexible and dynamic conceptualization of bilingualism (Garcia, Sylvan and Witt, 2011). Why do international schools adhere more to the separation model than independent schools? It could be their private nature, commercial goals, or fear of loss of customers. Further research is necessary to find a more definite answer.

\subsection{Bilingual Pedagogy}

The research questions addressed in this section are:

RQ6: What is the biliteracy teaching method adopted by language teachers?

RQ7: What is the biliteracy approach used most often in the classroom?

The finding of the case studies provided evidence to indicate the implementation of a certain biliteracy teaching method. Schools need to decide how to use the two languages in literacy practices, meaning which languages are used in the written mode, which are used in the oral mode and whether these are used in both modes. The data from Salam International School indicated that the school adopted a separation biliteracy model following its language use policy. This means that teachers and students "match" the language in which they are writing to the language of the written text (Garcia, 2009:343). The data from Jazeera Independent School, in contrast, indicated the use of a flexible model of biliteracy. Garcia (2009) differentiates between biliteracy practices that use both language in the written mode (the flexible multiple model) and practices that use two languages in communicating around written texts but only one language in the written mode (convergent monoliterate/biliterate model). Garcia describes convergent models of biliteracy use as belonging to an ideology of convergence and associated with subtractive 
bilingualism. In the case of Jazeera Independent School, this biliteracy practice is not a tool for convergence from one language to another. Within each language slot (Arabic or English) one language is used in the written mode and oral mode (English in English lessons) and the first language (Colloquial Dialect of Arabic) is used only in the oral form to support development of the language studied. This practice is also evident in Arabic classes where MSA is used in the written and oral mode and the colloquial dialect of Qatari Arabic is used orally only to explain or clarify vocabulary and support the learning of the main language (MSA in this case). Taking both English and Arabic classes into consideration, it can be argued that a "flexible biliteracy model" is used when two languages are being developed using three codes in different modes. This is not an entirely new method. In the Philippines it is reported that teachers will present a written text in Filipino, but will give the gist of the lesson in a local dialect of Tagalog. In many African countries, teachers refer to using a vernacular or the first language for instruction, but never in written form (Garcia, 2009).

As the biliteracy model was explored, I took into consideration not only the approach of second language teaching but also the instructional strategies employed by teachers to convey the linguistic and educational goals of the school. Lara-Alecio and Parker (2007) stress that:

"What is missing from literature, however, is (a) the knowledge base and empirical studies documenting classroom pedagogical occurrences for English language learners (ELLs), (b) the documented quality of instruction by languages of instruction, and (c) the interactions of pedagogy that may produce quality outcomes for such students. Such missing information is supported not only by our own review of literature, but also by recent syntheses from August and Shanahan 
(2006), Slavin and Cheung (2003), Gersten and Baker (2000), and Thomas and Collier (2003)."

The aim of the case studies was to explore different types of bilingual education underpinned by the theoretical frameworks and typology put forward by Garcia (2009). Exploring bilingual pedagogy and instructional strategies found in the English and Arabic language classes was essential to classify the different types of bilingual program, biliteracy methods, and biliteracy teaching approaches. Moreover, an analysis of instructional practices used by the two schools was conducted to index the ideological position with regard to the teaching of the two languages within the two schools.

Arabic classes in the independent school revealed use of context-embedded dense cognitive material, material with high relevance to students' culture, as well as a focus on explicit teaching of academic language registers.

In Salam International School there was a strong focus on the IRF sequence of interaction. A sequence of initiation, response, and feedback (Cazden, 1988) or initiation, response, and evaluation (IRE) was the most common type of interaction observed in the classroom. The classroom observations demonstrated a strong emphasis on this type of interaction from all three teachers in all lessons. This sequence has often been criticised (Hall and Welsh, 2002) as unproductive for most of the time, since the interaction is used to elicit answers that the teacher is expecting rather than being a tool for substantive conversation in productive pedagogy. Barron (2001) suggests that recent research has indicated that the IRF sequence may not be so unsuitable for the development of pragmatic competence. She notes that the productivity of this format of teaching depends mostly on the quality and level of participation. The available data from this study was not necessarily consistent with a more productive type of IRF format. The findings presented a mismatch between 
the international school's professed goals of communication and a lack of it in the classroom. Another mismatch was that the school documents stressed the importance of collaborative learning, whereas the observations in the classrooms revealed that most tasks and activities were conducted by the students acting either as a whole class, or individually, but only occasionally in groups. Overall, the observed instructional practices found through analysis of classroom data, and presented in the international school portrait, reflect a gap between its advertised educational goals, and their implementation in classroom practice. Perhaps one reason for this gap is a lack of teacher training, paired with a lack of a continuous professional development program for teachers.

The observations at Jazeera Independent School indicate slightly different features in regard to instructional practices. A high to medium frequency of occurrence of IRF and focus on grammar and vocabulary were reported, similar to the situation in the international school. However, L1 classes were reported to have a high frequency of teaching of academic language skills. The Arabic classes used dense cognitive content with explicit teaching of academic language skills. Both of these features were linked to academic success in L2 as well as L1 (Cummins, 2000). There was also high focus on reading fluency in the Arabic classes. The L2 classes, on the other hand, featured a high focus on co-operative learning and task-based pedagogy. This can be attributed to the influence of SEC central management, as the teaching plans suggested by the SEC depicted a checklist of methods to be used in the classrooms.

It was observed that pedagogies used in the two schools which appeared to be in line with recommended pedagogic practices in the literature, such as scaffolding (Wallaqui, 2000) read-aloud, and reading performance (Gibbons, 2002) were not used as frequently as the explicit teaching of grammar and vocabulary with IRF interaction prevailing classroom interaction. This finding is consistent with previous research in CLIL-type of programmes. 
Martin (1997) illustrated in a case study of 50 minutes geography lesson in Malaysia how student were unable to produce any interaction. Many teachers in his study were uncomfortable with the new methodology because they did not understand the theoretical assumption behind it.

To address RQ7 directly, the classroom observations indicated the frequent use by both schools of a grammatical approach to teach the second language. A grammatical approach was also used to teach Arabic. In both schools there was a great focus on explicit teaching of grammar and vocabulary, with minimum focus on developing students' communication skills or academic language skills responding to either a communicative approach or a cognitive approach.

Overall, the two schools present evidence of using a 'traditional pedagogy' characterized, in the classroom, by high teacher control as the person who 'imparts' knowledge and skills to students (Cummins, 2000:255). This is the opposite of what Cummins terms ‘transformative pedagogy’. The international school had some focus on extensive reading in its library sessions and extra-curricular activities, while the independent school focused on reading fluency in the Arabic classes. Both of these approaches are features of transformative pedagogy. However, their extensive focus on IRF-style exchanges and the lack of genuine communication among students or group work as evidence for

collaborative learning providing 'genuine opportunities' for language practice, as prescribed by August and Hakuta (1997:175) are all indicative of a traditional pedagogy.

\subsection{Type of bilingual program}

This section addresses the question:

RQ1: What model of bilingual program do the schools follow? 
I found that one school was following an early-immersion program while the other was following a CLIL-type of program. Salam International School implemented a strict subject-determined separation of L1 and L2. Code-switching was not permitted between L1 and L2 and MSA and the Qatari dialect. I observed that Jazeera Independent School was teaching two subjects in L2 only, namely mathematics and science. The school places great emphasis on the L1 culture. Both programs were promoting an additive type of bilingualism (Baker, 2001) where the two languages were being developed. These programs also corresponded to the enrichment model put forward by Hornberger (1990).

The subject-determined separation of language, and the refusal of teachers to use the L1, or the vernacular Qatari, in Arabic classes, highlights that there is a strict policy in the international school to keep English, MSA and Qatari dialect separated, for each function, in different ways. Thus, the international school appears to be working within a monoglossic orientation, working towards the development of students' bilingualism according to two monolingual standards. These kinds of program respond to what have been termed a monoglossic belief, which assumes that legitimate linguistic practices are only those enacted by monolinguals (Garcia, 2009). Moreover, organizational evidence and findings concerning the two schools' language distribution - and in turn their language policy - indicate that the international school had a notion of parallel monolingualism as the right kind of bilingualism. This notion derives from the specific goals of this international school (and possibly, by implication, all international schools in Qatar). Monoglossic beliefs counter the existing multilingual contexts by insisting on a strict separation of languages.

In contrast, the independent school was found to operate within a heteroglossic language framework, in which three linguistic codes operate within the school day. In addition to teaching English, there is strong support of the first language in the form of more MSA 
classes, plus a wide use of the students' local dialects. It was noted that an official policy regarding dialect use was not in placed at the independent school; however, based on the findings of this case study, it appears that the school program responds to a heteroglossic belief, because of the integration of Arabic and English during the school day, flexible language use in the classroom, and language alternation during language classes.

In summary, this study revealed that two very different language ideologies were present within two schools, within the same local context, that serve almost identical student demographics. The findings give a brief profile of the bilingual programs in Qatar, exemplified in these two cases. What is important to understand is that it is not the bilingual arrangements themselves that lead to language shift, maintenance or enrichment. It is the uses to which these arrangements and practices are put that encourage language mixing in ways which may achieve the goals of the schools.

\subsection{Bilingual Education in Qatar}

The validity of this study requires a brief discussion of the methodology used to answer the research questions. Qualitative research to understand the big picture is not a unique or novel technique in educational research, applied linguistics or the field of bilingual education. Heller's study of minority language education (2006) stresses how a big picture approach, which aims to identify larger issues, can be interwoven with the fine detail of research data in order to make sense of a significant linguistic problem. In her research, Conversation Analysis is used to understand ideologies in minority schools in Canada. The micro-macro levels of social structure are viewed in her study as parts of a bigger social theory rather than a linguistic or educational theory. However, the terms and the methodology are borrowed here to illustrate the same argument she uses: 
"[As] social scientists, if we want to understand how social reality is constructed we have to work with what is observable in the here and now" (p.212).

The school as an organization is part of the social structure, and defining the policies in placed and enacted by the different players of the programs called for a detailed description of various micro-practices. The current case study presents this kind of micro-level analysis to understand the bilingual programs offered in Qatar. Moreover, in her most recent paper Bonacina (2012) argues for the use of Conversation Analysis and careful analysis of classroom interaction to discover language policies. This can apply not only to top-down official polices, but the so-called "perceived" and "practised" policies of students and teachers and how they match or fail to match the overall goals of the school. In the same manner, the discussion of her findings adopts her differentiation of actual/perceived/practised language policy, and how these categories are rooted in classroom practice. Analysis of classroom interaction was not the only tool used in the current study. Ethnographic descriptions and various enumeration methods were also used to report the findings.

In this study, the big picture of bilingual education types found in Qatar was explored through the use of field notes, interviews, classroom activities and school-wide practices to explore the issues of (a) what kind of bilingual education was taking place; (b) how it could be compared to the known types and models of bilingual education in the literature; and (c) how it fitted with the theoretical framework of monoglossic and heteroglossic bilingual education posited by Garcia (2009).

In this section, the results will be placed within the wider context of the study, with the aim of establishing a coherent narrative with respect to the overarching research question. In essence, this study was an investigation into models of bilingual education within majority 
language learning contexts. The immediate context of Qatar was chosen for personal interest, but it also constitutes a sample of bilingual education programs in the Middle East, and informs the research of language education in similar contexts. In its attempt to decipher the micro/macro connections of bilingual models of education, the findings of the current study provide impressions about bilingual education in Qatar by addressing the overarching question:

\section{How is bilingual education manifested in schools in Qatar?}

The case studies, quantitative description of schools, portraits, summaries and charts, as well as the discussion of sub-questions in this dissertation, are directed towards answering this overarching question, from the background chapter to the conclusion. In the following paragraphs a summary of the findings will be presented and the ideology, policy and practice in Qatar are discussed in the light of the findings of the current study

Phase one of the study depicted quantitative reports of teachers and students features and numbers. The average teaching time in each language for each school type was also calculated from SEC data base. It was found that independent schools usually attracted most of the students in Qatar compared to international schools. Arabic female teachers dominated the teaching staff in the two school types. Independent schools operate a 50-50 time allocation model for each language while international schools offer an 80-20 model. This is on average as individual schools vary in their own time allocation for the two languages involved. The brief report was informative, but it did not present a clear picture of what bilingual education looked like and how it was organised and practiced. The two case studies provided such in-depth investigation.

In each case, I charted the school's organizational position (its official discourse about itself and the organizational beliefs within which it operates) by collecting relevant 
documents (school correspondence, official website material, official policy, teaching material, weekly and daily plans) and interviewing key actors (Arabic language teachers, English language teachers, and the academic vice-principal).

Mapping language practice at school also required getting a handle on the organization of space and time which meant in practical terms spending a lot of time in schools, exploring its different spaces and activities.

.Overall, the study’s main findings fall into two categories: the linguistic situation of Qatar, seeking to identify type of bilingual education used and language policies regarding use of the different codes available; The rest of the findings present a discussion of the pedagogical issues, through examining the instructional methods identified by the literature as being facilitative of successful bilingual education,

A main finding was that the social act of language education in the two settings described reveals various 'gaps' between what is claimed and what is practised. The cross-case comparison reveals how items such as 'learner-centred education' and 'support learning difficulties' were not evident in the observations. These findings are in congruence with previous research in Asian and Middle-East where most of the studies profess dissatisfaction with policies and practice of school system investigated (e.g. Fryer, 2009 and Shabaan, 1997) where claimed goals of the programmes do not match practices and outcomes.

Another related finding was the noted discrepancy between the views of the academic Vice-Principals, at both the international and independent schools, and the practices of the teachers. The Vice-Principal at the international school was enthusiastic about putting communication first and language teaching second. She was presenting a view that was not shared by the teachers, either in their interviews or actual practice. It was surprising that 
the Vice-Principal in the independent school was entirely opposing the bilingual program of the school and questioning the validity of teaching science and maths through the medium of English. The complexity of the decisions on the bilingual curriculum, and the implementation of these decisions, emphasises that the school leadership needs more understanding of bilingualism issues. The education of school leaders and administrators is an area that needs extensive attention. This is as important as the education of bilingual teachers, since teachers themselves will implement a "practised" policy.

In 2001, an initiative took place to change and develop the educational system in Qatar. A team of experts arrived from a reputable American non-profit institution (RAND) to oversee the changes. The Qatari government also invited various external institutes, such as CfBT, and renowned scholars such as Ofeila Garcia to advice upon educational reforms in Qatar.

These institutions described the old regime as rigid and bureaucratic, with little emphasis on science and technology and too much stress on memorization and teacher control. Accordingly, they recommended an entirely new system to eliminate centrality and tradition-bound education. In the following years, the government of Qatar launched decrees to construct new educational institutions. Along with these top-down western constructed reforms came partnerships with international institutions to help set up the new schools.

The international schools were also included in the reform. Any Qatari student attending these schools receives a voucher, so that the government of Qatar pays his fees. In return, international schools are obliged to abide by certain standards of teaching and learning, especially curriculum standards of teaching social studies, Islamic studies and Arabic 
(SEC, 2010). The inclusion of international schools in this way makes them essential partners in the national education sector.

Educators in language education have often warned against the blind importation of bilingual models; because policy makers may import systems that have nothing to do with the context in which children live (Mackey, 1978). When Qatar decided to inject English into its language-in-education initiative, a model of education was imported from the West. The practice of this model is exemplified in the case study of the independent school. The lack of clear policy documents that chart the language(s) used was a major caveat that probably affected the practice of these schools. Tucker (2000) suggests that a critical linchpin for moving forward policy or planning discussions in language education reform is to consider importing a 'cycle of discovery' rather than a ready-made model that may be taken out of context. According to Garcia, in an unpublished report prepared for the Qatari SEC (2004), the new initiative aims for monoglossic bilingualism with bilingual education seen as an additive attribute without the aim of cultural diversity. This experimentation with bilingualism remained an unprofessed aim in the lack of explicit formal policies in schools. Garcia in this report insists that "adopting a clear and explicit language-ineducation policy should be a most important priority for the Qatari Supreme Council” (p77). The findings from the independent school revealed that the perceived and practised policy was one of flexible language use, reflecting a heteroglossic ideology of using the three codes available to students in the development of their languages and literacy.

Tucker (2000) states that "policy makers have characterized bilingual education as high risk undertaking, by which they mean that it is necessary to attend to a complex set of interacting educational, sociolinguistic, economic and political factors” (p.4). The following quote depicts how educational change is a journey that must be taken by the stakeholders themselves: 
"All large-scale change is implemented locally. Change cannot be accomplished from afar. This cardinal rule crystalizes the previous six propositions. The idea that change is learning, change is a journey, change requires the power to manage, and change is systematic all embody the fact that local implementation by everyday teachers, principles, parents, and students, is the only way that change happens." (Fullen and Miles, 2002)

What was lacking (in my view) was a well-articulated language-in-education policy that involved members of the community. The findings presented in the pedagogy section of this chapter, as well as those related to the frequency of the instructional practices used in the classroom, indicate the same bureaucratic, teacher-centred type of learning evident in international and independent schools to a varying degree. The teachers in both schools report low awareness of formal language policies, resulting in the polarization of a perceived and practised policy of flexible language use. Despite the fact that some form of bilingual education is taking place, the word 'bilingual' was not included in any policy documents. Despite schools' claims about their policies, policy documents are not available to the public.

The study looked at international schools because (a) the reforms that took place in Qatar are looked upon as an example to follow (b) many Qatari and Arabic students attend these schools. The analysis and findings indicate that the international school does not measure up to its reputation. This bilingualism-through-education implemented in the independent school can be seen as a step into the journey of change and development of the educational system in Qatar. From a distance independent schools look overcrowded and underdisciplined: however, a closer look into the daily language education in the independent schools shows signs of hope. Compared to international schools they implemented better teaching methodologies. 
This overall finding is also linked to various other findings that bear significance in shaping the context of bilingual programmes in Qatar. The explicit instruction of academic language skills and the diglossic situation in the educational settings are two features that set the independent schools apart from the international school.

The language of school has often been termed 'standard academic language'. A standard language is defined as "a prestige variety of language providing a written institutionalized norm as a reference form for such purposes as language teaching and the media" (Coulmas, 2005:215). Modern Standard Arabic is the standard language in the Qatari context. It is the language of academia and formal communication in the Arab world. In the schools, findings indicate that academic language skills were only emphasised in the independent school within their Arabic language provision. This provided explicit teaching of different text genres, and various modes of expression in non-fictional writing with a focus on scientific writing.

The other main finding was related to how the schools viewed languages and dialects: whether codes were viewed as resources, where any code available can be used, or whether codes were viewed as separate entities and Code-switching is a deviation from the norm an error to be 'corrected'. Under this principle, we saw how differences in dialects between teachers and students can sometimes create challenges in communication of messages.

The diglossia situation in Qatar is unlike any other majority learning context in the world. In Spain when a teacher Cs she uses Spanish. A Hong Kong teacher switches to Cantonese to get the message across. In Qatar the Lebanese teacher, for example, will switch to her own dialect to communicate a message, but how many students have heard a Lebanese accent outside the school? 
Schools must be aware of the languages at the disposal of students and teachers, acknowledging the differences in student and teacher dialects, and the ramifications of these differences for students' understanding and interaction in the classes.

The on-going comparison in the case study between the organization and implementation of the program, between international and independent schools, between Arabic and English language teaching enabled the researcher to examine Qatar's sociolinguistic and educational system from a variety of perspectives.

\subsection{Implications and Future Research}

The information presented in this dissertation refers only to the situation at the time of data collection; however, schools evolve and personnel change. Educational contexts are dynamic, with policies changing all the time. Educational change in Qatar is rapid, and as I write this final chapter, new changes have been made, implemented and broadcast in the local media. Many independent schools have opted out of the bilingual program. Others have opted for more L1 in L2 classes, with textbooks published in L1 and scientific terminology in English. A subject called "Scientific English" is also used in some schools to support academic development of L2. The extent of the practice of these advertised changes is beyond the grasp of this dissertation, and further research is required to evaluate the impact of the changes. Effectiveness issues are another direction in which to follow up this study, in order to evaluate the relative effectiveness of programs in promoting literacy success in the two languages.

In conclusion, the study at hand brings two main issues into the foreground. One is bilingual and biliteracy policy awareness: students and staff having an explicit understanding of the languages they are studying, language use decisions, and differences between the codes used. The other issue is adhering to the pedagogical orientation of the 
instructional practices used in first and second language classes and whether it is more profitable to opt for a traditional or a transformative pedagogy. 


\section{CHAPTER NINE: CONCLUSION}

This study was an investigation into models of bilingual education programmes within majority language learning contexts. The immediate context of Qatar was chosen for personal interests but it also constitutes a sample of bilingual education programmes in the Middle East informing the research of bilingual education in similar settings. The doctoral thesis attempted to decipher the micro/macro connections of bilingual models providing impressions to answer the overarching question: how is bilingual education manifested in schools in Qatar? As is common in research, the questions preceded the design. However, deciding on a research agenda that matched the goals of the study was not a straightforward process because the interest was not on individual students or teachers but on how the schools functioned as systems with their organization and implementation of their bilingual programme. In order to counter a purely positivist theory and draw upon the perspectives of the individual within the school, an observational methodology was selected following an ethnographic approach in the research design.

An ethnographic approach to the study of bilingualism takes languages use as a form of social action that has consequences for the interlocutors as well as for researchers. (Myer, 2008). In other words the sociolinguistic perspective in language study differs from linguistic and psycholinguistic in terms of its research methodology and fundamental concerns (Wei and Moyer, 2008) the sociolinguistic perspective view bilingualism and multilingualism as socially constructed phenomenon and bilingual persons as actors. To identify an interest in the multilingual practice of a given 
context (i.e. the school) this sociolinguistic study has examined communicative practices within and across sites that can be ethnographically demonstrated to be linked. Working with the idea of trajectories of speakers, linguistic resource discourses and institution across time and space (Wii, 2008) many findings were illustrated and discussed. The study also included a mix of methods including quantitative review of all schools in Qatar, case studies that included enumerations and narrative interpretations to address the various concepts, factors and themes involved in organizing ad implementing a programme.

Policies of language-in-education in schools official documents of related public institutes such as SEC depicting how the two languages are to be used and the role of the local dialects seems vague and almost often non-existent. In particular the two schools provided few documents that show how the teaching and use of the two languages is to be carried out. It was important to refer to language policies as a first step into the investigation of how the schools structured its bilingual program. Compared to other studies in the literature (e.g. Lee, Hill-Bonnet and Gillespie, 2008 and Bartlett, Lesley and Garcia, 2011), it was expected that these are clearly stated for all stake holders. Findings show that stakeholders were unaware of school wide policies and enacted their own understanding of how the languages are to be used in the daily routines.

In addition to analysing various documents to locate verbal representations of the schools policy, teacher and students choices of the first language were observed and interpreted to link their language policy intakes. The evidence provided by the study seem to indicate that the two schools observed in this study present examples of 'separate' and 'flexible' bilingualism as goals of the bilingual programmes (Blackledge and Creese, 2010:122). Between design and practice, the social act of 
language education in the two settings described reveals various 'gaps' between what is claimed and what is practiced. Language provision in both schools was not organized by a well circulated discourse in the form of a policy document. The international school did abide by its claimed separate bilingualism approach while the independent school used a more flexible approach incorporating the first language and different none-written dialects of Arabic in its language provision. What is interesting is how the two academic vice principals expressed their own 'perceived' language policy which was not shared by the teachers or unknown to them. These policies also contrasted with the school's advertised material in the websites and other documents. This fact and the diglossia indeed makes Qatar a special case for exploring a unique example of bilingual education where dialects play a big role in the daily programme of these publically funded schools opening a 'Pandora's' box of questions and areas of interest for a country that falls into the expanding circle of use of world English's.

A deeper exploration of instructional methods used in language classes (Arabic and English) in the international and independent school was also included. Lave and Wagner (1991) view instructional practices in language education as a collaborative social practice that mediates ideas, actions and concepts through an additional language. It is within this view that Garcia (2009) as well as Ellis (2007) suggests an action-based pedagogy or task-based learning where teaching and learning activities are instilled with concepts such as collaborative dialogue, scaffolding and heteroglossia. Only recently that the idea of scaffolding as a strategy for teaching and learning in the second language classroom have been introduced. In the two schools investigated there was infrequent use of these instructional methodologies. The data from the independent school indicate more use of these strategies than the 
international school. These and other concepts associated with socio-cultural theory are employed as a tool to unveil instructional practices children in these schools undergo within the bilingual programmes on offer.

Overall, teachers at the two schools seemed ill-equipped for the challenges of injecting bilingualism as well as achieving academic success, both of which appear to be the goal of the initiative launched in 2001 by the state of Qatar.

Chapter two considered some of the frameworks available to explain differences in language use in schools. The study has offered support for previous literature arguing that the situation in Qatar is one of heteroglossia. Bakhtanian perspectives of heterglossia as embraced by Garcia (2009) within her typology of bilingual education were used to describe the context of bilingual education in Qatar in the current project. This was done at the conclusion of the phases of the study when all parts were assembled. Garcia stressed on the importance of adhering to the social practice inside the bilingual classroom. Within this framework the biliteracy practices of the teachers for both languages' classes in both schools were investigated. Findings pointed that the schools biliteracy practiced matched the schools ideology of language teaching. Both schools were implementing traditional pedagogies in their language provision focusing on grammatical approach to language teaching in the first and second language.

This doctoral thesis has sought to provide a better understanding of the issues surrounding bilingual education in this and similar contexts. It did so by gathering data from interviews, observations, field notes, recordings, and collecting artefacts. While traditional case studies often follow single cases, in this project the case is a programme and a country. It investigates institutionalized L2 learning that is 
community driven. In an inquiry of this nature espousing methodological stance is deemed vital.

Moreover, the results of the (2006) PISA and PEARL projects cast a dark shadow over the effectiveness of the schooling system in Qatar. It seems from findings presented here that educational change and reform were a helpful starting step. This step however, may well not succeed if it is taken without employing national strategies for teacher training and policy awareness among parents/student and teachers. In such scenario the educational system keeps being the testing grounds for experimentation with various models of bilingualism-through education and initiatives that are seen as the new answer to the problems in education looking up to private institutions as role-models. Private institutions that have their own challenges to tackle.

Overall, this study aimed at providing descriptive data that can pave the way for experimental research investigating effective ways for balanced and effective bilingual education that doesn't affect academic achievement. The importance of such work cannot be underestimated since its application is not only to the improvement of local education system but also to the endeavour of furthering our understanding of the various and complex issues that surround bilingual education even beyond the Middle East boundaries.

There is much work to be done which might focus on the outcomes of different teaching strategies in the language classes to stimulate even further development in the local and international context. The case points to various areas for improvement. ; such as understanding the linguistic situation of Qatar and the role of the different dialects in learning the MSA and English Falling within the expanding circle of 
world Englishes (Kachru, and Smith, 2008) the diglossia situation in Qatar is unique to any other majority learning context in the world. In Spain, for example, when a teacher code-switches from English she uses Spanish, and a Hong Kong teacher switches to Cantonese to get the message across. In Qatar the Lebanese teacher for example will switches to her own dialect to communicate a message, but how many students have heard Lebanese accent outside the school?

Schools must be aware of the languages at the disposal of students and teachers acknowledging the differences in student and teacher dialects and the ramifications of these differences on students understanding and interaction in the classes. The English classes must include academically challenging content. In addition to explicit teaching of grammar and vocabulary a cognitive approach as well as a communicative one might be beneficial to incorporate in the curriculum.

Other areas can include focus on extensive reading which can be implemented in a similar way to the ones used in the international school, by allowing and encouraging students to borrow books from the classroom and school library. It is recommended that there could be fewer students in the classroom or to provide a teaching assistant since each class contains over 30 students with little close interaction between teacher and students.

Many regions in the Middle East are currently implementing bilingual-type programmes in their national education. The abundance of initiatives in the region (e.g. Qatar, UAE, and Bahrain) suggests that this represents more than just a quantitative increase of second language provision in schools. This marks a shift from bilingual education being for the elite only towards encapsulating forms of bilingual education within public education. However, with the lack of formal 
documents and super-national language policies formulated to state the goals, policies and guidance for language education in the states (such as The European Commission's White Paper on Education and Training, 1995, or the Plurilingualism Promotion Plan issued by the Andalusian government in 2005) presents a caveat increased by the scarcity of research to surround these bilingual practices before and after the national changes in education and the language-in-education issues. Documenting this change is informative for the educational sector internationally especially with the recent interest in educational importation in the region.

Ethnographic research allows us to tell a story which connects ideologies and pedagogies in institutionalized linguistic practices. The story of bilingual education in Qatar is far from being finished. The current thesis attempted to offer parts of this story only to be followed by further research. 


\section{References}

Abu-Rabia, S. (2000). Effects of exposure to literacy in Arabic on reading comprehension in a diglossic situation. Reading and Writing: An International Disciplinary Journal, 13 (1-2), 147-157.

Abu-Rabia, S., \& Siegel, L. S. (2002). Reading, syntactic, orthographic, and working memory skills of bilingual Arab Canadian children. Journal of Psycholinguistic Research, 31, 661-678.

Abu-Rabia, S., Share, D., \& Mansour, N. (2003). Word recognition and basic cognition processes among reading-disabled and normal readers in the Arabic language. Reading and Writing: An International Disciplinary Journal, 16, 423-440.

Al-Ammari, J. A. (2004). Benefits and Barriers to Implementing Computer Use in Qatari Elementary Schools As Perceived by Female Teachers, An Exploratory Study. University of Ohio, Department of Education: PhD Dissertation, electronic version.

Al-Ghanim, K. (2002). The Qatari Society From Diving to Urbanization. Doha: The National Council for Culture Arts and Heritage.

Al-Khatib, H. (2000). Language Alternation Among Arabic and English Youth Bilinguals: Reflecting or Constructing Social Realities. International Journal of Bilingual Education and Bilingualism, 6 (6), 409-422.

Al-Misnad, S. (1985). The Development of Modern Education in The Gulf. London: Ithaca Press.

Al-Nueimi, S. N. (2003). Profile of the Information Society in the State of Qatar. Economic and Social Commission for Western Asia.

Arber, S. (1993). The research process. In N. Gilbert, Researching Social Life (pp. 32-50). London: Sage Publications.

Arksey, H., \& Knight, P. (1999). Interviewing for Social Scientists. London: Sage Publications.

August, D., \& Hakuta, K. (1997). Improving Schooling for Language Minority Children: A research agenda. Washington, DC: National Academy Press.

August, D., \& Shanahan, T. (2006). Developing Literacy in Second-Language Learners. Report of the National Literacy Panel on Language-Minority Children and Youth. NJ: Lawrence Erlbaum Mahwah. 
Baetens Beardsmore, H. (2009). Bilingual Education Factors and Variables. In O. Garcia, Bilingual Education in the 21st Century (pp. 137-158). Sussex: WileyBlackwell.

Bahgat, G. (1999). Education in the Gulf Monarchies: Retrospect and Prospect. International Review of Education, 45 (2), 127-136.

Baker, C. (1988). Key Issues in Bilingualism and Bilingual Education. Clevedon: Multilingual Matters.

Baker, C. (1995). A Parent's and Teacher's Guide to Bilingualism . Clevedon: Multilingual Matters.

Baker, C. (2001). Foundations of Bilingual Education and Bilingualism . Clevedon, UK: Multilingual Matters Ltd.

Baker, C., \& Prys Jones, S. (1998). Encyclopaedia of Bilingualism and Bilingual Education. Clevedon: Multilingual Matters.

Bartlett, L., \& Garcia, O. (2011). Additive Schooling in Subtractive Times: Bilingual Education and Dominican Immigrant Youth in the Heights. Tennessee: Vanderbilt University Press.

Bialystok, E., Luk, G., \& Kwan, E. (2005). Bilingualism, Biliteracy, and Learning to Read: Interactions among Languages and Writing Systems. Scientific Studies of Reading, 9 (1), 43-61.

Bialystok, E., McBride-Chang, C., \& Luk, G. (2005). Bilingualism, Language Proficieny, and Learning to Read in Two Writing Systems. Journal of Educational Psychology, 97 (4), 580-590.

Blackledge, A., \& Creese, A. (2010). Multilingualism: A Critical Perspective. London: Continuum.

Bloom, J. (2008). Pedagogical Code-Switching: A Case Study of three Bilingual Content Teachers' Language Practices. Unpublished Ed. D dissertation. Teachers College : Columbia University.

Bonacina, F. (2012). Researching ' practiced language policy' insights from conversation analysis. Language Policy, 11, 213-234.

Bonacina, F., \& Gafaranga, J. (2010). 'Medium of Instruction' vs. 'medium of classroom interaction': language choice in a French complementary school classroom in Scotland. International Journal of Bilingual Education and Bilingualism, 14 (3), 319-334.

Bostwick. (2000). Bilingual Education of Children in Japan: Year Four of Partial Immersion Programme. In M. G. Noguchi, \& S. Fotos, Studies in Japanese Bilingualism (pp. 272-310). Clevedon: Multilingual Matters. 
Brewer, D. J., Augustine, C. H., Zellman, G. L., \& Ryan, G. (2007). Education for a New Era: Design and Implementation of K-12 Education Reform in Qatar. Santa Monica: RAND Corporation.

Cambell, D. T. (1975). Degrees of freedom and the case study. Comparative Political Studies, 8 (1), 178-191.

Canagarajah, S. (2005). Accommodating Tension in Language-in-Education Policies An Afterword. In A.M.Y. Lin and P. Martin (eds.) Decolonisation, Globalisation, Language-in-Education Policy and Practice. (pp.194-202). Clevedon: Multilingual Matters.

Carder, M. (2007). Bilingualism in International Schools: a Model for Enriching Language Education. Clevedon: Multilingual Matters.

Cazden, C. B. (1988). Classroom discourse: The language of teaching and learning. Portsmouth: Heinemann.

Christian, D., \& Genesee, F. (2001). Case Studies in Bilingual Education. Alexandria, VA: TESOL.

Cohen, L., Manion, L., \& Morrison, K. (2011). Research Methods in Education. London: Routledge.

Cook, V. (2000). Using Linguistics and Second language acquisition: one person with two languages. In Aronoff, M. and Ress -Mille, J.(eds.) Blackwell's Handbook of linguistics. Oxford: Blackwell.

Cook, V. (2001). Second Language Learning and Language Teaching ( $3^{\text {rd }}$ Edition). London: Arnold.

Coulmas, F. (2005). Sociolinguistics: The Study of Speakers' Choice. Cambridge: Cambridge University Press .

Creese, A., \& Blackledge, A. (2010). Translanguaging in the bilingual classroom: a pedagogy for learning and teaching? The Modern Language Journal, 94 (1),103-115.

Cummins, James. (1976). The Influence of Bilingualism on Cognitive Growth: A synthesis of research findings and explanatory hypothesis. Working Papers on Bilingualism ,9. Retrieved from ERIC data Base (ED125311).

Cummins, J. (1991). Interdependence of First and Second Language Proficiency in Bilingual Children. In E. Bialystok, Language Processing in Bilingual Children (pp. 70-89). Cambridge: Cambridge University Press.

Cummins, J. (2000). Language, Power and Pedagogy: Bilingual Children in the Crossfire. Clevedon: Multilingual Matters . 
Cummins, J. (2003). Language Education: World Yearbook of Education 2003. In J. B. Reid, Language Education: World Yearbook of Education. London: Evans Bros.

Cummins, J. (2006). Identity Texts: The Imaginative Construction of Self through Multiliteracies Pedagogy. In O. Garcia, T. Skunabb-Kangas, and M. Torres-Guzman (eds.) Imagining Multilingual Schools: Languages in Education and Globalization. (pp. 51-68). Clevedon: Multilingual Matters .

Cummins, J., \& Swain, M. (1986). Bilingualism in Education. NY: Longman.

Davidson, J., \& Tesh, J. (1997). Theory and Practice in Language Program Organization Design. In M. A. Christison, A Handbook for Language Program Administrators. (pp. 177-198). CA: Ala Books.

Deviln, B., \& Jewson, N. (1995). The Development of Public Education and Training in the State of Qatar. Leicester: Centre for Labour Market Studies, University of Leicester.

Duff, P. A. (2010). Case Study Research in Applied Linguistics. New York: Routledge.

Duverger, J. (2005). L'Enseignement en Classe bilingue. Hechette, Paris.

ECSSR. (1999). Education \& the Arab World: Challenges of the Next Millennium. Abu-Dhabi: The Emirates Centre for Strategic Studies \& Research.

EFA Global Monitoring Report. (2006). Literacy for Life. Paris, France: UNESCO.

Eisenhardt, K. (October 1989). Building Theories from Case Study Research. Academy of Management Review, 14 (4), 532-550.

Ellis, R. (2003). Task-Based Language Learning and Teaching. Oxford : Oxford University Press.

Erickson, F. (1986). Qualitative Methods on Research on Teaching. In M. C. Whittrock, Handbook of Research on Teaching. N.J.: Macmillan.

Eviatar, Z., \& Ibrahim, R. (2000). Bilingual is as bilingual does: Metalinguistic abilities of Arabic-speaking children. Applied Psycholinguistics 21 (4), 451-471.

Feitelson , D., Goldstein , Z., Iraqi, J., \& Share, D. (1993). Effects of listening to story reading on aspects of literacy acquisition in a diglossic situation. Reading Research Quarterly, 28 (1), 70-79.

Feng, A. (2007). Bilingual Education in China. Clevedon: Multilingual Matters.

Feng, Z. J., \& Ke, S. (2003). Bilingual Teaching and Integrated English. Beijing: Sun Yat University Press.

Ferguson, C. (1959). Diglossia. Word, 15, 325-340. 
Ferguson, G. (2003). Classroom Code-Switching in Post-Colonial Contexts: Functions Attitudes and Policies. AILA Review, 16 (1), 38-51.

Fishman, J. A. (1976). Bilingual Education: An International Sociological Perspective. Rowley, MA: Newbury House.

Fishman, J. A. (1991). Reversing Language Shift: Theoretical and Empirical Foundations of Assistance in Threatened Languages. Clevedon: Multilingual Matters.

Flyvbjerg, B. (2006). Five Misunderstandings About Case-Study Research. Qualitative Inquiry, 12 (2), 219-245.

Foster, P. (1996). Observing Schools: A methodological guide. CA: Sage Publications.

Frohlich, M. S. (1985). Differences in the communicative orientation of L2 classroom. TESOL Quarterly, 19, 51-62.

Fryer, T. (2009). Stakeholders experiences of a dual-language international school. Journal of Research in International Education, 8 (2), 210-222.

Fullen, M. G., \& Miles, M. B. (1992). Getting Reform Right: What Works and What Doesn't. Phi Delta Kapan, 73 (10),745-752.

Gajo, J. (2007). Linguistic knowledge and subject knowledge: how does bilingualism contribute to subject development? International Journal of Bilingual Education and Bilingualism, 10 (5), 563-581.

Garcia, O. (2004). Language-in-Education Policies: Global Perspectives. Considerations for Qatar. Doha: Unpublished Report Submitted to Adel Al-Sayed. Garcia, O. (2009). Bilingual Education in the $21^{\text {st }}$ Century. UK: Wiley-Blackwell. Garcia, O., Sylvan, C., \& Witt, D. (2011). Pedagogies and practices in multilingual classrooms: singularities in pluralities. Modern Language Journal, 95 (3), 385-400.

Genesee, F. (1984). Historical and Theoretical Foundations of Immersion Education. In C. S. Education, Studies on Immersion Education : A Collection for United States Educators. California: California State Department of Education.

Genesee, F. (2001). Bilingual first language acquisition: exploring the limits of the language faculty. Annual Review of Applied Linguistics, 21, 153-68.

Genesee, F. (2004). What Do We Know About Bilingual Education for Majority Language Learners? In T. K. Bhatia, \& W. C. Ritchie, The Handbook of Bilingualism (pp. 547-576). Oxford: Blackwell. 
Genesee, F., Lindholm-leary, K., Saunders, W., \& Christian, D. (2006). Educating English Language Learners: A Synthesis of Research. Cambridge: Cambridge University Press.

Gersten, R., \& Baker, S. (2001). What we know about effective instructional practices for English language Learners. Exceptional Children, 66, 454-470.

Geva, E. (2006). Learning to read in a second language: research, implications and recommendations for services. Encyclopaedia on Early Childhood Development (published online), 1-12.

Gibbons, P. (2002). Scaffolding Language, Scaffolding Learning: Teaching Second Language in the Mainstream Classroom. Portsmouth: Heinemann.

Gill, S. K. (2004). Medium-of-Instruction Policy in Higher Education in Malaysia: Nationalism versus Internationalization. In J. W. Tollefson, \& A. B. Tsui, Medium of Instruction Policies: Which Agenda? Whose Agenda? (pp. 135-52). NJ: Lawrence Erlbaum.

Glasser, S. B. (2003, February Sunday 2). Qatar Reshapes Its Schools, Putting English Over Islam. The Washington Post, p. A20.

Gonzalez, G., Karoly, L. A., Constant, L., Salem, H., \& Goldman, C. A. (2008). Facing Human Capital Challenges of 21 Century: Education and Labour Market initiatives in Lebanon, Oman, Qatar, and UAE. CA: Rand Corporation.

Gulf Times. (2009, January 11). Academic Studies: Ways to Keep Standard Arabic Alive. Gulf Times.

Haeri, N. (2000). Form and Ideology: Arabic Sociolinguistics and Beyond. Annual Review of Anthropology, 29, 61-87.

Haggan, M., \& Farghal, M. (2006). Compliment Behaviour in Kuwait College Students. International Journal of Bilingual Education and Bilingualism, 9 (1), 94118.

Hakuta, K. (1990). Bilingualism and bilingual education: A research perspective. Occasional Papers Series, No. 1. Washington, DC: National Clearinghouse for Bilingual Education.

Hall, J. K., \& Walsh, M. (2002). Teacher-Student Interaction and Language Learning. Annual Review of Applied Linguistics, 22, 186-203.

Halliday, M. (2001). New Ways Of Meaning: The Challenge to Applied Linguistic. In A. Fill, \& P. Muhlhausler, The Ecolinguistics Reader: Language, Ecology and Environment (pp. 175-202). London: Continuum.

Hamers, J. F., \& Blanc, M. H. (2000). Bilinguality and Bilingualism. Cambridge: Cambridge University Press. 
Heller, M. (2001). Undoing the macro/micro dichotomy: Ideology and categorisation in a linguistic minority school. In N. Coupland, S. Sarangi, \& C. N. Candlin, Sociolinguistic Theory (pp. 212-234). Harlow: Pearson Education.

Heller, M. (2006). Linguistic Minorities and Modernity: A Sociolinguistic Ethnography ( $2^{\text {nd }}$ edition). London: Continuum.

Holes, C. (1995). Modern Arabic: Structures, Functions, and Varieties. London: Longman.

Hornberger. (1991). Continua of Biliteracy: Ecological Framework for Educational Policy, Research and Practice in Multilingual Settings. Clevedon: Multilingual Matters.

Hornberger, N. (1989). Continua of biliteracy. Review of Educational Research, 59(3), 271-296.

Hornberger, N. (1990). Teacher ‘Quechua’ use in bilingual and non-bilingual classroom of Puno, Peru. In R. Jacobson, \& C. Faltis, Language Distribution Issues in Bilingual Schooling (pp. 163-173). Clevedon: Multilingual Matters.

Hu, G. (2009, December). The Craze for English-Medium Education in China. English Today, 100.

Hunt, M., Barnes, A., Powell, B., Lindsay, G., \& \& Muijs, D. (2005). Primary foreign language: an overview of recent research, key issues and challenges for educational policy and practice. Research Papers in Education, 20, 371-390.

Jacobson , R., \& Faltis, C. (1990). Language Distribution Issues in Bilingual Schooling. Multilingual Matters, Clevedon.

Jacobson, R. (1981). The Implementation of Bilingual Instructional Model: The New Concurrent Approach. In P. Gonzalez (ed.) Proceedings of the English Annual International Bilingual Bicultural Education Conference at Seattle. Rosslyn, VA: National Clearing House for Bilingual Education.

Johnson, R. K. (1983). Bilingual switching strategies: a study of the modes of teacher-talk in bilingual secondary school classrooms in Hong Kong. Language Learning in Communication, 2 (3), 267-85.

Johnson, R. K. (1997). The Hong Kong Education System: Late immersion under stress. In R. K. Johnson, \& M. Swain, Immersion Education: International Perspectives (pp. 171-89). Cambridge: Cambridge University Press.

Johnson, R. K., \& Swain, M. (1997). Immersion Education : International Perspectives. Cambridge : Cambridge University Press.

Kachru, Y., \& Smith, L. E. (2008). Cultures, Contexts, and World Englishes. New York: Routledge. 
Kuper, A., \& Kuper, J. (eds.) (1985). The Social Science Encyclopaedia. London: Routledge.

Lam, A. S. (2007). Bilingual or Multilingual Education in China: Policy and Learner Experience. In A. Feng, Bilingual Education in China (pp. 13-33). Clevedon: Multilingual Matters.

Lambert, W. F., \& Tucker, G. R. (1972). Bilingual Education of Children. Rowley, MA: Newbury House.

Lasagabaster, D., \& Sierra, J. (2010). Immersion and CLIL in English: more differences than similarities. ELT, 64 (4), 367-375.

Lee, J. S., Hill-Bonnet, L., \& Gillispie, J. (2008). learning in two languages: interactional spaces for becoming bilingual speakers. International Journal of Bilingual Education and Bilingualism, 11 (1), 75-94.

Lesko, J. (2002). Qatar. World Education Encyclopaedia , 2, 1109-1114.

Lin, A. (1997). Bilingual Education in Hong Kong. In J. Cummins, \& D. Corson, Encyclopaedia of Language and Education, Volume 5. Bilingual Education (pp. 2819). Dordrecht: Kluwer Academic.

Lin, A. (2006). Beyond Linguistic Purism in Language-in-education Policy and Practice. Language and Education, 20 (4), 287-305.

Lin, A., \& Luke, J. (2002). Beyond progressive liberalism and cultural relativism: Towards critical postmodernist and socio-historically situated perspectives in ethnographic classroom studies. Canadian Modern Language Review, 59 (1), 97124.

Lo, Y. Y., \& Murphy, V. (May 2010). vocabulary knowledge and growth in immersion and regular language-learning programmes in Hong Kong. Language and Education, 24 (3), 215-238.

Lorenzo, F., Casal, S., \& Moore, P. (2009). The effects of content and language integrated learning in European education: key findings from the Andalusian Bilingual sections evaluation project. Applied Linguistics, 31 (3),1-25.

Maamouri, M. (September,1998). Language Education and the Human Development: Arabic Diglossia and its Impact on the Quality of Education in the Arab Region. Unpublished paper presented at the Mediterranean Development Forum of the World Bank. Philadelphia: International Literacy Institution.

Mackey, W. (1978). The importation of bilingual education models. In J. Alatis (ed.),Georgetown University Roundtable: International Dimensions of Education. Washington DC: Georgetown University Press. 
MacKey, W. F. (1972). Bilingual Education in a Binational School. Rowley, MA: Newbury House.

Maja, D. (2002). Power, Prestige, and Bilingualism: International Perspectives on Elite Bilingual Education. Clevedon: Multilingual Matters.

Malallah, S. (2000). English in An Arabic Environment: Current Attitudes to English Among Kuwaiti University Students. International Journal of Bilingual Education and Bilingualism, 3 (1), 19-43.

Marshall, C., \& Rossman, G. (2006). Designing Qualitative Research. London: Sage.

Martin, P. W. (1997). Accomplishing Lessons Bilingually in Three Primary

Classrooms in Negara Brunei Darussalam Insights into the Dwibahsa Programme, Unpublished doctoral dissertation. University of Lancaster.

Martin-Jones, M. (2000). Multilingual Literacies: Reading and Writing Different Worlds. Amsterdam: J. Benjamin.

Mathews, A., \& Ross, A. (2010). Research Methods. Harlow: Pearson Education Limited.

May, S., Hill, R., \& Tiakiwai, S. (2004). Bilingual/Immersion Education: Indicators of Good Practice. New Zealand: Ministry of Education.

Mayer, R. E. (2002). Rote versus meaningful learning. Theory into Practice, 41 (4), 226-232.

Merriam, S. B. (2010). Qualitative Research and Case Study Applications in Education. San Francisco: Jossey-Bass.

Miles, M. B., \& Huberman, A. M. (1994). Qualitative Data Analysis. London: Sage Publications.

Noguchi, M. G., \& Fotos, S. (2000). Studies in Japanese Bilingualism. Clevedon: Multilingual Matters.

Nortier, J. (2008). Types and Sources of Bilingual Data. In L.W. (eds.), Research Methods in Bilingualism and Multilingualism (pp. 35-52). Oxford: Blackwell Publishing.

OECD. (2010). PISA 2009 Results: Executive Summary.

O'Neill, J., \& Valasco, P. (2007). Understanding the Power of Scaffolds. Unpublished manuscript.

Parker, Lara-Alico, R., \& Parker, R. (1994). A Pedagogical model for transitional English bilingual classrooms . Bilingual Research Journal, 18 (3\&4), 119-133. 
Parkinson, D. B. (1991). Searching for a Modern fus'ha: Real life formal Arabic. AlArabiyya, 24, 31-64.

Patton, M. (1990). Qualitative Evaluation and Research Methods ( $2^{\text {nd }}$ edition). London: Sage Publications.

Patton, M. Q. (2002). Qualitative Research \& Evaluation Methods (3 ${ }^{\text {rd }}$ edition). CA: Sage Publications.

PIRLS. (2006). Technical Report. Retrieved from www.pirls.org.

Report. (2009). Schools and Schooling 2008-2009 Report. Evaluation Institute, Supreme Education Council: Doha, Qatar.

Richards, J. (2001). Curriculum Development in Language Teaching. Cambridge: Cambridge University Press.

Richie, \& Lewis. (2003). Qualitative research practice: A guide for social science students and researchers. London: Sage Publications.

Rossell, C., \& Baker, K. (1996). The effectiveness of bilingual education. Research in the Teaching of English, 30, 70-74.

Rubin, H. J., \& Rubin, I. S. (1995). Qualitative Interviewing. London: Sage Publications.

Saeed, A. T., \& Fareh, S. (2006). Difficulties Encountered by Bilingual Arab Learners in Translating 'fa' into English. International Journal of Bilingual education and Bilingualism, 9 (1), 91-32.

Saiegh-Haddad, E. (2003). Linguistic distance and initial reading acquisition: The case of Arabic diglossia. Applied Psycholinguistics 24, 431-451

Saif, A. A. (2008). Deconstructing Before Building: Perspectives on Democracy in Qatar. In A. Ehteshami, \& S. Wright, Reform in The Middle East Oil Monarchies (pp. 103-125). Reading, UK: Ithaca Press.

SEC. (2004). The Development of Education . Doha: The Ministry of Education.

SEC. (2010). The Development Of Education . Doha: The Ministry of Education.

Serra, C. (2007). Assessing CLIL at Primary School: A Longitudinal Study. International Journal of Bilingual Education and Bilingualism 10 (5), 582-602.

Shaaban, K. A. (1997). Bilingual Education in Lebanon. In J. Cummins, \& D. Corson, Bilingual Education, Vol.5 of the Encyclopaedia of language and Education. Dordrecht, The Netherlands: Kluwer Academic Publishers. 
Short, D. J., \& Echevarria, J. (1999). The Sheltered Instruction Observation Protocol: A tool for teacher-researcher collaboration and professional development. Washington D.C.: CREDE.

Silverman, D. (2005). Doing Qualitative Research. London: Sage Publications. Skutnabb-Kangas, T. (2000). Linguistic Genocide in Education- Or Worldwide Diversity and Human Rights . Mahwan, NJ: Erlbaum.

Slavin, R. E., \& Cheung, A. (2005). Effective reading programs for English language learners. Baltimore, MD: Johns Hopkins University, Centre for DataDriven Reform in Education

Smith, M., \& Dickinson, D. K. (2002). Early Language \& Literacy Classroom Observation (ELLCO) toolkit, Research Edition. Baltimore, MD: Brookes Publishing Company.

Spolsky, B. (1972). The Language Education of Minority Children. Rowley, MA: Newbury House.

Stake, R. (2005). Case studies. In N. Denzin, \& Y. Lincoln, Handbook of Qualitative Research ( $2^{\text {nd }}$ edition). (pp. 435-54). Thousand Oaks, CA: Sage Publications.

Stein, M., Stuen, C., Carnine, D., \& Long, R. (2001). Textbook evaluation and adaptation. Reading and Writing Quarterly, 17 (1), 5-23.

Strauss, A., \& Corbin, J. (1998). Basics of Qualitative Research Techniques and Procedures for Developing Grounded Theory . London : Sage Publications.

Suleiman, S. M. (1986). Jordanian Arabic between Diglossia and Bilingualism: Linguistic Analysis. Amsterdam: J. Benjamin.

Swain, M. (1978). Home-school language switching. In J. Richards (ed.).Understanding Second and Foreign Language Learning: Issues and approaches. Rowley, Mass.: Newbury House Publishers

Swain, M. (1997). French Immersion Programs in Canada. In J. Cummins, \& D. Corson, Bilingual Education, Volume 5 of The Encyclopaedia of Language and Education. Dordrecht: Kluwer.

Swain, M., \& Johnson, R. (1997). Immersion Education : A Category within Bilingual Education. In R. K. Swain, Immersion Education : International Perspectives. Cambridge: Cambridge University Press.

Swain, M., \& Lapkin, S. (1982). Evaluating Bilingual Education: A Canadian Case Study . Clevedon: Multilingual Matters.

Thomas, W., \& Collier, V. (2003). The multiple benefits of dual language. Educational Leadership,61 (2), 61-64. 
Tosi, A. (1989). Bilingual Education. Annual Review of Applied Linguistics, 10, 103121.

Tsui, A. B. (2004). Medium of instruction in Hong Kong: One country, two languages, whose system? In J. W. Tollefson, \& A. B. Tsui, Medium of Instruction Policies: Which Agenda Whose Agenda? (pp. 97-116). NJ: Erlbaum.

Tucker, R. G. (2001). A Global Perspective on Bilingual and Bilingual Education. In James E. Alatis \& Ai-Hui Tan (eds.) Georgetown University Roundtable on Languages and Linguistics. Washington D.C. :Georgetown University Press.

Wagner, D. A. (1993). Literacy, Culture and Development: Becoming Literate in Morocco. Cambridge: Cambridge University Press.

Walqui, A. a. (2004). Principles for Quality Teaching for English Language Learners. San Francisco: WestEd.

Walqui, A., Garcia, O., \& Humburger, L. (2004). Quality Teaching for English Language Learners in Classroom Observation Scoring Manual. San Francisco, CA: WestEd.

Yamani, S. (Spring 2006). Toward a National Education Development Paradigm in the Arab World. The Fletcher School Online Journal for issues related to Southwest Asia and Islamic Civilization, 1-8.

Yin, R. K. (2003). Case Study Research: Design and Method. Thousand Oaks: Sage Publications.

Yu, V. S., \& Atkinson, P. S. (1998). An Investigation of the language difficulties experience by Hong Kong secondary school students . Journal of Multilingual and Multicultural Development, 9 (4), 302-22.

Zakaria, Z. (2009). The Arab Middle East and North Africa. In O. Garcia, Bilingual Education in the $21^{\text {st }}$ Century: A Global Perspective (pp. 27-280). London: WileyBlackwell.

Zhang, E. Y., \& Adamson, B. (2007). Implementing Language Policy: Lessons from Primary School. In A. Feng, Bilingual Education in China (pp. 166-181). Clevedon: Multilingual Matters. 